\title{
CÁLCULO DE LAJES-COGUMELO PELA TEORIA DAS CHARNEIRAS PLÁSTICAS
}

MÔNICA CRISTINA CARDOSO DA GUARDA

Dissertação apresentada à Escola de Engenharia de São Carlos, da Universidade de São Paulo, como parte dos requisitos para a obtenção do Título de Mestre em Engenharia de Estruturas.

ORIENTADOR: Prof. Dr. Libânio Miranda Pinheiro

São Carlos 1995 


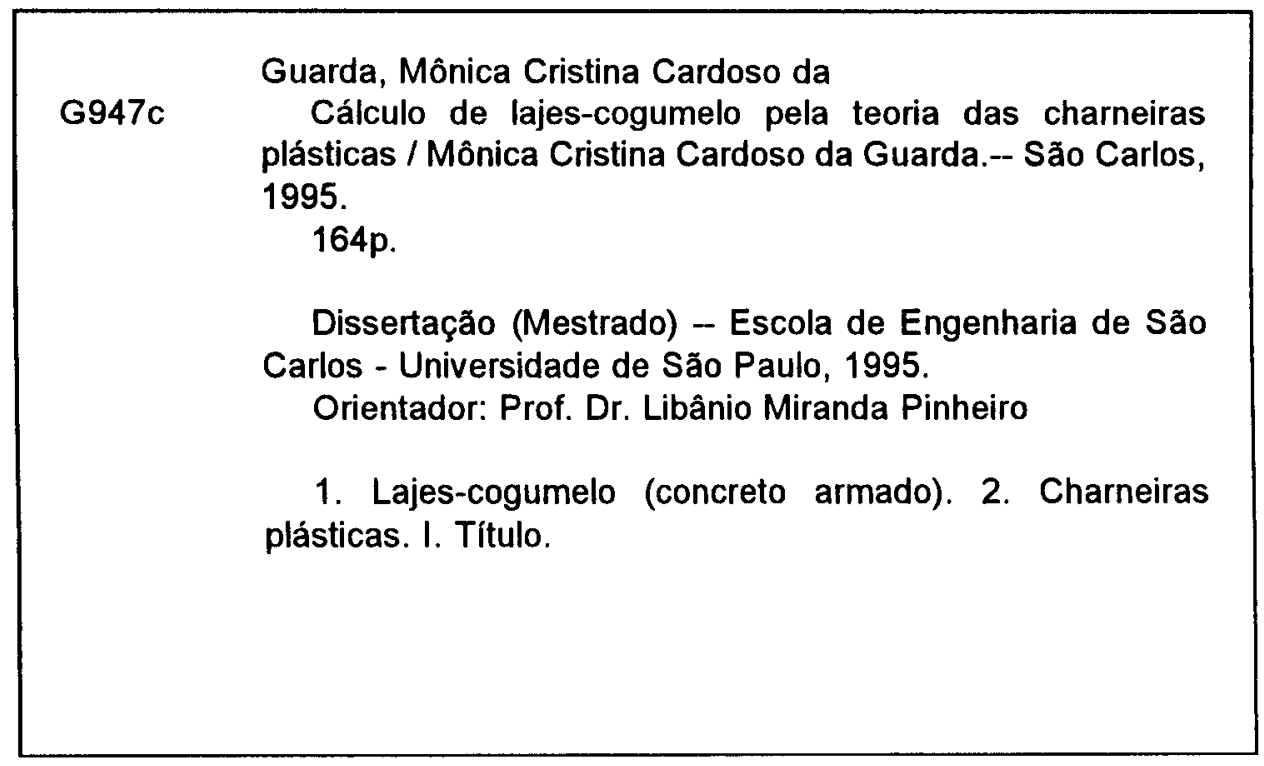


A meus pais, Adelino Bastos da Guarda e Maria Rosa Cardoso da Guarda 


\section{AGRADECIMENTOS}

Aos meus familiares pelo apoio e incentivo, sempre presentes em todos os momentos.

Ao Prof. Dr. Libânio Miranda Pinheiro, orientador, que sempre demonstrou muita competência, contribuindo com valiosas sugestões para o desenvolvimento do trabalho e, especialmente, por sua amizade.

À Inês Santana da Silva, pela amizade e pelo apoio.

Aos Professores Hernani Sávio Sobral, Ney Luna Cunha e Antônio Carlos Mascarenhas (in memoriam), pelo incentivo dado para a realização deste trabalho.

À Maria Nadir Minatel, pelo capricho com que realiza sua atividade de bibliotecária.

A Francisco Carlos de Brito, pela execução primorosa dos desenhos.

A todos os professores e funcionários do Departamento de Engenharia de Estruturas, que colaboraram para a realização deste trabalho.

Ao CNPq pela bolsa de estudos.

E a todos, que de alguma forma contribuiram para a realização deste trabalho 


\section{SUMÁRIO}

LISTA DE FIGURAS $\ldots \ldots \ldots \ldots \ldots \ldots \ldots \ldots \ldots \ldots \ldots \ldots \ldots \ldots \ldots$

LISTA DE TABELAS $\ldots \ldots \ldots \ldots \ldots \ldots \ldots \ldots \ldots \ldots \ldots$ vi

LISTA dE SIMBOLos $\ldots \ldots \ldots \ldots \ldots \ldots \ldots \ldots \ldots \ldots$ ix

LISTA DE ABREVIATURAS E SIGLAS .............. xii

RESUMO $\ldots \ldots \ldots \ldots \ldots \ldots \ldots \ldots \ldots \ldots \ldots \ldots \ldots \ldots \ldots \ldots$

ABSTRACT $\ldots \ldots \ldots \ldots \ldots \ldots \ldots \ldots \ldots \ldots \ldots \ldots \ldots \ldots \ldots \ldots \ldots$

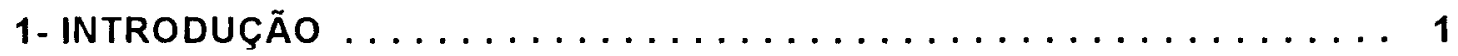

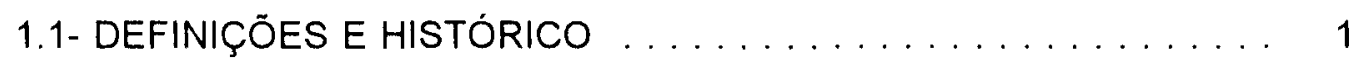

1.2 - VANTAGENS DAS LAJES-COGUMELO ............ 3

1.3- DESVANTAGENS DAS LAJES- COGUMELO . . . . . . . . . 4

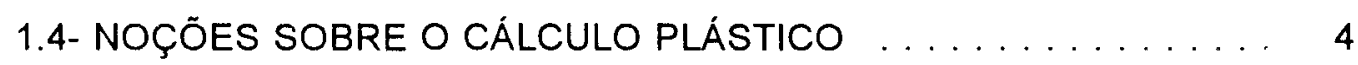

1.4.1- Teoremas Fundamentais do Cálculo Plástico . . . . . . 4

1.4.2- A Teoria das Charneiras Plásticas .......... 5

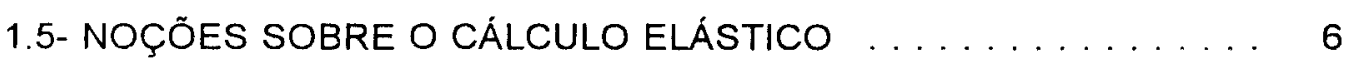

1.5.1- Equação Diferencial das Placas . . . . . . . . . 6

1.5.2- Processos de Cálculo ............... 7

1.6- OBJETIVOS .................... 7

1.7- PLANEJAMENTO $\ldots \ldots \ldots \ldots \ldots \ldots \ldots \ldots \ldots$ 
2.1- MÉTODO DIRETO .................... 9

2.1.1- Definições ................... 9

2.1.2- Notação Utilizada . . . . . . . . . . . . . . 11

2.1.3- Limitaçōes do Método Direto . . . . . . . . . . . . . . 12

2.1.4- Momento Total de Referência para um Vão . . . . . . . 13

2.1.5- Momentos de Referência Positivos e Negativos . . . . . . 13

2.1.6- Distribuição dos Momentos entre as Faixas . . . . . . . 15

2.2- PROCESSO DOS PÓRTICOS MÚLTIPLOS . . . . . . . . . . . . 16

2.2.1- Definição dos Pórticos . . . . . . . . . . . . . . 16

2.2.2- Cálculo e Distribuição dos Momentos Fletores . . . . . . 18

2.3- PROCESSO DOS PÓRTICOS EQUIVALENTES . . . . . . . . . . 19

2.3.1- Definição dos Pórticos . . . . . . . . . . . . 19

2.3.2- Cálculo dos Momentos Fletores . . . . . . . . . . 19

2.3.3- Distribuição dos Momentos Fletores entre as Faixas . . . 20

2.3.4- Vantagens do Processo dos Pórticos Equivalentes . . . . . 21

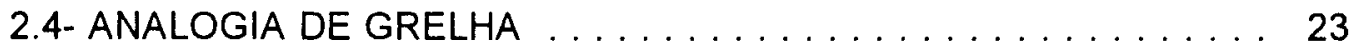

2.4.1- Definição da Malha . . . . . . . . . . . . . . . 24

2.4.2- Propriedades Geométricas das Barras . . . . . . . . 26

2.4.3- Parâmetros Elásticos Equivalentes para o Concreto . . . . 27

2.4.4- Influência das Rigidezes dos Pilares . . . . . . . . . 28

2.4.5- Análise dos Resultados . . . . . . . . . . . . . 28

2.5- MÉTODO DOS ELEMENTOS FINITOS . . . . . . . . . . . . 30

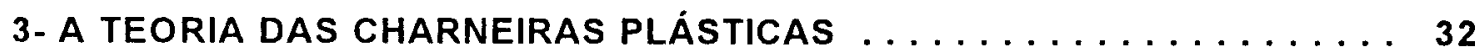

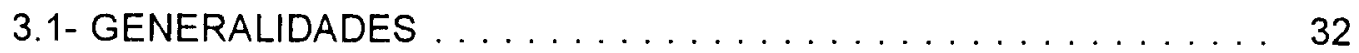

3.1.1- Tipos de Ruina por Flexão . . . . . . . . . . . . . 32

3.1.2- Momentos de Plastificação . . . . . . . . . . . 33

3.1.3- Reserva de Resistência . . . . . . . . . . . . . . 34

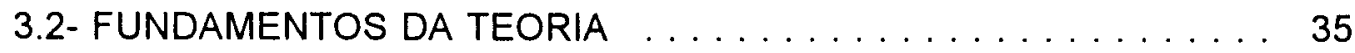

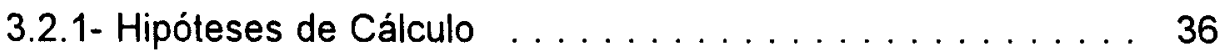

3.2.2 Configurações das Charneiras $\ldots \ldots \ldots \ldots \ldots \ldots$ 


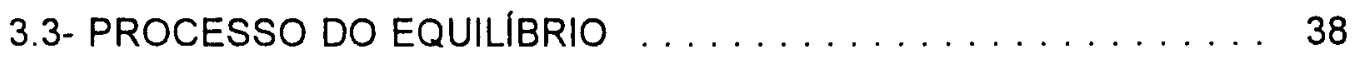

3.3.1- Definição das Forças Nodais . . . . . . . . . . . 38

3.3.2- Determinação das Forças Nodais . . . . . . . . . . 39

3.3.3- Exemplo de Aplicação do Processo do Equilíbrio . . . . . 45

3.4- PROCESSO DA ENERGIA . . . . . . . . . . . . . . 46

3.4.1- Trabalhos das Forças Internas $\left(T_{i}\right) \ldots \ldots \ldots \ldots . \ldots 4$

3.4.2- Trabalho das Forças Externas $\left(T_{e}\right) \ldots \ldots \ldots . \ldots 48$

3.4.3- Determinação dos Momentos de Plastificação . . . . . . . 48

3.4.4- Exemplo de Aplicação do Processo da Energia . . . . . . . 49

3.5- CARGAS CONCENTRADAS ............... 51

3.5.1- Efeito das Cargas Concentradas . . . . . . . . . 51

3.5.2- Carga Concentrada Atuando em um Vértice . . . . . . . . 55

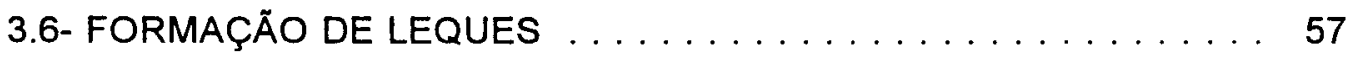

3.7- LAJES ORTÓTROPAS . . . . . . . . . . . . . . . . 61

3.7.1- Definição de Anisotropia e Ortotropia . . . . . . . . . . 61

3.7.2- Transformação de Lajes Ortótropas em Isótropas . . . . . 63

4- A TEORIA DAS CHARNEIRAS PLÁStICAS APLICADA ÀS LAJESCOGUMELO .......................65

4.1- GENERALIDADES . . . . . . . . . . . . . . . . 65

4.1.1- Tipos de Configurações das Charneiras . . . . . . . . 65

4.1.2- Divisão do Pavimentc em Painéis . . . . . . . . 67

4.2- PAINÉIS INTERNOS . . . . . . . . . . . . . . . . . . . . . . 67

4.3- PAINÉIS LATERAIS . . . . . . . . . . . . . . . . . . 72

4.3.1- Painéis Laterais com Apoios Pontuais . . . . . . . . . 72

4.3.2- Painéis Laterais com Apoios Lineares . . . . . . . . . . . 74

4.4- PAINÉIS DE CANTO . . . . . . . . . . . . . . . . . 79

4.4.1- Canto sobre Apoio Pontual . . . . . . . . . . . 79

4.4.2- Painéis de Canto com Apoios Lineares . . . . . . . . . . 80

4.5- DISTRIBUIÇÃO DAS ARMADURAS . . . . . . . . . . 83 
5.1- DISPOSIÇÕES CONSTRUTIVAS .............. 85

5.1.1- Cobrimento ................... 85

5.1.2- Diâmetro das Barras . . . . . . . . . . . 86

5.1.3- Armadura Minima . . . . . . . . . . . . . 86

5.1.4- Espaçamento entre as Barras das Armaduras . . . . . . . 86

5.1.5- Comprimento das Barras . . . . . . . . . . 87

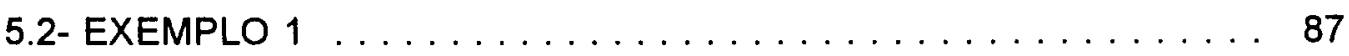

5.2.1- Estimativa da Espessura da Laje . . . . . . . . 88

5.2.2- Definição das Faixas de Projeto . . . . . . . . . . 89

5.2.3- Definição dos Pórticos . . . . . . . . . . . . . 89

5.2.4- Propriedades das Barras $\ldots \ldots \ldots \ldots \ldots . \ldots . \ldots 9$

5.2.5- Determinação do Carregamento . . . . . . . . . . 93

5.2.6- Cálculo dos Esforços Solicitantes . . . . . . . . . . 96

5.2.7- Distribuição dos Momentos nas Faixas de Projeto . . . . . 97

5.2.8- Compatibilização dos Momentos Elásticos . . . . . . . 102

5.2.9- Cálculo das Armaduras de Flexão Relativas aos Momentos elásticos . . . . . . . . . . . . . . . . . . . 103

5.2.10- Detalhamento das Armaduras do Cálculo Elástico . . . 106

5.2.11- Cálculo dos Momentos de Plastificação . . . . . . . . 109

5.2.12- Cálculo das Armaduras de Flexão Relativas aos Momentos de plastificação . . . . . . . . . . . . . 120

5.2.13- Detalhamento das Armaduras do Cálculo Plástico . . . 121

5.3- EXEMPLO $2 \ldots \ldots \ldots \ldots$. . . . . . . . . . . . . 127

5.3.1- Propriedades das Barras dos Pórticos . . . . . . . . 127

5.3.2- Determinação do Carregamento dos Pórticos . . . . . . 129

5.3.3- Determinação dos Esforços Solicitantes . . . . . . . . . . 131

5.3.4- Distribuição dos Momentos nas Faixas de Projeto . . . . . 133

5.3.5- Compatibilização dos Momentos . . . . . . . . . . . 134

5.3.6- Cálculo das Armaduras de Flexão . . . . . . . . . . . 135

5.3.7- Detalhamento das Armaduras do Cálculo Elástico . . . . . 137

5.3.8- Cálculo dos Momentos de Plastificação e das Áreas de Aço 142

5.3.9- Detalhamento da Armadura de Flexão . . . . . . . . . . 145 


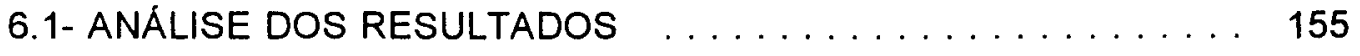

6.2- CONCLUSÕES . . . . . . . . . . . . . . . . . . 158

6.3- SUGESTÕES PARA OUTRAS PESQUISAS . . . . . . . . . 158

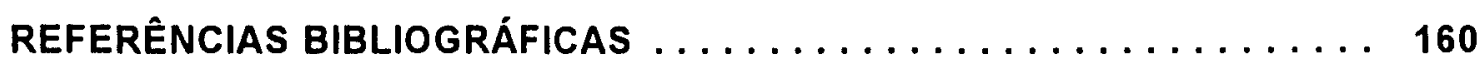




\section{LISTA DE FIGURAS}

FIGURA 1.2 Alguns Tipos de Capitéis. $\ldots \ldots \ldots \ldots \ldots \ldots \ldots$

FIGURA $1.2-$ Flat Slab. $\ldots \ldots \ldots \ldots \ldots \ldots \ldots \ldots \ldots \ldots \ldots$

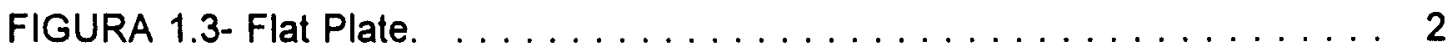

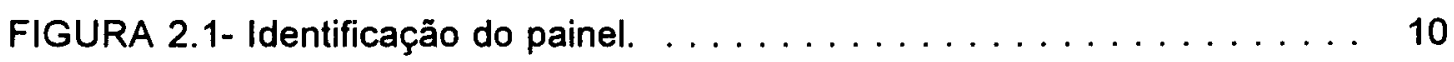

FIGURA 2.2- Identificação das meias-faixas centrais e laterais em um painel. . 10

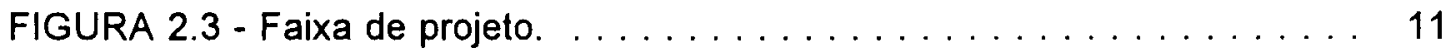

FIGURA 2.4- Pilares equivalentes para pilares de seções não retangulares. . . 13

FIGURA 2.5- Distribuição dos momentos totais de referência para cada vão. . 15

FIGURA 2.6- Definição dos pórticos múltiplos. $\ldots \ldots \ldots \ldots \ldots$

FIGURA 2.7- Divisão de um painel em faixas $\ldots \ldots \ldots \ldots \ldots \ldots \ldots$

FIGURA 2.8-Definição dos pórticos equivalentes. . . . . . . . . . . 20

FIGURA 2.9- Divisão dos painéis para distribuição dos momentos fletores. . . 22

FIGURA 2.10 - Laje e grelha equivalente. . . . . . . . . . . 23

FIGURA 2.11- Representação esquemática de uma laje por analogia de grelha. 24

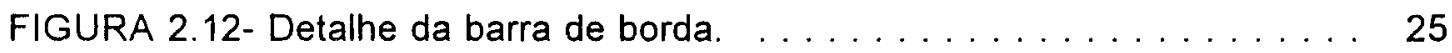

FIGURA 2.13- Obtenção do diagrama de momentos fletores da laje. . . . . . 29

FIGURA 2.14- Arredondamento dos diagramas de momentos fletores junto aos

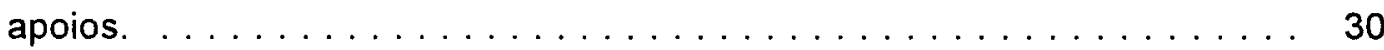


FIGURA 3.1- Diagramas momento-deformação das lajes subarmadas. . . . . . 33

FIGURA 3.2- Efeito compressivo de membrana (arqueamento). . . . . . . . 35

FIGURA 3.3- Efeito de membrana tracionada. . . . . . . . . . . . . . . 35

FIGURA 3.4- Exemplos de configurações possíveis. . . . . . . . . . . 37

FIGURA 3.5- Equilibrio de uma região e forças de transmissão. . . . . . . . . 39

FIGURA 3.6- Nó com duas charneiras positivas e uma negativa. . . . . . . . 40

FIGURA 3.7- Determinação das forças nodais. . . . . . . . . . . 41

FIGURA 3.8- Charneira concorrente com borda não engastada. . . . . . . . . . 44

FIGURA 3.9- Laje quadrada com carga uniforme. . . . . . . . . . . . . 45

FIGURA $3.10-$ Laje quadrada com carga uniforme. . . . . . . . . . . . . 49

FIGURA 3.11- Configurações de charneiras provocadas por carga concentrada. 51

FIGURA 3.12- Carga $P$ distribuida em um círculo de raio $r_{0} \ldots \ldots 53$

FIGURA 3.13- Carga concentrada próxima a uma borda livre ou simplesmente

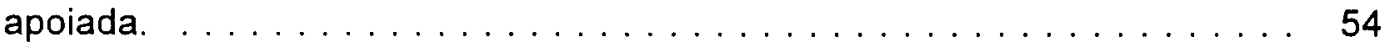

FIGURA 3.14- Carga concentrada atuando em um vértice. . . . . . . . . 56

FIGURA $3.15-$ Charneiras plásticas no canto de uma laje. . . . . . . . 58

FIGURA 3.16- Bifurcação de charneira em um canto. . . . . . . . . . . . . . 59

FIGURA 3.17- Charneira não coincidente com a bissetriz do ângulo . . . . . . 59

FIGURA 3.18- Charneira inclinada de $\beta \ldots \ldots \ldots \ldots \ldots \ldots$

FIGURA 3.19- Obtenção de laje isótropa afim. . . . . . . . . . . . 64

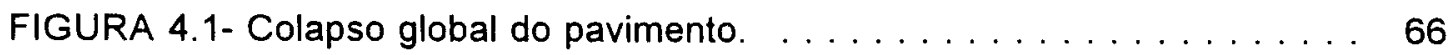


FIGURA 4.2- Colapso local ao redor do apoio. . . . . . . . . . 66

FIGURA 4.3- Lajes-cogumelo com vigas no contorno. . . . . . . . . . . . . 67

FIGURA 4.4- Divisão do pavimento em painéis. $\ldots \ldots \ldots \ldots$. . . . . 68

FIGURA 4.5- Configuração de ruína local para painéis internos. . . . . . . . . . 69

FIGURA 4.6- Configuração de ruina global para painéis internos. . . . . . . . 70

FIGURA 4.7- Painéis laterais com apoios pontuais. $\ldots \ldots \ldots \ldots$

FIGURA 4.8- Painéis laterais com apoios lineares. . . . . . . . . . . . 75

FIGURA 4.9- Canto sobre apoio pontual. $\ldots \ldots \ldots \ldots \ldots \ldots$

FIGURA 4.10- Painéis de canto com apoios lineares. . . . . . . . . 81

FIGURA 4.11- Distribuição dos momentos de plastificação. . . . . . . . . . 84

FIGURA 5.1- Comprimentos minimos e disposição das barras das armaduras. $\quad 87$

FIGURA 5.2- Pavimento analisado no exemplo $1 \ldots \ldots \ldots \ldots$

FIGURA 5.3- Definição das faixas de projeto e dos pórticos equivalentes . . . 89

FIGURA 5.4- Numeração das barras dos pórticos. . . . . . . . . . . 90

FIGURA 5.5- Esquema das partes em balanço . . . . . . . . . . . . . . . 94

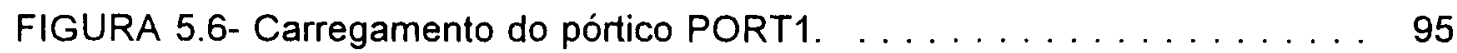

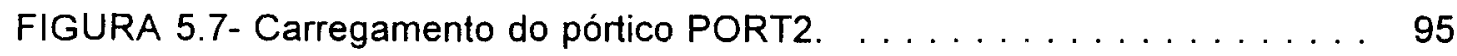

FIGURA 5.8- Momentos elásticos distribuídos nas faixas $(\mathrm{kNm} / \mathrm{m}) . \ldots \ldots 102$

FIGURA 5.9- Momentos negativos compatibilizados e positivos corrigidos $(\mathrm{kNm} / \mathrm{m}) \ldots \ldots \ldots \ldots \ldots \ldots \ldots \ldots$

FIGURA 5.10- Detalhamento da armadura positiva. . . . . . . . . . . . . . 107 
FIGURA 5.11 - Detalhamento da armadura negativa. . . . . . . . . 108

FIGURA 5.12- Momentos negativos elásticos médios $(\mathrm{kNm} / \mathrm{m}), \ldots \ldots \ldots \ldots$

FIGURA 5.13- Detalhamento da armadura positiva. . . . . . . . . . . . . 122

FIGURA 5.14- Detalhamento da armadura negativa. . . . . . . . . . . . . . 124

FIGURA $5.15-$ Pavimento do exemplo $2 . \ldots \ldots \ldots \ldots 127$

FIGURA 5.16- Faixas de projeto e pórticos múltiplos. . . . . . . . . . 128

FIGURA 5.17 - Numeração das barras dos pórticos. . . . . . . . . . . . 128

FIGURA 5.18- Carregamento do pórtico PORT1. . . . . . . . . . . . . . . . 130

FIGURA 5.19- Carregamento do pórtico PORT2 . . . . . . . . . . . . . . . 130

FIGURA 5.20- Carregamento do pórtico PORT3 . . . . . . . . . . . . . . 130

FIGURA 5.21- Carregamento do pórtico PORT4 . . . . . . . . . . . 131

FIGURA 5.22- Momentos distribuídos nas faixas de projeto, para a direção $x$

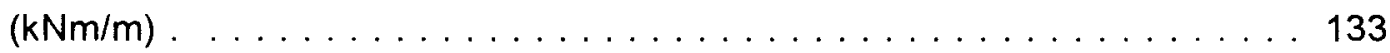

FIGURA 5.23- Momenta distribuidos nas faixas de projeto, para a direção y

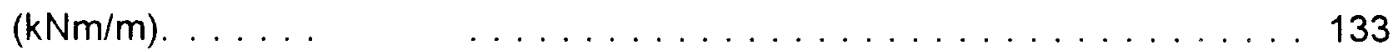

FIGURA 5.24- Momentos negativos compatibilizados e positivos corrigidos, para a

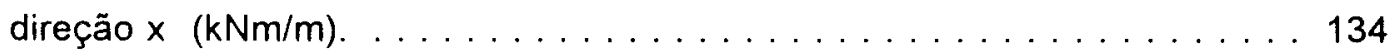

FIGURA 5.25- Momentos negativos compatibilizados e positivos corrigidos, para a direção y $(\mathrm{kNm} / \mathrm{m}) \ldots \ldots \ldots \ldots \ldots \ldots \ldots \ldots . \ldots \ldots \ldots$

FIGURA 5.26- Detalhamento da armadura positiva (direção $\mathrm{x}$ ). . . . . . 138

FIGURA 5.27- Detalhamento da armadura positiva (direção y). . . . . . 138

FIGURA 5.28- Detalhamento da armadura negativa (direção $\mathrm{x}$ ). . . . . . . . 139

FIGURA 5.29- Detalhamento da armadura negativa (direção y). . . . . . . . . 139 
FIGURA 5.30- Momentos negativos elásticos médios $(\mathrm{kNm} / \mathrm{m})$.

FIGURA 5.31- Denominação dos painéis do pavimento.

FIGURA 5.32- Detalhamento da armadura positiva (direção x). 146

FIGURA 5.33- Detalhamento da armadura positiva (direção y). 146

FIGURA 5.34- Detalhamento da armadura negativa (direção x). 147

FIGURA 5.35- Detalhamento da armadura negativa (direção y). 


\section{LISTA DE TABELAS}

TABELA 2.1- Fatores de Multiplicação para $M_{0} . \ldots \ldots \ldots \ldots \ldots$

TABELA 2.2- Fatores de Multiplicação dos Momentos para Distribuição entre as Faixas. . . . . . . . . . . . . . . . . . . . . . . 21

TABELA 2.3- Módulo de Deformação do Concreto. . . . . . . . . . . . 27

TABELA 5.1- Propriedades das barras do pórtico PORT1 . . . . . . . . . . 91

TABELA 5.2- Propriedades das barras do pórtico PORT 2. . . . . . . . . 92

TABELA 5.3- Momentos fletores no pórtico PORT1. . . . . . . . . . . . 96

TABELA 5.4- Momentos fletores no pórtico PORT2. . . . . . . . . . . 96

TABELA 5.5- Área de aço e armadura dos momentos negativos elásticos. . . 105

TABELA 5.6- Área de aço dos momentos positivos elásticos. . . . . . . . 106

TABELA 5.7- Resumo da armadura positiva. . . . . . . . . . . . . 107

TABELA 5.8- Consumo de aço da armadura positiva. . . . . . . . . . . . 108

TABELA 5.9- Resumo da armadura negativa. . . . . . . . . . . . . . . 109

TABELA 5.10- Consumo de aço da armadura negativa. . . . . . . . . . . . 109

TABELA 5.11- Área de aço e armadura dos momentos de plastificação negativo\$20

TABELA 5.12- Área de aço e armadura dos momentos de plastificação positivos121

TABELA $5.13-$ Resumo da armadura positiva. . . . . . . . . . . . 123

TABELA 5.14- Consumo de aço do detalhamento da armadura positiva. . . . . 124

TABELA 5.15- Resumo da armadura negativa. . . . . . . . . . . . . . . 125 
TABELA 5.16- Consumo de aço da armadura negativa. . . . . . . . . . 126

TABELA 5.17- Propriedades das barras do pórtico PORT 1. . . . . . . . . 129

TABELA 5.18- Propriedades das barras do pórtico PORT 2. . . . . . . . . . 129

TABELA 5.19 Propriedades das barras do pórtico PORT 3. . . . . . . . . . 129

TABELA 5.20- Propriedades das barras do pórtico PORT 4. . . . . . . . 129

TABELA 5.21- Momentos fletores atuantes no pórtico PORT1 . . . . . . . . 131

TABELA 5.22- Momentos fletores atuantes no pórtico PORT2. . . . . . . . . . 132

TABELA 5.23- Momentos fletores atuantes no pórtico PORT3. . . . . . . . . 132

TABELA 5.24- Momentos fletores atuantes no pórtico PORT4. . . . . . . . . . 132

TABELA 5.25- Área de aço dos momentos negativos (direção x). . . . . . . 135

TABELA 5.26- Área de aço dos momentos negativos (direção y). . . . . . . 136

TABELA 5.27- Área de aço dos momentos positivos (direção x). . . . . . . . . 136

TABELA 5.28- Área de aço dos momentos positivos (direção y). . . . . . . . 137

TABELA 5.29- Resumo da armadura positiva. . . . . . . . . . . . . . . . 140

TABELA 5.30- Consumo de aço da armadura positiva. . . . . . . . . . . . . 140

TABELA 5.31- Resumo da armadura negativa. . . . . . . . . . . . 141

TABELA 5.32- Consumo de aço da armadura negativa. . . . . . . . . . . . . . 141

TABELA 5.33- Momentos de plastificação positivos e suas áreas de aço. . . . 142

TABELA 5.34- Momentos de plastificação negativos, na direção $x$, e suas áreas de aço. . . . . . . . . . . . . . . . . . . . . . . . . . . . . . . . . 144

TABELA 5.35- Momentos de plastificação negativos, na direção y, e suas áreas de aço. 
TABELA 5.36- Resumo da armadura positiva.

TABELA 5.37- Consumo de aço da armadura positiva.

TABELA 5.38- Resumo da armadura negativa. 150

TABELA 5.39- Consumo de aço da armadura negativa.

TABELA 6.1- Consumo de aço do exemplo 1

TABELA 6.2- Consumo de aço do exemplo 2.

TABELA 6.3- Razão entre os momentos de plastificação negativo e positivo (exemplo 1).

TABELA 6.4- Razão entre os momentos de plastificação negativo e positivo (exemplo 2). 


\section{LISTA DE SÍMBOLOS}

Letras romanas maiúsculas:

A área da seção transversal do elemento da estrutura

$A_{8}$ área de aço

C momento de inércia à torção

D rigidez de placas à flexão

$E_{c}$ módulo de deformação longitudinal do concreto

FP faixa de projeto

G módulo de deformação transversal do concreto

I momento de inércia à flexão

$K_{1} \quad$ forças nodais

$M_{0} \quad$ momento total de referência para o vão

$M_{A}, M_{B}$ momentos negativos nas extremidades dos vãos livres

$M_{c} \quad$ momento positivo máximo no centro do vão

R fator pelo qual se divide o momento negativo elástico

T. trabalho das forças externas

$T_{1} \quad$ Trabalho das forças internas

V forças de transmissão 
Letras romanas minúsculas:

a vão de painel

a $_{1}$ posição das charneiras

b vão de painel

b

c momento de inércia à torção, por unidade de largura de uma placa isótropa

$\mathbf{f}_{\mathrm{ck}}$ resistência característica à compressão do concreto

g carga permanente uniformemente distribuída sobre a laje

h altura da seção transversal ou espessura da laje

$\ell \quad$ comprimento das charneiras

ln comprimento do vão livre, medido na direção em que se estiver calculando os esforços

$h_{1}$ comprimento do vão teórico, medido na mesma direção de $\ell_{n}$

$\ell_{2}$ comprimento do vão teórico, medido segundo a direção perpendicular a $\ell_{1}$

m momento de plastificação positivo

$m_{i} \quad$ momentos de plastificação negativos

p carga total uniformemente distribuida sobre a laje $(g+q)$

q carga acidental uniformemente distribuida sobre a laje

s espaçamento entre as barras de aço

$w(x, y)$ função que determina os deslocamentos verticais dos pontos $(x, y)$ do plano médio da placa. 
Letras gregas:

$\gamma \quad$ ângulo entre a carga linear e a direção da seção que resiste ao momento $\mathrm{m}$

$\theta \quad$ rotação das charneiras

$\kappa \quad$ indice de ortotropia

$\boldsymbol{\mu} \quad$ razão entre os momentos de vãos

$\rho \quad$ curvatura

$v \quad$ coeficiente de Poisson.

$\phi \quad$ razão entre o momento de plastificação negativo e positivo 


\section{LISTA DE ABREVIATURAS E SIGLAS}

$\mathrm{ACl} \quad$ American Concrete Institute

CEB Comité Euro-International du Béton

EESC Escola de Engenharia de São Carlos

FIP Fédération Internationale de la Précontrainte

NBR Norma Brasileira Registrada

USP Universidade de São Paulo 


\section{RESUMO}

GUARDA, M. C. C. (1995). Cálculo de lajes-cogumelo pela teoria das charneiras plásticas. São Carlos. 164p. Dissertação (Mestrado) - Escola de Engenharia de São Carlos, Universidade de São Paulo.

O objetivo principal deste trabalho é apresentar uma associação dos cálculos elástico e plástico, para análise de lajes-cogumelo. Foram considerados painéis retangulares, com carregamento uniformemente distribuido.

O cálculo elástico é utilizado como pré-dimensionamento, fornecendo a razão entre os momentos de vão e permitindo a fixação dos momentos de plastificação negativos.

O cálculo plástico é feito através da Teoria das Charneiras Plásticas, que é utilizada na obtenção dos momentos de plastificação, com os quais é feito o dimensionamento.

Também se apresentam dois exemplos completos, para comparar os resultados do cálculo elástico com aqueles relativos ao procedimento ora proposto. O cálculo elástico foi feito através do Processo dos Pórticos Equivalentes.

Não houve diferença significativa entre os resultados obtidos com os dois processos, para os exemplos considerados. Novas pesquisas são sugeridas para aprimorar o procedimento proposto.

Palavras-chave: Lajes-cogumelo; Teoria das Charneiras Plásticas 


\section{ABSTRACT}

GUARDA, M. C. C. (1995). Beamless slabs design by yield line theory. São Carlos. 164p. Dissertação (Mestrado) - Escola de Engenharia de São Carlos, Universidade de São Paulo.

The main aim of this work is to present an association of elastic plate theory and plastic analysis, to beamless slabs (flat slabs and flat plates) analysis. Rectangular panels uniformly loaded were considered.

Elastic plate theory is used to predimensioning, determining the relation between positive bending moments and permiting to fix the ultimate negative moments of resistance.

Plastic analysis is made by Yield Line Theory, that is used to obtain ultimate moments of resistance, which are used in dimensioning.

Two complete examples are also presented, to compare results of elastic plate theory with those relative to proposed proceeding. Elastic calculus is made by Equivalent Frame Method.

There was not significant difference between results obtained with the two processes in the considered examples. New researches are suggested in order to perfect proposed proceeding.

Keywords: Flate plates; Yield Line Theory 


\section{1- INTRODUÇÃO}

\subsection{DEFINIÇÕES E HISTÓRICO}

Lajes-cogumelo, ou lajes sem vigas, são aquelas que se apóiam diretamente sobre pilares, sem a interposição de vigas. Os pilares podem ou não possuir um aumento da sua seção transversal, próximo da ligação com a laje, que é chamado capitel (figura 1.1), cuja principal finalidade é diminuir as tensões de cisalhamento nessa região, evitando o puncionamento da laje pelo pilar. Com o mesmo intuito, pode-se também aumentar a espessura da laje na região da ligação com os pilares.
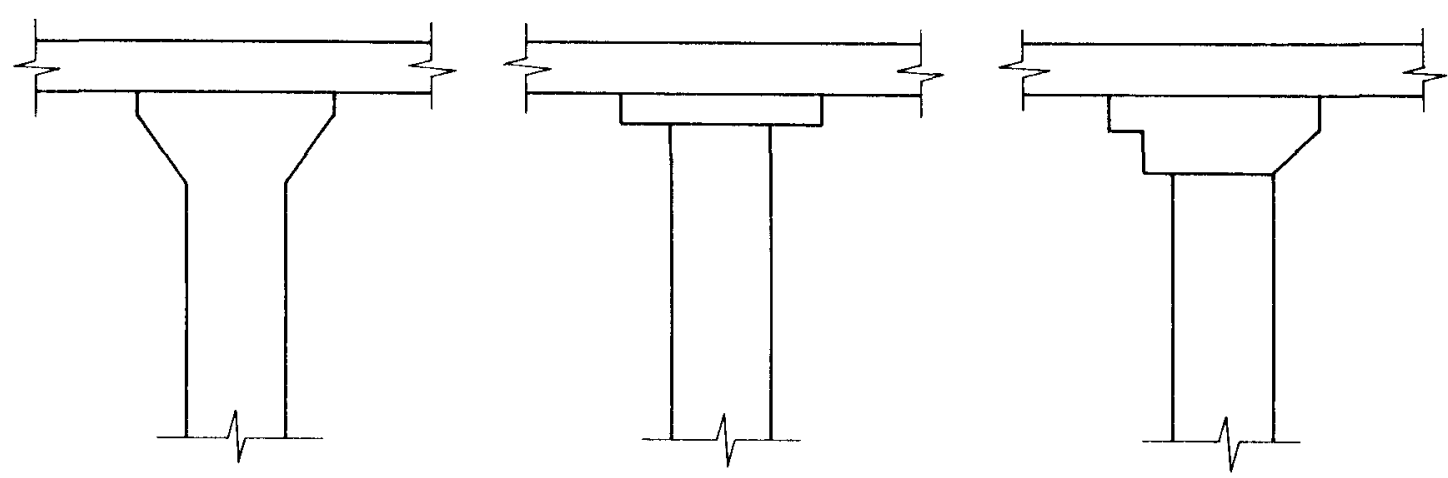

FIGURA 1.1 Alguns Tipos de Capitéis.

Nas primeiras lajes-cogumelo, o uso de capitéis era muito comum, fazendo com que os conjuntos constituídos pelas lajes, pilares e capitéis se assemelhassem aos cogumelos, daí a denominação laje-cogumelo. Porém, com o passar do tempo, o uso de capitéis foi sendo reduzido, chegando-se aos tetos planos. Nesses casos, diversos nomes são utilizados, entre os quais se encontram: lajes sem vigas, lajes lisas e lajes planas. 
Nos Estados Unidos, o aumento da espessura das lajes é denominado drop panel e as estruturas com capitéis ou drop panels são chamadas de flat slabs (figura 1.2). As estruturas sem capitéis ou drop panels são chamadas de flat plates (figura 1.3). No Brasil, há uma tendência de se chamar de lajes-cogumelo, as lajes apoiadas sobre pilares com capitel e lajes planas ou lisas as lajes apoiadas sobre pilares sem capitel.

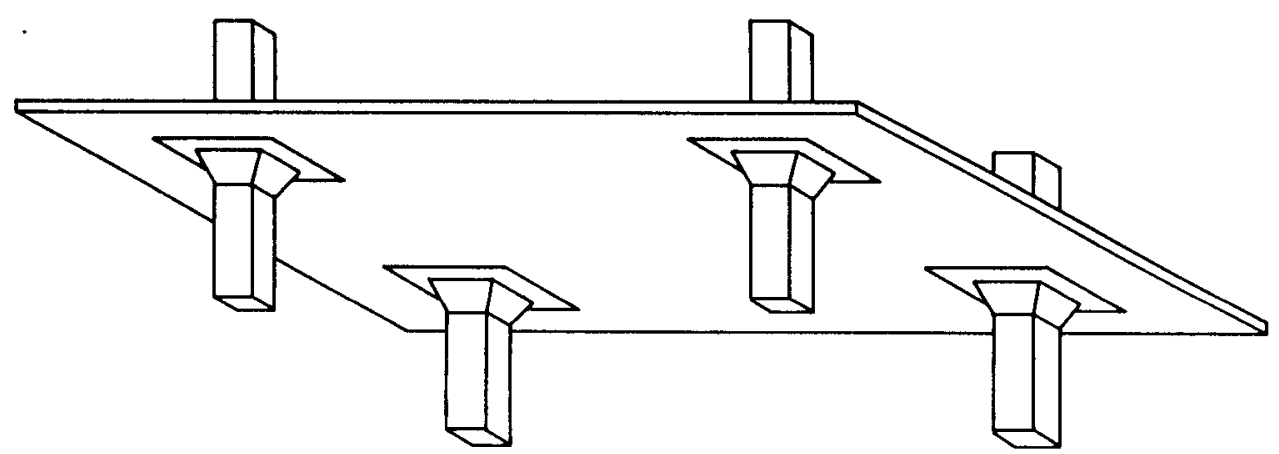

FIGURA 1.2- Flat Slab (laje-cogumelo com capitel).

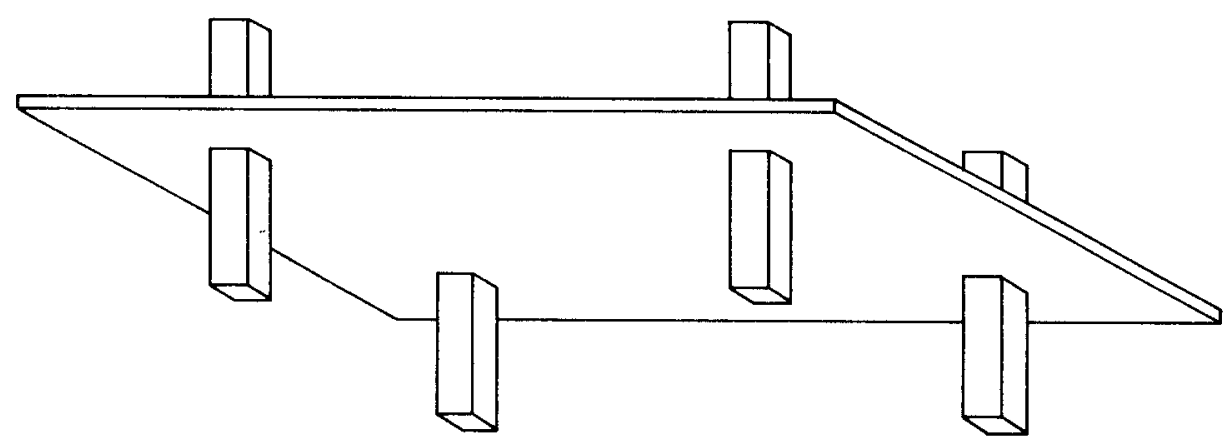

FIGURA 1.3- Flat Plate (laje-cogumelo sem capitel).

As lajes-cogumelo surgiram nos Estados Unidos, em 1905, por iniciativa de TURNER (1905) , com a construção do edifício C. A. Bovey Building em Minneapolis, Minnesota. Houve grande polêmica entre os engenheiros, que pode ser entendida pelos resultados apresentados nos trabalhos de MCMILLAN (1910) e BRAYTON 
(1910), que mostraram variações de até $400 \%$ na quantidade de armadura requerida por vários processos de cálculo, para a mesma laje e o mesmo carregamento.

A necessidade de se conhecer melhor o comportamento e formular processos de cálculo eficientes e seguros levou vários pesquisadores a estudar este novo sistema estrutural.

TALBOT (1913) realizou estudos experimentais em lajes sem armaduras de combate à punção; entre 1911 e 1914, BACH e GRAF (1915) realizaram ensaios em laboratórios para estudar a resistência à flexão das lajes-cogumelo. Em seguida a estes trabalhos, vieram inúmeros outros, podendo ser citados os de GRAF (1933), RICHART (1948), HOGNESTAD (1953), MOE (1961) e KINNUNEN (1963).

Houve grande evolução também nos processos de cálculo. MARCUS (1924) estudou as lajes-cogumelo pela Teoria de Elasticidade, resultando na formulação do Processo dos Pórticos Múltiplos. JOHANSEN (1943) publicou sua tese de doutoramento sobre a formulação da teoria das "Linhas de Ruptura", que contribuiu bastante para o do cálculo das lajes-cogumelo.

Com o advento dos computadores, e atualmente dos microcomputadores, o cálculo das lajes-cogumelo pode ser feito utilizando-se os processos das Diferenças Finitas, Analogia de Grelha, Método dos Elementos Finitos e outros, apresentando resultados com precisão satisfatória e a vantagem de permitir a análise de sistemas com qualquer forma, disposição de pilares e carregamento.

\section{2- VANTAGENS DAS LAJES-COGUMELO}

As estruturas em lajes-cogumelo apresentam uma série de vantagens em relação às estruturas com lajes, vigas e pilares, tais como:

- simplificação na execução e redução nos custos das fôrmas;

- armaduras mais simples, possibilitando o emprego de telas soldadas;

- maior facilidade no lançamento, adensamento e desforma do concreto;

- diminuição dos revestimentos;

- possibilidade de obtenção de tetos planos;

- redução da altura total do edifício;

- redução do tempo de execução da obra. 


\section{3- DESVANTAGENS DAS LAJES- COGUMELO}

Apesar de todas as vantagens citadas, existem algumas desvantagens do ponto de vista estrutural que devem ser bem analisadas, pois podem inviabilizar o uso deste sistema em certas situações.

\section{a) Punçăo}

É o principal problema das lajes-cogumelo e pode ser solucionado adequando a espessura das lajes e as dimensões dos pilares ou adotando armadura especifica de combate à punção.

\section{b) Deslocamentos tranversais}

Para mesma rigidez e mesmos vãos, o deslocamento central das lajescogumelo é maior do que aquele nas lajes sobre vigas.

c) Instabilidade global do edificio

A ausência de vigas, no caso de edificios altos, diminui a estabilidade global; nesse caso, deve-se vincular as lajes em paredes estruturais ou em núcleos rigidos.

\section{4- NOÇÕES SOBRE O CÁLCULO PLÁSTICO}

O cálculo plástico é baseado na Teoria da Plasticidade e admite que o material tenha comportamento rígido-plástico. Como o cálculo é feito na ruptura, permite a obtenção adequada da carga de ruína; por isso o cálculo plástico é mais coerente com o dimensionamento no estado limite último, uma vez que representa mais fielmente o comportamento da estrutura na ruina.

\subsection{1- Teoremas Fundamentais do Cálculo Plástico}

O cálculo plástico possui dois teoremas fundamentais: o Teorema Cinemático e o Teorema Estático. 


\section{a) Teorema Cinemático ou do Limite Superior}

Toda configuração de ruína cinematicamente admissivel é considerada um mecanismo. Segundo o teorema cinemático, toda carga correspondente a um mecanismo é igual ou superior à carga de ruína. Como a carga obtida é um limite superior, pode-se estar superestimando o valor da carga de ruina, sendo, portanto, contra a segurança.

\section{b) Teorema Estático ou do Limite Inferior}

Uma distribuição de esforços estaticamente admissivel e segura é aquela que em nenhum ponto ultrapassa a capacidade resistente da laje e satisfaz as condições de contorno. O teorema estático diz que todo carregamento, para o qual existe uma distribuição de esforços estaticamente admissivel e segura, é igual ou inferior à carga de ruina. O valor obtido para a carga de ruina é um limite inferior, portanto, a favor da segurança.

\subsection{2- A Teoria das Charneiras Plásticas}

A teoria das charneiras plásticas é uma aplicação do teorema cinemático, fornecendo um limite superior para a carga de ruina, portanto um valor contra a segurança. Na prática, porém, essa insegurança teórica não se verifica; os resultados experimentais demonstram que a carga efetiva de ruina é superior à obtida pela teoria das charneiras plásticas. Isto ocorre devido a uma reserva de resistência da laje, dada principalmente pelo efeito de membrana (PINHEIRO, 1988).

Num trabalho publicado em dinamarquês, INGERSLEV (1921) introduziu a teoria das charneiras plásticas. Nesse trabalho, publicado em inglês em 1923, Ingerslev não considerava as forças cortantes ao longo das linhas de plastificação, o que não permitia seu uso em todos os casos.

JOHANSEN (1931) apresentou um trabalho, também publicado em dinamarquês e em alemão no ano seguinte, no qual considerou as forças cortantes, substituindo seus efeitos por forças nodais, ou seja, forças que atuam nas interseções das linhas de plastificação e que são estaticamente equivalentes às forças cortantes ao longo das linhas de plastificação. 
Nos anos seguintes, muito pouco foi acrescentado à teoria; somente depois de 1950 é que ela tomou impulso, com inúmeros trabalhos publicados, entre os quais se pode citar no Brasil os de LANGENDONCK $(1970,1975)$.

\section{5- NOÇÕES SOBRE O CÁLCULO ELÁSTICO}

O método elástico, também conhecido como método clássico, é fundado na Teoria da Elasticidade e admite que o material seja homogêneo, isótropo, e tenha comportamento linear.

Nas condiçōes de serviço, as lajes comportam-se elasticamente, tornando o cálculo elástico indispensável para a verificação dos estados limites de utilização; é útil também como pré-dimensionamento para o cálculo plástico, na escolha da razão dos momentos de vão e na avaliação da relação entre os momentos negativos e positivos, que são dados de partida para o cálculo plástico.

\subsection{1- Equaçăo Diferencial das Placas}

O cálculo elástico das lajes de concreto armado baseia-se na teoria das placas delgadas e teve origem com Lagrange que, em 1816, estabeleceu a equação diferencial da deformada elástica.

Uma placa delgada, submetida a cargas normais ao seu plano, apresenta a deformada definida pela função $w(x, y)$, que determina os deslocamentos verticais dos pontos $(x, y)$ do plano médio. Admite-se que os pontos do referido plano médio só sofram deslocamentos verticais e que as retas normais ao plano médio permaneçam normais à superfície média deslocada.

Expressando as tensões e os esforços que aparecem na placa, em função dos deslocamentos verticais $w$, e impondo-se as condições de equilibrio em relação aos eixos $x, y$ e $z$, obtém-se a conhecida equação das placas elásticas ou de Lagrange:

$$
\frac{\partial^{4} w}{\partial x^{4}}+\frac{2 \partial^{4} w}{\partial x^{2} \partial y^{2}}+\frac{\partial^{4} w}{\partial y^{4}}=\frac{p}{D}
$$


onde,

p - é a carga total uniformemente distribuída,

D - é a rigidez à flexão da placa e vale:

$$
D=\frac{E h^{3}}{12(1-v)^{2}}
$$

E - é o módulo de deformação longitudina!,

h - é a espessura da placa,

$v$ - é o coeficiente de Poisson.

\subsection{2- Processos de Cálculo}

O cálculo pela teoria das placas exigiria a solução analítica da equação diferencial, que só existe para placas circulares. Pode-se obter soluções aproximadas com a utilização das séries de Fourier, para certos tipos de placas, ou por integração numérica (processo das diferenças finitas). Porém, essas soluções são muito trabalhosas para cálculo manual, nos casos de situações mais complexas.

Com a introdução de computadores e microcomputadores e com a evolução das técnicas computacionais, grandes avanços têm ocorrido na análise das placas.

Para o cálculo de lajes-cogumelo, têm-se diversos processos de cálculo, entre os quais se encontram:

- Método Direto, proposto pelos códigos do $\mathrm{ACl}(A C /$ 318-89 e versões anteriores);

- Processo dos Pórticos Múltiplos, proposto pela NBR 6118;

- Processo dos Pórticos Equivalentes, proposto pelo $\mathrm{ACl}$ ( $\mathrm{ACl} 318-89)$;

- Analogia de Grelha;

- Método dos Elementos Finitos.

\section{6- OBJETIVOS}

Apesar de haver vários trabalhos sobre os sistemas estruturais em lajescogumelo, são poucos os que utilizam o método plástico, que é o mais indicado para o dimensionamento das lajes de concreto armado. Pensando em minimizar essa 
carência de dados sobre o assunto é que se idealizou este trabalho, cujo principal objetivo é o projeto de lajes-cogumelo, através da associação do cálculo elástico com a Teoria das Charneiras Plásticas.

Utiliza-se o cálculo elástico na determinação da razão das armaduras de vão e dos momentos de plastificação negativos; a Teoria das Charneiras Plásticas é empregada na determinação dos momentos de plastificação, com os quais é feito o dimensionamento.

\section{7- PLANEJAMENTO}

Nesta parte inicial, foram apresentadas algumas considerações gerais sobre as lajes-cogumelo, o cálculo plástico e o cálculo elástico.

No capítulo 2, encontra-se uma análise sucinta dos processos de cálculo em regime elástico, onde se apresentam noções sobre o Método Direto, o Processo dos Pórticos Múltiplos, o Processo dos Pórticos Equivalentes, a Analogia de Grelha e o Método dos Elementos Finitos.

Os fundamentos da Teoria das Charneiras Plásticas, juntamente com a descrição dos processos do equilibrio e da energia, noções dos efeitos das cargas concentradas e dos leques são apresentados no capítulo 3. A Teoria das Charneiras Plásticas, aplicada às lajes-cogumelo, é apresentada no capítulo 4 , onde se encontra a formulação para o cálculo dos momentos de plastificação, para os diversos tipos de painéis.

Exemplos de projetos de lajes-cogumelo, usando-se o cálculo elástico e a Teoria das Charneiras Plásticas, são apresentados no capitulo 5.

No capitulo 6 faz-se uma comparação dos resultados obtidos nos exemplos do capitulo 5 e apresentam-se também as conclusões e sugestões para novas pesquisas. 


\section{2- MÉTODOS ELÁSTICOS}

Neste capitulo são apresentados, de maneira sucinta, alguns dos métodos de cálculo de lajes-cogumelo, em regime elástico.

\section{1- MÉTODO DIRETO}

O Método Direto, para determinação de momentos em lajes, é apresentado no código $A C l$ 318-89, nos seus comentários, $A C l$ 318R-89, e também em MONTOYA et al (1976).

Este método se aplica a sistemas de lajes armadas em duas direções, tanto para aqueles com vigas entre todos os apoios, como para os sem vigas; aqui, porém, serão destacadas apenas as lajes sem vigas ou com vigas só nas bordas dos pavimentos. Ele possibilita a determinação, de forma simples e rápida, dos esforços de flexão em lajes e vigas de um painel, sem considerar dimensões e ações relativas a outros painéis.

O método consiste em se calcular nas duas direções, para cada painel, um momento total de referência, que é transformado, por meios de coeficientes, em um momento de referência positivo na seção central e dois momentos negativos nas seções dos apoios; em seguida, os momentos nas seções são divididos entre as faixas do painel.

\subsection{1- Definições}

A seguir são apresentadas algumas definições necessárias à apresentação do método. 
a) Painel - região delimitada pelas retas que unem os centros de pilares alinhados (figura 2.1).

b) Faixas de pilares ou faixas laterais - são faixas definidas para fins de projeto, que incluem a viga, caso exista, constituídas de duas partes; uma de cada lado da reta que delimita dois painéis adjacentes, cada uma com largura igual ou menor do dois valores: $0,25 \ell_{1}$ ou $0,25 \ell_{2}$ (figura 2.2 ).

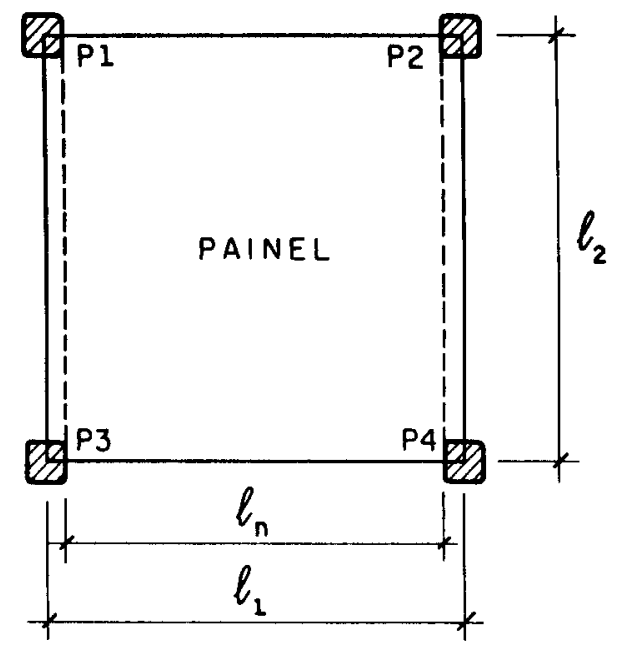

FIGURA 2.1- Identificação do painel.

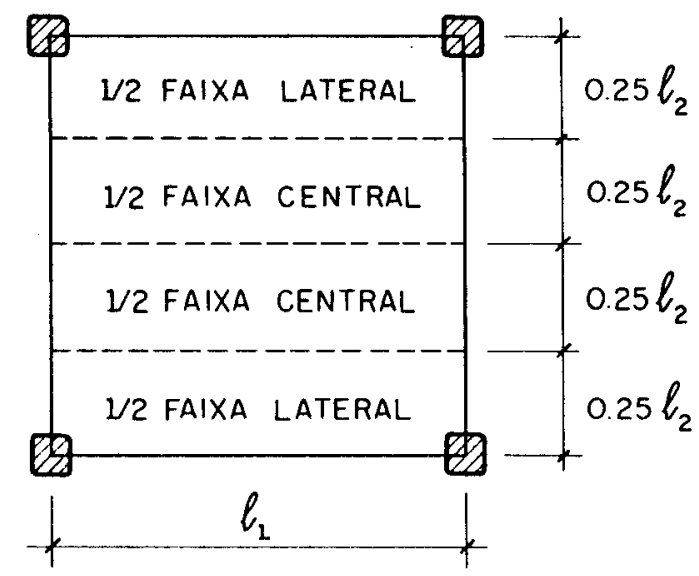

FIGURA 2.2- Identificação das meias-faixas centrais e laterais em um painel.

c) Faixas centrais - são as faixas delimitadas por duas faixas laterais (figura 2.2). 
d) Faixas de projeto - são faixas delimitadas pelos eixos de simetria de dois painéis adjacentes (figura 2.3), sendo formadas por uma faixa lateral e duas meiasfaixas centrais. Quando se tratar de vãos adjacentes e paralelos às bordas, as faixas de projeto serão delimitadas pelo eixo de simetria do painel de extremidade e pela borda do pavimento.

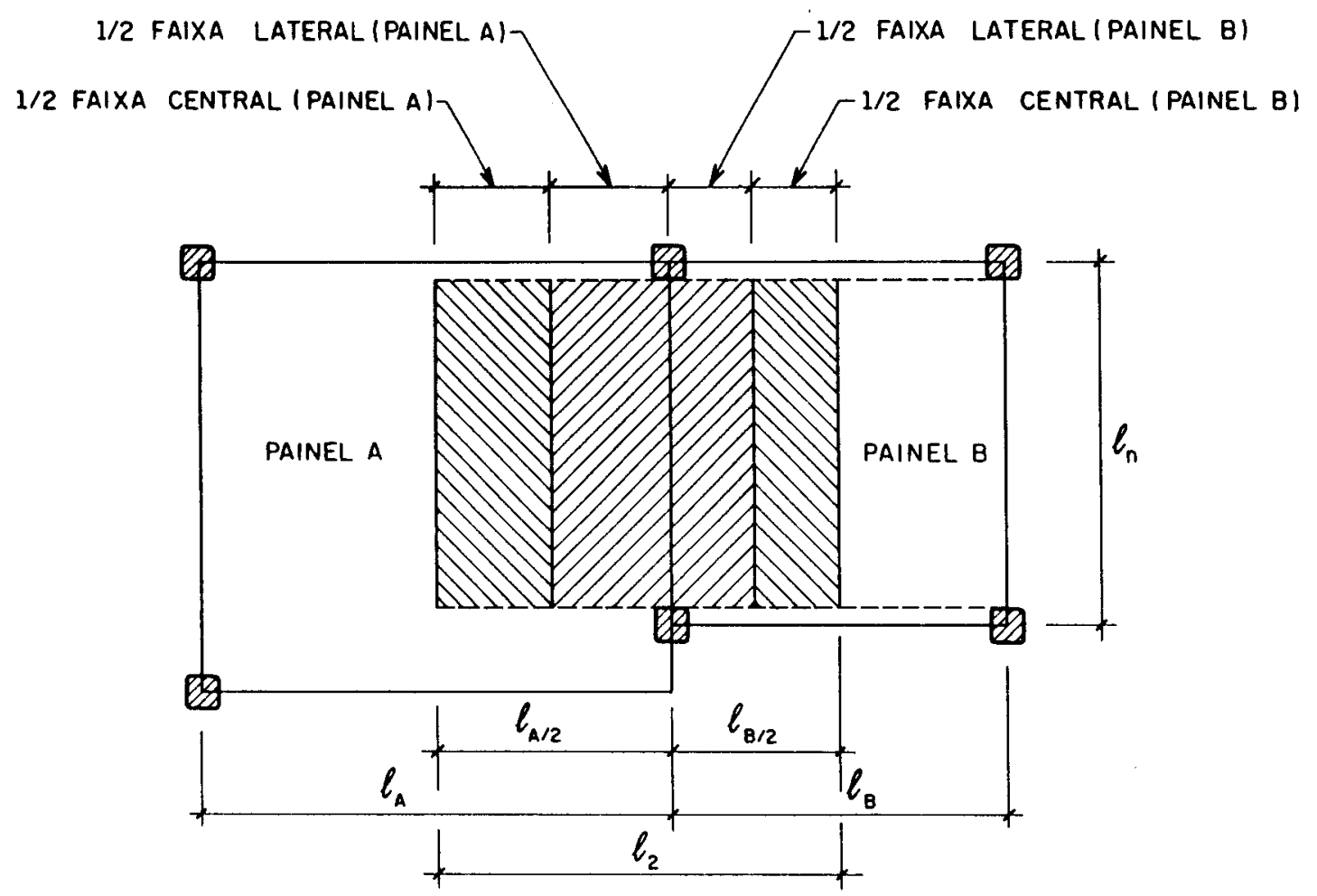

FIGURA 2.3 - Faixa de projeto.

\subsection{2- Notação Utilizada}

FP faixa de projeto;

ln comprimento do vão livre, medido na direção em que se estiver calculando os esforços (figura 2.1);

$\ell_{1}$ comprimento do vão teórico, medido na mesma direção de $\ell_{n}$ (figura 2.1);

l comprimento do vão teórico, medido segundo a direção perpendicular a $\ell_{1}$ (figura 2.1); quando as larguras dos dois painéis adjacentes 
forem diferentes, $\ell_{2}$ será tomado como a soma das médias dessas duas larguras (figura 2.3); quando se tratar de vão adjacente e paralelo a uma borda, $\ell_{2}$ será igual à distância entre essa borda e 0 centro do painel;

$M_{0}$ momento total de referência para o vão;

$M_{c} \quad$ momento positivo máximo no centro do vão;

$M_{A}, M_{B}$ momentos negativos nas extremidades dos vãos livres;

p carga total uniformemente distribuida sobre a laje $(g+q)$.

\subsection{3- Limitaçøes do Método Direto}

Por ser este um método aproximado, para que se possa aplicá-lo, o código $A C /$ 318-89 impõe as seguintes limitações:

a) o pavimento a ser analisado deve ser formado por, pelo menos, três painèis, segundo cada direção; a razão para esta limitação é o maior valor dos momentos negativos em apoios internos em estruturas com apenas dois vãos contínuos;

b) os painéis devem ser retangulares, com relação entre o maior e o menor vão teórico de cada painel não podendo ser maior que 2; caso contrário a laje trabalhará essencialmente em uma direção, situação para a qual o método não se aplica;

c) os vãos teóricos sucessivos, em cada direção, não poderão diferir em mais de um terço do comprimento do maior vão;

d) o desalinhamento máximo permitido para um pilar, em relação aos demais, é de $10 \%$ do vão teórico, medido em relação ao alinhamento dos demais pilares e segundo a direção em que ocorrer o desalinhamento;

e) todas as ações devem ser devidas à gravidade e uniformemente distribuidas sobre todo o painel, pois o método é baseado em informações obtidas só de ações gravitacionais uniformes, sendo que ações laterais requerem análise de pórtico;

f) a carga acidental não deve ser maior que o triplo da carga permanente (q $\leq 3 g)$. 


\subsection{4- Momento Total de Referência para um Vão}

O momento total de referência $M_{0}$ para um vão deve ser determinado para o carregamento total em uma faixa da laje de largura $\ell_{2}$ (figura 2.3) e é dado por:

$$
M_{0}=\frac{\left(p \ell_{2}\right) \ell_{n}^{2}}{8}
$$

O valor de $\ell_{n}$, na expressão acima, não deve ser menor que $0,65 \ell_{1}$.

Os pilares de seções tranversais circulares ou poligonais devem, para efeito de cálculo, ser tratados como sendo quadrados de mesma área, chamados pilares equivalentes (figura 2.4).
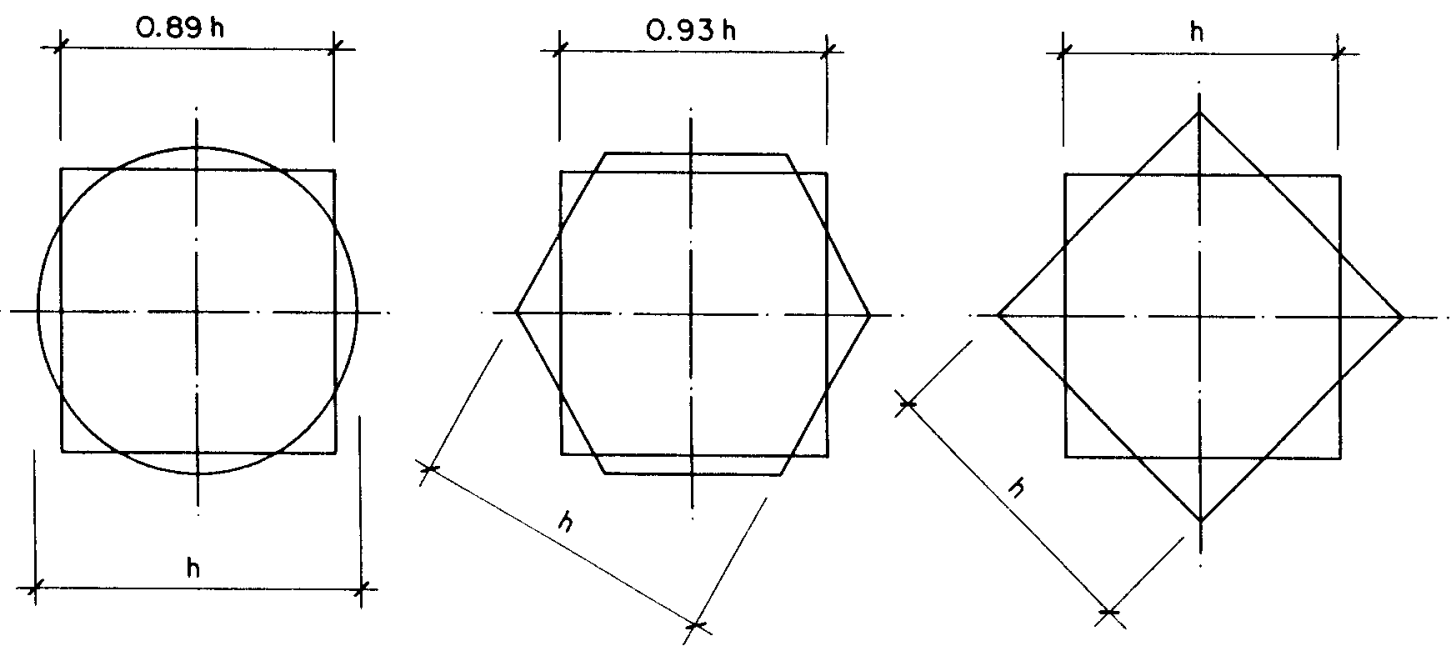

FIGURA 2.4- Pilares equivalentes para pilares de seções não retangulares.

\subsection{5- Momentos de Referência Positivos e Negativos}

O momento de referência positivo no meio do vão $M_{C}$ (seção $C$ da figura 2.5) e os momentos de referência negativos $M_{A}$ e $M_{B}$, que são supostos como atuando junto às faces dos pilares (seções $A$ e $B$ da figura 2.5), são obtidos, para vãos de extremidade ou central, a partir do momento total de referência $M_{0}$. 
a) Văos Centrais

Em vãos centrais, o momento total de referência deve ser distribuido como se indica a seguir.

$$
\begin{array}{ll}
\text { Momentos positivos: } & M_{C}=0,35 M_{0} ; \\
\text { Momentos negativos: } & M_{A}=M_{B}=0,65 M_{0} .
\end{array}
$$

\section{b) Văos de Extremidade}

Os vãos de extremidade possuem momentos negativos com valores diferentes nos dois extremos, dependendo do tipo de apoio. O momento total de referência é distribuido, neste caso, segundo os fatores de multiplicação para as diversas situações apresentados na tabela 2.1 .

\begin{tabular}{|c|c|c|c|c|c|}
\hline \multirow{3}{*}{$\begin{array}{c}\text { Tipo } \\
\text { de } \\
\text { Momento }\end{array}$} & 1 & 2 & 3 & 4 & 5 \\
\hline & \multirow{2}{*}{$\begin{array}{c}\text { Lajes com } \\
\text { borda } \\
\text { externa } \\
\text { livre }\end{array}$} & \multirow{2}{*}{$\begin{array}{l}\text { Lajes com } \\
\text { vigas em } \\
\text { todos os } \\
\text { lados }\end{array}$} & \multicolumn{2}{|c|}{$\begin{array}{c}\text { Lajes sem vigas entre } \\
\text { os apoios internos }\end{array}$} & \multirow{2}{*}{$\begin{array}{c}\text { Borda } \\
\text { externa } \\
\text { engastada }\end{array}$} \\
\hline & & & $\begin{array}{c}\text { Sem viga } \\
\text { na borda } \\
\text { externa }\end{array}$ & $\begin{array}{c}\text { Com viga } \\
\text { na borda } \\
\text { interna }\end{array}$ & \\
\hline $\begin{array}{c}\text { Momento } \\
\text { negativo } \\
\text { interno }\end{array}$ & 0,75 & 0,70 & 0,70 & 0,70 & 0,65 \\
\hline $\begin{array}{l}\text { Momento } \\
\text { positivo } \\
\text { no centro } \\
\text { do vão }\end{array}$ & 0,63 & 0,57 & 0,52 & 0,50 & 0,35 \\
\hline $\begin{array}{l}\text { Momento } \\
\text { negativo } \\
\text { na borda }\end{array}$ & 0,00 & 0,16 & 0,26 & 0,30 & 0,65 \\
\hline
\end{tabular}

TABELA 2.1- Fatores de Multiplicação para $M_{0}$. 
Para a utilização da tabela 2.1 devem ser observados os seguintes itens:

- os coeficientes da coluna 1 deverão ser utilizados quando a borda externa da laje for apoiada sobre paredes de alvenaria ou sobre paredes de concreto com articulação;

- os coeficientes da coluna 5 deverão ser utilizados quando a borda externa da laje for apoiada em uma parede de concreto, formando um conjunto monolítico, e a rigidez da parede à flexão for infinitamente maior que a da placa.

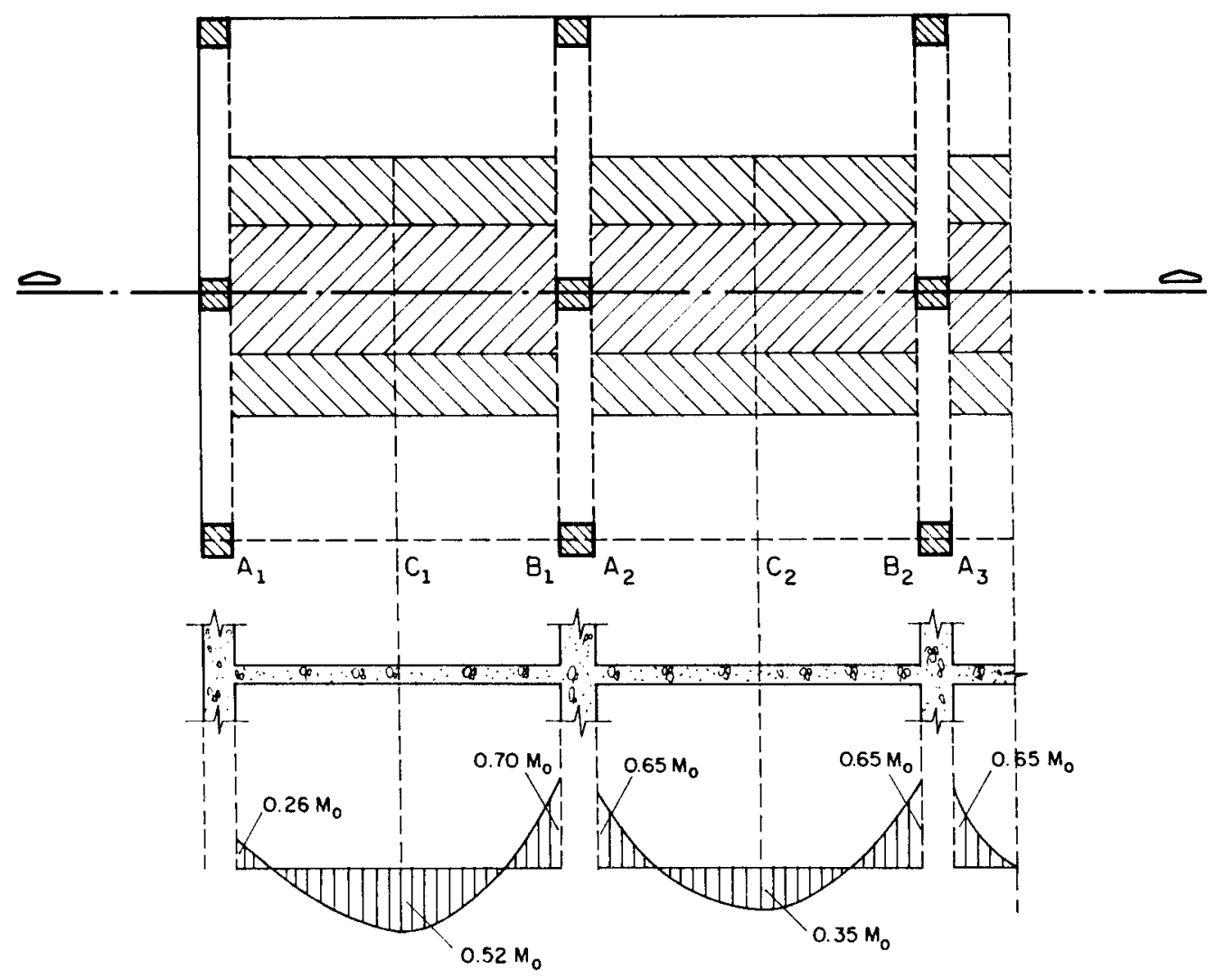

FIGURA 2.5- Distribuição dos momentos totais de referência para cada vão.

\subsection{6- Distribuição dos Momentos entre as Faixas}

É necessária a distribuição dos momentos de referência positivos e negativos, atuantes nas seções $A, B$ e $C$ da figura 2.5 , entre as faixas dos pilares e as faixas centrais. 
a) Momentos negativos

Para pilares internos, $75 \%$ do momento negativo serão absorvidos pela faixa de pilares e os $25 \%$ restantes serão divididos pelas duas meias-faixas centrais adjacentes a ela.

Para pilares de canto ou pilares de borda, o momento negativo será totalmente absorvido pela faixa de pilares.

\section{b) Momentos positivos}

Para o momento positivo, independente de ser um vão central ou externo, $60 \%$ do seu valor serão absorvidos pela faixa de pilares e os $40 \%$ restantes, divididos pelas duas meias-faixas centrais.

\section{2- PROCESSO DOS PÓRTICOS MÚLTIPLOS}

Este processo é baseado em estudo feito por MARCUS (1924), pela Teoria da Elasticidade. Consiste em representar uma estrutura de lajes, pilares e vigas, se houver, através de uma série de pórticos tomados nas duas direções dos planos ortogonais às bordas da laje; considerando-se que os pórticos correspondentes a cada direção recebam a totalidade da carga nas lajes, cada um deles é então calculado para as ações verticais contidas em sua área de influência, agindo no seu plano.

Apresenta-se a seguir como devem ser definidos os pórticos para o cálculo dos momentos fletores, seguindo o modelo sugerido pela NBR 6118 (1978).

\subsection{1- Definição dos Pórticos}

Para a divisão de um pavimento em duas séries ortogonais de pórticos, como recomenda a NBR 6118, traçam-se retas pelos centros dos pilares alinhados, dividindo o pavimento em faixas com largura $\ell_{2}$ (figura 2.6) iguais aos vãos teóricos dos painéis, segundo a direção perpendicular à que se estiver calculando os momentos. 


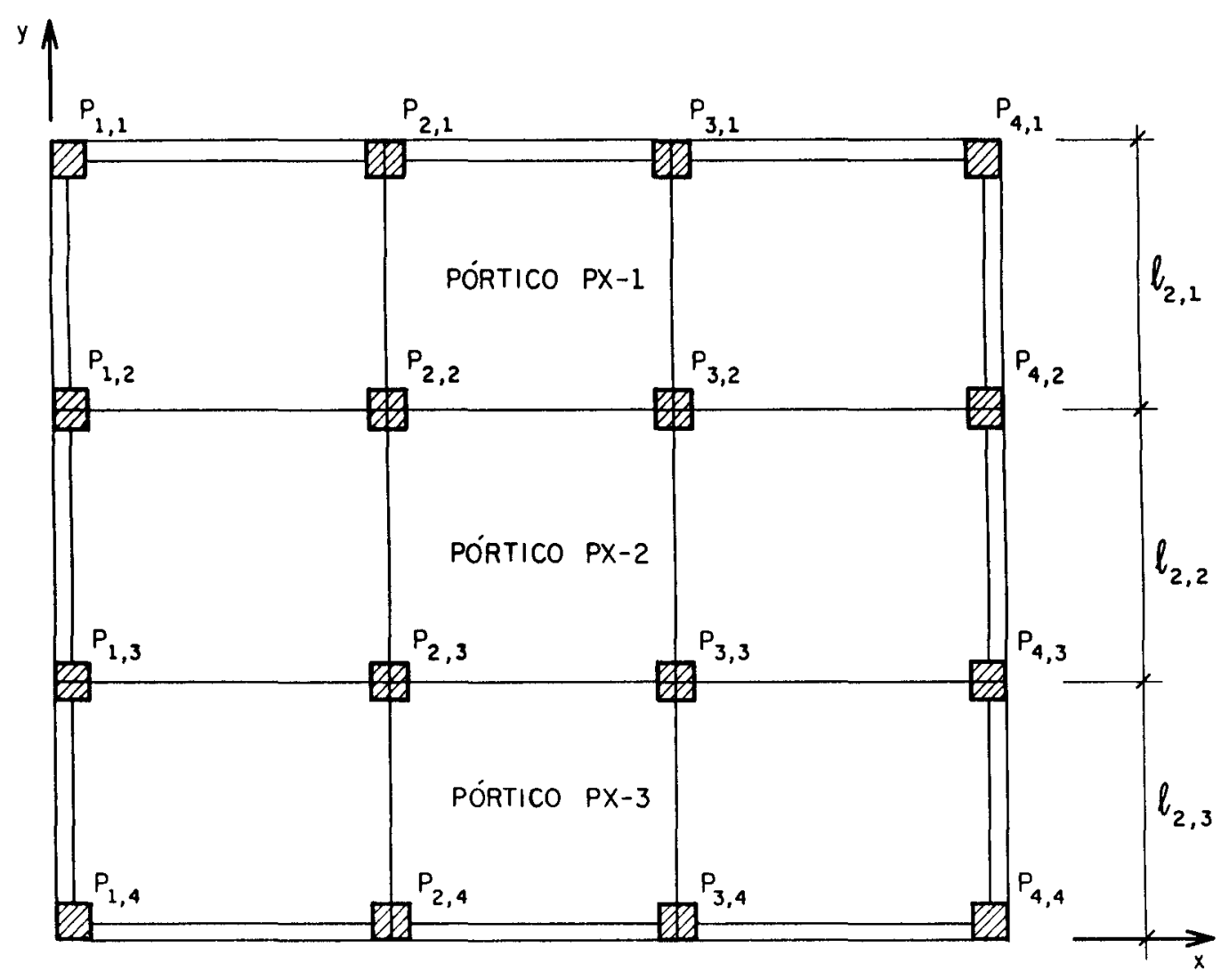

FIGURA 2.6- Definição dos pórticos múltiplos.

As vigas dos pórticos serão as faixas de largura $\ell_{2}$ e terão as alturas iguais às espessuras dos repectivos painéis e as larguras iguais a $\ell_{2}$.

Seja um pórtico genérico $i$ de um pavimento; sua viga terá as seguintes características geométricas:

a) área da seção transversal

$$
A_{i}=\ell_{2, i} \cdot h
$$

b) momento de inércia

$$
I_{i}=\frac{\ell_{2, i} h^{3}}{12}
$$

Para se determinarem as características dos pilares, deve-se lembrar que as retas que delimitam o pórtico dividem os pilares ao meio; portanto, as características geométricas do pilar $j$ do pórtico genérico $i$ serão dadas por: 
a) área da seção transversal

$$
A_{j, i}=\frac{A_{j, i}+A_{j, i+1}}{2}
$$

b) momento de inércia

$$
I_{j, i}=\frac{I_{j, i}+I_{j, i+1}}{2}
$$

$O$ índice $i$ no segundo membro das equações 2.4 e 2.5 se refere ao número da linha de pilares.

\subsection{2- Cálculo e Distribuiçăo dos Momentos Fletores}

Uma vez definidos os pórticos, o cálculo dos esforços pode ser feito manualmente, através do processo dos esforços ou do processo dos deslocamentos, ou por computadores, através de programas para resolução de pórticos.

De posse dos momentos fletores atuantes no pórtico, é necessário que se faça a distribuição desses momentos no painel. Para isso, divide-se cada painel em quatro faixas de igual largura (figura 2.7), sendo duas faixas centrais, ou internas, e duas faixas laterais, ou externas, e procede-se a distribuição, segundo a NBR 6118 , da seguinte maneira:

$45 \%$ dos momentos positivos para as duas faixas internas;

$27,5 \%$ dos momentos positivos para cada uma das faixas externas;

$25 \%$ dos momentos negativos para as duas faixas internas;

$37,5 \%$ dos momentos negativos para cada uma das faixas externas.

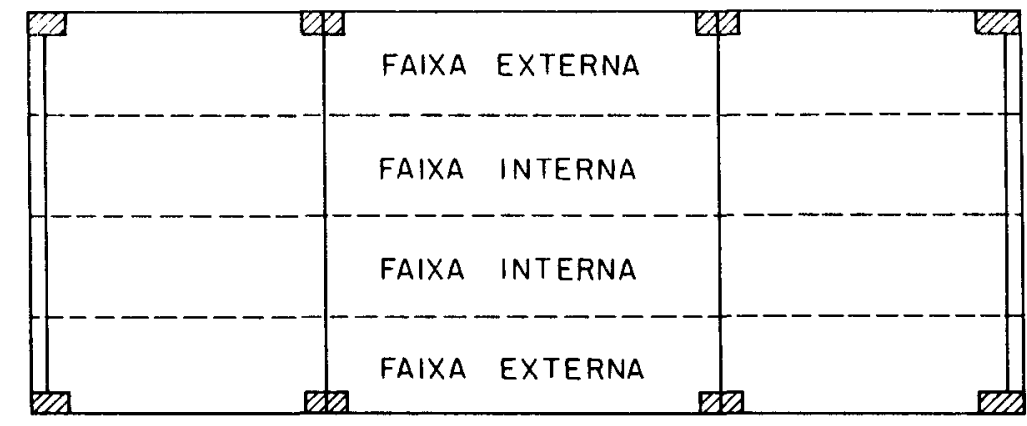

FIGURA 2.7- Divisão de um painel em faixas 
Após a distribuição dos momentos entre as faixas deve-se dividir os valores referentes a cada faixa por suas repectivas larguras, obtendo-se assim os valores dos momentos para faixas de 1,0 metro de largura.

\section{3- PROCESSO DOS PÓRTICOS EQUIVALENTES}

É um modelo estrutural alternativo para o Processo dos Pórticos Múltiplos proposto em MONTOYA et al (1976) e é baseado nas prescrições do código $\mathrm{ACl}$ 318-89.

\subsection{1- Definiçăo dos Pórticos}

Os pórticos devem ser centrados nas linhas que unem os centros dos pilares e ter larguras delimitadas pelas linhas centrais dos painéis adjacentes (figura 2.8). As faixas da laje são as mesmas do Método Direto, apresentadas anteriormente (figura 2.2).

\subsection{2- Cálculo dos Momentos Fletores}

Para o cálculo dos momentos fletores pode-se considerar, como hipótese de carregamento, a carga total em todos os vãos, não necessitando que se procurem as situações mais desfavoráveis, se a soma das cargas acidentais não ultrapassar $75 \%$ da carga permanente. Se essa condição não for atendida, deve-se estudar as seguintes hipóteses:

a) carga permanente em todos os vãos e $75 \%$ da carga acidental em vãos alternados, para se determinar os momentos positivos;

b) carga permanente em todos os vãos e $75 \%$ da carga acidental em vãos adjacentes, para se determinar os momentos negativos.

Se os vãos não forem muito diferentes entre si, e se forem consideradas apenas cargas verticais, pode-se calcular cada pórtico piso a piso, supondo-se os pilares engastados nos pisos contíguos. Dessa forma, e para edifício regulares, bastará calcular-se apenas alguns pórticos em cada direção. 


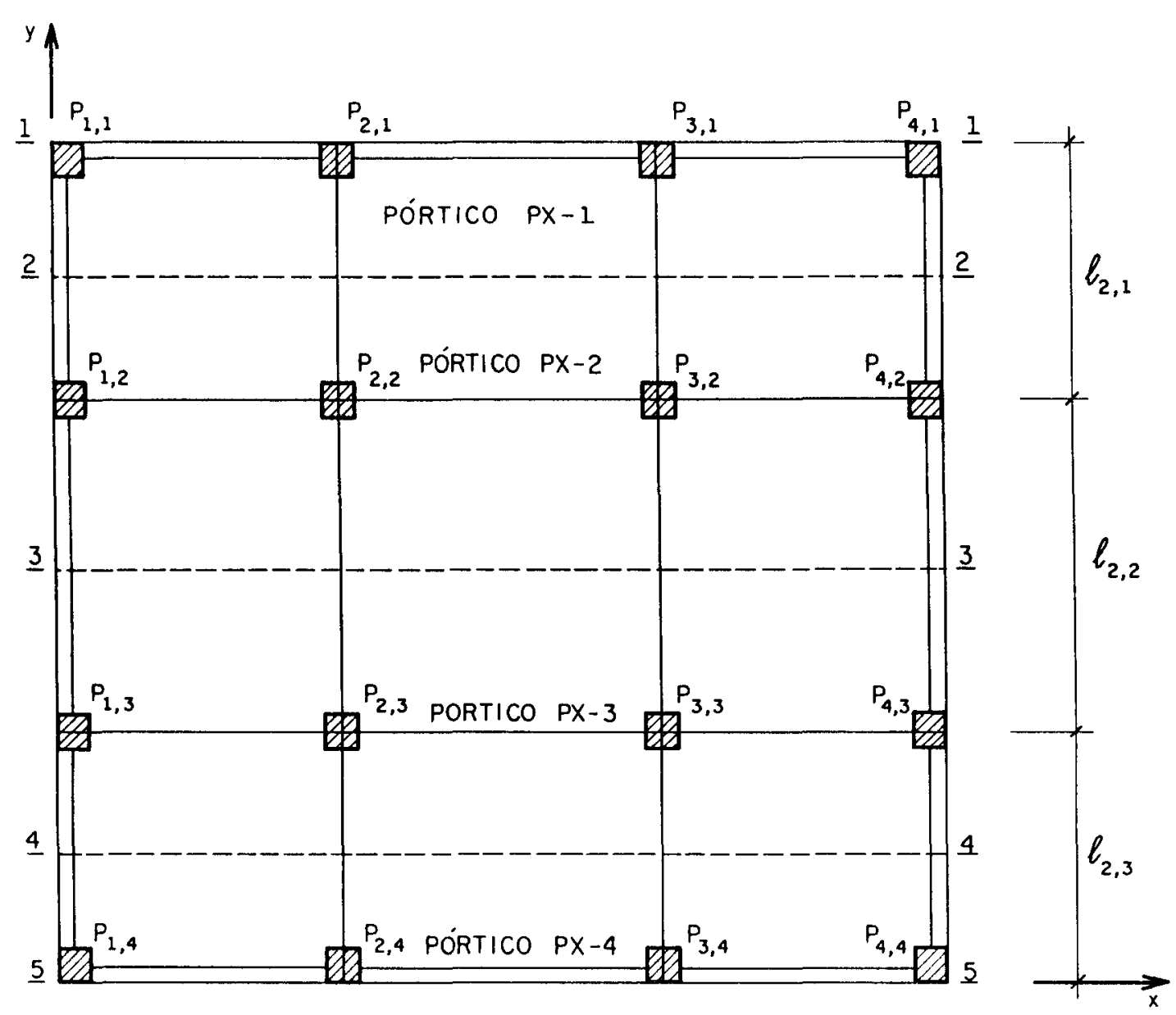

FIGURA 2.8- Definição dos pórticos equivalentes.

\subsection{3- Distribuição dos Momentos Fletores entre as Faixas}

Se a relação entre o maior vão teórico a e o menor $b$ for menor ou igual a $4 / 3$ (figura 2.9.a), ou seja,

$$
\frac{a}{b} \leq \frac{4}{3}
$$

então os momentos serão distribuidos de acordo com a tabela 2.2 (caso 1).

Se a relação $a / b$ for maior que $4 / 3$, as seguintes situações devem ser analisadas:

a) se os momentos estiverem sendo calculados na direção do lado menor (figura 2.9.b), a distribuição dos momentos será feita também de acordo com a tabela 2.2 (caso 1); 
b) se os momentos estiverem sendo calculados na direção do lado maior (figura 2.9.c), a distribuição de momentos será conforme a tabela 2.2 (caso 2).

TABELA 2.2- Fatores de Multiplicação dos Momentos para Distribuição entre as Faixas.

\begin{tabular}{|c|c|c|c|c|c|}
\hline \multirow{2}{*}{ Faixa } & \multirow{2}{*}{ Caso } & \multicolumn{2}{|c|}{ Painéis internos } & \multicolumn{2}{c|}{$\begin{array}{c}\text { Painéis externos } \\
\text { (momentos negativos } \\
\text { sobre o apoio } \\
\text { externo) }\end{array}$} \\
\cline { 3 - 6 } & & $\begin{array}{c}\text { Momentos } \\
\text { negativos }\end{array}$ & $\begin{array}{c}\text { Momentos } \\
\text { positivos }\end{array}$ & Caso A & Caso B \\
\hline \multirow{2}{*}{$\begin{array}{c}\text { Faixa } \\
\text { lateral }\end{array}$} & Caso 1 & 0,76 & 0,60 & 0,80 & 0,60 \\
\cline { 2 - 6 } & Caso 2 & 0,66 & 0,50 & 0,73 & 0,50 \\
\hline \multirow{2}{*}{$\begin{array}{c}\text { Faixa } \\
\text { Central }\end{array}$} & Caso 1 & 0,24 & 0,40 & 0,20 & 0,40 \\
\cline { 2 - 6 } & Caso 2 & 0,34 & 0,50 & 0,27 & 0,50 \\
\hline
\end{tabular}

* Os demais momentos devem ser distribuidos como nos painéis internos.

** Neste caso, faixa central se refere às duas meias-faixas centrais de cada pórtico múltiplo, cabendo, portanto, a cada uma a metade dos seus valores obtidos com o uso da tabela.

Para a tabela 2.2 valem as seguintes observações:

CASO 1 - Situações onde $a / b \leq 4 / 3$ ou $a / b>4 / 3$, se os momentos estiverem sendo calculados na direção do lado menor, de acordo com a figura 2.9.b.

CASO 2- Situações onde $a / b>4 / 3$ e os momentos estiverem sendo calculados na direção do lado maior, de acordo com a figura 2.9.c.

CASO A - Placa apoiada na borda sobre pilares.

CASO B - Placa apoiada na borda sobre parede de concreto armado ou sobre vigas com altura maior ou igual a três vezes a espessura da placa.

\subsection{4- Vantagens do Processo dos Pórticos Equivalentes}

O processo dos pórticos equivalentes, em relação ao processo dos pórticos múltiplos, apresentado no item 2.2.1, tem as seguintes vantagens: 
a) $\mathrm{Na}$ definição dos pórticos, as faixas de laje seriam as mesmas adotadas no pré-dimensionamento pelo Método Direto e estariam sujeitas ao mesmo carregamento uniformemente distribuido.

b) Não seria necessário dividir nem somar as áreas e os momentos de inércia das seções transversais dos pilares, já que os mesmos estariam situados inteiramente dentro das faixas de projeto.
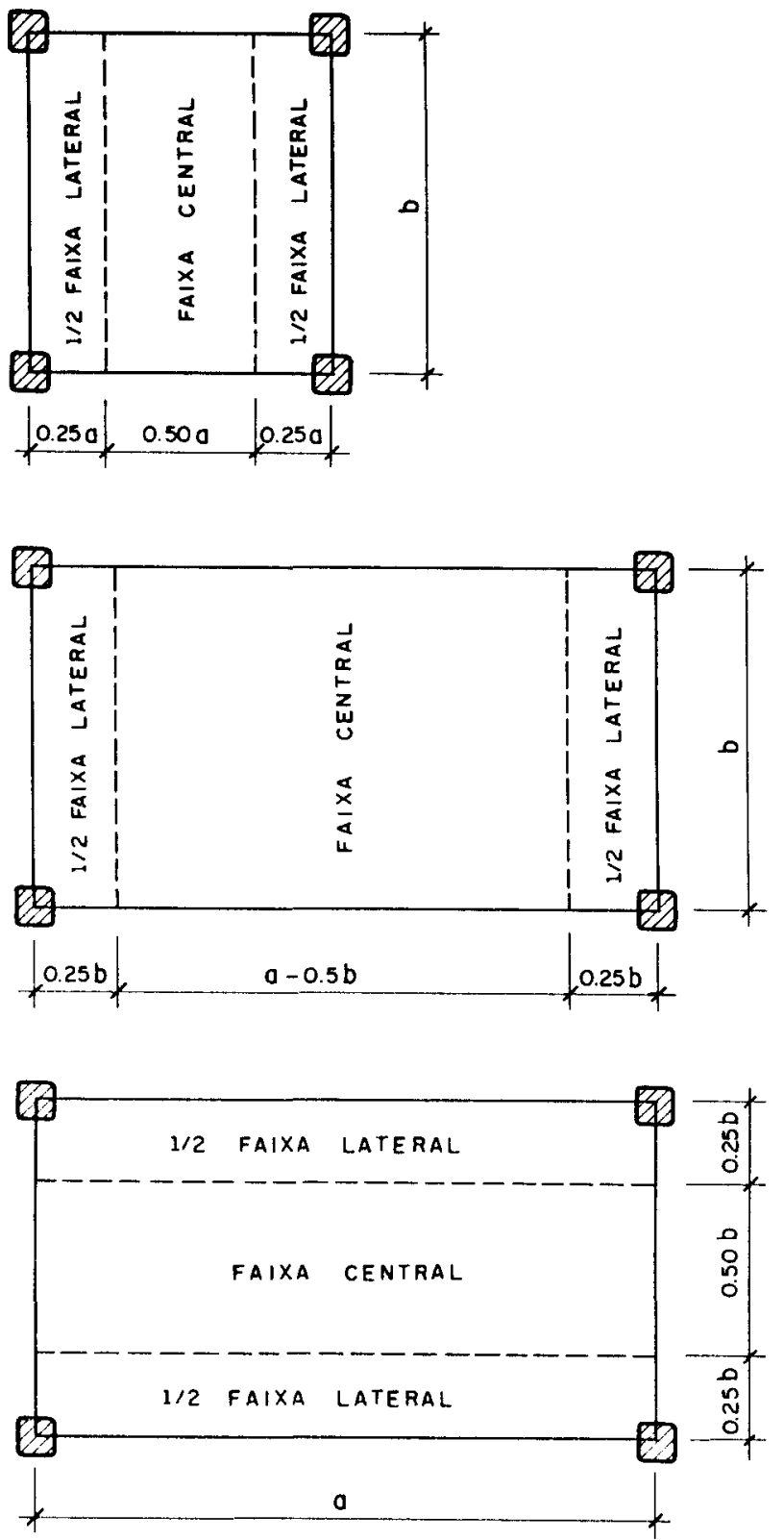

FIGURA 2.9-Divisão dos painéis para distribuıçäo dos momentos fletores. 


\section{4- ANALOGIA DE GRELHA}

Este método consiste em representar a laje por uma grelha (figura 2.10), chamada grelha equivalente, de forma que as rigidezes à flexão e à torção, distribuidas por toda a laje, sejam supostas concentradas nas barras dessa grelha.
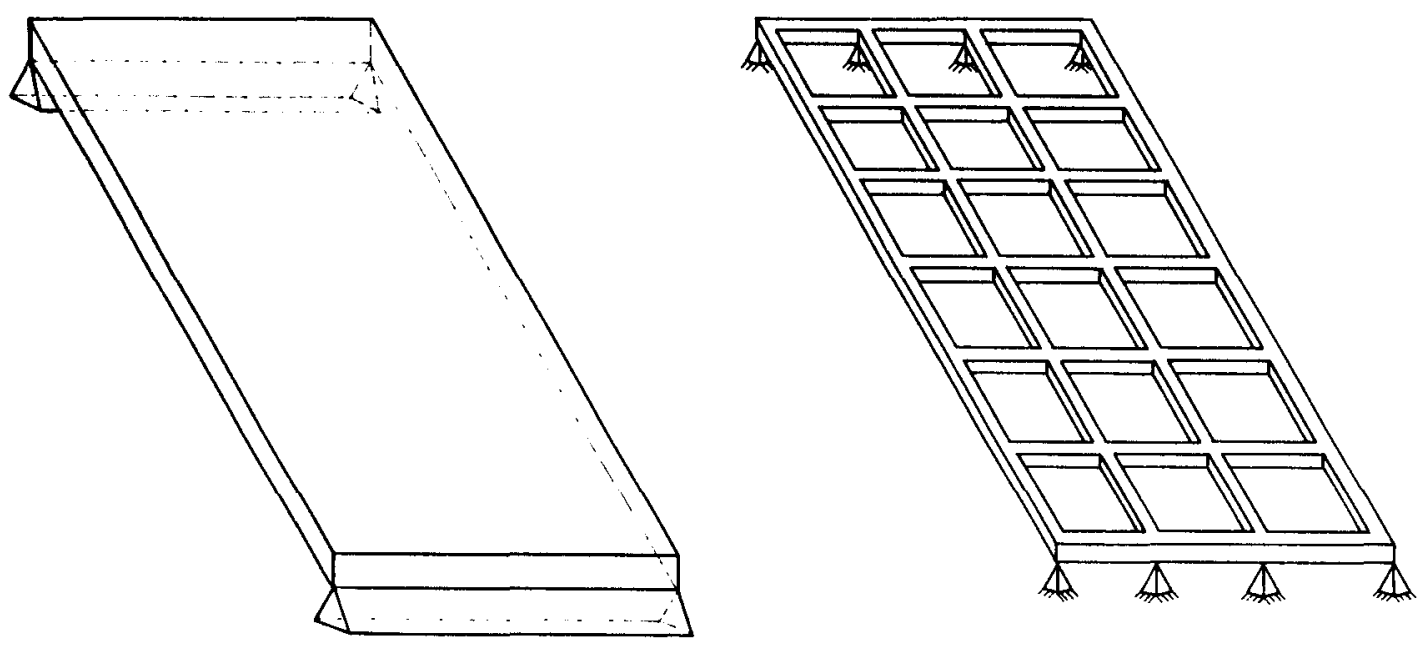

FIGURA 2.10- Laje e grelha equivalente.

As rigidezes das vigas devem ser tais que, quando a laje e a grelha equivalente são submetidas ao mesmo carregamento, as duas estruturas se deformem de modo idêntico. Momentos fletores, forças cortantes e momentos torçores, em qualquer viga da grelha equivalente, devem ser iguais às resultantes dos esforços na seção transversal da parte da laje que a viga representa. Isso nem sempre ocorre, em razão das diferenças características dos dois tipos de estruturas, mas se forem tomados cuidados na definição da malha e se forem conferidas propriedades adequadas às barras, as duas estruturas se comportarão de modo bastante próximo nas situações usuais de malhas uniformes.

As cargas distribuidas se dividem entre as vigas, de acordo com a área de influência de cada uma. Cargas concentradas, que não possam ser consideradas como distribuidas, devem ser aplicadas diretamente às vigas ou aos nós, adequandose à malha. 


\subsection{1- Definição da Malha}

Em razão da grande variedades de forma, dimensões, condições de apoio e carregamento das lajes-cogumelo, é difícil estabelecer roteiros que conduzam à malha mais adequada para a grelha equivalente. Entretanto, existem algumas regras gerais, propostas por HAMBLY (1976) e TAKEYA et al (1985), que devem ser adaptadas a cada situação de projeto. Essas regras são apresentadas a seguir.

a) Procurar colocar vigas da grelha equivalente em posições pré-determinadas pelo projeto, tais como em linhas de apoio, ao longo de vigas de borda ou de outras que existirem, que contenham uma ação especifica, etc.

b) Para placas isótropas, cada barra deverá ter uma largura no máximo igual a $1 / 4$ do vão transversal a seu eixo (figura 2.11),

$$
\begin{aligned}
& b_{x} \leq \frac{l_{x}}{4}, \\
& b_{y} \leq \frac{l_{y}}{4},
\end{aligned}
$$

sendo placa isótropa aquela que possui as mesmas caracteristicas elásticas, segundo todas as direções no seu plano.

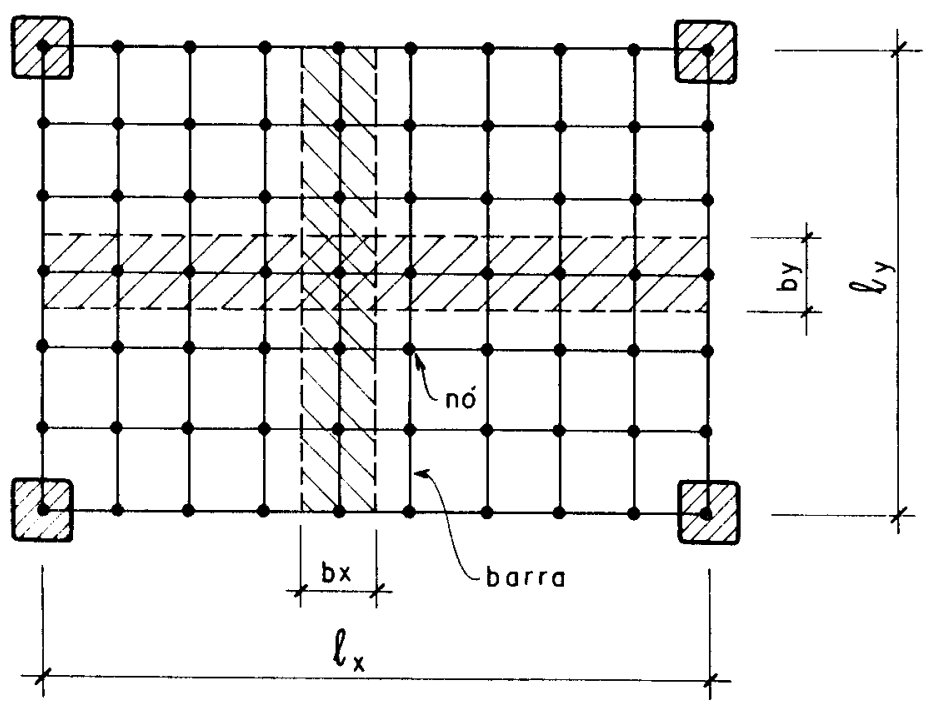

FIGURA 2.11- Representação esquemática de uma laje por analogia de grelha. 
c) Para placas ortótropas, ou seja, aquelas que possuem diferentes propriedades elásticas em duas direções ortogonais no seu plano, na direção da menor inércia, deve-se considerar a largura das barras no máximo igual a $40 \%$ do vão transversal ao seu eixo.

d) Quanto menores forem a largura e o comprimento das barras e, portanto, mais densa a malha, melhores serão os resultados. Entretanto, essa melhora cessará quando a largura das barras for menor que 2 ou 3 vezes a espessura da placa.

e) Para as partes da laje em balanço, será necessário colocar pelo menos duas barras tranversais ao seu vão.

f) Deve-se sempre colocar uma barra no contorno livre da laje, cuja largura para o cálculo do momento de inércia à torção deve ser diminuida de $0,3 h$, pois é aproximadamente nessa distância a partir da borda que atua a força cortante vertical, resultante das tensões verticais de cisalhamento devidas à torção; $h$ é a espessura da laje na região (figura 2.12).

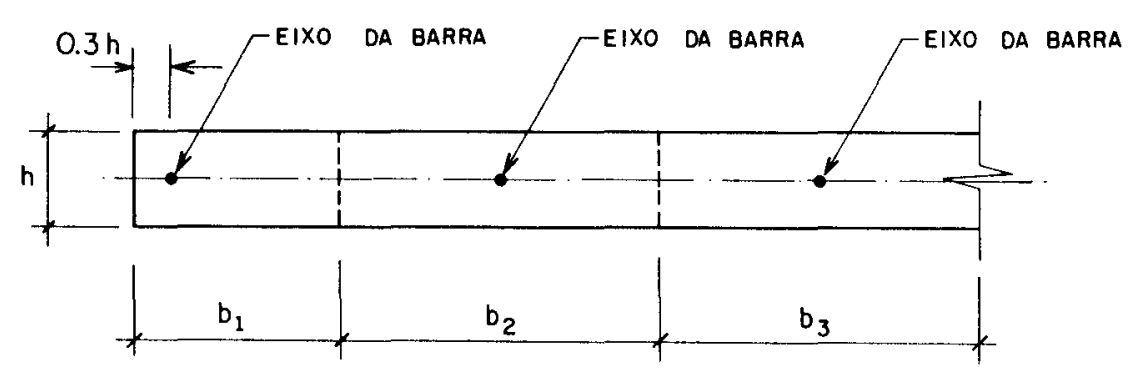

FIGURA 2.12- Detalhe da barra de borda.

g) Junto às regiões de grandes concentrações de esforços, tais como apoios ou cargas concentradas, é recomendável dispor-se uma malha, cuja largura das barras não seja superior a 3 ou 4 vezes a espessura das lajes.

h) Orifícios na laje cuja maior dimensão não exceda a $3 h$ não precisam ser considerados, a não ser que estejam muito próximos dos pilares.

i) Aberturas na laje de grande dimensão devem ser tratadas como borda livre, valendo as recomendações anteriores.

j) Os espaçamentos das barras, em cada uma das direções, não devem ser muito diferentes, para permitir uma distribuição uniforme de cargas. 


\subsection{2- Propriedades Geométricas das Barras}

Serão considerados os momentos de inércia à flexão e à torção.

\section{a) Momento de inércia à flexăo}

Para o cálculo do momento de inércia à flexão, das barras longitudinais e transversais, considera-se que cada uma representa uma largura $b$ de laje igual à distância entre os centros dos vãos adjacentes ao elemento (figura 2.11); assim:

$$
I=\frac{b \cdot h^{3}}{12}
$$

\section{b) Momento de inércia à torção}

O momento de inércia à torção, por unidade de largura de uma placa isótropa, é dado por,

$$
C=\frac{h^{3}}{6}
$$

e, para a viga da grelha equivalente que representa uma largura $b$ de laje,

$$
C=\frac{b \cdot h^{3}}{6}
$$

que é o dobro do momento de inércia à flexão; logo, $C=2 I$.

O momento de inércia à torção, por unidade de largura de placa ortótropa, deve ser igual nas duas direções e, portanto, também deve ser igual para as barras da grelha equivalente, podendo ser tomado como,

$$
C=2 \sqrt{I_{x} \cdot I_{y}}
$$

sendo

$I_{x}$ - momento de inércia por unidade de largura, das barras na direção $x$;

$I_{y}$ - momento de inércia por unidade de largura, das barras na direção $y$.

Portanto, para barras paralelas ao eixo $x$,

$$
C_{x}=b_{y} \cdot c
$$


e, para barras paralela ao eixo $y$,

$$
c_{y}=b_{x} \cdot c
$$

sendo

$b_{x}$ - largura das barras paralelas ao eixo $y$;

$b_{y}$ - largura das barras paralelas ao eixo $x$,

Lembrando que, para barra junto ao contorno livre da placa, deve-se considerar a largura de cálculo igual a $b-0,3 h$, tem-se, para a borda paralela ao eixo $\mathbf{x}$,

$$
C_{x}=\left(b_{y}-0,30 h\right) \cdot c
$$

e, para borda paralela ao eixo y,

$$
C_{y}=\left(b_{x}-0,30 h\right) \cdot C
$$

\subsection{3- Parâmetros Elásticos Equivalentes para o Concreto}

Para a avaliação aproximada das flechas que surgem nas lajes, devem-se fixar os parâmetros elásticos equivalentes para o concreto. Como parte da laje trabalha no Estádio I e parte no Estádio II e existe o efeito da retração e da deformação lenta do concreto, a fixação desses parâmetros torna-se uma tarefa difícil. Segundo TAKEYA et al (1985), verificou-se que, para pré-dimensionamento, pode-se ter uma avaliação relativamente segura das flechas, em lajes-cogumelo, considerando-se os valores, para o módulo de deformação do concreto, dados na tabela 2.3 .

TABELA 2.3- Módulo de Deformação do Concreto.

\begin{tabular}{|c|c|}
\hline$f_{c k}(M P a)$ & $E_{c}(M P a)$ \\
\hline 15 & 14000 \\
\hline 18 & 16600 \\
\hline 20 & 17500 \\
\hline
\end{tabular}

Para regiões onde a umidade relativa do ar é muito baixa, devem-se multiplicar por 0,75 os valores do módulo de deformação apresentados na tabela 2.3. 
O módulo de deformação transversal, também segundo TAKEYA et al (1985), pode ser determinado utilizando-se a seguinte relação:

$$
G_{c}=0,15 E_{c}
$$

\subsection{4- Influência das Rigidezes dos Pilares}

Para se considerar o efeito das rigidezes dos pilares nas lajes-cogumelo, pode-se utilizar um processo aproximado, que consiste em se acrescentar molas ortogonais aos apoios da grelha equivalente, com rigidezes equivalentes às do pilar.

Rigidezes dos pilares à flexão:

a) Para lajes do primeiro pavimento:

$$
K=\frac{7 E_{c} I}{\ell}
$$

b) Para lajes de cobertura:

$$
K=\frac{3 E_{c} I}{\ell}
$$

c) Para lajes intermediárias:

$$
K=\frac{6 E_{c} I}{\ell}
$$

sendo $\ell$ o pé direito médio entre os pavimentos.

\subsection{5- Análise dos Resultados}

Uma vez definida e carregada a grelha equivalente, são calculados os esforços nela atuantes e, para se obter os esforços por unidade de largura que atuam na laje, devem-se dividir os esforços pela largura das barras correspondentes.

Os diagramas de momentos fletores da grelha apresentam descontinuidades junto aos nós, como pode ser observado na figura 2.13. Isso ocorre devido ao efeito do momento torçor das barras transversais à linha de barras considerada. Para se 
obter o diagrama de momentos fletores da laje, deve-se considerar o momento fletor médio nos pontos de descontinuidades (figura 2.13).

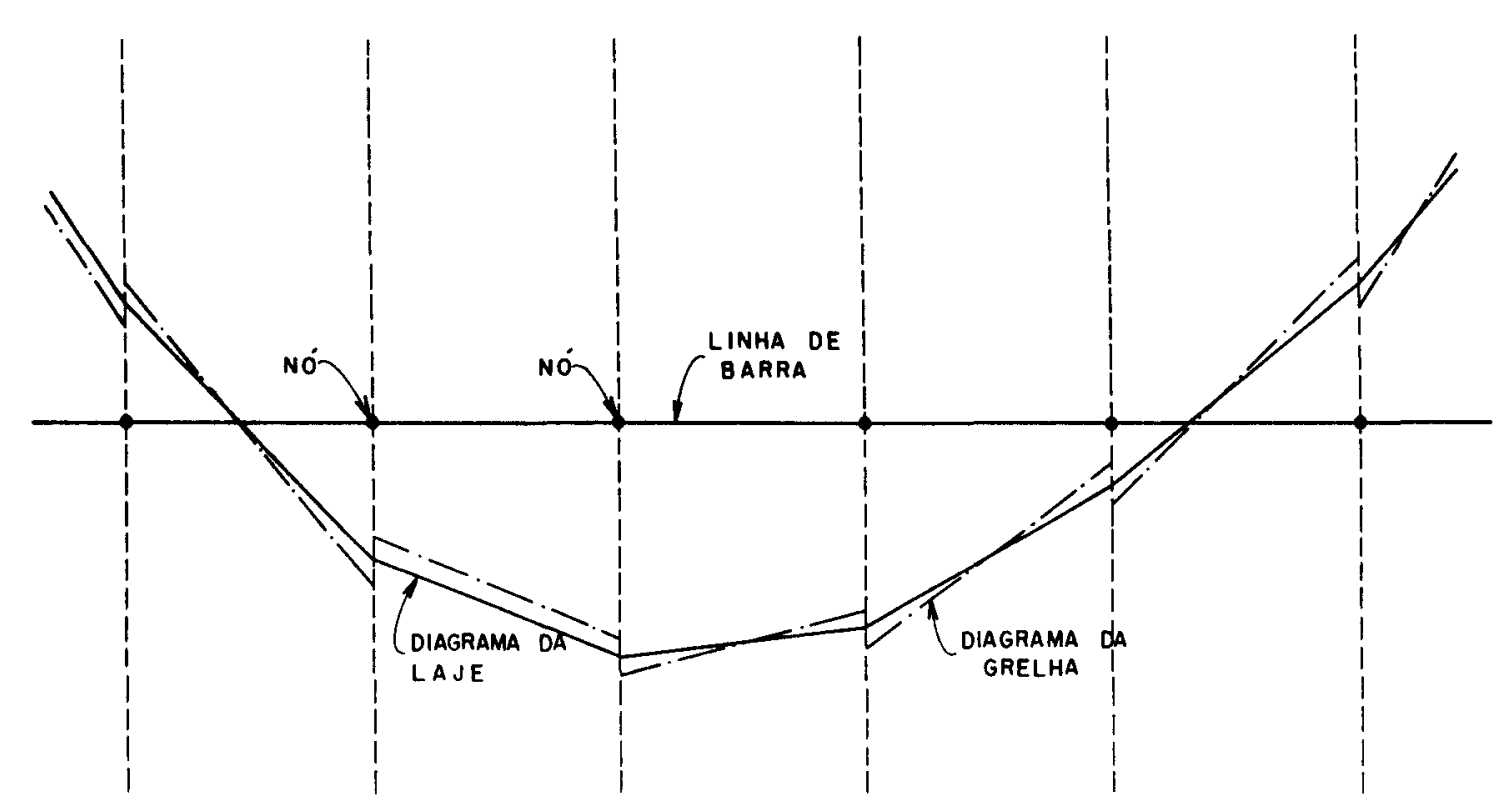

FIGURA 2.13- Obtenção do diagrama de momentos fletores da laje.

A grelha é calculada admitindo-se apoios pontuais, o que não ocorre na laje. Por isso, segundo CASTELO BRANCO (1989), pode-se arredondar o diagrama de momentos fletores da laje, procedendo da seguinte maneira:

Sejam $M_{A}$ e $M_{B}$ os momentos fletores que atuam nos nós $A$ e $B$, como mostrado na figura 2.14, e $M_{\text {MAX }}$ O momento no nó do apoio. No dimensionamento usa-se,

$$
M_{A R R E D}=\frac{M_{M A X}}{2}+\frac{M_{A}+M_{B}}{4}
$$




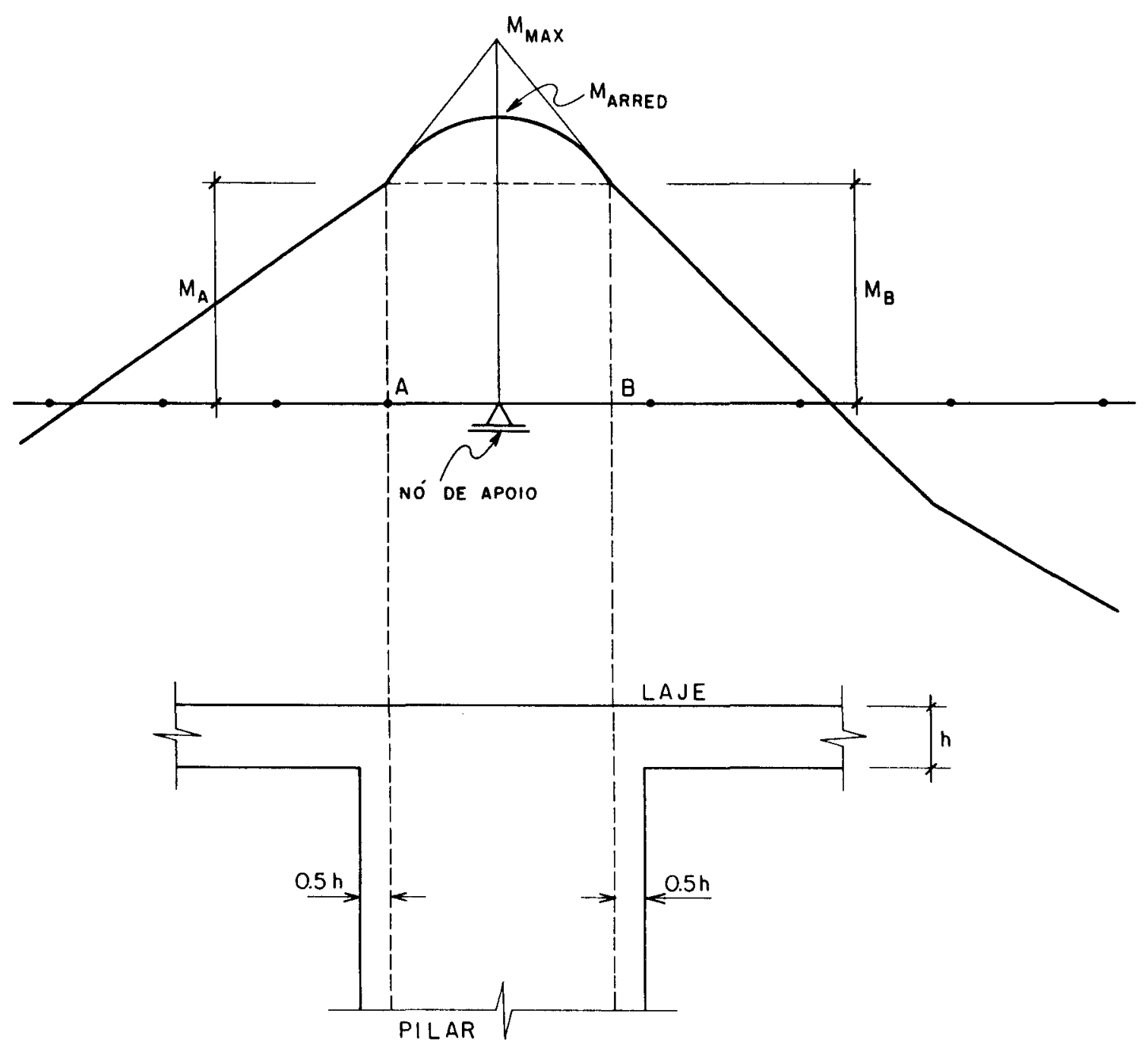

FIGURA 2.14- Arredondamento dos diagramas de momentos fletores junto aos apoios.

\section{5- MÉTODO DOS ELEMENTOS FINITOS}

O método dos elementos finitos consiste em modelar a estrutura através de elementos de dimensões finitas - os elementos finitos - por exemplo de forma retangular ou triangular, sendo possivel variar as dimensões e as caracteristicas elásticas de um elemento para o outro. Para esses elementos, estabelecem-se relações entre esforços e deslocamentos em um certo número de pontos, geralmente no seu contorno, resultando num sistema de equaçōes lineares. 
Através da consideração das condições de contorno, esse sistema de equações pode ser resolvido, permitindo o cálculo imediato dos esforços na laje. Os deslocamentos em pontos internos dos elementos são determinados em função dos deslocamentos nodais.

Este método pode ser aplicado a vários tipos de estruturas, principalmente em placas, das mais variadas formas e condições de apoio.

Mais informações sobre o método dos elementos finitos no cálculo de placas podem ser encontradas em ZIENKIEWICZ (1980). 


\section{3- A TEORIA DAS CHARNEIRAS PLÁSTICAS}

A Teoria das Charneiras Plásticas é um método de cálculo baseado no comportamento plástico da estrutura. Foi introduzida por INGERSLEV (1923) e melhorada e ampliada por JOHANSEN (1932), fazendo com que ficasse conhecida como Teoria de Johansen. Consiste em uma aplicação do teorema cinemático do cálculo plástico.

É importante observar que a Teoria das Charneiras Plásticas trata da ruína por flexão. A resistência à punção, bem como a resistência às forças cortantes, devem ser estudadas por métodos adequados.

\section{1- GENERALIDADES}

São apresentadas a seguir algumas noções básicas, necessárias ao entendimento da teoria das charneiras plásticas.

\subsection{1- Tipos de Ruína por Flexão}

As peças de concreto armado quando solicitadas à flexão podem atingir a ruina ou por ruptura do concreto à compressão ou por alongamento plástico excessivo da armadura de tração.

A ruptura do concreto à compressão pode ocorrer com o esmagamento das fibras comprimidas do concreto antes que o aço das fibras tracionadas tenham entrado em escoamento; por isso, a ruína ocorre de maneira súbita, sem que haja grandes deformações. As peças que apresentam este tipo de ruína são chamadas superarmadas. Elas devem ser evitadas, pois além de apresentarem uma ruina brusca, são antieconômicas, pois fazem mau aproveitamento do aço. 
A ruptura por alongamento plástico excessivo ocorre quando na armadura tracionada a barra de aço mais deformada apresenta um alongamento igual ao valor do alongamento último convencional $\varepsilon_{\text {su }}=10 \%$. Pode ocorrer também que 0 aço, ao ultrapassar seu limite de escoamento, faça com que surjam grandes acréscimos de deformação nas fibras tracionadas, sob tensão constante, provocando elevações sucessivas da linha neutra, com consequentes diminuições da área comprimida, fazendo com que a peça entre em processo de ruina por excesso de compressão, sem que 0 aço tenha atingido $o$ alongamento último convencional $\varepsilon_{\mathrm{su}}=10 \%$. As peças que rompem desta maneira são chamadas subarmadas.

As lajes usuais devem ser subarmadas, para não apresentarem os inconvenientes das lajes superarmadas, citados anteriormente.

\subsection{2- Momentos de Plastificação}

Uma laje subarmada, quando submetida a um carregamento proporcional, isto é, um sistema de forças que pode variar de zero até seu valor máximo, mas conservando-se proporcionais entre si, apresenta deformações como mostradas na figura 3.1.a.

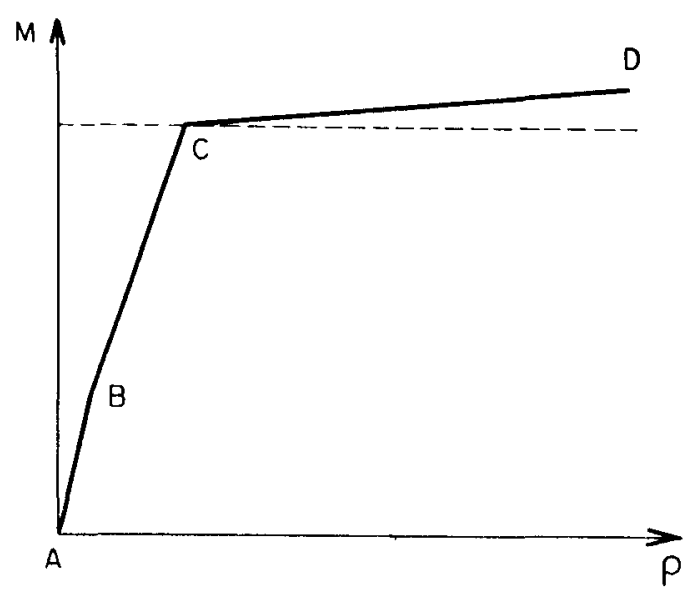

(a)

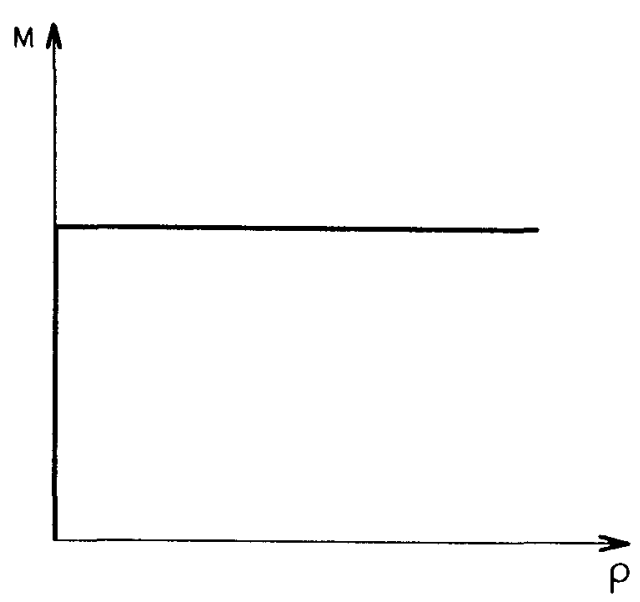

(b)

FIGURA 3.1- Diagramas momento-curvatura das lajes subarmadas.

O diagrama esquemático da figura 3.1.a apresenta uma fase inicial elástica $(A B)$, onde o concreto ainda resiste à tração e a laje trabalha no Estádio l; na 
segunda fase ( $B C$ ), apresenta-se o início da fissuração, com a laje trabalhando no Estádio II; a terceira fase vai do inicio do escoamento da armadura de tração, ponto $C$, até a ruptura do concreto por compressão, ponto $D$. É nesta terceira fase que as seções começam a plastificar-se, definindo as linhas de plastificação, também chamadas charneiras plásticas. O momento fletor atuante nas linhas de plastificação, admitido como constante, é o que se considera como momento de plastificação $M_{P}$. Após o desenvolvimento de todas as linhas de plastificação, a laje transforma-se num mecanismo. Quando a laje atinge a ruína, a carga máxima atuante é chamada carga de ruina e a configuração com que as linhas de plastificação se apresentam é chamada de configuração de ruína.

Como o momento fletor na fase de plastificação é considerado constante e as deformações elásticas em face das deformações plásticas podem ser desprezadas, o diagrama ideal a ser usado é o de material rígido-plástico, indicado na figura 3.1.b.

\subsection{3-Reserva de Resistência}

A aplicação da Teoria das Charneiras Plásticas leva a uma carga de ruína geralmente menor que a carga efetiva de ruina. Isto ocorre devido a uma reserva de resistência da laje, proveniente do endurecimento do aço e dos efeitos de membrana.

\section{a) Endurecimento do aço}

Para efeito de cálculo, considera.se que a tensão na armadura permanece constante após o início do escoamento, fato que não ocorre na realidade, pois mesmo para os aços de dureza natural e para os aços encruados, a tensão cresce com o aumento das deformações.

\section{b) Efeitos de membrana}

Para lajes com restrições aos deslocamentos horizontais, a mudança de forma do plano médio da laje faz com que surjam os efeitos de membrana, que aumentam a resistência da laje. São dois os efeitos de membrana: o efeito compressivo de membrana ou arqueamento e o efeito de membrana tracionada. 
O efeito compressivo de membrana surge quando, iniciada a fase de fissuração, a superficie neutra desloca-se em direção à face comprimida, caminhando para baixo na região dos apoios e para cima na região central da laje (figura 3.2). Este fato, para deslocamentos transversais pequenos, dá origem a um comportamento de casca.
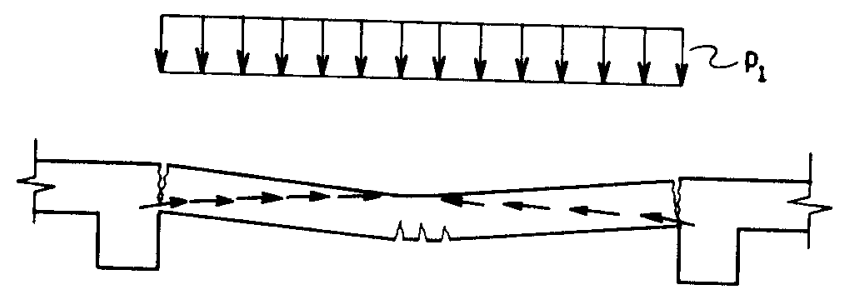

FIGURA 3.2- Efeito compressivo de membrana (arqueamento).

O efeito de membrana tracionada aparece na fase de plastificação, onde grandes deslocamentos fazem com que o efeito de arqueamento diminua até as forças longitudinais de compressão mudarem para tração, fazendo com que a laje se comporte como uma estrutura pênsil (figura 3.3), situação em que, praticamente, só as armaduras é que resistem aos esforços.
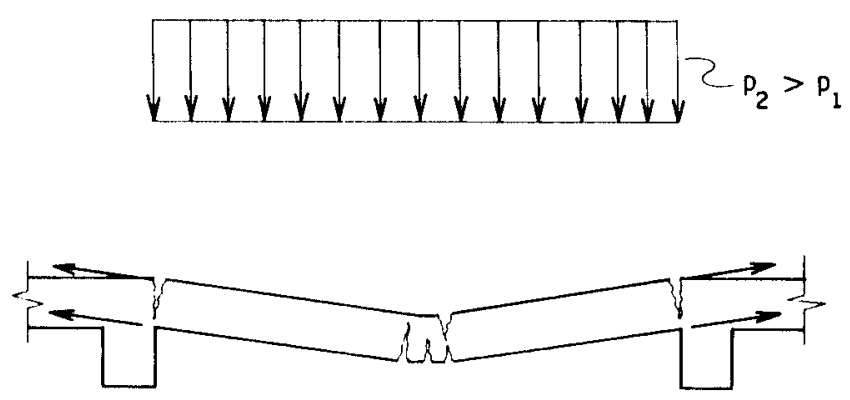

Higura 3.3- Efelto de membrana tracionada.

\section{2- FUNDAMENTOS DA TEORIA}

A Teoria das Charneiras Plásticas tem como finalidade a determinação dos momentos de plastificação, que devem ser atribuidos à laje, para que a ruina se dê sob a ação de cargas superiores às impostas no projeto. 


\subsection{1- Hipóteses de Cálculo}

Apresentam-se a seguir as hipóteses de cálculo da teoria das charneiras plásticas.

a) Não deverá ocorrer a ruptura do concreto comprimido antes do escoamento da armadura de tração, para que seja possivel o completo desenvolvimento das linhas de plastificação, com consequente formação do mecanismo de colapso. Ou seja, as lajes devem ser subarmadas.

b) Admite-se que a laje seja constituida por um material rigido-plástico (figura 3.1.b). Portanto, a superfície média da laje plastificada é poliédrica, sendo as charneiras consideradas retas delimitando regiões planas.

c) Não poderá ocorrer ruína prematura por cisalhamento ou por punção.

d) Como a laje é suposta constituída de material rígido-plástico, os momentos de plastificação, $m$ nos vãos e $m$ ' nos apoios, são admitidos constantes ao longo das charneiras plásticas.

e) A influência dos efeitos de membrana, provenientes do impedimento dos deslocamentos no plano da laje, é desprezada.

\subsubsection{Configurações das Charneiras}

Existem diversas configurações geometricamente possiveis para as charneiras, isto é, configurações que satisfazem às condições de apoio da laje, de maneira a ser geometricamente possivel a formação da superfície poliédrica da laje deformada. Para cada configuração das charneiras, encontra-se um determinado valor para o momento de plastificação; a configuração que apresentar o maior valor do momento de plastificação é denominada configuração de ruína. Portanto, devemse analisar todas as configurações possiveis para a determinação da configuração de ruína.

Para a determinação das diversas configurações possiveis, podem ser seguidas as seguintes regras:

- cargas distribuidas geralmente dão origem a charneiras retilíneas; 
- ao longo dos contornos engastados, aparecem charneiras superiores, chamadas de charneiras negativas, pois sorrespondem aos momentos considerados negativos (figura 3.4.a e figura 3.4.b);

- cada charneira passa pelo ponto de interseção dos eixos de rotação das regiões delimitadas por essas charneiras, sendo eixo de rotação aquele em torno do qual gira cada região da laje, delimitada pelas charneiras plásticas;

- os eixos de rotação das diversas regiões coincidem com os lados simplesmente apoiados, com lados engastados ou passam pelos pontos de apoio isolados (figura 3.4.b e figura 3.4.c);

- carga concentrada dá origem a charneiras positivas (radiais), que concorrem para ela, limitadas por charneira negativa curvilínea (figura 3.4.d).

a)
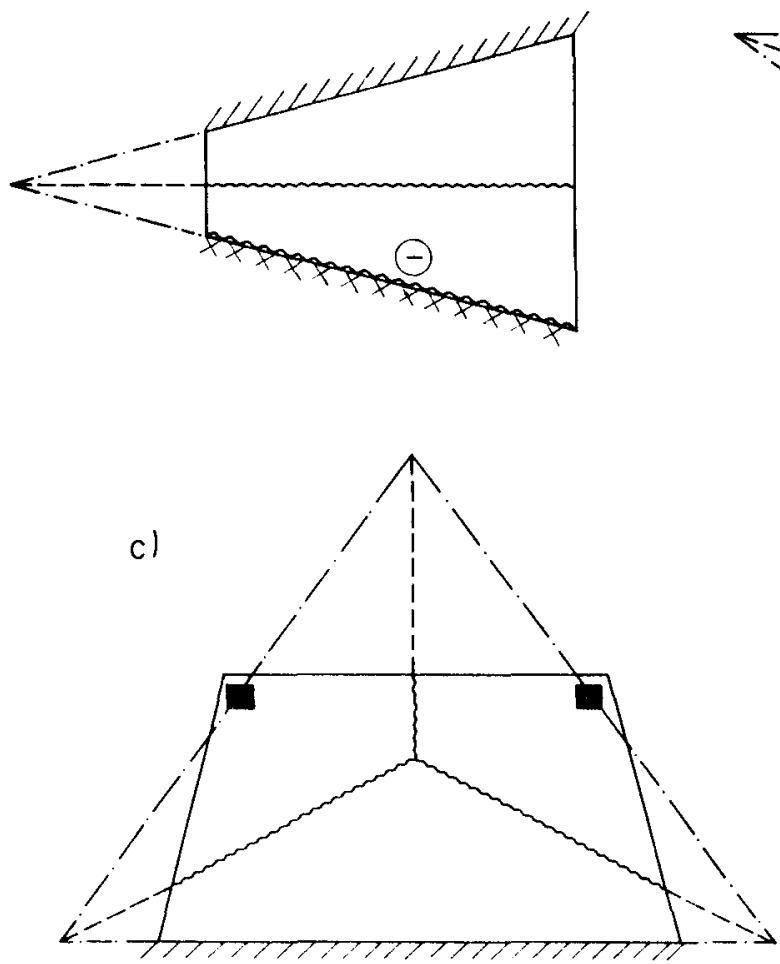

Legenda:

Пோ borda simplesmente apoiada;

$\times \times \times \times \times$ borda engastada;

borda livre, eixo de rotação; b)

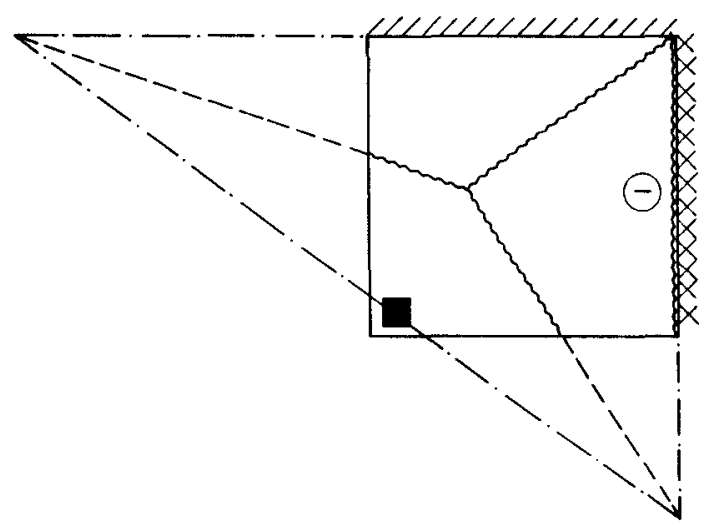

d)

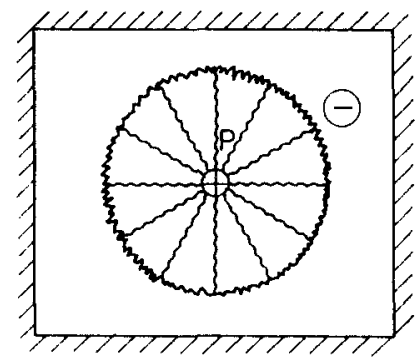

- ponto de apoio isolado; charneira plástica;

$\Theta \quad$ charneira negativa.

FIGURA 3.4- Exemplos de configurações possiveis. 


\section{3- PROCESSO DO EQUILÍBRIO}

A teoria das charneiras plásticas possui dois processos de cálculo: o primeiro é denominado processo do equilibrio ou processo das forças nodais e vem sendo utilizado desde o trabalho inicial de JOHANSEN (1932); o outro é o denominado processo da energia, que é mais recente e será visto no item 3.4 .

O processo do equilibrio consiste em se estabelecerem as equações de equilibrio de cada região da laje, delimitada pelas linhas de plastificação.

Seja uma laje, como a apresentada na figura 3.5.a, destacando-se a parte 1 da laje (figura 3.5.b) no instante que precede à ruína. Para que o equilíbrio da laje seja mantido deve-se aplicar, na parte destacada, a reação de apoio ao longo do contorno e, nas linhas de plastificação, os momentos de plastificação, as forças cortantes e os momentos torçores (figura 3.5.b). Como ao longo de uma linha de plastificação atua um momento $m$ por unidade de comprimento, o momento total atuante ao longo da linha de plastificação é igual ao produto do seu comprimento pelo valor de $m$. Resta então, determinar as forças cortantes e os momentos torçores. Estes esforços podem, segundo JOHANSEN (1962), ser considerados conjuntamente e substituidos por pares de forças concentradas estaticamente equivalentes $V_{E F}$ e $V_{F E}$ (figura 3.5.c), atuantes nas extremidades das linhas de plastificação, chamadas forças de transmissão.

$\mathrm{Na}$ figura 3.5.a, os pontos indicam forças de transmissão para cima, supostas positivas, e o sinal $x$ corresponde a forças de transmissão para baixo e de sinal negativo.

\subsection{1- Definiçăo das Forças Nodais}

Para o nó E da figura 3.5.a, pode-se escrever,

$$
\begin{aligned}
& K_{E 1}=V_{E A}-V_{E F} \\
& K_{E 2}=V_{E F}-V_{E D} \\
& K_{E 3}=V_{E D}-V_{E A}
\end{aligned}
$$




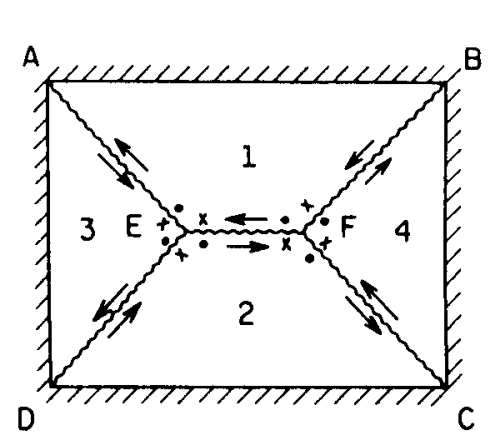

(a)

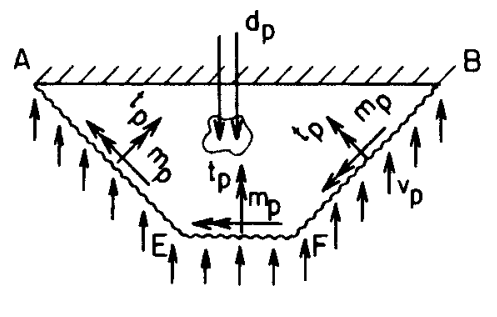

(b)

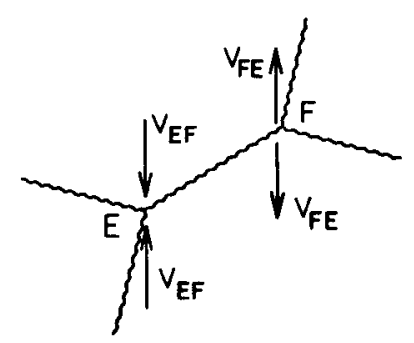

(c)

Legenda:

$$
\begin{aligned}
& m_{p}-\text { momento de plastificação; } \\
& t_{p} \text { - momento torçor; } \\
& v_{p} \text { - força cortante. }
\end{aligned}
$$

FIGURA 3.5- Equilíbrio de uma região e forças de transmissão.

As forças $K_{E 1}, K_{E 2}$ e $K_{E 3}$ são chamadas forças nodais, sendo que o primeiro índice representa o nó que está sendo considerado e o segundo indica a região da laje. Fazendo-se o somatório das forças nodais do nó $E$, tem-se,

$$
K_{E 1}+K_{E 2}+K_{E 3}=\left(V_{E A}-V_{E F}\right)+\left(V_{E F}-V_{E D}\right)+\left(V_{E D}-V_{E A}\right)=0 \text {, }
$$

podendo-se então enunciar:

A soma algébrica das forças nodais, em um nó qualquer, é igual a zero.

Esta conclusão pode ser generalizada para nós com qualquer número de linhas de plastificação e independe da convenção de sinais adotada.

\subsection{2- Determinação das Forças Nodais}

Para a determinação das forças nodais, parte-se da hipótese de que nas proximidades das linhas de plastificação o momento fletor é o mesmo que existe ao longo dessas linhas. 
Admite-se a situação mostrada na figura 3.6, ou seja, duas charneiras positivas e uma charneira negativa, com momentos de plastificação $m$ e $m^{\prime}$ respectivamente, concorrendo para um nó de uma laje isótropa.

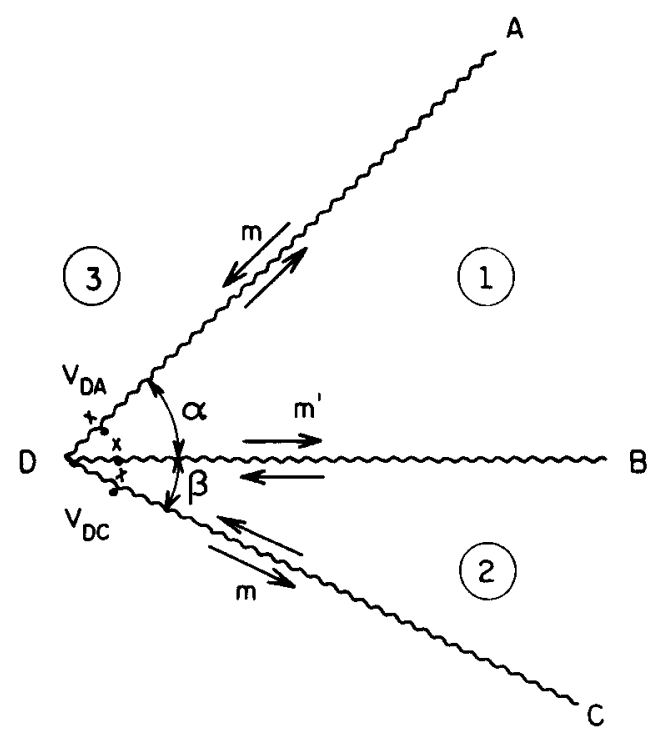

FIGURA 3.6- Nó com duas charneiras positivas e uma negativa.

Considerando um comprimento infinitesimal $\mathrm{dx}=\mathrm{DO}$ sobre a charneira negativa DB (figura 3.7.a), obtêm-se os triângulos DAO e DCO.

Analisando o triângulo DAO tem-se que, sobre a charneira DA atua o momento total $m . D A$ e as forças de transmissão $V_{D A}$ e $V_{A D}$; sobre a charneira $D O$, atuam o momento total $\mathrm{m}^{\prime} . \mathrm{dx}$, a força cortante $d V=\tau d x$ e o momento torçor $\mathrm{dM}_{\mathrm{t}}$; sobre - triângulo DAO age a carga $\mathrm{dP}$, que, se considerada como uniformemente distribuída com intensidade $p$, vale:

$$
d P=\frac{1}{2} p D A d x \operatorname{sen} \alpha
$$

No nó $D$, a força nodal, devida à região 3 , é dada por:

$$
K_{D 3}=V_{D C}-V_{D A}
$$

Utilizando-se a hipótese de que nas proximidades das linhas de plastificação o momento fletor é o mesmo que existe ao longo dessas linhas, tem-se que na seção AO haverá um momento fletor total m.AO. 

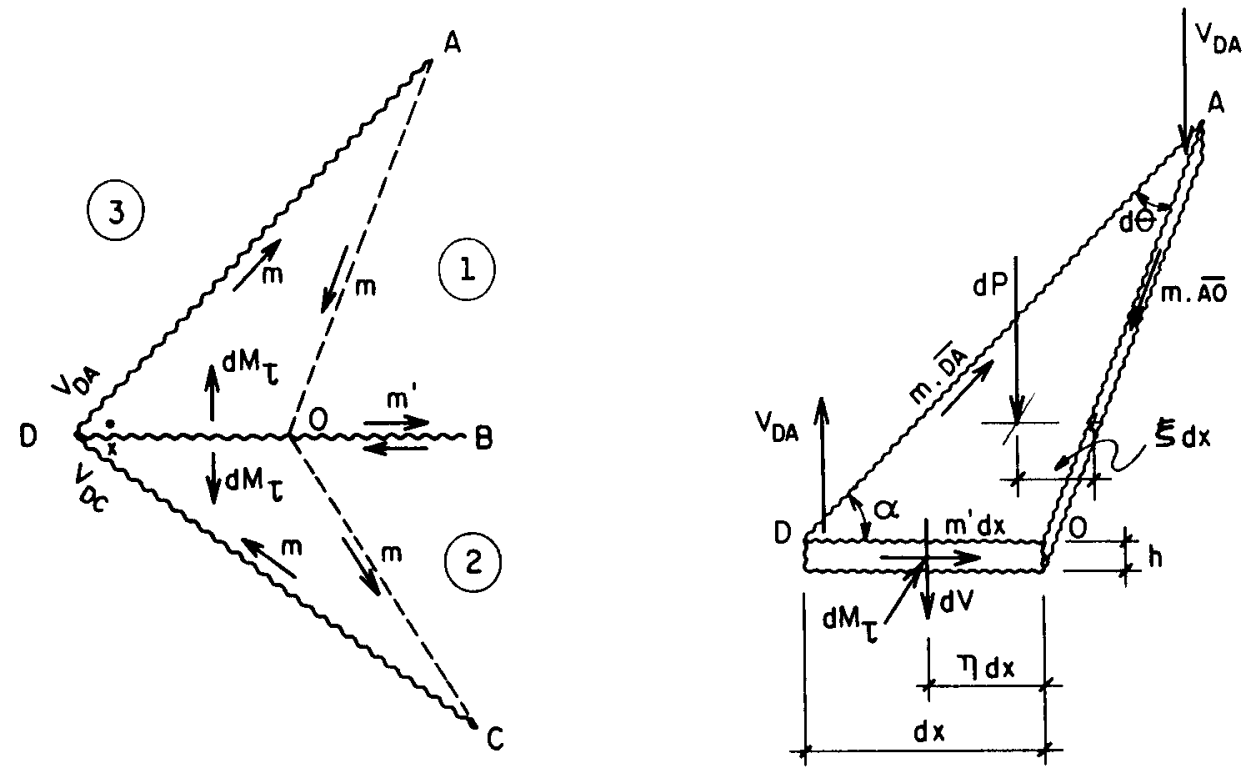

FIGURA 3.7- Determinação das forças nodais.

Como $d x$ é um comprimento infinitesimal, tem-se que $d \theta$ é um ângulo muito pequeno, de maneira que pode-se considerar $\cos d \theta=1$.

Fazendo-se o equilíbrio de momento em torno de $A O$, obtém-se:

$-V_{D A} d x \operatorname{sen} \alpha+m A O-m^{\prime} d x \cos \alpha-d M_{t} \operatorname{sen} \alpha+d V \eta d x \operatorname{sen} \alpha+$

$+\frac{1}{2} p D A d x \operatorname{sen} \alpha \xi d x \operatorname{sen} \alpha-m D A=0$

Como DA $=\mathrm{AO}+\mathrm{dx} \cdot \cos \alpha$, tem-se

$-V_{D A} d x \operatorname{sen} \alpha+m A O-m^{\prime} d x \cos \alpha-d M_{t} \operatorname{sen} \alpha+\tau \eta \operatorname{sen} \alpha d x^{2}+$

$+\frac{1}{2} p D A \operatorname{sen}^{2} \alpha \xi d x^{2}-m A O-m d x \cos \alpha=0$

e, desprezando-se os infinitésimos de segunda ordem, chega-se a

$-V_{D A} d x \operatorname{sen} \alpha-m^{\prime} d x \cos \alpha-d M_{t} \operatorname{sen} \alpha-m d x \cos \alpha=0$ 
onde, dividindo-se toda a equação por $\mathrm{dx} \operatorname{sen} \alpha$, tem-se:

$$
V_{D A}=\frac{-d M_{t}}{d x}-\left(m+m^{\prime}\right) \operatorname{cotg} \alpha
$$

Do mesmo modo, para o triângulo DCO (figura 3.7.a), a equação de equilíbrio de momentos em torno de OC fornece

$$
V_{D C} d x \operatorname{sen} \beta-m d x \cos \beta-m^{\prime} d x \cos \beta+d M_{t} \operatorname{sen} \beta=0
$$

donde:

$$
V_{D C}=\frac{-d M_{t}}{d x}+\left(m+m^{\prime}\right) \operatorname{cotg} \beta
$$

Substituindo-se as eqs. (3.3) e (3.4) na (3.2) resulta,

$$
K_{D 3}=\frac{-d M_{t}}{d x}+\left(m+m^{\prime}\right) \operatorname{cotg} \beta-\left[\frac{-d M_{t}}{d x}-\left(m+m^{\prime}\right) \operatorname{cotg} \alpha\right]
$$

ou

$$
K_{D 3}=\left(m+m^{\prime}\right)(\operatorname{cotg} \beta+\operatorname{cotg} \alpha)
$$

Utilizando-se o mesmo artifício de escolher triângulos de maneira que a soma algébrica elimine o momento torçor, obtêm-se as outras forças nodais do nó $D$ :

$$
\begin{aligned}
& K_{D 1}=-\left(m+m^{\prime}\right) \operatorname{cotg} \alpha, \\
& K_{D 2}=-\left(m+m^{\prime}\right) \operatorname{cotg} \beta
\end{aligned}
$$

Observa-se então, que para nó com duas charneiras positivas e uma negativa (figura 3.6), as forças nodais são dadas por 


$$
\begin{aligned}
& K_{D 1}=-\left(m+m^{\prime}\right) \operatorname{cotg} \alpha \\
& K_{D 2}=-\left(m+m^{\prime}\right) \operatorname{cotg} \beta \\
& K_{D 3}=\left(m+m^{\prime}\right)(\operatorname{cotg} \beta+\operatorname{cotg} \alpha)
\end{aligned}
$$

nas quais se pode notar que a soma algébrica das forças nodais também é zero.

Do exposto acima pode-se demonstrar que:

Em um nó para o qual convergem somente charneiras de mesmo sinal, todas as forças nodais são nulas.

Para esta demonstração basta supor que para o nó $D$ da figura 3.6 concorram três charneiras negativas. Então, substituindo-se $m$ por $-m^{\prime}$ nas eqs. (3.8), chega-se a

$$
\begin{aligned}
& K_{D 1}=-\left(-m^{\prime}+m^{\prime}\right) \operatorname{cotg} \alpha=0 \\
& K_{D 2}=-\left(-m^{\prime}+m^{\prime}\right) \operatorname{cotg} \beta=0 \\
& K_{D 3}=-\left(-m^{\prime}+m^{\prime}\right)(\operatorname{cotg} \beta+\operatorname{cotg} \alpha)=0
\end{aligned}
$$

ou, supondo-se que para o mesmo nó $D$ concorram três charneiras positivas, substituindo-se $m$ ' por $-m$ chega-se a:

$$
\begin{aligned}
& K_{D 1}=-(m-m) \operatorname{cotg} \alpha=0 \\
& K_{D 2}=-(m-m) \operatorname{cotg} \beta=0 \\
& K_{D 3}=(m-m)(\operatorname{cotg} \beta+\operatorname{cotg} \alpha)=0
\end{aligned}
$$

Analisa-se agora o caso em que uma charneira, positiva ou negativa, atinja uma borda livre ou simplesmente apoiada (figura 3.8). 

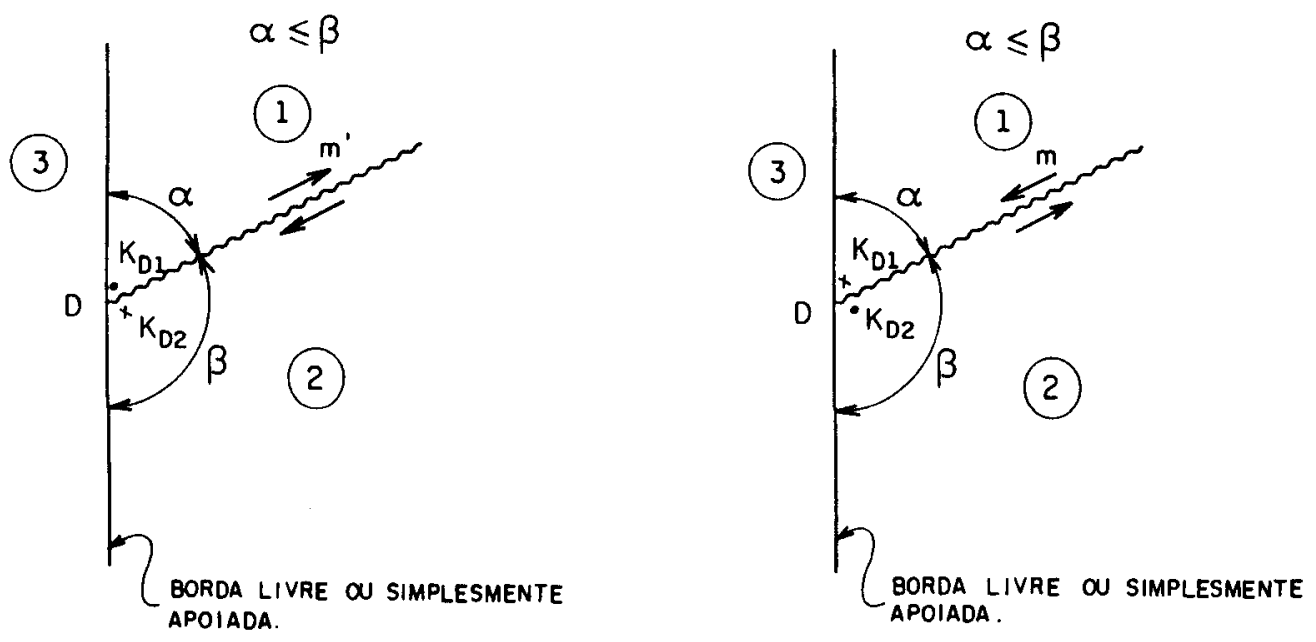

FIGURA 3.8- Charneira concorrente com borda não engastada.

Se a charneira for negativa (figura 3.8.a), as forças nodais são obtidas das eqs. (3.8), fazendo-se $m=0$ na borda e $\alpha+\beta=180^{\circ}$; tem-se então:

$$
\begin{aligned}
& K_{D 1}=-m^{\prime} \operatorname{cotg} \beta=m^{\prime} \operatorname{cotg} \alpha \\
& K_{D 2}=-m^{\prime} \operatorname{cotg} \alpha \\
& K_{D 3}=0
\end{aligned}
$$

Se a charneira for positiva (figura 3.8.b), substitui-se $m^{\prime}$ por $-m$ nas eqs. (3.9), resultando:

$$
\begin{aligned}
& K_{D 1}=-m \operatorname{cotg} \alpha \\
& K_{D 2}=m \operatorname{cotg} \alpha \\
& K_{D 3}=0
\end{aligned}
$$

Se a charneira, positiva ou negativa, chegar perpendicular à borda, $\alpha=\beta=$ $90^{\circ}$ e as forças nodais são nulas, pois $\operatorname{cotg} \alpha=\operatorname{cotg} \beta=\operatorname{cotg} 90^{\circ}=0$.

De acordo com a figura 3.8 e com as eqs. (3.9) e (3.10), pode-se enunciar: 
Em um nó formado por uma borda livre ou simplesmente apoiada e uma charneira plástica, têm-se duas forças nodais iguais e contrárias, com valor igual ao produto do momento de plastificação pela cotangente do ângulo agudo, sendo a deste dirigida para baixo no caso da charneira ser positiva e para cima no caso contrário.

\subsection{3- Exemplo de Aplicação do Processo do Equilíbrio}

Deve-se estabelecer as equações de equilibrio de cada região da laje, delimitada pela linhas de plastificação, considerando que cada região está em equilibrio sob a ação das forças nodais, dos momentos de plastificação e das cargas externas.

Conhecendo-se, então, a configuração das charneiras, determinam-se as forças nodais $e$, através das equações de equilíbrio de momentos de cada região, determina-se o momento de plastificação ou a carga de ruina, se for o caso.

É apresentado a seguir um exemplo de aplicação do processo do equilíbrio, para uma laje quadrada isótropa simplesmente apoiada no contorno com carga $p$ uniformemente distribuida (figura 3.9).

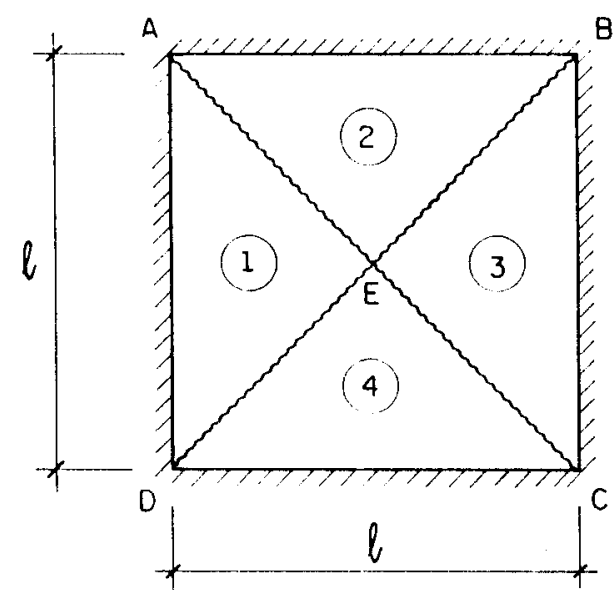

(a)

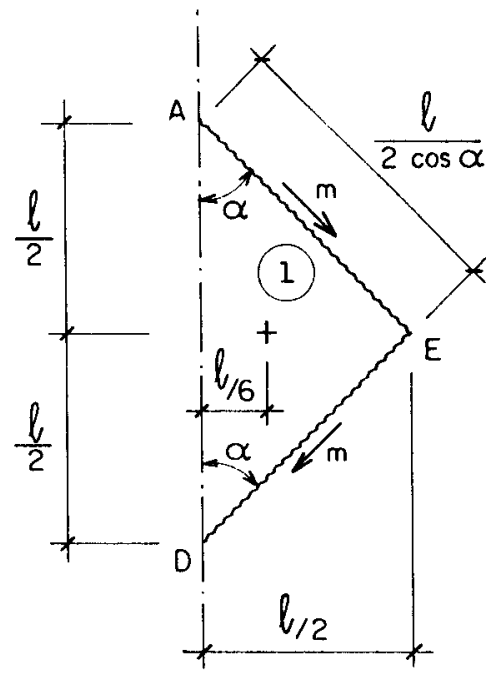

(b)

FIGURA 3.9- Laje quadrada com carga uniforme. 
Devido à simetria de forma e de carregamento, conclui-se que as charneiras plásticas coincidem com as diagonais e que as regiões 1, 2, 3 e 4 apresentam a mesma equação de equilíbrio.

Separando-se, por exemplo, a região 1 do resto da laje (figura 3.9.b) e calculando-se a equação de equilibrio de momentos em relação ao eixo de rotação $A D$, obtém-se

$$
m \frac{\ell}{2 \cos \alpha} \cos \alpha+m \frac{\ell}{2 \cos \alpha} \cos \alpha=\frac{p \ell^{2}}{4} \frac{\ell}{6}
$$

ou seja:

$$
m=\frac{p \ell^{2}}{24}
$$

Observa-se, nas eqs. (3.11) e (3.12), que basta multiplicar o momento de plastificação pelo comprimento das projeções das charneiras sobre o eixo de rotação, não sendo necessário, então, calcular o momento resultante da charneira e depois calcular sua projeção em relação ao eixo de rotação, como foi feito na eq. (3.11).

Caso a laje fosse engastada em todo o seu contorno, apareceriam as charneiras negativas ao longo dele e ter-se-ia que somar $m^{\prime} \ell$ no primeiro membro da eq. (3.12), resultando:

$$
m+m^{\prime}=\frac{p \ell^{2}}{24}
$$

\section{4- PROCESSO DA ENERGIA}

O processo da energia nada mais é que uma aplicação do principio dos trabalhos virtuais. Permite que as equações de equilibrio sejam escritas de uma forma concisa. É também chamado de processo do trabalho.

Admitindo-se conhecida a configuração de ruina, bem como os eixos de rotação, escolhe-se convenientemente um ponto da laje e dá-se um deslocamento virtual. A soma dos trabalhos virtuais, produzidos pelos esforços internos e externos, para toda a laje, deve ser nula. Ou seja, o trabalho das forças externas $\left(T_{e}\right)$, que equivale à energia gasta pelas forças externas durante a deformação virtual, é igual 
ao trabalho das forças internas $\left(T_{i}\right)$, que equivale à energia consumida pelas charneiras para efetuarem uma rotação compativel com o deslocamento virtual. Nessas condições o trabalho produzido pelas forças nodais é nulo.

Caso a configuração de ruina dependa de vários parâmetros $\mathrm{x}, \mathrm{y}$, etc, 0 momento de plastificação da laje é função desses parâmetros.

$$
m=F(x, y, \ldots)
$$

Como a Teoria das Charneiras Plásticas é uma aplicação do teorema cinemático, o momento de plastificação é o maior entre aqueles correspondentes às diversas configurações possíveis. Pode-se, então, obter o valor dos parâmetros $x, y$, etc, através das condições de máximo:

$$
\frac{\partial F}{\partial x}=0 ; \frac{\partial F}{\partial y}=0 ; \ldots
$$

\subsection{1- Trabalhos das Forças Internas $\left(T_{i}\right)$}

Como foi dito anteriormente, o trabalho das forças internas equivale à energia consumida pelas charneiras para efetuarem uma rotação compatível com 0 deslocamento virtual imposto à laje, que por ser um deslocamento arbitrário, é usual considerá-lo unitário. A energia consumida é, então, o produto de sua rotação $\theta$ pelo seu momento de plastificação $m_{p}$, que é considerado constante ao longo de uma charneira. Tem-se então,

$$
T_{i}=\mathcal{L}\left(m_{p} \ell \theta\right)
$$

sendo $\ell$ o comprimento da charneira.

Chamando $\theta_{i}$ e $\theta_{i}$ as rotações de todas as charneiras positivas e negativas respectivamente, sendo $m$ e $m^{\prime}$ os momentos de plastificação por unidade de comprimento e $\ell$ e $\ell$ os comprimentos das charneiras positivas e negativas respectivamente, a eq. (3.16), pode ser escrita da seguinte forma:

$$
T_{i}=m \ell_{i} \theta_{i}+m^{\prime} \ell_{i}^{\prime} \theta_{i}^{\prime}
$$




\subsection{2- Trabalho das Forças Externas $\left(T_{e}\right)$}

Como o trabalho das forças externas é igual à energia gasta por estas durante a deformação da laje, devida ao deslocamento virtual, pode-se escrevê-lo como

$$
T_{e}=P_{j} f_{j}+\int_{A} p f d A
$$

sendo:

$P_{1}=$ carga concentrada,

$\mathbf{f}_{\mathrm{l}}=$ deslocamento relativo à carga concentrada,

$\mathbf{p}=$ carga uniformemente distribuida,

$f=$ deslocamento relativo à carga distribuida.

A parcela devida à carga distribuida pode, também, ser expressa em função do volume desenvolvido pela superfície deformada, resultando:

$$
T_{e}=P_{j} f_{j}+p V
$$

Caso haja cargas lineares $p_{1}$, o deslocamento $f$, será função do elemento ds sob carga linear, resultando na seguinte equação do trabalho externo:

$$
T_{e}=P_{j} f_{j}+p V+\int p_{l} f_{l} d s
$$

\subsection{3- Determinação dos Momentos de Plastificação}

Para a obtenção dos momentos de plastificação, deve-se igualar as eqs. (3.17) e (3.20), onde já se conhecem as cargas $P_{j}, p_{1}, p$.

Este é um problema típico de dimensionamento, onde se conhecem as cargas de cálculo e se tem como incógnita o momento. 


\subsection{4- Exemplo de Aplicação do Processo da Energia}

É apresentado a seguir um exemplo de aplicação do processo da energia para uma laje quadrada simplesmente apoiada no contorno, submetida a carga $p$ uniformemente distribuida (figura 3.10).
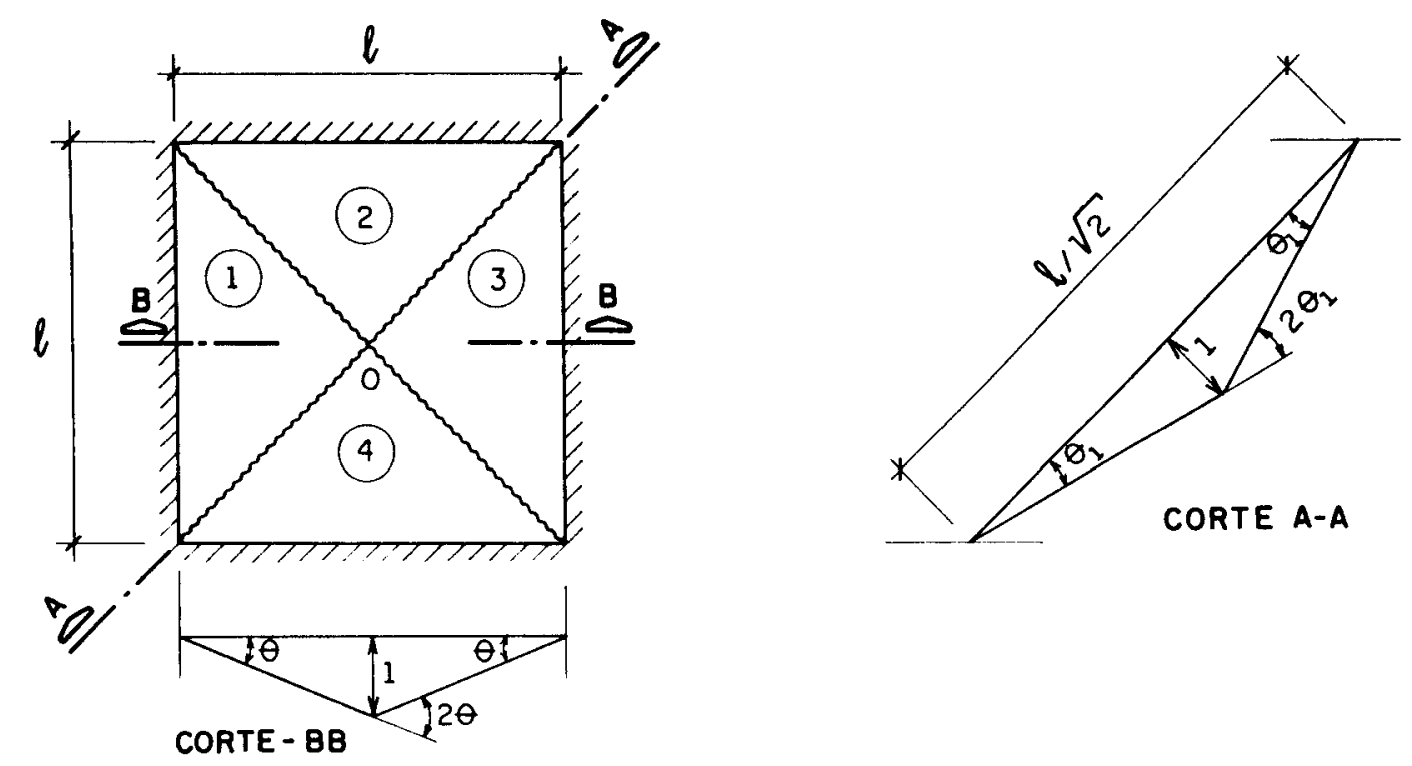

FIGURA 3.10- Laje quadrada com carga uniforme.

Admitindo-se que o ponto $O$ sofra um deslocamento virtual unitário, de acordo com a figura 3.10, devido à simetria de forma e carregamento, as charneiras coincidem com as diagonais, tendo, portanto, o comprimento $\ell \sqrt{2}$, sendo $2 \theta_{1} \circ$ ângulo de rotação das duas charneiras (figura 3.10, corte A). Logo, o trabalho das forças internas é dado por

$$
T_{i}=m\left(\ell \sqrt{2} 2 \theta_{1}+\ell \sqrt{2} 2 \theta_{1}\right)=m 4 \sqrt{2} \ell \theta_{1},
$$

onde:

$$
\theta_{1}=\frac{1}{\frac{\ell \sqrt{2}}{2}}=\frac{2}{\ell \sqrt{2}}
$$


Substituindo-se o valor de $\theta_{1}$ na eq. (3.21) resulta:

$$
T_{i}=8 m
$$

Pode-se, também, calcular o trabalho das forças internas para cada uma das partes da laje, bastando para isso, multiplicar $m$ pelo comprimento da projeção da charneira ao longo do eixo de rotação e pelo ângulo de rotação $\theta$ do elemento de laje em relação ao mesmo eixo de rotação (figura 3.10 , corte $B$ ). Como para a laje em questão, devido à simetria, as quatro regiões são iguais, tem-se,

$$
T_{i}=4(m \ell \theta)
$$

onde

$$
\theta=\frac{1}{\frac{\ell}{2}}=\frac{2}{\ell},
$$

resultando

$$
T_{i}=8 \mathrm{~m},
$$

que coincide com a eq. (3.22).

Para o cálculo do trabalho das forças externas $\left(T_{e}\right)$, aplica-se a eq. (3.20) para cada uma das quatro partes da laje, ou seja, multiplica-se a resultante da carga pela distância percorrida por esta resultante, eriquanto a laje se deforma. Logo,

$$
T_{e}=4 p \ell \frac{\ell}{2} \frac{1}{2} \frac{1}{3}=\frac{p \ell^{2}}{3}
$$

Igualando-se $T_{i}$ a $T_{e}$, obtém-se,

$$
m=\frac{p \ell^{2}}{24}
$$

que coincide com o resultado obtido pelo processo do equilíbrio (item 3.3.3) 


\section{5- CARGAS CONCENTRADAS}

As cargas concentradas geralmente atuam em conjunto com um carregamento uniformemente distribuido, mesmo que seja somente o peso próprio. A ação simultânea destas cargas pode acarretar em uma configuração de ruina cujo cálculo exato torna-se trabalhoso. Por isso, costuma-se tratar em separado cada tipo de carga e considerar superposição de efeitos para análise dos dois carregamentos atuando juntos. Desta forma obtêm-se resultados próximos do correto e a favor da segurança (PINHEIRO, 1988).

\subsection{1- Efeito das Cargas Concentradas}

Quando uma carga concentrada atua numa laje, surgem charneiras positivas concorrendo para ela, formando, quer um número limitado de elementos triangulares (figura 3.11.a), quer um número infinito de elementos triangulares, limitados por uma charneira negativa circular (figura 3.11.b).

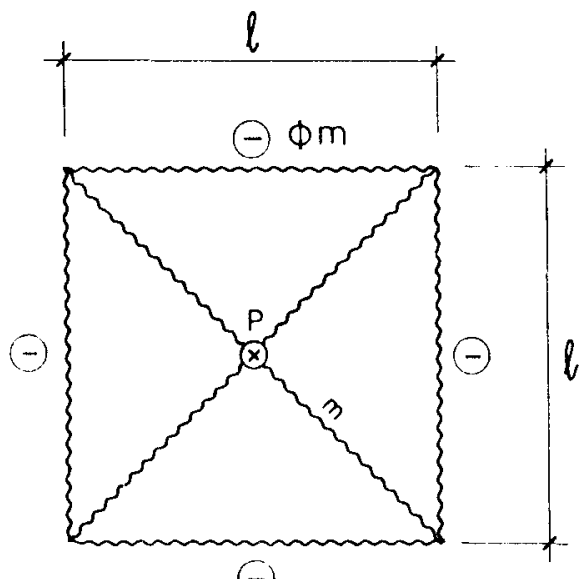

$\Theta$

(a)

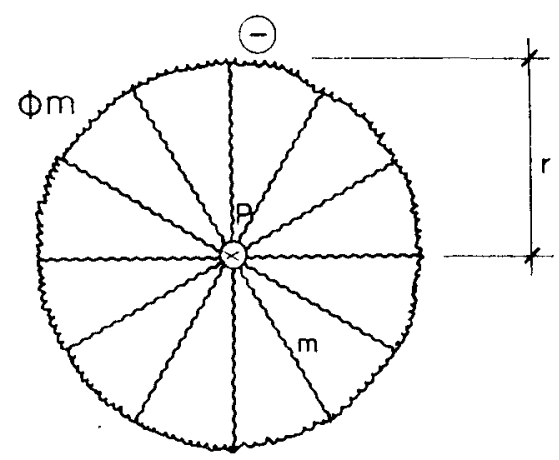

(b)

FIGURA 3.11- Configurações de charneiras provocadas por carga concentrada.

Utilizando-se o processo da energia para a determinação do momento de plastificação, para o caso da figura 3.11.a, tem-se 


$$
T_{i}=4\left(m \ell \frac{2}{\ell}+m^{\prime} \ell \frac{2}{\ell}\right)=8\left(m+m^{\prime}\right)
$$

Chamando de $\phi$ a razão entre o momento negativo e momento positivo, ou seja,

$$
\phi=\frac{m^{\prime}}{m}
$$

e substituindo-se a eq. (3.25) na (3.24), tem-se,

$$
T_{i}=8 m(1+\phi)
$$

Já o trabalho externo é dado por

$$
T_{e}=P .1
$$

Igualando-se os trabalhos externo e interno resulta:

$$
m=\frac{P}{8(1+\phi)}
$$

Para a situação da figura 3.11.b, tem-se:

$$
\begin{aligned}
& T_{i}=m 2 \pi r \frac{1}{I}+m^{\prime} 2 \pi r \frac{1}{r}=2 \pi m(1+\phi), \\
& T_{e}=P .1
\end{aligned}
$$

Novamente, igualando-se $T_{i}$ a $T_{e}$ resulta,

$$
m=\frac{P}{2 \pi(1+\phi)}
$$

Observa-se que o momento de plastificação dado pela eq. (3.30) é maior que o dado pela eq. (3.28), indicando que a configuração da figura 3.11.b é a mais crítica $e$, portanto, a que deve ocorrer. Observa-se, também, que o lado $\ell$ do quadrado $e$ o raio $r$ do círculo não entram nas eqs. (3.28) e (3.30) respectivamente. Isto provém do fato de tomar-se $P$ concentrada em um ponto. 


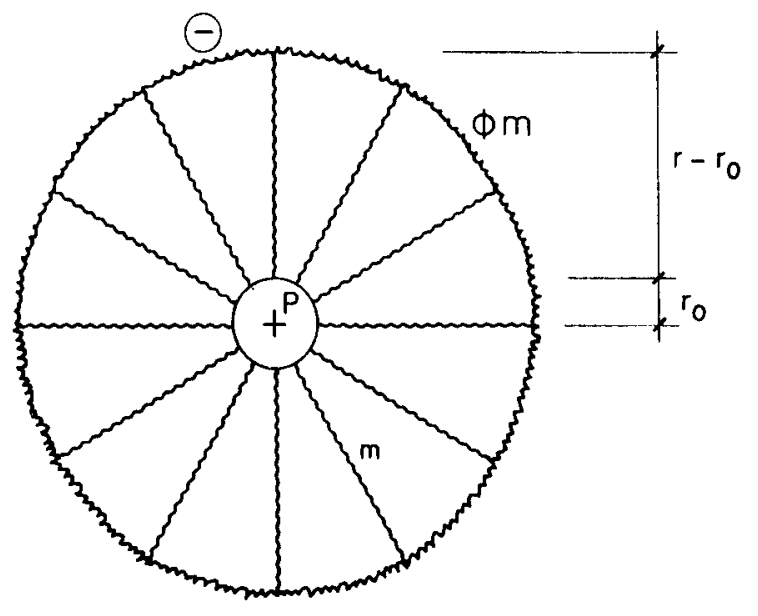

FIGURA 3.12- Carga $P$ distribuida em um círculo de raio $r_{0}$.

Considerando-se a força $P$, para a configuração da figura 3.11.b, distribuída em um pequeno círculo de raio $r_{0}$ (figura 3.12), o trabalho interno é o mesmo dado pela eq. (3.29) e o trabalho externo é, agora, dado por

$$
T_{e}=p V,
$$

sendo:

$$
\begin{aligned}
& p=\frac{P}{\pi r_{0}^{2}} \\
& V=\pi r_{0}^{2}-\frac{2 \pi r_{0}^{3}}{3 r}
\end{aligned}
$$

Substituindo-se as eqs. (3.33) e (3.32) na eq. (3.31) resulta:

$$
T_{e}=P\left(1-\frac{2 I_{0}}{3 r}\right)
$$

O momento de plastificação para este caso é, então, dado por:

$$
m=\frac{P}{2 \pi(1+\phi)}\left(1-\frac{2 r_{0}}{3 r}\right)
$$


Observa-se que o valor do momento de plastificação $m$ dado pela eq. (3.35) será tanto maior quanto maior for o valor de $r$. Desta forma, o círculo tenderá a ser o maior possivel e tangenciar o contorno, caso seja ele engastado. Para valores de $r_{0}$ muito pequenos, pode-se usar a eq. (3.30) que está a favor da segurança.

As considerações anteriores são válidas também para o caso em que $\phi=0$, no caso de apoio simples, quando não há armadura superior.

Caso a força esteja próxima de uma borda livre ou simplesmente apoiada, a configuração das charneiras é a apresentada na figura 3.13.

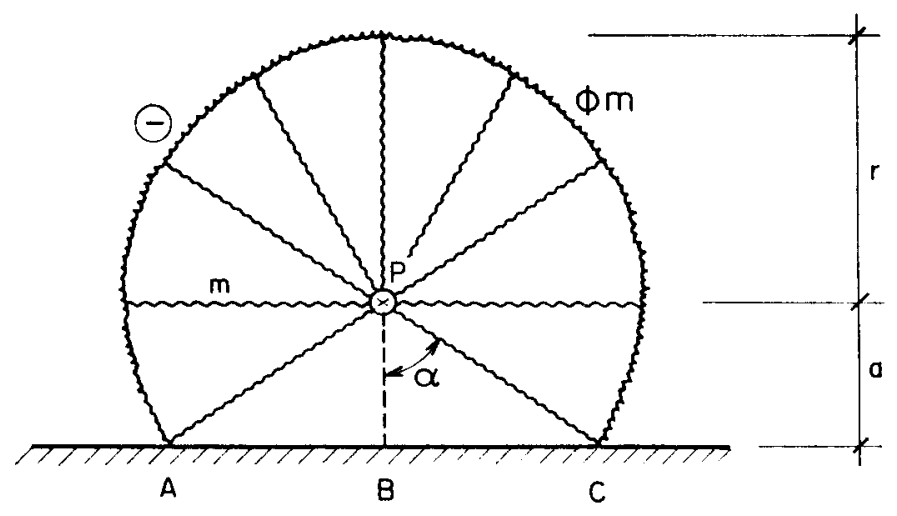

FIGURA 3.13- Carga concentrada próxima a uma borda livre ou simplesmente apoiada.

O trabalho externo, para a configuração da figura 3.13 , é o dado pela eq. (3.27) e o trabalho interno será:

$$
\begin{aligned}
& T_{i}=m(2 \pi-2 \alpha) r(1+\phi) \frac{1}{r}+m 2 \operatorname{atg} \alpha \frac{1}{a} \\
& \left.T_{i}=m[(2 \pi-2 \alpha)(1+\phi)+2 \operatorname{tg} \alpha)\right]
\end{aligned}
$$

Portanto o momento de plastificação obtido igualando-se as eqs. (3.27) e (3.36) é:

$$
m=\frac{P}{(2 \pi-2 \alpha)(1+\phi)+2 \operatorname{tg} \alpha}
$$


Para a determinação do valor máximo de $m$, utiliza-se a condição de máximo,

$$
\frac{\partial m}{\partial \alpha}=0
$$

que fornece

$$
\operatorname{tg} \alpha=\sqrt{\Phi}
$$

ou seja, o valor máximo de $m$ se dá quando $\operatorname{tg} \alpha=\sqrt{\Phi}$. Portanto:

$$
m=\frac{P}{(2 \pi-2 \operatorname{arctg} \sqrt{\phi})(1+\phi)+2 \sqrt{\phi}}
$$

Supondo $m=m^{\prime}$, tem-se $\phi=1, \operatorname{tg} \alpha=1, \alpha=\pi / 4$; pela eq. (3.38), referente à configuração das charneiras com leque interrompido, obtém-se $m=P / 11,42 \mathrm{e}$, pela eq. (3.30), referente à configuração com círculo completo, obtém-se $m=P / 12,57$. Percebe-se, então, que a configuração das charneiras mostrada na figura 3.13 leva a um momento de plastificação maior que a da figura 3.11.b, sendo, portanto, mais perigosa.

\subsection{2- Carga Concentrada Atuando em um Vértice}

Considerando-se a carga concentrada atuando em um vértice correspondente a duas bordas livres, a configuração com a qual as charneiras se apresentam é mostrada na figura 3.14.a.

Se $m=0$, a configuração da figura 3.14.a se transforma em um arco de círculo, sem charneiras radiais, tendo o trabalho interno dado por

$$
T_{i}=m^{\prime} \omega r \frac{1}{r}=m^{\prime} \omega
$$

e o trabalho externo

$$
T_{e}=P \cdot 1=P
$$




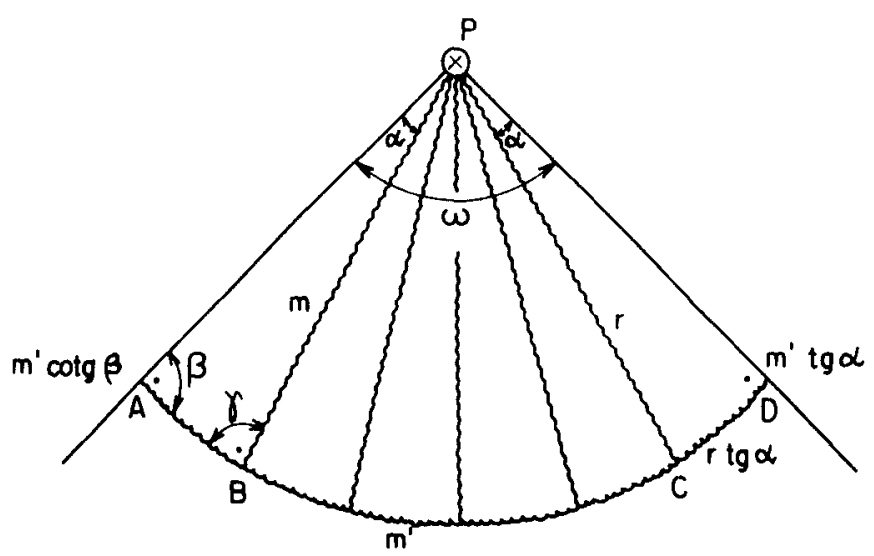

(a)

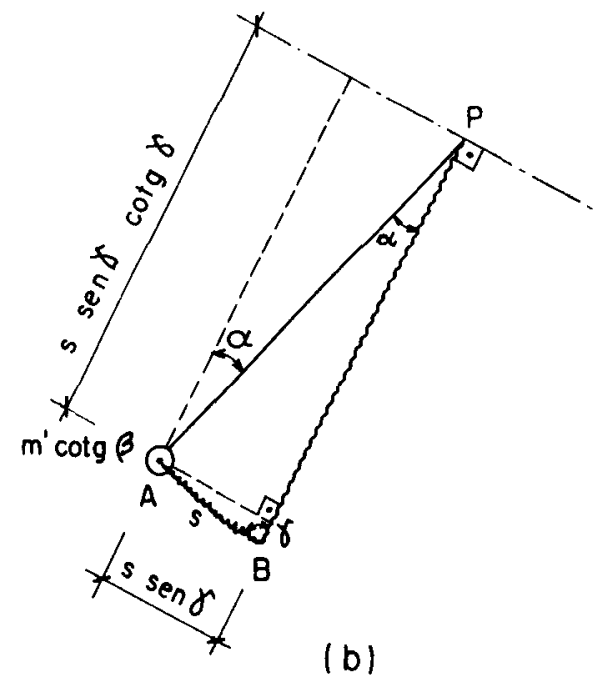

(b)

FIGURA 3.14- Carga concentrada atuando em um vértice.

Portanto, o momento de plastificação será

$$
m^{\prime}=\frac{P}{\omega}
$$

Se $m \neq 0$, a configuração das charneiras passa a ser a da figura 3.14.a, com o surgimento dos triângulos de transição delimitados pelas charneiras radiais. Para esta configuração, o trabalho externo é o mesmo dado pela eq. (3.40) e o trabalho interno é:

$$
\begin{aligned}
& T_{i}=m(1+\phi)(\omega-2 \alpha) r \frac{1}{r}+2 m^{\prime} \operatorname{tg} \alpha I \frac{1}{r} \\
& T_{i}=m[(1+\phi)(\omega-2 \alpha)+2 \phi \operatorname{tg} \alpha]
\end{aligned}
$$

Igualando-se as eqs. (3.40) e (3.42), chega-se a

$$
m=\frac{P}{(1+\phi)(\omega-2 \alpha)+2 \phi \operatorname{tg} \alpha}
$$


que pela condição de máximo $\partial m / \partial \alpha=0$ fornece

$$
\operatorname{tg} \alpha=\sqrt{\frac{1}{\phi}}
$$

significando que o máximo valor de $m$ ocorre para este valor de $\alpha$, sendo igual a:

$$
m=\frac{P}{(1+\phi)\left(\omega-2 \operatorname{arctg} \sqrt{\frac{1}{\phi}}\right)+2 \sqrt{\phi}}
$$

\section{6- FORMAÇÃO DE LEQUES}

Até então foi admitido que uma charneira plástica, formando-se próximo a um canto da laje, entrasse nele passando pela interseção dos eixos de rotação, como mostrado na figura 3.15.a. Entretanto, pela teoria da elasticidade, sabe-se que na região dos cantos da laje existem grandes momentos torçores e que o canto de uma laje simplesmente apoiada tende a se levantar do apoio, devido à ação desses momentos. Quando isto ocorre, a charneira plástica tende a bifurcar-se antes de atingir o canto, como mostrado na figura 3.15.b, e a parte triangular (figura 3.15.c) tende a girar em torno de $a b$. Se não existe armadura superior no canto, ou se a que existe não é suficiente para resistir ao efeito de levantamento do canto, a configuração das charneiras será a mostrada na figura 3.15.c, sendo a linha ab uma charneira. Se a configuração das charneiras da figura 3.15.c se forma, há uma redução na carga de ruína da laje, em relação à configuração com charneira única entrando no canto (figura 3.15.a). Esta redução é ainda maior quando se considera a formação de leques, como mostrado na figura 3.15.d.

Embora a consideração da formação de leques nos cantos da laje leve a uma redução da sua carga de ruina, nem sempre esta formação é considerada, pois sua análise torna-se muito mais complexa e, em muitos casos, o erro obtido é muito pequeno. Porém, existem situações onde pode ser importante sua consideração, tais como:

- fortes cargas concentradas;

- deficiência de uma armadura superior adequada nos cantos das lajes; 
- encontro de bordas formando um ângulo agudo;

- bordas engastadas ou livres.

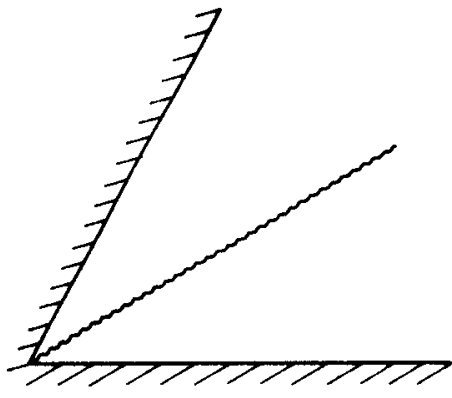

(a)

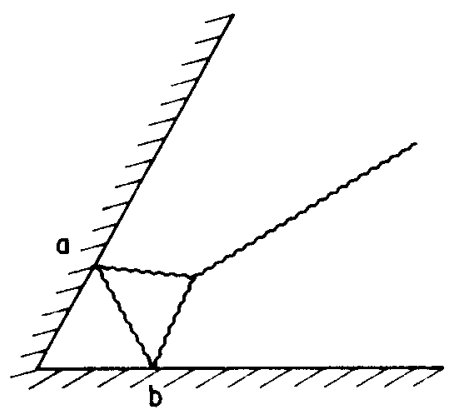

(c)

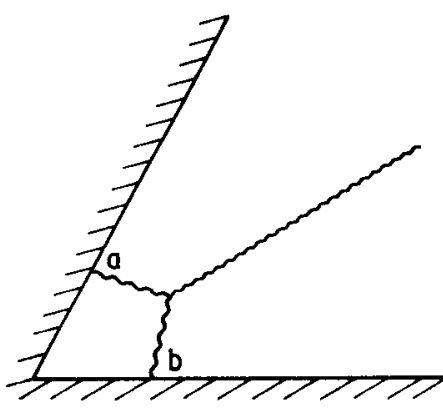

(b)

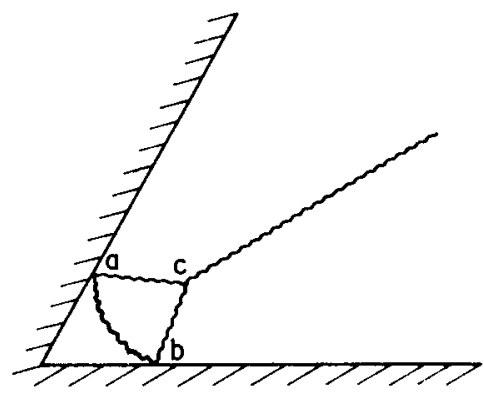

(d)

FIGURA 3.15- Charneiras plásticas no canto de uma laje.

Podem ser considerados perigosos os casos de fortes cargas concentradas ou de reações de apoio sobre pilares, que conduzem a leques com ângulo central de até $360^{\circ}$ (figura 3.11.b)

Como foi dito anteriormente, as charneiras positivas que se dirigem para os vértices do contorno da laje podem bifurcar-se antes de atingi-lo, formando duas ramificações positivas ac e $b c$ e uma negativa $a b$ (figura 3.15.d).

Esta bifurcação ocorre se a carga necessária para provocá-la for menor do que a carga que dá origem à charneira positiva única (figura 3.15.a). 
Segundo LANGENDONCK (1970), o efeito das bifurcações pode ser considerado como independente para cada bifurcação. Admite-se que a charneira $A B$ da figura 3.16 situa-se sobre a bissetriz do ângulo do vértice $A$, sendo $\delta \circ$ valor desse ângulo.

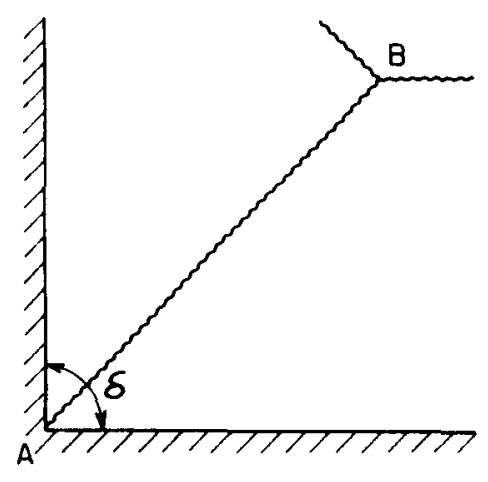

(a)

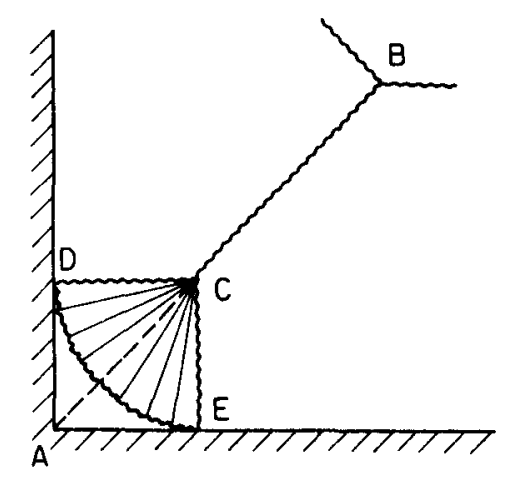

(b)

FIGURA 3.16- Bifurcação de charneira em um canto.

Caso a charneira $A B$ não esteja situada sobre a bissetriz do ângulo $\delta$, podese admitir que o efeito estudado, para o lado que faz ângulo $\alpha$ com a charneira (figura 3.17), seja o mesmo que se teria se esta fosse a bissetriz do ângulo $\delta$, tomado, neste caso, como $\delta=2 \alpha$.

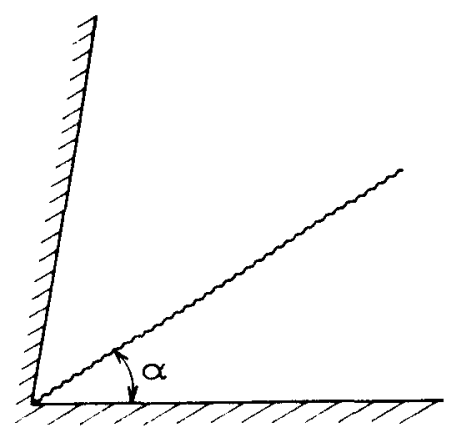

FIGURA 3.17- Charneira não coincidente com a bissetriz do ângulo.

A redução da carga de ruína, provocada pela bifurcação da charneira, pode, então, ser obtida através do parâmetro

$$
u=1-k
$$


que deve ser multiplicado pela carga de ruína da configuração com charneira única (figura 3.16.a ), resultando na carga de ruína da configuração da figura 3.16.b.

O valor adotado para $k$ é o correspondente a uma charneira circular simétrica, que vale

$$
k=0,45 \omega^{2}
$$

onde $\omega$ depende do ângulo $\delta$ e da relação entre $m$ e $m^{\prime}$, valendo

$$
\omega=1-\left(\frac{\delta}{\pi}\right) \frac{\left(m+m^{\prime}\right)}{m}
$$

se o contorno for simplesmente apoiado, com deslocamento vertical impedido, ou

$$
\omega=1-\frac{\delta}{\pi}
$$

se o contorno for engastado.

Caso $\omega \leq 0$, não haverá bifurcação e adota-se $k=0$, fazendo-se com que a eq. (3.50) possa, então, ser substituida por:

$$
k= \begin{cases}0,45 \omega^{2} & \text { se } \omega>0 \\ 0 & \text { se } \omega \leq 0\end{cases}
$$

Quando a laje não tem a forma de um poligono regular, precisa-se separar dois fatores $t$ e $v$, que levam ao coeficiente $u$. $O$ fator $t$ refere-se à energia, $T_{i}=\left(m+m^{\prime}\right) T$, consumida pelas charneiras, sendo $T$ a energia de deformação das charneiras para $\left(m+m^{\prime}\right)$ unitário. E o fator $v$ refere-se à energia $p V$ desenvolvida pela carga externa. Decompondo-se a laje em várias partes e adotando-se $o$ índice $i$ para as partes da laje onde possam ocorrer leques e $O$ índice $O$ para as outras partes, tem-se:

$$
\frac{p}{\left(m+m^{\prime}\right)}=\frac{T_{0}+\sum\left(1-t_{i}\right) T_{i}}{V_{0}+\sum\left(1-V_{i}\right) V_{i}}=\frac{T-\sum t_{i} T_{i}}{V-\sum V_{i} V_{i}}
$$

Obtém-se os $T_{i}$ e os $V_{i}$ como se não houvesse bifurcação e, em seguida, multiplica-se os resultados pelos coeficientes $(1-t)$ e $(1-v)$, que são funções do ângulo $\delta$. 
$\mathrm{Na}$ eq. (3.54), $T$ e $V$ referem-se a toda a laje, sem bifurcação das charneiras, sendo $T$ a energia consumida pelas charneiras para $\left(m+m^{\prime}\right)=1$ e $V$ o volume da laje deformada.

Se a laje tem a forma de um polígono regular, $T_{0}$ e $V_{0}$ são nulos e os coeficientes $t$ e $v$ são todos iguais. Portanto, a eq. (3.54) fica

$$
\frac{p}{m+m^{\prime}}=\left[\frac{(1-t)}{(1-V)}\right] \frac{T}{V}
$$

com $(1-t) /(1-v)$ igual ao coeficiente $u$ dado pela eq. (3.49). Para os demais casos, $t$ e $v$ são analisados separadamente e, segundo LANGENDONCK (1975), tem-se uma boa aproximação dada por

$$
\begin{aligned}
& t=0,65 \omega^{2} \\
& v=0,25 \omega^{2}
\end{aligned}
$$

As fórmulas aqui apresentadas só se aplicam se $\delta \geq \pi / 6=30^{\circ}$.

Para uma análise mais aprofundada sobre a bifurcação de charneiras, ver LANGENDONCK (1970) e (1975).

\section{7- LAJES ORTÓTROPAS}

Em todas as análises feitas até agora, só foram consideradas lajes isótropas, ou seja, que apresentam a mesma resistência à flexão, qualquer que seja a direção da seção transversal considerada. Porém, na maioria dos casos as lajes não são isótropas e sim anisótropas. A seguir é apresentada a definição de anisotropia e de ortotropia, bem como procedimentos para a determinação dos momentos de plastificação para esses casos.

\subsection{1- Definiçăo de Anisotropia e Ortotropia}

Conside-se uma laje armada em duas direções ortogonais $x$ e $y$, com momentos de plastificação $m_{x}$ e $m_{y}$ respectivamente (figua 3.18). Para a seção inclinada de $\beta$ em relação a direção $x$, o momento de plastificação é dado por: 


$$
m_{\beta}=m_{x} \operatorname{sen}^{2} \beta+m_{y} \cos ^{2} \beta
$$

A eq. (3.57) é válida se forem desprezados os efeitos dos momentos torçores e dos momentos fletores atuantes na seção normal à seção considerada, o que pode ser feito, pois, segundo LANGENDONCK (1970), ensaios demonstraram que o momento de plastificação para uma charneira inclinada nunca é maior do que aquele dado por essa equação.

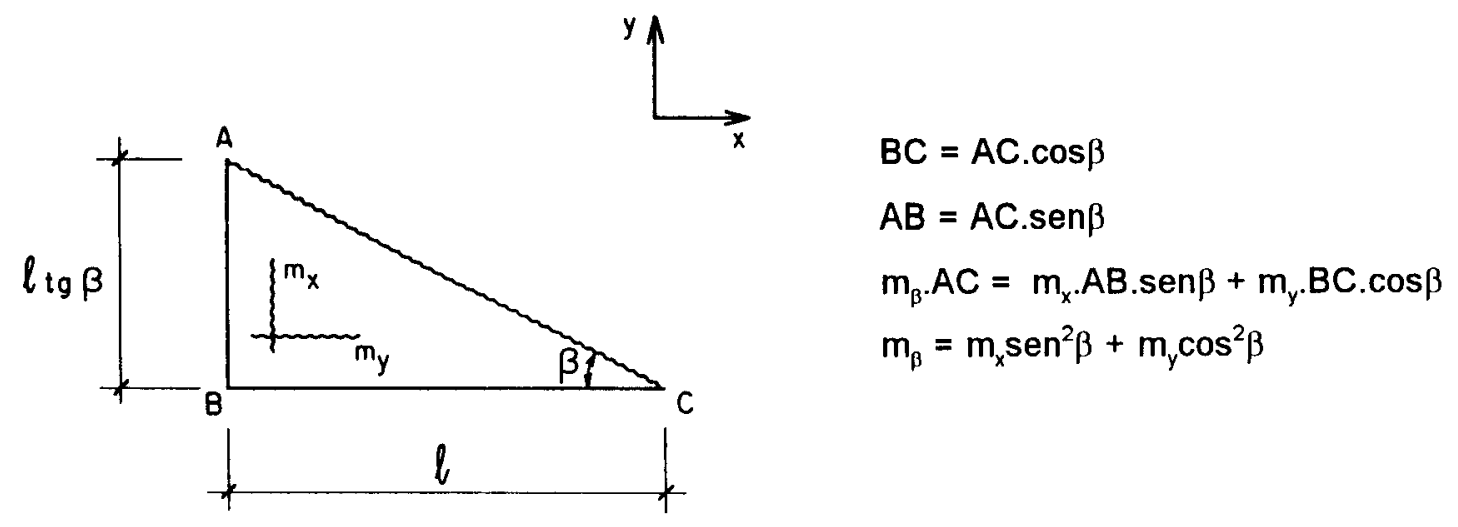

FIGURA 3.18- Charneira inclinada de $\beta$.

Sabe-se que uma laje é considerada isótropa se apresentar a mesma resistência à flexão, qualquer que seja a direção da seção transversal considerada. Então $m_{x}$ é igual a $m_{y} e$, portanto, $m_{\beta}$ deve ter o mesmo valor, pois:

$$
m_{\beta}=m_{x}\left(\operatorname{sen}^{2} \beta+\cos ^{2} \beta\right)=m_{x}
$$

Se isso não acontece, ou seja, a laje não apresenta a mesma resistência à flexão em qualquer direção que seja tomada a seção transversal, a laje é denominada anisótropa. Porém, admite-se que numa mesma direção o momento de plastificação seja sempre o mesmo.

Se para uma laje anisótropa que possua armaduras dispostas em direções ortogonais e apresente momentos de plastificação $m_{x}$ e $m_{y}$ positivos e $m_{x}^{\prime}$ e $m_{y}^{\prime}$ negativos, de modo que 


$$
\begin{aligned}
& m_{y}=\kappa m_{x} \\
& m_{y}^{\prime}=\kappa m_{x}^{\prime}
\end{aligned}
$$

esta laje é denominada ortótropa e a relação $\kappa$ é denominada indice de ortotropia.

\subsection{2- Transformaçăo de Lajes Ortótropas em Isótropas}

As lajes ortótropas podem ser calculadas como se fossem isótropas (processo da afinidade, ver RIOS ,1990, por exemplo), bastando para isto fazer uma modificação nas suas dimensões.

Considere-se uma laje ortótropa que apresente os momentos de plastificação $m, m^{\prime}$ e $\mathrm{km}, \mathrm{km}$ ', como mostrado na figura 3.19.a. Para se obter uma laje isótropa, afim à ortótropa, deve-se multiplicar as dimensões nas direções onde $m$ e $m^{\prime}$ atuam (dimensão a da figura 3.19.a), por $1 / \sqrt{\kappa}$ (figura 3.19.b). Se a carga for uniformemente distribuida, ela permanece inalterada; se existe carga concentrada $P$, esta deve ser dividida por $\sqrt{\kappa}$ se houver carga linear $p_{1}$, esta deve ser dividida por $\sqrt{\kappa \operatorname{sen}^{2} \gamma+\cos ^{2} \gamma}$, sendo $\gamma \circ$ ângulo entre a carga linear e a seção que resiste ao momento $m$, ou seja,

$$
\begin{aligned}
& p_{\text {afim }}=p \\
& P_{\text {afim }}=\frac{P}{\sqrt{\kappa}} \\
& p_{l_{\text {afim }}}=\frac{p_{l}}{\sqrt{\kappa \operatorname{sen}^{2} \gamma+\cos ^{2} \gamma}}
\end{aligned}
$$

A dedução das fórmulas aqui apresentadas pode ser encontrada em PINHEIRO (1989) e RIOS (1990), por exemplo. 

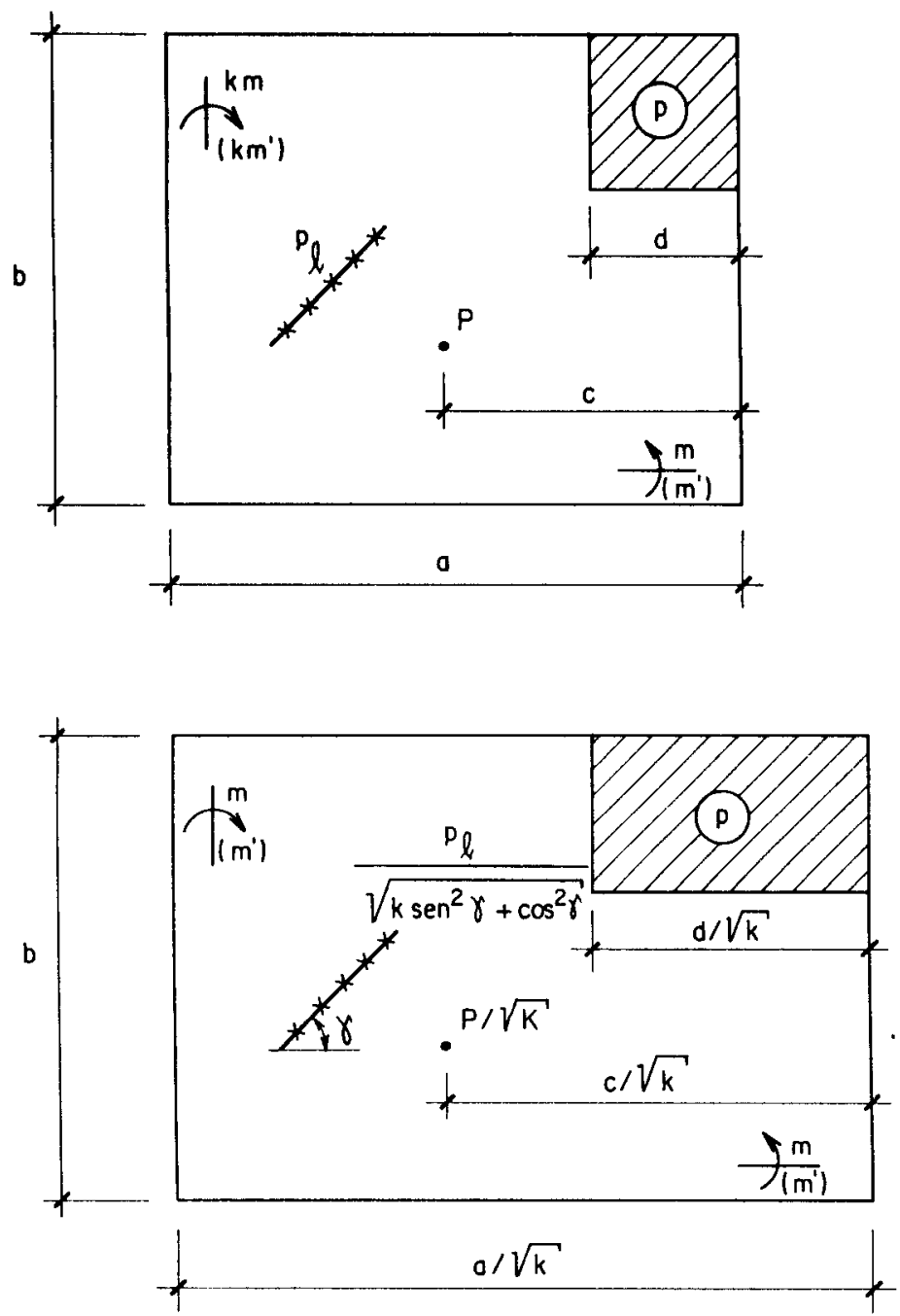

FIGURA 3.19- Obtenção de laje isótropa afim. 


\section{4- A TEORIA DAS CHARNEIRAS PLÁSTICAS APLICADA ÀS LAJES-COGUMELO}

Este capitulo trata do cálculo das lajes-cogumelo pela teoria das charneiras plásticas, utilizando o processo do equilibrio e o processo da energia. Os pavimentos são divididos em painéis retangulares, sujeitos a cargas uniformemente distribuidas. Não é considerada a formação de leques nos cantos, no caso de haver vigas de borda.

$\mathrm{Na}$ formulação apresentada neste capitulo, admitem-se, como dados do painel, os momentos negativos $m_{i}$ e a relação entre os momentos positivos $\mu$, obtidos através do cálculo elástico.

No item 4.5 são apresentadas algumas recomendações para a distribuição das armaduras.

\section{1- GENERALIDADES}

Apresenta-se a seguir os principais tipos de configurações das charneiras para lajes-cogumelo, bem como a divisão do pavimento em painéis.

\subsection{1- Tipos de Configuraçðes das Charneiras}

Para lajes-cogumelo são duas as principais configurações das charneiras que devem ser analisadas, admitindo-se carga uniformemente distribuida nos pavimentos: uma envolvendo o colapso global do pavimento, ou na direção $x$ (figura 4.1a) ou na direção y (figura 4.1b), e outra envolvendo o colapso local ao redor do apoio (figura 4.2). 
Para as configurações das charneiras apresentadas na figura 4.1 , as charneiras negativas são supostas atuando na linha dos pilares e as charneiras positivas no meio do vão, atravessando todo o pavimento.

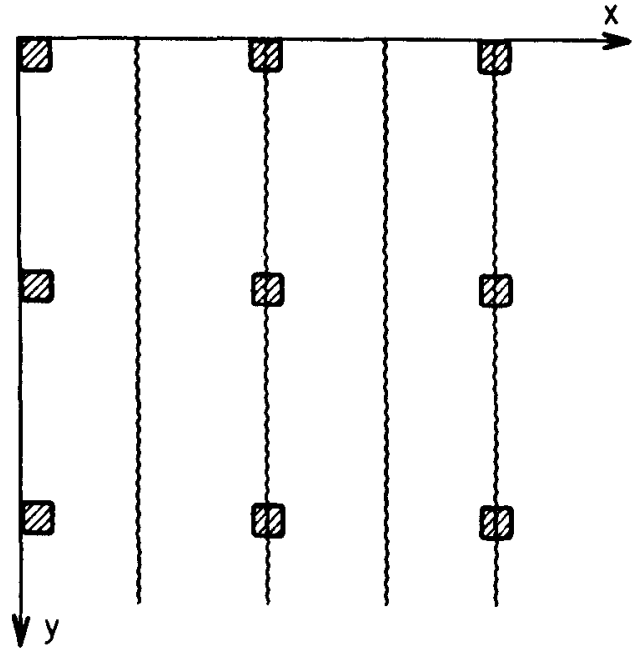

(a)

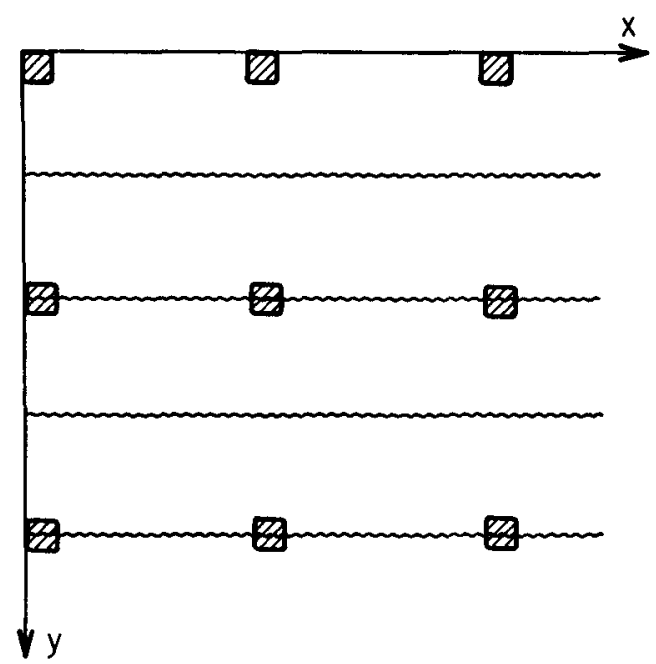

(b)

FIGURA 4.1- Colapso global do pavimento.

A configuração das charneiras na região dos apoios é semelhante à apresentada no capitulo 3 para cargas concentradas e consiste na formação de leque circular com charneiras negativas concorrendo para o apoio, delimitadas por uma charneira positiva (figura 4.2), se a laje for isótropa. Caso a laje seja ortótropa, forma-se um leque elíptico, com eixo maior na direção de maior momento.

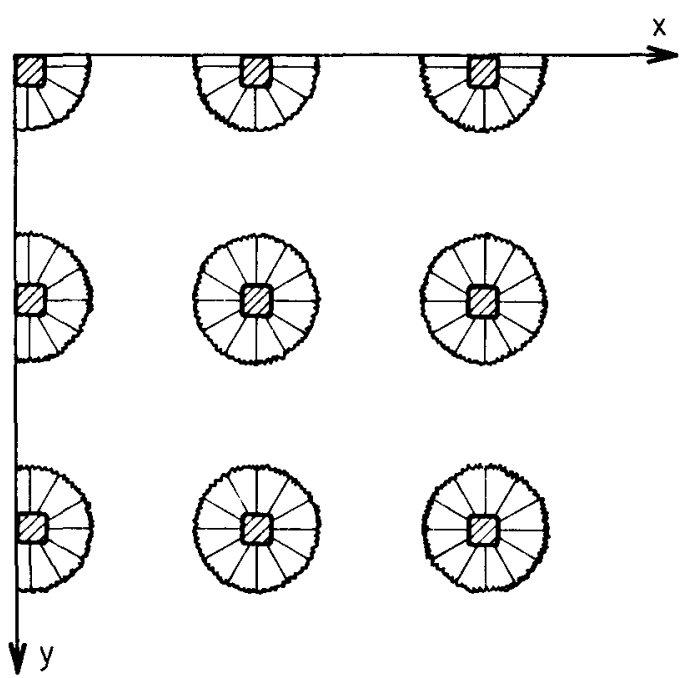

FIGURA 4.2- Colapso local ao redor do apoio. 
Caso existam vigas no contorno do pavimento, outros tipos de configurações das charneiras também devem ser analisados (figura 4.3).

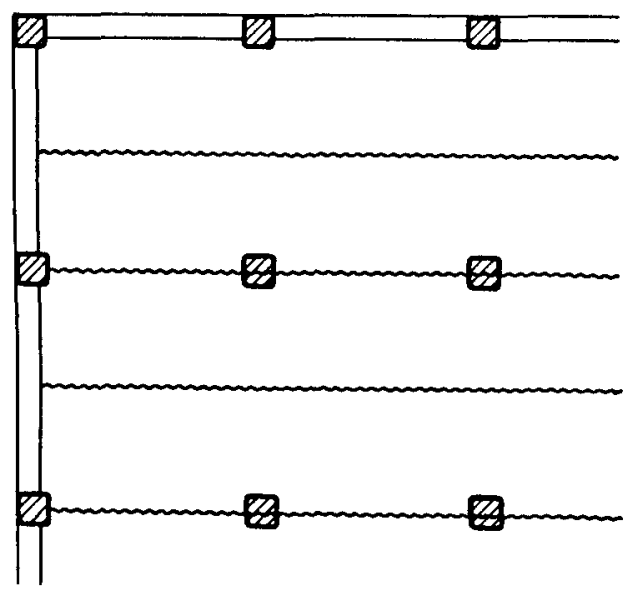

(a)

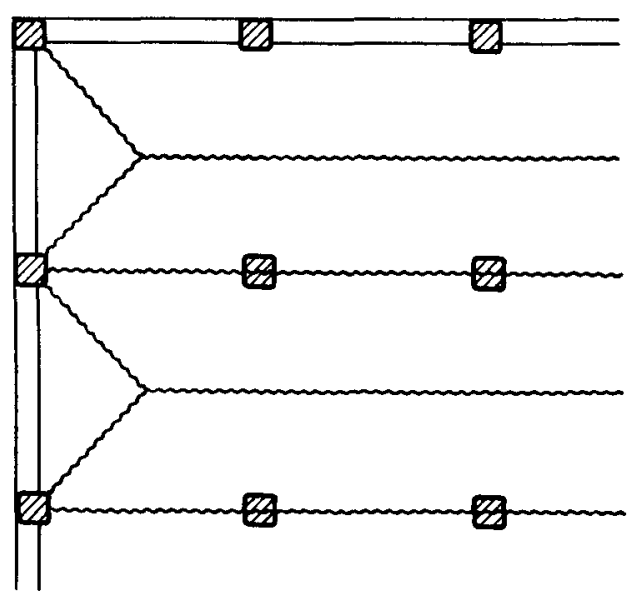

(b)

FIGURA 4.3- Lajes-cogumelo com vigas no contorno.

\subsection{2- Divisão do Pavimento em Painéis}

O pavimento analisado deve ser dividido em painéis que, segundo suas localizações, são denominados painéis internos, painéis laterais ou painéis de canto. Essa divisão é feita a partir dos eixos que ligam os centros dos pilares, como mostrado na figura 4.4 .

Analisa-se a seguir cada um desses painéis, estudando os principais tipos de configurações das charneiras e determinando os momentos de plastificação para cada um deles.

\section{2- PAINÉIS INTERNOS}

Para painéis internos deve-se analisar a configuração das charneiras na região do apoio (figura 4.5) e as configurações envolvendo o colapso de todo o painel (figura 4.6), deprezando-se a influência dos painéis vizinhos, ficando-se assim a favor da segurança. 


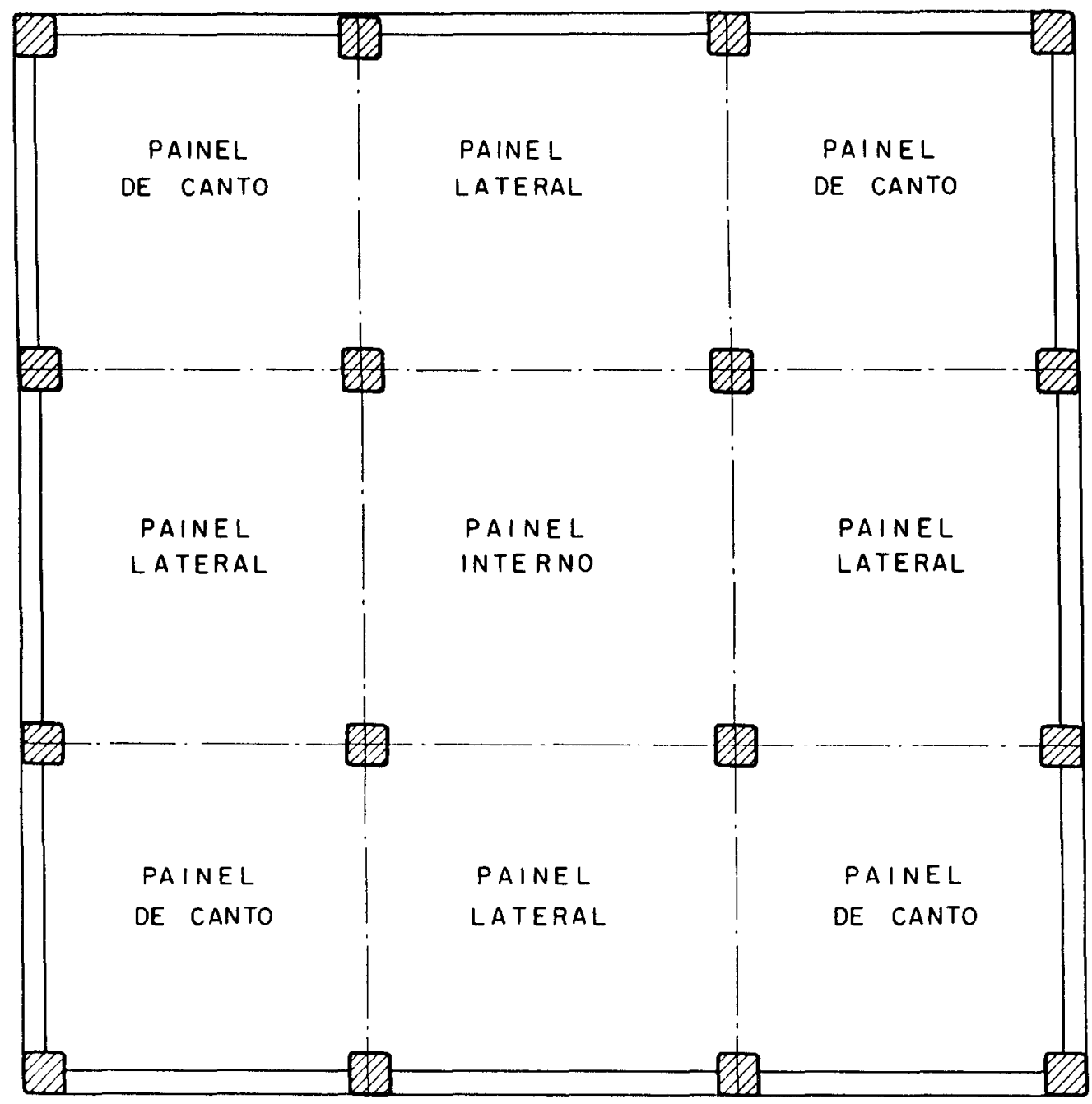

FIGURA 4.4- Divisão do pavimento em painéis.

Considerando-se a configuração da figura 4.5, o trabalho externo $T_{\theta}$, desenvolvido pela carga $p$ uniformemente distribuida no painel, quando é dado um deslocamento transversal virtual unitário ao longo da charneira positiva circular, vale

$$
T_{e}=p\left(a b-\frac{\pi r^{2}}{3}\right)
$$

sendo o trabalho interno produzido pelas charneiras

$$
T_{i}=\left(m+m^{\prime}\right) 2 \pi r \frac{1}{r}=2 \pi\left(m+m^{\prime}\right)
$$




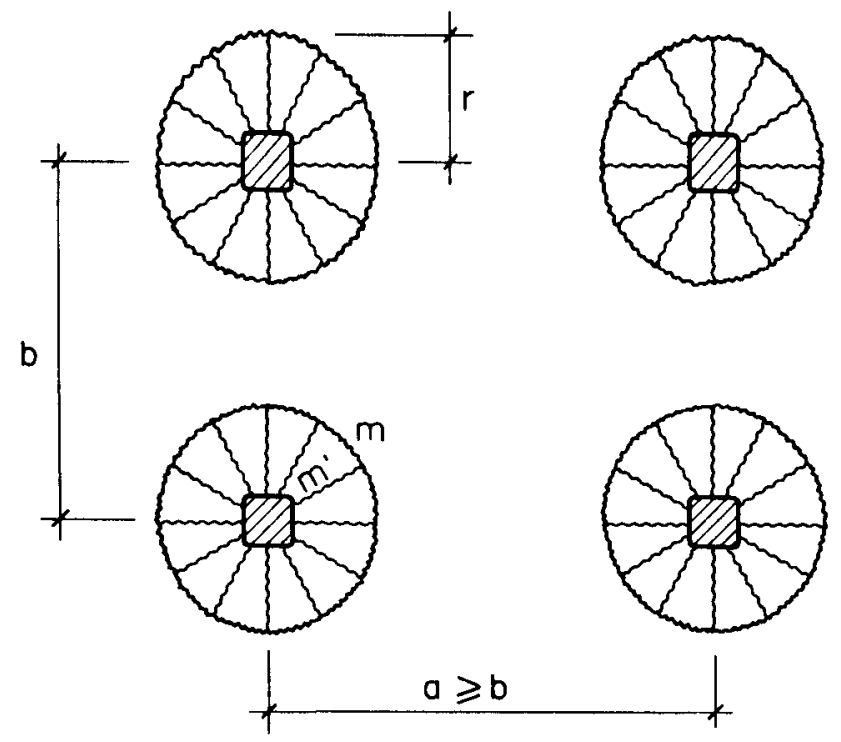

FIGURA 4.5- Configuração de ruína local para painéis internos.

Igualando-se os trabalhos, obtém-se

$$
m+m^{\prime}=p\left(\frac{a b}{2 \pi}-\frac{r^{2}}{6}\right)
$$

ou, considerando-se $\phi=\mathrm{m}^{\prime} / \mathrm{m}$

$$
m=\frac{p}{1+\phi}\left(\frac{a b}{2 \pi}-\frac{r^{2}}{6}\right)
$$

Observa-se na eq. (4.1) que $m+m$ 'é máximo para $r=0$, quando se dá a pior condição. Logo,

$$
m+m^{\prime}=\frac{p a b}{2 \pi}
$$

ou

$$
m=\frac{p a b}{2 \pi(1+\phi)}
$$

$\mathrm{Na}$ obtenção das eqs. (4.3) e (4.4) a laje é considerada isótropa. Se a laje for ortótropa, deve-se transformá-la em uma laje isótropa afim, como mostrado no item 3.7.2. 
Para a determinação do momento de plastificação da configuração da figura 4.6a, utiliza-se o processo do equilibrio. Para a região 1 , tem-se a seguinte equação de equilibrio de momentos, em relação ao eixo de rotação $A B$ :

$$
\left(m_{1}+m\right) b=p a_{1} b \frac{a_{1}}{2}
$$

que resulta

$$
m=\frac{p a_{1}^{2}}{2}-m_{1}
$$

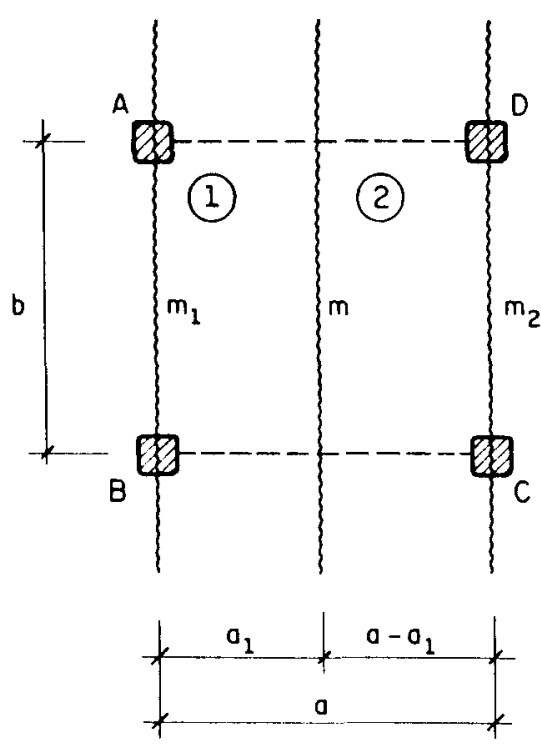

(a)
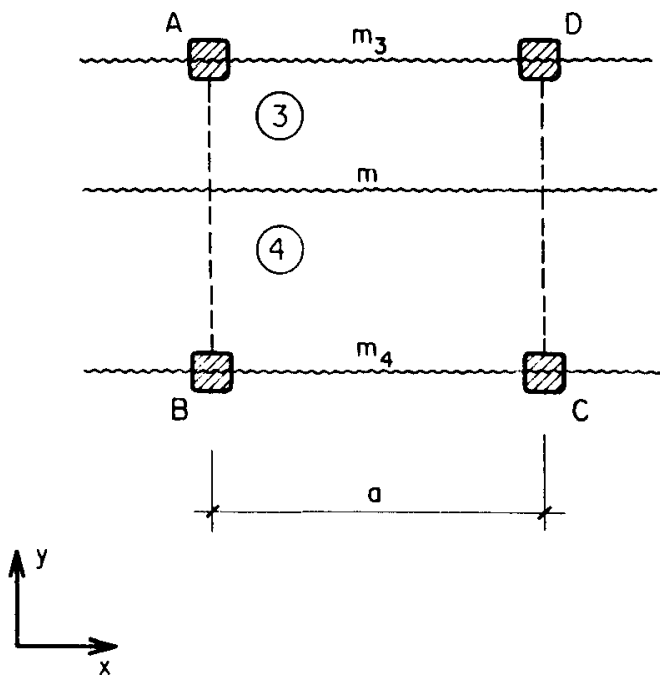

(b)

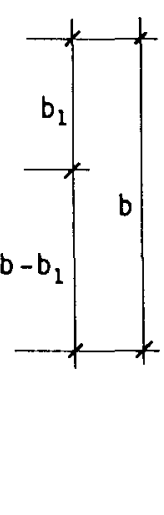

FIGURA 4.6- Configuração de ruína global para painéis internos.

Para a região 2 , a equação de equilibrio de momentos em relação ao eixo de rotação $C D$ vale

$$
\left(m_{2}+m\right) b=p b\left(a-a_{1}\right) \frac{\left(a-a_{1}\right)}{2}
$$


ou

$$
m=\frac{p\left(a-a_{1}\right)^{2}}{2}-m_{2}
$$

A determinação da posição das charneiras è feita igualando-se as equações (4.5) e (4.6), resultando

$$
a_{1}=\frac{\left(m_{1}-m_{2}\right)}{p a}+\frac{a}{2}
$$

Substituindo-se a eq. (4.7) na (4.5) ou na (4.6), encontra-se o momento de plastificação $m$ :

$$
m=\frac{p}{2}\left[\frac{\left(m_{1}-m_{2}\right)^{2}}{p^{2} a^{2}}-\frac{\left(m_{1}+m_{2}\right)}{p}+\frac{a^{2}}{4}\right]
$$

sendo $m_{1}$ e $m_{2}$ os momentos de plastificação negativos, que podem ser fixados a partir dos momentos negativos obtidos no cálculo elástico.

Portanto, o momento de plastificação que deve ser usado no dimensionamento do painel, para a direção $x$, é o dado pela eq. (4.8).

Para a configuração da figura $4.6 \mathrm{~b}$, o momento de plastificação é obtido de maneira análoga ao da figura $4.6 a$, podendo ser expresso por:

$$
m=\frac{p}{2}\left[\frac{\left(m_{3}-m_{4}\right)^{2}}{p^{2} b^{2}}-\frac{\left(m_{3}+m_{4}\right)}{p}+\frac{b^{2}}{4}\right]
$$

Este momento deve ser usado no dimensionamento do painel, para a direção $y$.

Deve-se comparar os momentos dados pelas eqs. (4.8) e (4.9) com o momento dado pela eq. (4.3) ou (4.4), para que seja evitada a possibilidade de colapso na região do apoio. 


\section{3- PAINÉIS LATERAIS}

Os painéis laterais podem apresentar apoios pontuais ou apoios lineares no seu contorno.

\subsection{1- Painéis Laterais com Apoios Pontuais}

Para painéis laterais com apoios pontuais, considera-se também a configuração mais desfavorável, desprezando-se, em favor da segurança, a influência dos painéis vizinhos. Para a obtenção da configuração mais desfavorável, devem ser analisadas a configuração da figura 4.5 , relativa ao colapso local na região dos apoios, e as configurações relativas ao colapso global do painel, apresentadas na figura 4.7 .

Para a configuração da figura 4.5 , valem todas as considerações feitas no item 4.2, sendo o momento de plastificação dado pelas eqs. (4.3) ou (4.4).

Para a configuração da figura $4.7 \mathrm{a}$, segue-se o mesmo procedimento adotado na análise das configurações da figura 4.6: utiliza-se o processo do equilibrio e faz-se o equilibrio de momentos de cada região, em torno do seu eixo de rotação, obtendose

- para a região 1 :

$m=\frac{p a_{1}^{2}}{2}-m_{1}$

- para a região 2 :

$m=\frac{p\left(a-a_{1}\right)^{2}}{2}-m_{2}$

Igualando-se as equações (4.10) e (4.11), encontra-se o valor de $a_{1}$ :

$a_{1}=\frac{\left(m_{1}-m_{2}\right)}{p a}+\frac{a}{2}$ 
que substituido na eq. (4.10) ou (4.11) fornece o momento de plastificação $m$ :

$$
m=\frac{p}{2}\left[\frac{\left(m_{1}-m_{2}\right)^{2}}{p^{2} a^{2}}-\frac{\left(m_{1}+m_{2}\right)}{p}+\frac{a^{2}}{4}\right]
$$

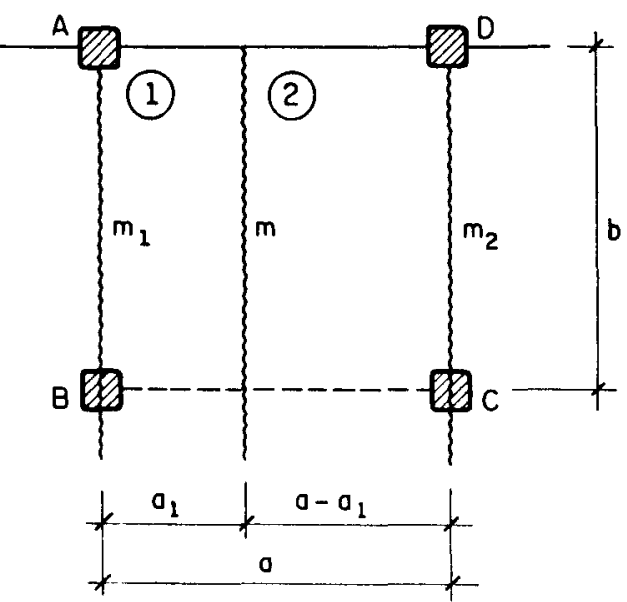

(a)

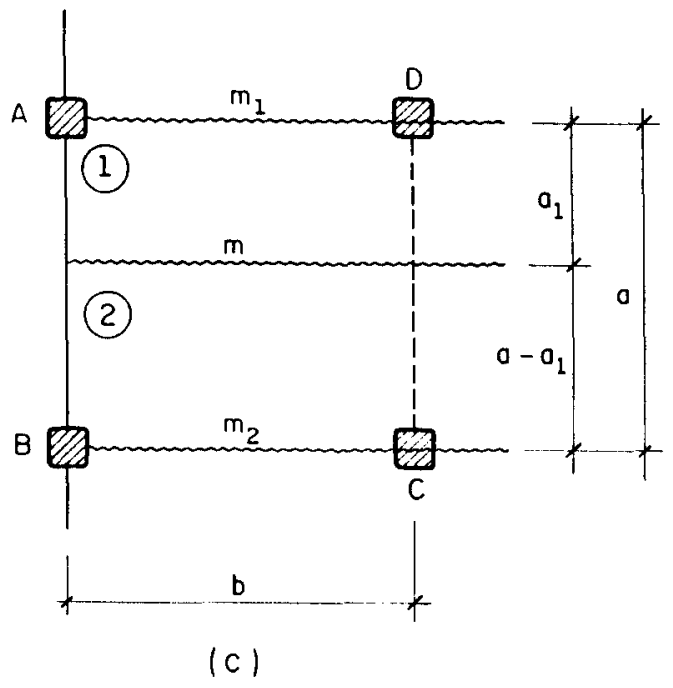

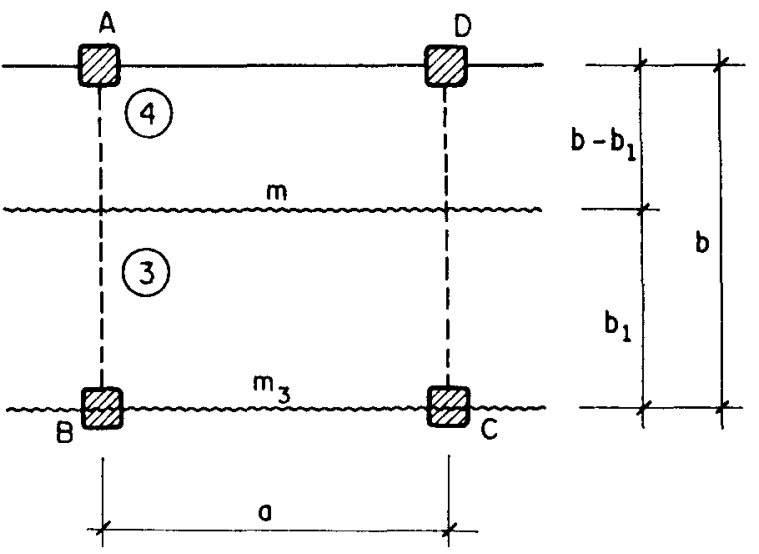

(b)

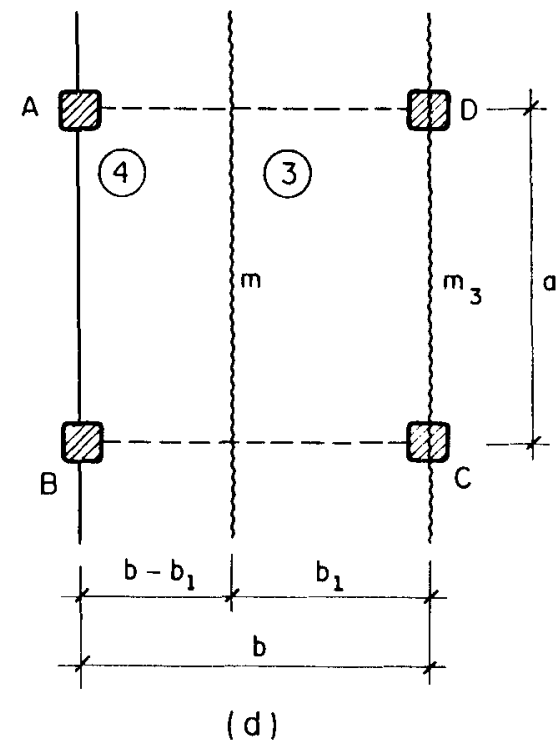

FIGURA 4.7- Painéis laterais com apoios pontuais.

A eq. (4.12) também é válida para a configuração da figura $4.7 c$, com a tomado sempre como o vão paralelo à borda do painel. 
Para a configuração da figura $4.7 \mathrm{~b}$, o equilíbrio de momentos, em torno dos eixos de rotação de cada região em que foi dividido o painel, resulta

- para a região 3 :

$$
m=\frac{p b_{1}^{2}}{2}-m_{3}
$$

- para a região 4:

$$
m=\frac{p}{2}\left(b-b_{1}\right)^{2}
$$

A partir das eqs. (4.13) e (4.14) encontra-se o valor de $b_{1}$ em função de $m_{3}$ :

$$
b_{1}=\frac{m_{3}}{p b}+\frac{b}{2}
$$

De posse do valor de $b_{1}$, pode-se substituí-lo na eq. (4.13) ou na (4.14), obtendo-se o momento de plastificação $m$ :

$$
m=\frac{p}{2}\left(\frac{b}{2}-\frac{m_{3}}{p b}\right)^{2}
$$

que também pode ser utilizada para a configuração apresentada na figura $4.7 \mathrm{~d}$, sendo $b$ o vão perpendicular à borda do painel.

\subsection{2- Painéis Laterais com Apoios Lineares}

Para o dimensionamento dos painéis laterais com apoios lineares, engaste ou apoio simples, devem ser analisadas as configurações da figura 4.8. Para o dimensionamento na direção $x$, utiliza-se a configuração da figura 4.8a ou 4.8c e para a direção $y$, utiliza-se a configuração da figura $4.8 \mathrm{~b}$ ou $4.8 \mathrm{~d}$. Como nos casos anteriores, não se considera a influência dos painéis vizinhos.

Utilizando-se o processo do equilibrio, para a configuração da figura 4.8a, tem-se o seguinte, para cada uma das regiões em que foi dividido o painel: 
- para a região 1 (equação de equilíbrio de momentos em relação ao eixo de rotação $A D)$ :

$$
\left(\mu m+m_{1}\right) a=p a \frac{b_{1}}{2} \frac{b_{1}}{3}
$$

ou

$$
b_{1}=\sqrt{\frac{6}{p}\left(\mu m+m_{1}\right)}
$$
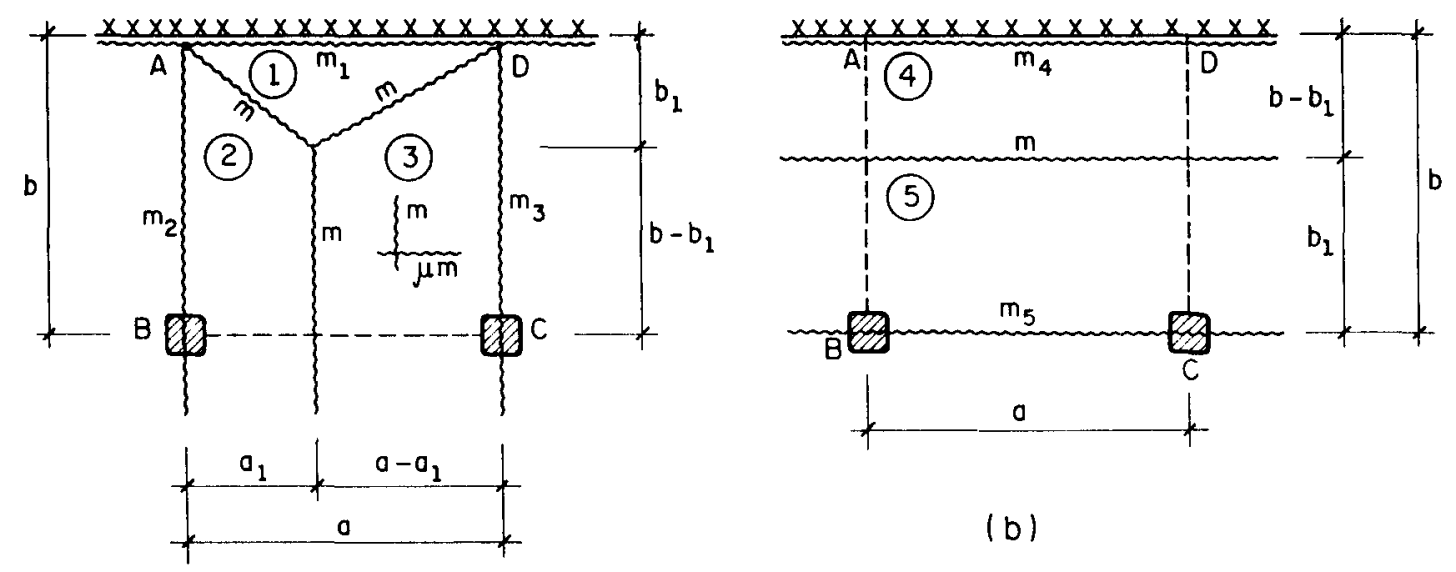

(b)

(a)

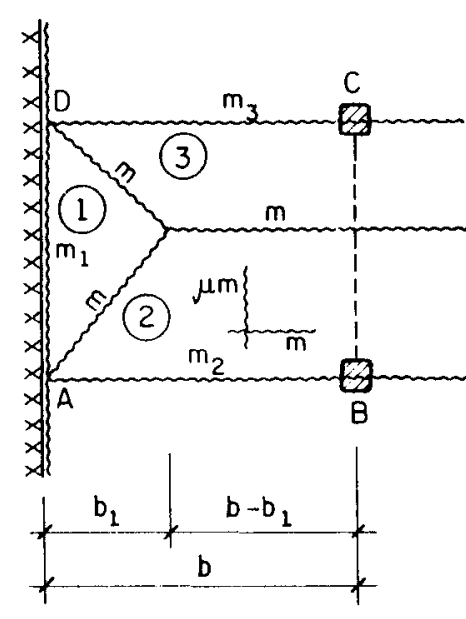

(c)
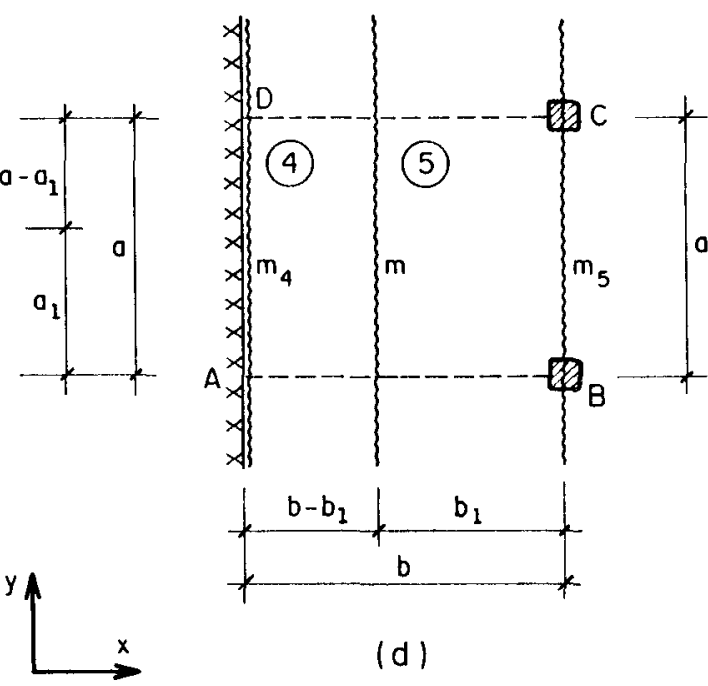

(d)

FIGURA 4.8- Painéis laterais com apoios lineares. 
- para a região 2 (equação de equilíbrio de momentos em relação ao eixo de rotação $A B)$ :

$$
\left(m+m_{2}\right) b=p\left[a_{1}\left(b-b_{1}\right) \frac{a_{1}}{2}+\frac{a_{1} b_{1}}{2} \frac{a_{1}}{3}\right]
$$

ou

$$
m+m_{2}=\frac{p a_{1}^{2}}{b}\left(\frac{b}{2}-\frac{b_{1}}{3}\right)
$$

- para a região 3 (equação de equilibrio de momentos em relação ao eixo de rotação $C D)$ :

$$
\left(m+m_{3}\right) b=p\left[\frac{\left(a-a_{1}\right)^{2}\left(b-b_{1}\right)}{2}+\frac{b_{1}\left(a-a_{1}\right)^{2}}{6}\right]
$$

ou

$$
m+m_{3}=\frac{p\left(a-a_{1}\right)^{2}}{b}\left(\frac{b}{2}-\frac{b_{1}}{3}\right)
$$

A determinação da posição das charneiras é feita substituindo-se a eq. (4.17) na (4.18) e na (4.19), resultando, respectivamente:

$$
\begin{aligned}
& a_{1}=\sqrt{\frac{2 b\left(m+m_{2}\right)}{p b-2 \sqrt{\frac{2 p}{3}\left(\mu m+m_{1}\right)}}} \\
& \left(a-a_{1}\right)=\sqrt{\frac{2 b\left(m+m_{3}\right)}{p b-2 \sqrt{\frac{2 p}{3}\left(\mu m+m_{1}\right)}}}
\end{aligned}
$$


Somando-se as equações (4.20) e (4.21), obtém-se

$$
a=\frac{\sqrt{2 b}\left(\sqrt{m+m_{2}}+\sqrt{m+m_{3}}\right)}{\sqrt{p b-2 \sqrt{\frac{2 p}{3}\left(\mu m+m_{1}\right)}}}
$$

que pode ser escrita da seguinte forma:

$$
\left(\sqrt{m+m_{2}}+\sqrt{m+m_{3}}\right)=\frac{a}{\sqrt{2 b}} \sqrt{p b-2 \sqrt{\frac{2 p}{3}\left(\mu m+m_{1}\right)}}
$$

Sendo $m_{1}, m_{2}$ e $m_{3}$ os momentos negativos e $\mu$ a razão entre os momentos positivos, obtidos através do cálculo elástico, a eq. (4.22) é função somente de $m$, que é determinado calculando-se a interseção das duas funções apresentadas abaixo:

$$
f_{1}=\left(\sqrt{m+m_{2}}+\sqrt{m+m_{3}}\right)
$$

e

$$
f_{2}=\frac{a}{\sqrt{2 b}} \sqrt{p b-2 \sqrt{\frac{2 p}{3}\left(\mu m+m_{1}\right)}}
$$

Como os momentos $m_{1}, m_{2}$, e $m_{3}$ são dados em valor absoluto, para que seja atendido o domínio de validade, deve ser imposta a seguinte restrição na eq. (4.24):

$$
\sqrt{p b-2 \sqrt{\frac{2 p}{3}\left(\mu m+m_{1}\right)}} \geq 0
$$

portanto,

$$
\sqrt{\left(\mu m+m_{1}\right)} \leq \frac{b}{2} \sqrt{\frac{3 p}{2}}
$$


E para que a configuração de ruína seja a que está em estudo, deve-se ter $b_{1} \leq b$

$\sqrt{\frac{6}{p}\left(\mu m+m_{1}\right)} \leq b$

$$
\sqrt{\left(\mu m+m_{1}\right)} \leq b \sqrt{\frac{p}{6}}
$$

A condição (4.26) já atende a (4.25), sendo então suficiente que apenas ela se verifique.

Este mesmo procedimento pode ser adotado para a análise da configuração da figura 4.8c, sendo o momento de plastificação obtido através da interseção das funções $f_{1}$ e $f_{2}$, dadas pelas eqs. (4.23) e (4.24), a é o vão paralelo à borda e $b$ o vão perpendicular à borda do painel.

Da mesma forma, para a configuração da figura $4.8 \mathrm{~b}$, tem-se

- para a região 4 :

$m=\frac{p}{2}\left(b-b_{1}\right)^{2}-m_{4}$

- para a região 5 :

$m=\frac{p b_{1}^{2}}{2}-m_{5}$

Igualando-se as eqs. (4.27) e (4.28), encontra-se o valor de $b_{1}$ :

$$
b_{1}=\frac{\left(m_{5}-m_{4}\right)}{p b}+\frac{b}{2}
$$

Substituindo-se o valor de $b_{1}$, dado pela eq. (4.29), na (4.27) ou na (4.28), chega-se a

$$
m=\frac{p}{2}\left[\frac{\left(m_{5}-m_{4}\right)^{2}}{p^{2} b^{2}}-\frac{\left(m_{5}+m_{4}\right)}{p}+\frac{b^{2}}{4}\right]
$$


Esta equação também fornece o momento de plastificação para a configuração apresentada na figura 4.8d. Mais uma vez lembra-se que $b$ é o vão perpendicular à borda do painel.

Se os contornos dos painéis da figura 4.8 forem simplesmente apoiados, utilizam-se as expressões anteriores com $m_{1}=0$, para as figuras 4.8. a e 4.8.c, e $m_{4}=0$, para as figuras 4.8.b e 4.8.d.

\section{4- PAINÉIS DE CANTO}

Duas situações devem ser analisadas para os painéis de canto: uma para canto sobre apoio pontual e outra para canto com apoios lineares, quer com contorno engastado, quer com contorno simplesmente apoiado.

\subsection{1- Canto sobre Apoio Pontual}

Para canto sobre apoio pontual devem ser analisadas a configuração referente ao colapso local na região dos apoios, mostrada na figura 4.5 , e as configurações referentes ao colapso de todo o painel, mostradas na figura 4.9.
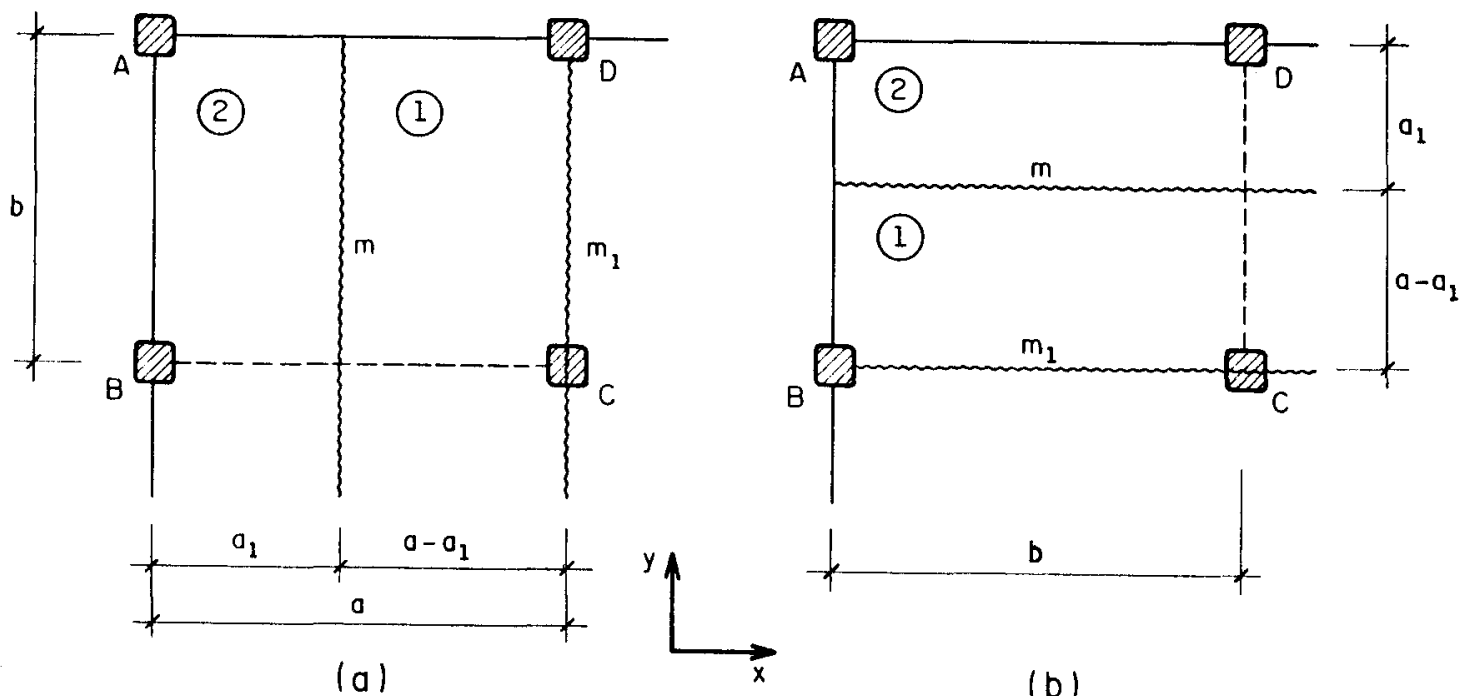

FIGURA 4.9- Canto sobre apoio pontual. 
Para a configuração da figura 4.5 , vale a análise feita no item 4.2 , sendo o momento de plastificação dado pela eq. (4.3) ou (4.4).

Para a configuração da figura $4.9 a$, as equações de equilíbrio de momentos em relação aos eixos de rotação da regiōes do painel resultam,

- para a região 1:

$m=\frac{p\left(a-a_{1}\right)^{2}}{2}-m_{1}$

- para a região 2 :

$$
m=\frac{p a_{1}^{2}}{2}
$$

Igualando-se as eqs. (4.31) e (4.32) determina-se a posição das charneiras, ou seja,

$$
a_{1}=\frac{a}{2}-\frac{m_{1}}{p a}
$$

O momento de plastificação é obtido pela substituição da eq. (4.33) na (4.31) ou na (4.32):

$$
m=\frac{p}{2}\left(\frac{a}{2}-\frac{m_{1}}{p a}\right)^{2}
$$

Este momento é comparado com o momento dado pela eq. (4.4) e o maior entre os dois valores é que deve ser usado no dimensionamento do painel.

Para a configuração da figura $4.9 b$, que é semelhante à configuração da figura 4.9a, o momento de plastificação também é dado pela eq. (4.34), com a e $b$ tomados de acordo com a figura $4.9 \mathrm{~b}$.

\subsection{2- Painéis de Canto com Apoios Lineares}

Para um painel de canto com o contorno engastado ou simplesmente apoiado, as configurações das charneiras a serem analisadas são apresentadas na 
figura 4.10. Para o dimensionamento na direção $x$, utiliza-se a configuração mostrada na figura 4.10a e para a direção $y$, utiliza-se a configuração apresentada na figura 4.10b. Nestas configurações não é considerada a formação de leque no canto.

Para a configuração da figura 4.10a, fazendo-se o equilíbrio de momentos para cada região, em torno do seu eixo de rotação, encontra-se

- para a região 1 :

$$
\left(\mu m+m_{1}\right) a=\frac{p a b_{1}^{2}}{6}
$$

ou

$$
b_{1}=\sqrt{\frac{6}{p}\left(\mu m+m_{1}\right)}
$$

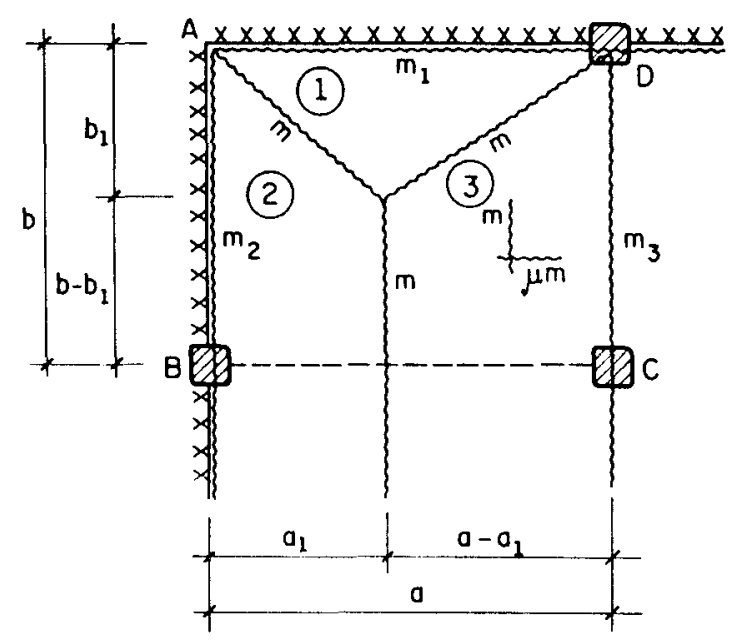

(a)

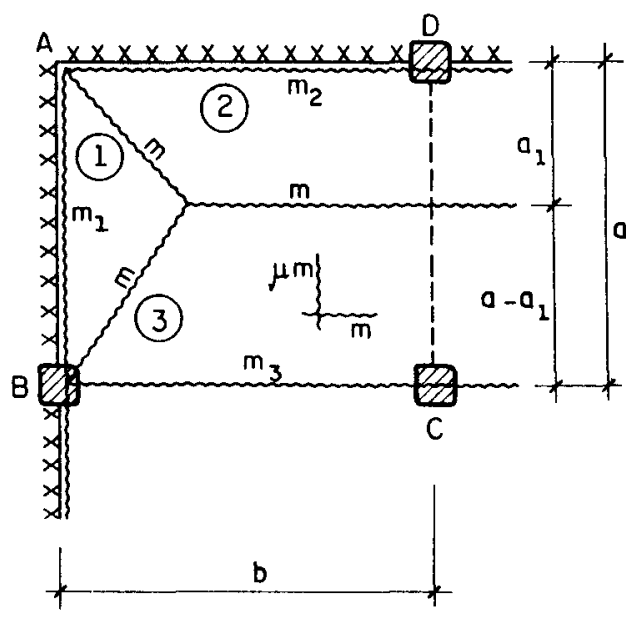

(b)

FIGURA 4.10- Painéis de canto com apoios lineares.

- para a região 2:

$$
m+m_{2}=\frac{p a_{1}^{2}}{b}\left(\frac{b}{2}-\frac{b_{1}}{3}\right)
$$


- para a região 3 :

$m+m_{3}=\frac{p\left(a-a_{1}\right)^{2}}{b}\left(\frac{b}{2}-\frac{b_{1}}{3}\right)$

Substituindo-se a eq. (4.35) na (4.36) e na (4.37), obtém-se, respectivamente:

$$
\begin{aligned}
& a_{1}=\sqrt{\frac{2 b\left(m+m_{2}\right)}{p b-2 \sqrt{\frac{2 p}{3}\left(\mu m+m_{1}\right)}}} \\
& \left(a-a_{1}\right)=\sqrt{\frac{2 b\left(m+m_{3}\right)}{p b-2 \sqrt{\frac{2 p}{3}\left(\mu m+m_{1}\right)}}}
\end{aligned}
$$

Somando-se as equações (4.38) e (4.39), encontra-se

$$
a=\frac{\sqrt{2 b}\left(\sqrt{m+m_{2}}+\sqrt{m+m_{3}}\right)}{\sqrt{p b-2 \sqrt{\frac{2 p}{3}}\left(\mu m+m_{1}\right)}}
$$

ou

$$
\left(\sqrt{m+m_{2}}+\sqrt{m+m_{3}}\right)=\frac{a}{\sqrt{2 b}} \sqrt{p b-2 \sqrt{\frac{2 p}{3}\left(\mu m+m_{1}\right)}}
$$

A eq. (4.40) é idêntica à eq. (4.22) e sua resolução é feita da mesma forma, ou seja, a partir do cálculo da interseção das funções $f_{1}$ e $f_{2}$, dadas pelas eqs. (4.23) e (4.24), respectivamente.

Também deve ser verificada a condição:

$$
\sqrt{\left(\mu m+m_{1}\right)} \leq b \sqrt{\frac{p}{6}}
$$


A análise da configuração apresentada na figura $4.10 \mathrm{~b}$ é análoga à da configuração mostrada na figura $4.10 a$, podendo-se utilizar a formulação acima, sendo que $a$ e $b$ devem ser tomados de acordo com a figura 4.10 .

\section{5- DISTRIBUIÇÃO DAS ARMADURAS}

As equaçōes apresentadas neste capítulo, para o cálculo dos momentos de plastificação, podem ser usadas no projeto de lajes-cogumelo. Contudo, a distribuição das armaduras não deve ser uniforme, pois, sabe-se que os momentos negativos nas faixas dos pilares são maiores que nas faixas centrais.

O CEB, Bulletin d'Information $n^{\circ} 35^{1}$ apud PARK \& GAMBLE (1980), recomenda que o momento de plastificação, em cada direção, seja distribuído segundo a disposição 1 ou a disposição 2, apresentadas na figura 4.11, e que a razão entre os momentos de plastificação negativo e o positivo esteja entre 1,0 a 1,5. PARK \& GAMBLE (1980) sugerem que essa razão seja 1,5. Com a fixação dos momentos negativos obtidos pelo pré-dimensionamento em regime elástico, pode-se calcular os valores dos momentos de plastificação positivos pelas equações apresentadas neste capitulo. Esses momentos de plastificação são, então, modificados para seguir uma das disposições da figura 4.11.

Segundo PARK \& GAMBLE (1980), apesar da disposição 2 ter sido aprovada em diversos testes, a distribuição da armadura nas faixas dos pilares é considerada exagerada por alguns projetistas e caso haja fissuração na faixa central, não haverá armadura para controlá-la. Por isso, a distribuição dos momentos negativos da disposição 1 é mais utilizada. Entretanto, para os momentos positivos, a disposição 2 costuma ser mais utilizada.

COMITÉ EUROPÉEN DU BÉTON. (1962). Dalles et planchers dalles, applications de la théorie des lignes de rupture aux calculs de résistance en flexion, Bulletin d'Information $n^{\circ} 35$ apud PARK, R.; GAMBLE, W. L. (1980). Reinforced Concrete slabs. New York, John Wiley \& Sons. 


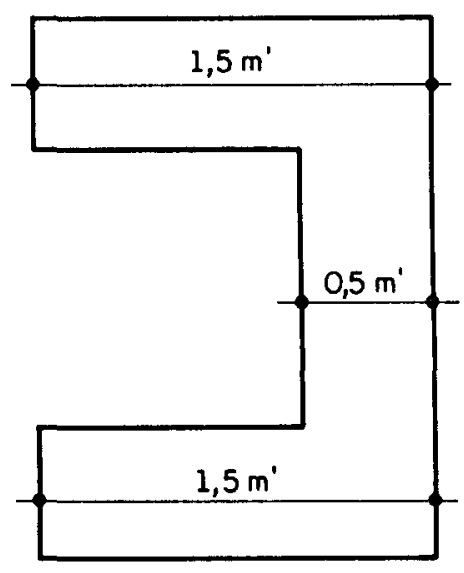

MOMENTOS NEGATIVOS

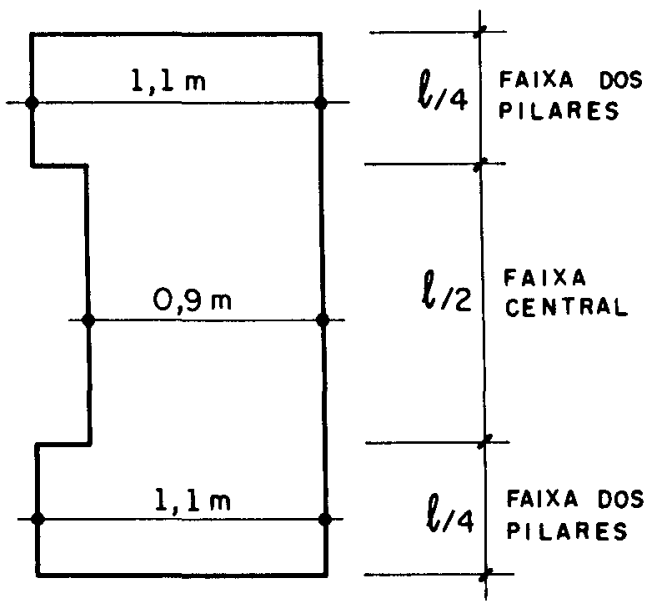

MOMENTOS POSITIVOS

(a) Disposicāo 1

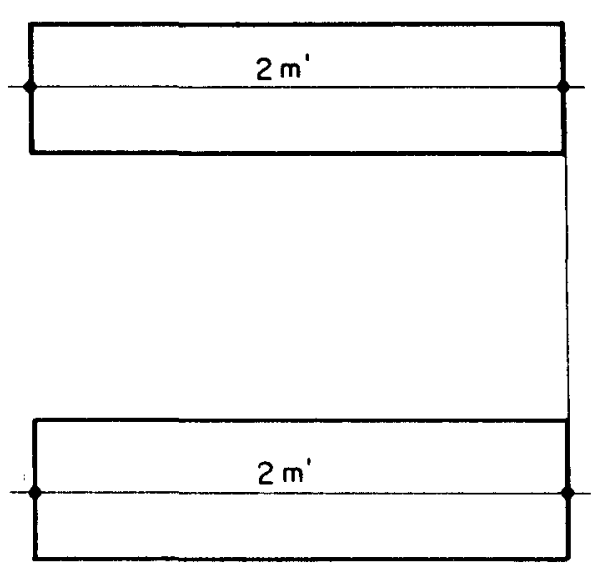

MOMENTOS NEGATIVOS

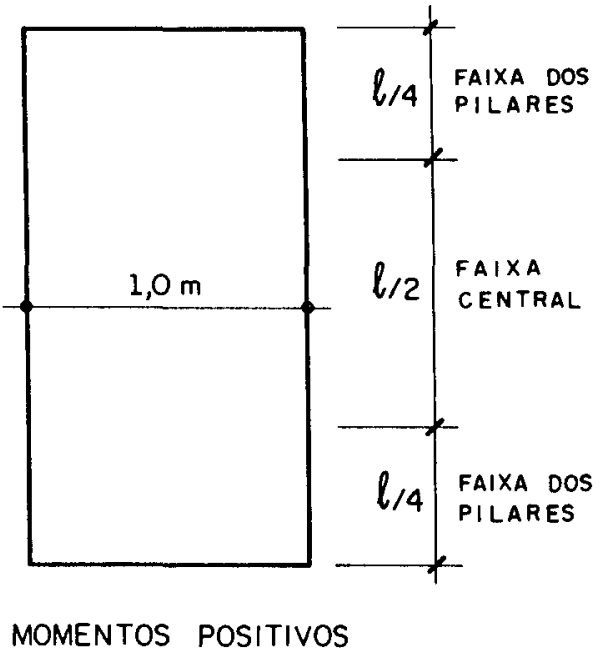

(b) Disposicāo 2

FIGURA 4.11- Distribuição dos momentos de plastificação. 


\section{5- EXEMPLOS}

Neste capitulo são apresentados exemplos de lajes-cogumelo, abordando aspectos relativos ao cálculo dos momentos pela Teoria das Charneiras Plásticas e ao detalhamento das armaduras.

Inicialmente são calculados os momentos pelo cálculo elástico, utilizando-se o Processo dos Pórticos Equivalentes, apresentado no item 2.3. As vantagens desse processo encontram-se no item 2.3.4. A partir desses momentos, calculam-se os momentos de plastificação, usando a formulação apresentada no capítulo 4 .

\section{1- DISPOSIÇÕES CONSTRUTIVAS}

Para cálculo e detalhamento das armaduras são adotadas algumas recomendações, baseadas nas prescrições da NBR 6118 (1978) e nos trabalhos de TAKEYA et al (1985) e MONTOYA et al (1976), apresentadas a seguir.

\subsection{1- Cobrimento}

Para as armaduras inferiores, utiliza-se o cobrimento igual a $2 \mathrm{~cm}$, pois se costuma deixar o concreto aparente na face inferior das lajes-cogumelo. E para as armaduras superiores, utiliza-se o cobrimento de $0,5 \mathrm{~cm}$.

É recomendado que se especifique em qual camada se encontra cada conjunto de barras. Normalmente se costuma dispor as barras correspondentes à direção de maiores momentos, nas camadas mais externas, e as outras barras, correspondentes à direção ortogonal à de maiores momentos, nas camadas mais internas. 


\subsection{2- Diåmetro das Barras}

Segundo a NBR 6118 (1978), no seu item 6.3.1.1, o diâmetro das barras das armaduras principais não deve ultrapassar um décimo da espessura da laje, isto é:

$$
\phi_{b} \leq \frac{1}{10} h
$$

onde $\phi_{b}$ é o diâmetro da barra da armadura principal e $h$ é a espessura da laje.

\subsection{3- Armadura Mínima}

Para a armadura mínima utiliza-se a recomendada pela NBR 6118 (1978), ou seja:

$A_{s, \min }=0,25 \%$ b h, para aços CA-25 e CA-32

$A_{s, \min }=0,15 \% \mathrm{~b} h$, para aços CA-40, CA-50 e CA-60

sendo $b$ tomado igual a $100 \mathrm{~cm}$ e $h$ igual à espessura da laje em $\mathrm{cm}$.

Pelo menos três barras da armadura inferior devem passar por dentro do espaço entre as armaduras dos pilares, nas regiões das ligações laje-pilar, para evitar colapso progressivo, na eventualidade de ruína por punção.

Para armaduras positivas, na direção menos solicitada em cada painel, utilizam-se armaduras de distribuição não menores que a quarta parte das armaduras principais correspondentes (MONTOYA et al, 1976).

\subsection{4- Espaçamento entre as Barras das Armaduras}

TAKEYA et al (1985) recomendam que o espaçamento máximo entre as barras da armadura principal não ultrapasse a:

$$
\begin{aligned}
& 1,5 \mathrm{~d} \\
& 20 \mathrm{~cm} \text { para barras lisas } \\
& 15 \mathrm{~cm} \text { para barras corrugadas }
\end{aligned}
$$

Para a armadura de distribuição este espaçamento não deve ser maior que $33 \mathrm{~cm}$. 


\subsection{5- Comprimento das Barras}

Segundo TAKEYA et al (1985), os comprimentos minimos das barras e suas disposições construtivas devem estar de acordo com a figura 5.1.

Os comprimentos e as disposições das barras, apresentados na figura 5.1, valem tanto para a direção $x$ quanto para a direção $y$.

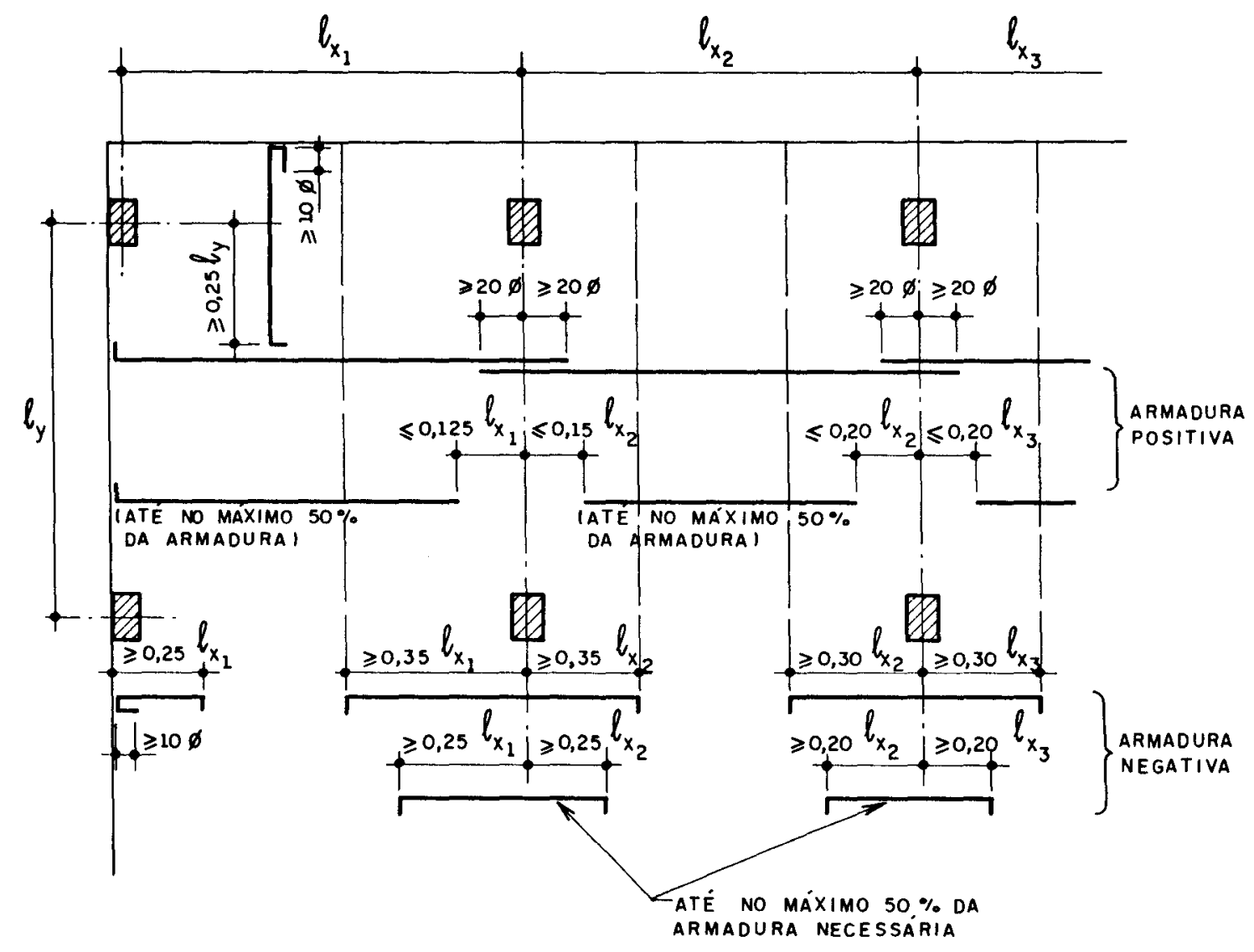

FIGURA 5.1- Comprimentos mínimos e disposição das barras das armaduras.

\section{2- EXEMPLO 1}

Na figura 5.2 é apresentado o pavimento a ser analisado. 


\subsection{1 - Estimativa da Espessura da Laje}

Segundo o critério de BARKER (1967) e BAYKOV (1980), a espessura de lajes-cogumelo deve estar entre $\ell / 32$ a $\ell / 35$, sendo $\ell(e m \mathrm{~cm})$ o maior vão dos painéis. Portanto, para o pavimento da figura 5.2 , tem-se $\ell=600 \mathrm{~cm}$. Logo,

$$
h=\frac{600}{35}=17,14 \mathrm{~cm}
$$

adotando-se, então, $h=18 \mathrm{~cm}$, que também está de acordo com a espessura mínima exigida pela NBR 6118 (1978).

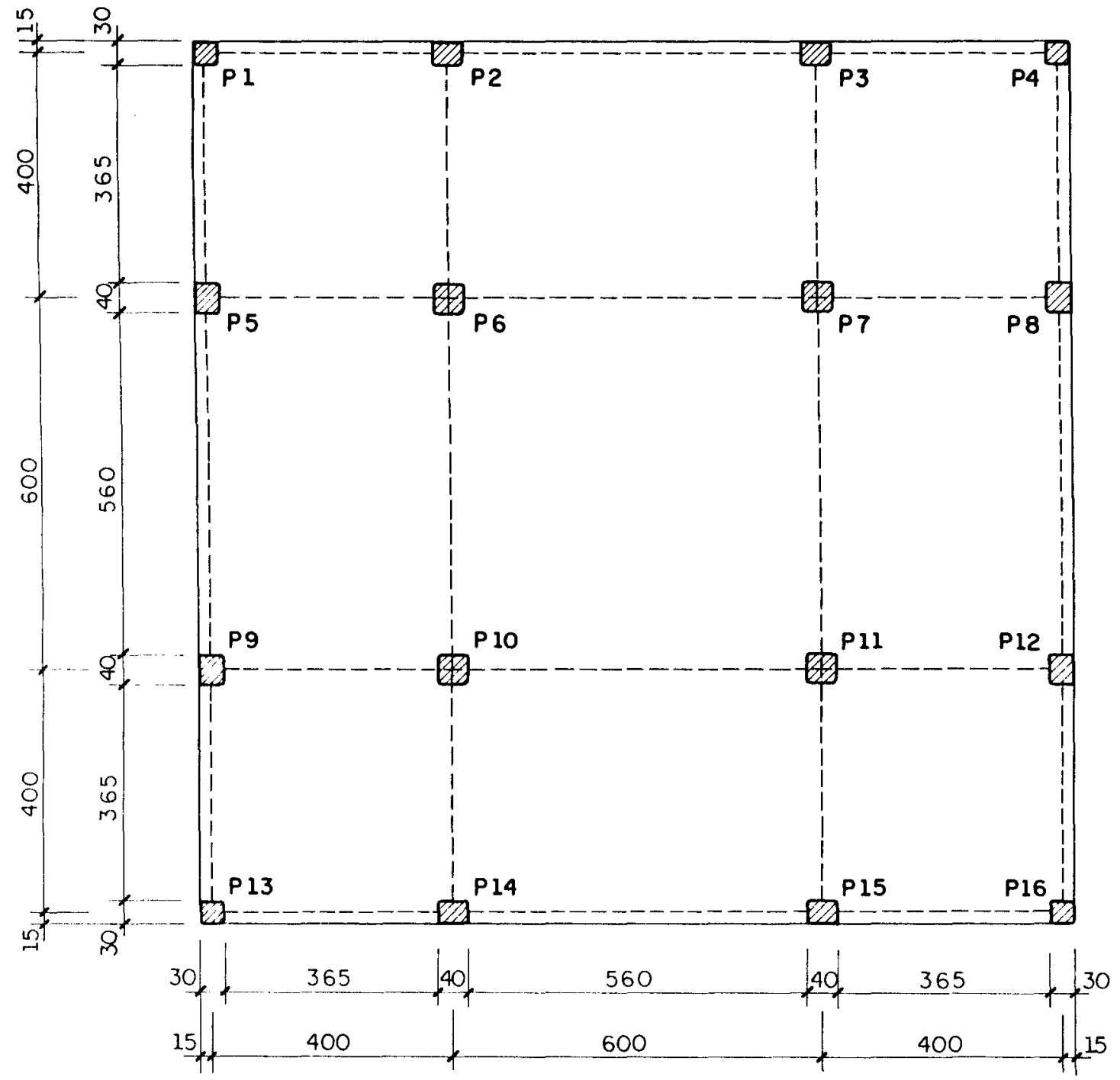

FIGURA 5.2- Pavimento analisado no exemplo 1. 


\subsection{2- Definição das Faixas de Projeto}

Como o pavimento analisado apresenta dupla simetria, é necessário apenas que se definam duas faixas de projeto, FP1 e FP2, como mostrado na figura 5.3.

\subsection{3- Definição dos Pórticos}

Utilizando o processo dos pórticos equivalentes, apresentado no item 2.3, definem-se os pórticos PORT 1 e PORT 2 (figura 5.3), suficientes para representar todo o pavimento.

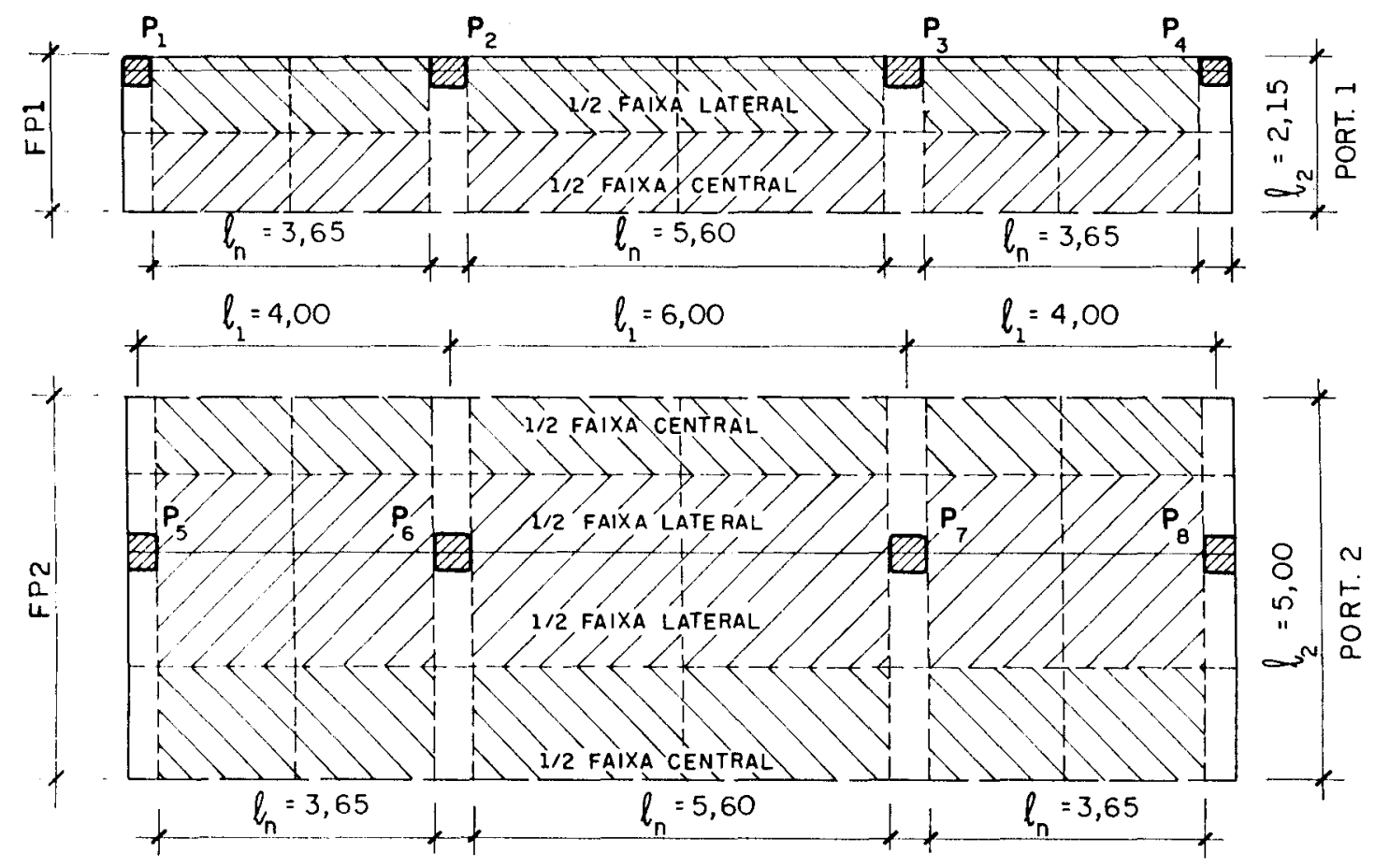

FIGURA 5.3- Definição das faixas de projeto e dos pórticos equivalentes.

\subsection{4- Propriedades das Barras}

Para a determinação das propriedades das barras dos pórticos, numeram-se os nós e as barras de acordo com a figura 5.4 . 


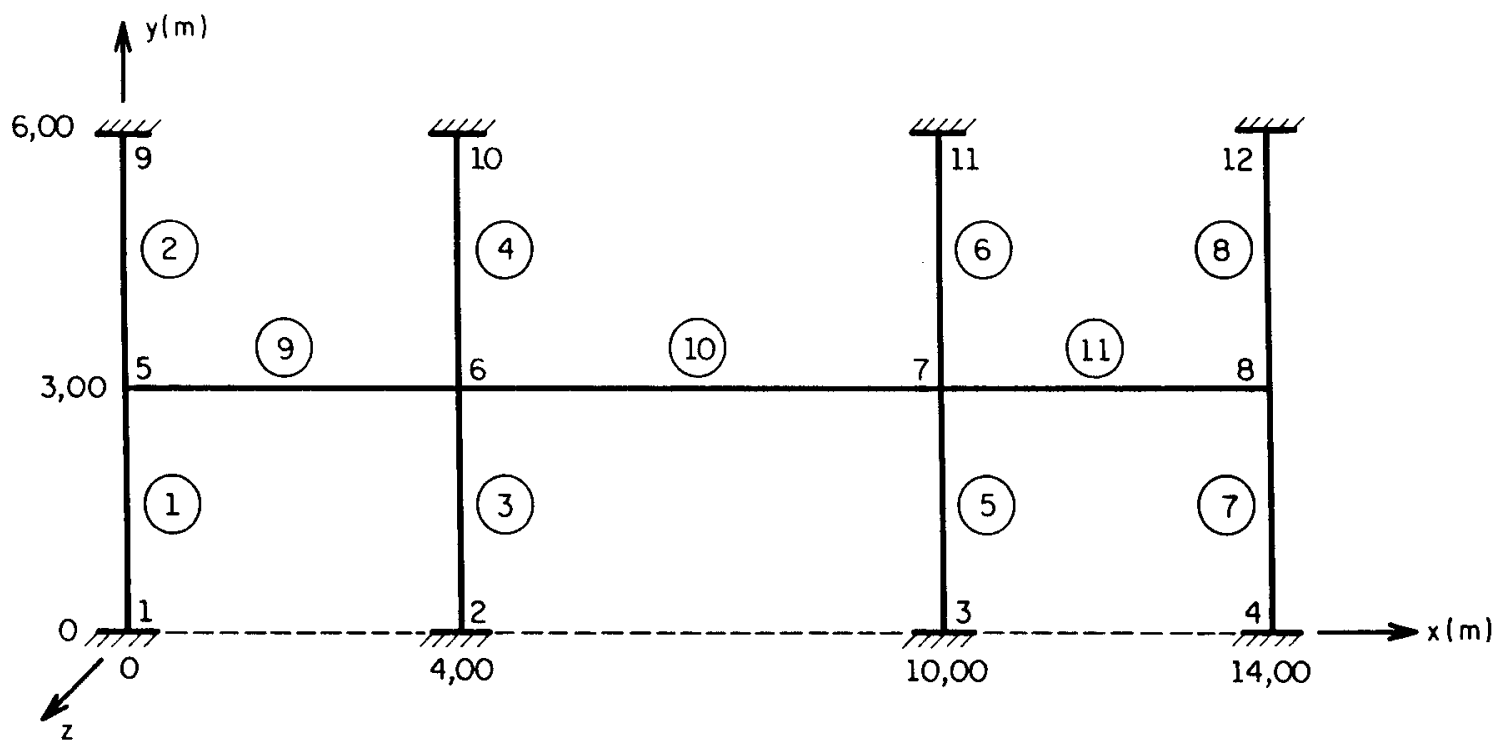

FIGURA 5.4- Numeração das barras dos pórticos.

a) Barras do pórtico PORT 1

Barra $1=$ barra $2=$ barra $7=$ barra 8 (pilares)

Dados: largura $(b)=0,30 \mathrm{~m}$

$$
\text { altura }(h)=0,30 \mathrm{~m}
$$

Área da seção transversal:

$$
A=b \cdot h=0,30 \cdot 0,30=0,09 \mathrm{~m}^{2}
$$

Momento de inércia:

$$
I=\frac{b \cdot h^{3}}{12}=\frac{0,30 \cdot 0,30^{3}}{12}=0,000675 \mathrm{~m}^{4}
$$

Barra $3=$ barra $4=$ barra $5=$ barra 6 (pilares)

Dados: largura $(b)=0,30 \mathrm{~m}$

$$
\text { altura }(h)=0,40 \mathrm{~m}
$$

Área da seção transversal:

$$
A=b \cdot h=0,30 \cdot 0,40=0,12 \mathrm{~m}^{2}
$$


Momento de inércia:

$$
I=\frac{b \cdot h^{3}}{12}=\frac{0,30 \cdot 0,40^{3}}{12}=0,0016 \mathrm{~m}^{4}
$$

Barra $9=$ barra $10=$ barra 11 (vigas)

Dados: largura $\left(h_{2}\right)=2,15 \mathrm{~m}$

$$
\text { altura }(h)=0,18 \mathrm{~m}
$$

Área da seção transversal:

$$
A=\ell_{2} \cdot h=2,15 \cdot 0,18=0,387 \mathrm{~m}^{2}
$$

Momento de inércia:

$$
I=\frac{\ell_{2} \cdot h^{3}}{12}=\frac{2,15 \cdot 0,18^{3}}{12}=0,0010449 \mathrm{~m}^{4}
$$

Na tabela 5.1 foram lançadas as áreas e os momentos de inércia das seções transversais das barras do PORT1, calculadas anteriormente.

TABELA 5.1- Propriedades das barras do pórtico PORT1.

\begin{tabular}{|c|c|c|c|}
\hline Propriedade & Barras 1, 2, 7, 8 & Barras 3, 4, 5, 6 & Barras 9, 10, 11 \\
\hline Área $\left(\mathrm{m}^{2}\right)$ & 0,08 & 0,120 & 0,387 \\
\hline $\begin{array}{l}\text { M. de Inércia } \\
\left(\mathrm{m}^{4}\right)\end{array}$ & 0,000675 & 0,001600 & 0,001045 \\
\hline
\end{tabular}

b) Barras do pórtico PORT 2

Barra 1 = barra $2=$ barra $7=$ barra 8 (pilares)

Dados: largura $(b)=0,40 \mathrm{~m}$

$$
\text { altura }(h)=0,30 \mathrm{~m}
$$

Área da seção transversal:

$$
A=b \cdot h=0,40 \cdot 0,30=0,120 \mathrm{~m}^{2}
$$


Momento de inércia:

$$
I=\frac{b \cdot h^{3}}{12}=\frac{0,40 \cdot 0,30^{3}}{12}=0,0009 \mathrm{~m}^{4}
$$

Barra $3=$ barra $4=$ barra $5=$ barra 6 (pilares)

Dados: largura $(b)=0,40 \mathrm{~m}$

$$
\text { altura }(h)=0,40 \mathrm{~m}
$$

Área da seção transversal:

$$
A=b \cdot h=0,40 \cdot 0,40=0,160 \mathrm{~m}^{2}
$$

Momento de inércia:

$$
I=\frac{b \cdot h^{3}}{12}=\frac{0,40 \cdot 0,40^{3}}{12}=0,00213 \mathrm{~m}^{4}
$$

Barra $9=$ barra $10=$ barra 11 (vigas)

Dados: largura $\left(l_{2}\right)=5,00 \mathrm{~m}$

$$
\text { altura }(h)=0,18 \mathrm{~m}
$$

Área de seção transversal:

$$
A=\ell_{2} \cdot h=5,00 \cdot 0,18=0,900 \mathrm{~m}^{2}
$$

Momento de inércia:

$$
I=\frac{\ell_{2} \cdot h^{3}}{12}=\frac{5,00 \cdot 0,18^{3}}{12}=0,00243 \mathrm{~m}^{4}
$$

Na tabela 5.2 apresentam-se as propriedades das barras do PORT2.

TABELA 5.2- Propriedades das barras do pórtico PORT 2.

\begin{tabular}{|l|c|c|c|}
\hline Propriedade & Barras 1, 2, 7, 8 & Barras 3, 4, 5, 6 & Barras 9, 10, 11 \\
\hline Área $\left(\mathrm{m}^{2}\right)$ & 0,120 & 0,160 & 0,900 \\
\hline M. de Inércia $\left(\mathrm{m}^{4}\right)$ & 0,00090 & 0,00213 & 0,00243 \\
\hline
\end{tabular}




\subsection{5- Determinaçăo do Carregamento}

Determinam-se dois grupos de cargas atuantes: as cargas permanentes $(\mathrm{g})$ e as cargas acidentais (q).

a) Carga permanente

São utilizadas as seguintes cargas permanentes:

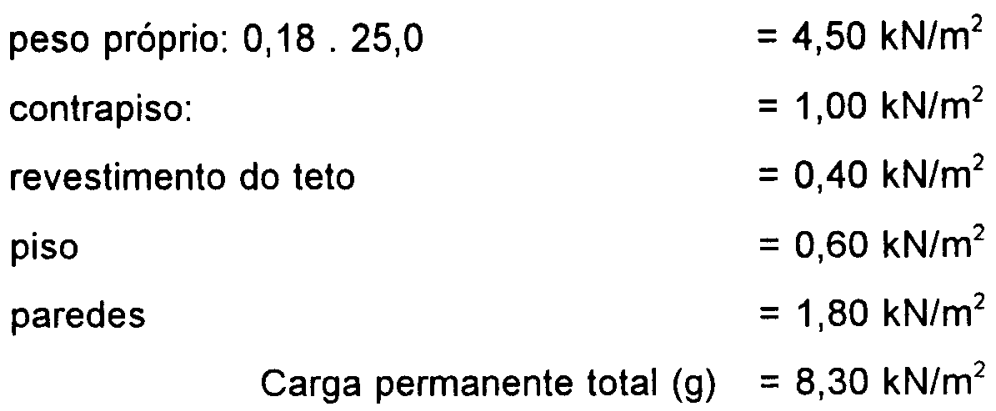

b) Carga acidental

Supondo o pavimento como de edificio de escritórios, segundo a NBR 6120 (1980), a carga acidental vale:

$$
q=2,00 \mathrm{kN} / \mathrm{m}^{2}
$$

c) Carga distribuida total $p$

$$
p=q+g=10,30 \mathrm{kN} / \mathrm{m}^{2}
$$

d) Carregamento do pórtico PORT1

Deve-se considerar, devida à existência de paredes e da faixa da laje situada fora dos painéis, em balanço (figura 5.5.a), uma carga linear nas bordas livres das lajes. Nos casos de faixas de projeto adjacentes às bordas, esta carga linear deve ser acrescida à carga distribuída na faixa.

Como no pórtico PORT1 a faixa de projeto é adjacente à borda, deve-se acrescentar a carga linear devida à parede, $\mathbf{p}_{\mathrm{par}}$, à carga distribuída na faixa. Sendo o peso por metro linear de parede igual a $1,80 \mathrm{kN} / \mathrm{m}^{2}$ e a altura da parede igual a $3,00 \mathrm{~m}$, tem-se:

$$
p_{p a r}=1,80 \cdot 3,00=5,40 \mathrm{kN} / \mathrm{m}
$$


$E$ as cargas devidas aos balanços (figura 5.5.b), $P_{b}$ e $M_{b}$ são dadas por: $P_{b}$ : carga da faixa de laje em balanço: $0,15.10,30=1,545 \mathrm{kN} / \mathrm{m}$ carga linear devida à parede:

$=5,400 \mathrm{kN} / \mathrm{m}$

Como a largura do pórtico é igual a 2,15 m, tem-se:

$$
P_{b}=(1,545+5,400) \cdot 2,15=14,932 \mathrm{kN}
$$

$M_{b}$ :

$$
M_{b}=14,932 \cdot \frac{0,15}{2}=1,120 \mathrm{kN} \cdot \mathrm{m}
$$
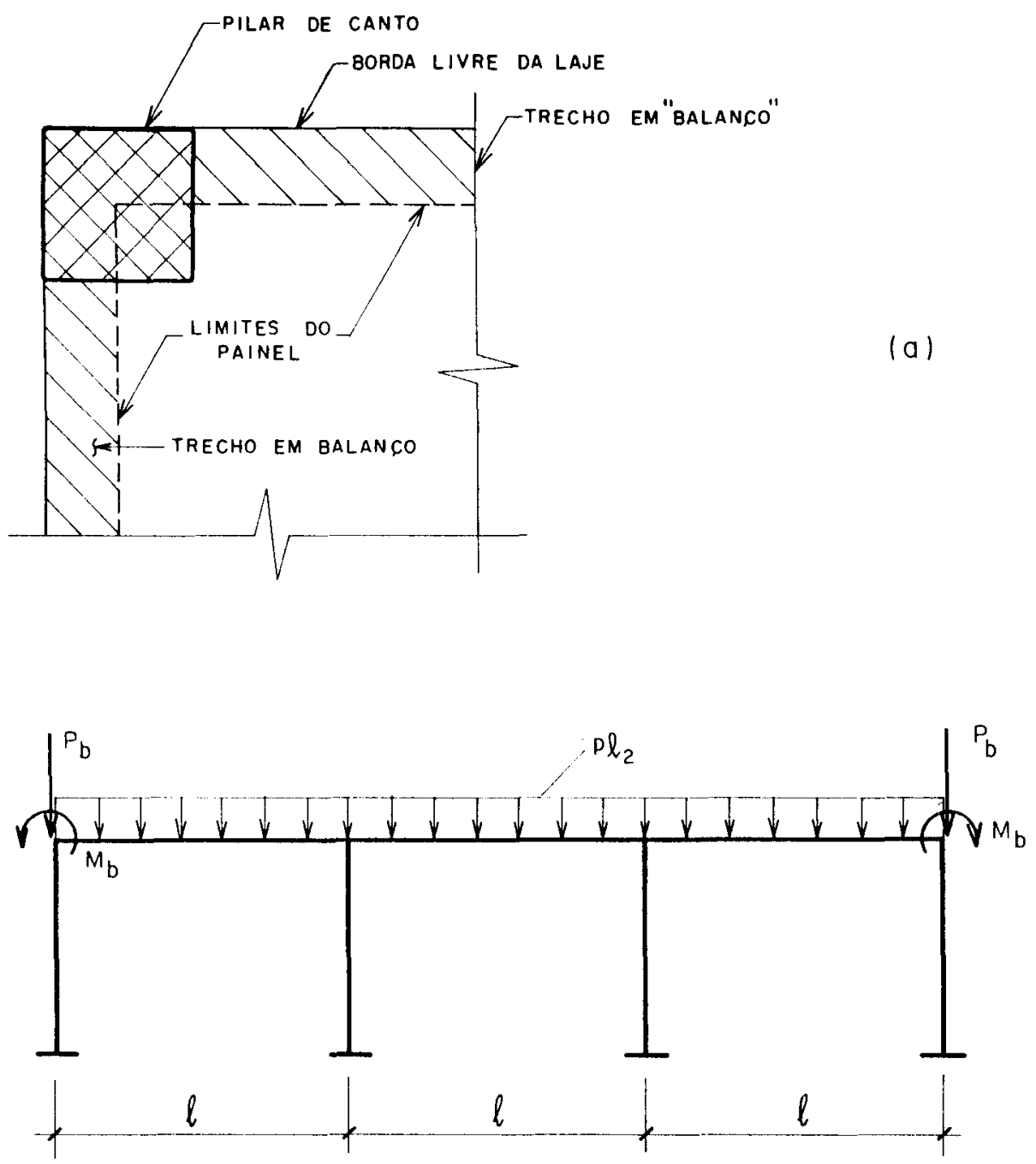

FIGURA 5.5- Esquema das partes em balanço. 
A carga linear atuante nas barras 9, 10, 11 (figura 5.4) do pórtico PORT1 vale:

$$
10,30 \cdot 2,15+5,400=27,545 \mathrm{kN} / \mathrm{m}
$$

A figura 5.6 mostra o carregamento do pórtico PORT1.

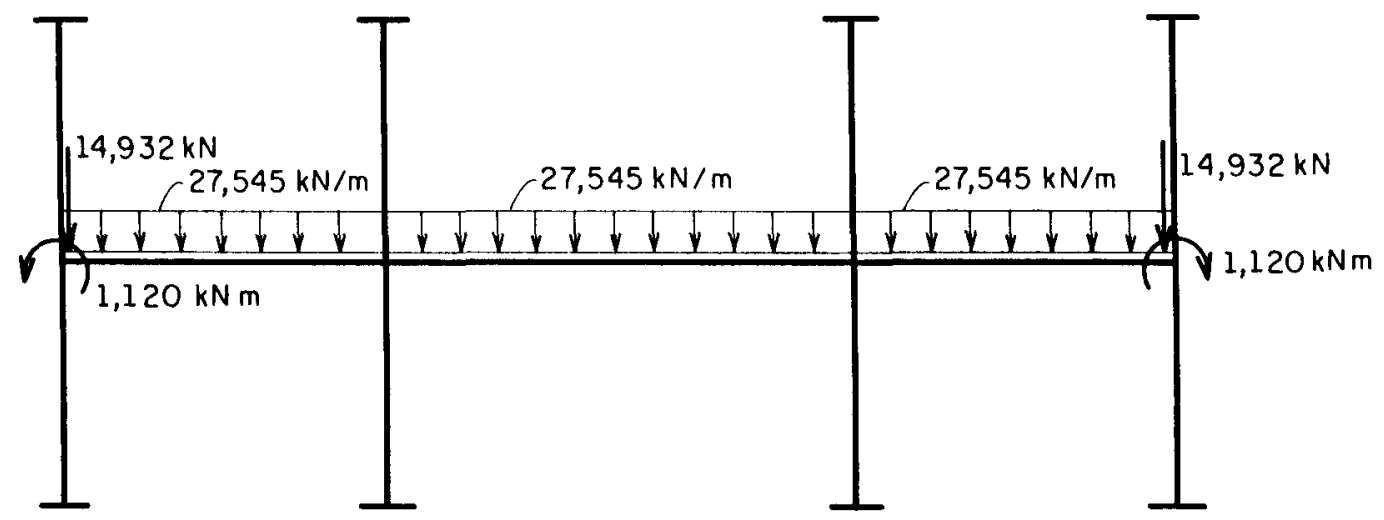

FIGURA 5.6- Carregamento do pórtico PORT1.

e) Carregamento do pórtico PORT2

As cargas devidas aos balanços $P_{b}$ e $M_{b}$ são dadas por:

$$
\begin{aligned}
& P_{b}=(1,545+5,400) \cdot 5,00=34,725 \mathrm{kN} \\
& M_{b}=34,725 \cdot \frac{0,15}{2}=2,604 \mathrm{kN} \cdot \mathrm{m}
\end{aligned}
$$

E a carga linear atuante nas barras $9,10,11$ (figura 5.4) vale:

$$
5,00 \cdot 10,30=51,500 \mathrm{kN} / \mathrm{m}
$$

Na figura 5.7 é representado o carregamento do pórtico PORT 2.

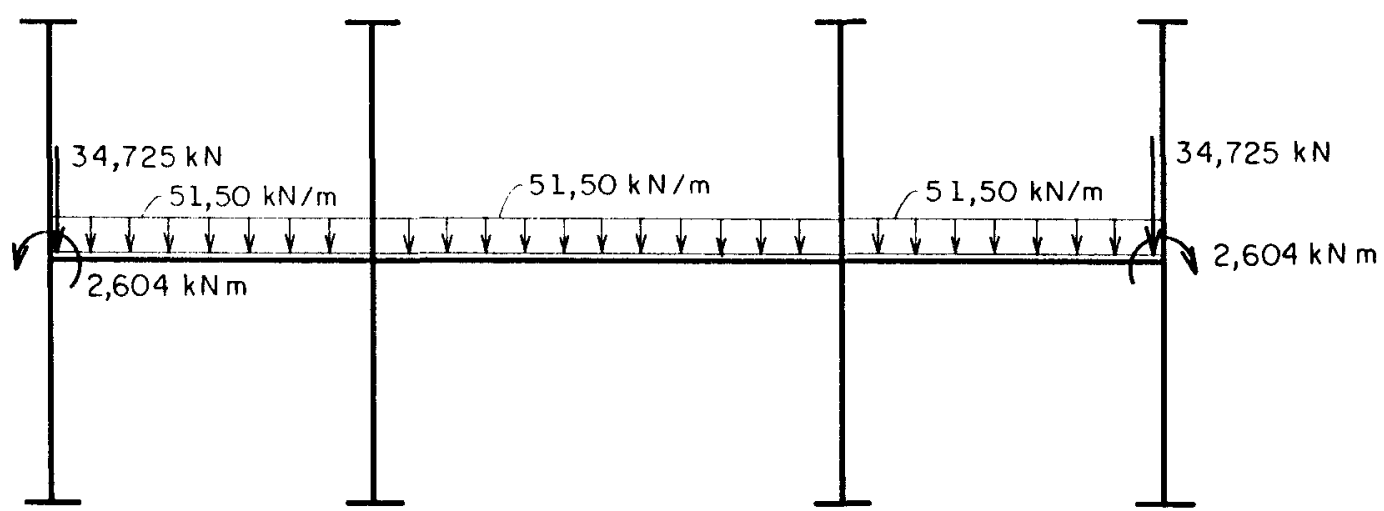

FIGURA 5.7- Carregamento do pórtico PORT2. 
É importante ressaltar que, por se tratar apenas de um exemplo demonstrativo, as reações dos pavimentos superiores não são consideradas.

\subsection{6- Cálculo dos Esforços Solicitantes}

Os esforços solicitantes foram calculados através de um programa de resolução de pórticos planos (Programa PPLAN, de autoria dos Professores Márcio Ramalho e Márcio Côrrea).

Nas tabelas 5.3 e 5.4 , encontram-se os momentos fletores obtidos para os pórticos PORT1 e PORT2, respectivamente.

TABELA 5.3- Momentos fletores no pórtico PORT1.

\begin{tabular}{|c|c|}
\hline $\begin{array}{c}\mathbf{X} \\
(\mathbf{m})\end{array}$ & $\begin{array}{c}\mathbf{M} \\
(\mathbf{k N m})\end{array}$ \\
\hline 0,0 & $-21,483$ \\
\hline 1,6 & 20,085 \\
\hline 4,0 (esq.) & $-49,779$ \\
\hline 4,0 (dir.) & $-80,155$ \\
\hline 7,0 & 43,797 \\
\hline
\end{tabular}

TABELA 5.4- Momentos fletores no pórtico PORT2.

\begin{tabular}{|c|c|}
\hline $\begin{array}{c}x \\
(\mathbf{m})\end{array}$ & $\begin{array}{c}\mathbf{M} \\
(\mathbf{k N m})\end{array}$ \\
\hline 0,0 & $-31,021$ \\
\hline 1,6 & 39,554 \\
\hline 4,0 (esq.) & $-101,783$ \\
\hline 4,0 (dir.) & $-147,929$ \\
\hline 7,0 & 83,821 \\
\hline
\end{tabular}




\subsection{7- Distribuição dos Momentos nas Faixas de Projeto}

Os momentos fletores, apresentados no item anterior, foram obtidos para as barras dos póticos que representam as faixas da laje; portanto, é necessária a distribuição desses momentos entre as meias-faixas laterais e centrais das faixas de projeto que essas barras representam. Essa distribuição é feita de acordo com o item 2.3.3, utilizando a tabela 2.2 .

\section{a) PORT1}

$$
M=-21,483 \mathrm{kNm}
$$

Utilizando a tabela 2.2, caso 1, para painel externo e laje apoiada em pilares isolados, para a meia-faixa lateral a porção do momento fletor vale:

$$
\Delta M=0,80 M=0,80(-21,483)=-17,186 \mathrm{kNm}
$$

que distribuido na faixa lateral de largura $1,15 \mathrm{~m}$, resulta:

$$
m=\frac{-17,186}{1,15}=-14,945 \mathrm{kNm} / \mathrm{m}
$$

Para a faixa central o momento que esta absorve vale:

$$
\Delta M=0,20 M=0,20(-21,483)=-4,297 \mathrm{kNm}
$$

e distribuindo-o na largura de $1,00 \mathrm{~m}$, tem-se

$$
\begin{aligned}
& m=\frac{-4,297}{1,00}=-4,297 \mathrm{kNm} / \mathrm{m} \\
& M=20,085 \mathrm{kNm} \\
& \text { Da mesma forma, para a faixa lateral, tem-se: } \\
& \Delta M=0,60 \mathrm{M}=0,60(20,085)=12,051 \mathrm{kNm} \\
& m=\frac{12,051}{1,15}=10,479 \mathrm{kNm} / \mathrm{m}
\end{aligned}
$$


$E$, para a faixa central, tem-se:

$$
\begin{aligned}
\Delta M & =0,40 \mathrm{M}=0,40(20,085)=8,034 \mathrm{kNm} \\
m & =\frac{8,034}{1,00}=8,034 \mathrm{kNm} / \mathrm{m} \\
M & =-49,779 \mathrm{kNm}
\end{aligned}
$$

Para a faixa lateral, tem-se:

$$
\begin{aligned}
& \Delta M=0,76 M=0,76(-49,779)=-37,832 \mathrm{kNm} \\
& m=\frac{-37,832}{1,15}=-32,897 \mathrm{kNm} / \mathrm{m} \\
& E, \text { para a faixa central, tem-se: } \\
& \Delta M=0,24 \mathrm{M}=0,24(-49,779)=-11,947 \mathrm{kNm} \\
& m=\frac{-11,947}{1,00}=-11,947 \mathrm{kNm} / \mathrm{m} \\
& M=-80,155 \mathrm{kNm}
\end{aligned}
$$

Da mesma forma, utilizando agora a tabela 2.2 , caso 2, para a faixa lateral, tem-se:

$$
\begin{aligned}
& \Delta M=0,66 M=0,66(-80,155)=-52,902 \mathrm{kNm} \\
& m=\frac{-52,902}{1,15}=-46,002 \mathrm{kNm} / \mathrm{m} \\
& E, \text { para a faixa central, obtém-se: } \\
& \Delta M=0,34 \mathrm{M}=0,34(-80,155)=-27,253 \mathrm{kNm} \\
& m=\frac{-27,253}{1,00}=-27,253 \mathrm{kNm} / \mathrm{m} \\
& M=43,797 \mathrm{kNm}
\end{aligned}
$$

Para a faixa lateral, tem-se:

$\Delta M=0,50 M=0,50(43,797)=21,899 \mathrm{kNm}$ 


$$
m=\frac{21,899}{1,15}=19,042 \mathrm{kNm} / \mathrm{m}
$$

E, para a faixa central, tem-se:

$$
\begin{aligned}
\Delta M & =0,50 M=0,50(43,797)=21,899 \mathrm{kNm} \\
m & =\frac{21,899}{1,00}=21,899 \mathrm{kNm} / \mathrm{m}
\end{aligned}
$$

b) PORT2

$$
M=-31,021 \mathrm{kNm}
$$

Para a faixa lateral de largura $2,50 \mathrm{~m}$, tem-se:

$$
\begin{aligned}
\Delta M & =0,80 \mathrm{M}=0,80(-31,021)=-24,817 \mathrm{kNm} \\
m & =\frac{-24,817}{2,50}=-9,927 \mathrm{kNm} / \mathrm{m}
\end{aligned}
$$

Para a faixa central, tem-se:

$\Delta M=0,20 M=0,20(-31,021)=-6,204 \mathrm{kNm}$

Distribuindo-se metade desse momento na meia-faixa central de largura igual a $1,00 \mathrm{~m}$, encontra-se

$$
m=\frac{\frac{\Delta M}{2}}{1,00}=\frac{-3,102}{1,00}=-3,102 \mathrm{kNm} / \mathrm{m}
$$

e na meia-faixa central de largura igual a $1,50 \mathrm{~m}$, obtém-se:

$$
\begin{aligned}
& m=\frac{\frac{\Delta M}{2}}{1,50}=\frac{-3,102}{1,50}=-2,068 \mathrm{kNm} / \mathrm{m} \\
& M=39,554 \mathrm{kNm}
\end{aligned}
$$

Para a faixa lateral de largura 2,50m, tem-se:

$\Delta M=0,60 M=0,60(39,554)=23,732 \mathrm{kNm}$ 


$$
m=\frac{23,732}{2,50}=9,493 \mathrm{kNm} / \mathrm{m}
$$

Para a faixa central, tem-se

$$
\Delta M=0,40 M=0,40(39,554)=15,822 \mathrm{kNm}
$$

que, para a meia-faixa central de largura igual a $1,00 \mathrm{~m}$, tem-se

$$
m=\frac{\frac{\Delta M}{2}}{1,00}=\frac{7,911}{1,00}=7,911 \mathrm{kNm} / \mathrm{m}
$$

e para a meia-faixa central de largura igual a $1,50 \mathrm{~m}$, tem-se:

$$
\begin{aligned}
& m=\frac{\frac{\Delta M}{2}}{1,50}=\frac{7,911}{1,50}=5,274 \mathrm{kNm} / \mathrm{m} \\
& M=-101,783 \mathrm{kNm}
\end{aligned}
$$

Para a faixa lateral de largura $2,50 \mathrm{~m}$, tem-se:

$$
\begin{aligned}
\Delta M & =0,76 M=0,76(-101,783)=-77,355 \mathrm{kNm} \\
m & =\frac{-77,355}{2,50}=-30,942 \mathrm{kNm} / \mathrm{m}
\end{aligned}
$$

Para a faixa central, tem-se

$$
\Delta M=0,24 M=0,24(-101,783)=-24,428 \mathrm{kNm}
$$

que, para a meia-faixa central de largura igual a $1,00 \mathrm{~m}$, tem-se

$$
m=\frac{\frac{\Delta M}{2}}{1,00}=\frac{-12,214}{1,00}=-12,214 \mathrm{kNm} / \mathrm{m}
$$

e para a meia-faixa central de largura igual a $1,50 \mathrm{~m}$, tem-se:

$$
m=\frac{\frac{\Delta M}{2}}{1,50}=\frac{-12,214}{1,50}=-8,143 \mathrm{kNm} / \mathrm{m}
$$


$M=-147,929 \mathrm{kNm}$

Para a faixa lateral de largura $2,50 \mathrm{~m}$, tem-se:

$\Delta M=0,76 M=0,76(-147,929)=-112,426 \mathrm{kNm}$

$$
m=\frac{-112,426}{2,50}=-44,970 \mathrm{kNm} / \mathrm{m}
$$

Para a faixa central, tem-se

$$
\Delta M=0,24 M=0,24(-147,929)=-35,503 \mathrm{kNm}
$$

que, para a meia-faixa central de largura igual a $1,00 \mathrm{~m}$, encontra-se

$$
m=\frac{\frac{\Delta M}{2}}{1,00}=\frac{-17,751}{1,00}=-17,751 \mathrm{kNm} / \mathrm{m}
$$

e para a meia-faixa central de largura igual a $1,50 \mathrm{~m}$, tem-se:

$$
\begin{aligned}
& m=\frac{\frac{\Delta M}{2}}{1,50}=\frac{-17,751}{1,50}=-11,834 \mathrm{kNm} / \mathrm{m} \\
& M=83,821 \mathrm{kNm}
\end{aligned}
$$

Para a faixa lateral de largura $2,50 \mathrm{~m}$, tem-se:

$$
\begin{gathered}
\Delta M=0,60 M=0,60(83,821)=50,293 \mathrm{kNm} \\
m=\frac{50,293}{2,50}=20,117 \mathrm{kNm} / \mathrm{m}
\end{gathered}
$$

Para a faixa central, tem-se

$\Delta M=0,40 M=0,40(83,821)=33,528 \mathrm{kNm}$

que, para a meia-faixa central de largura igual a $1,00 \mathrm{~m}$, tem-se

$$
m=\frac{\frac{\Delta M}{2}}{1,00}=\frac{16,764}{1,00}=16,764 \mathrm{kNm} / \mathrm{m}
$$


e para a meia-faixa central de largura igual a $1,50 \mathrm{~m}$, tem-se:

$$
m=\frac{\frac{\Delta M}{2}}{1,50}=\frac{16,764}{1,50}=11,176 \mathrm{kNm} / \mathrm{m}
$$

Na figura 5.8 mostram-se os momentos já distribuidos nas faixas.

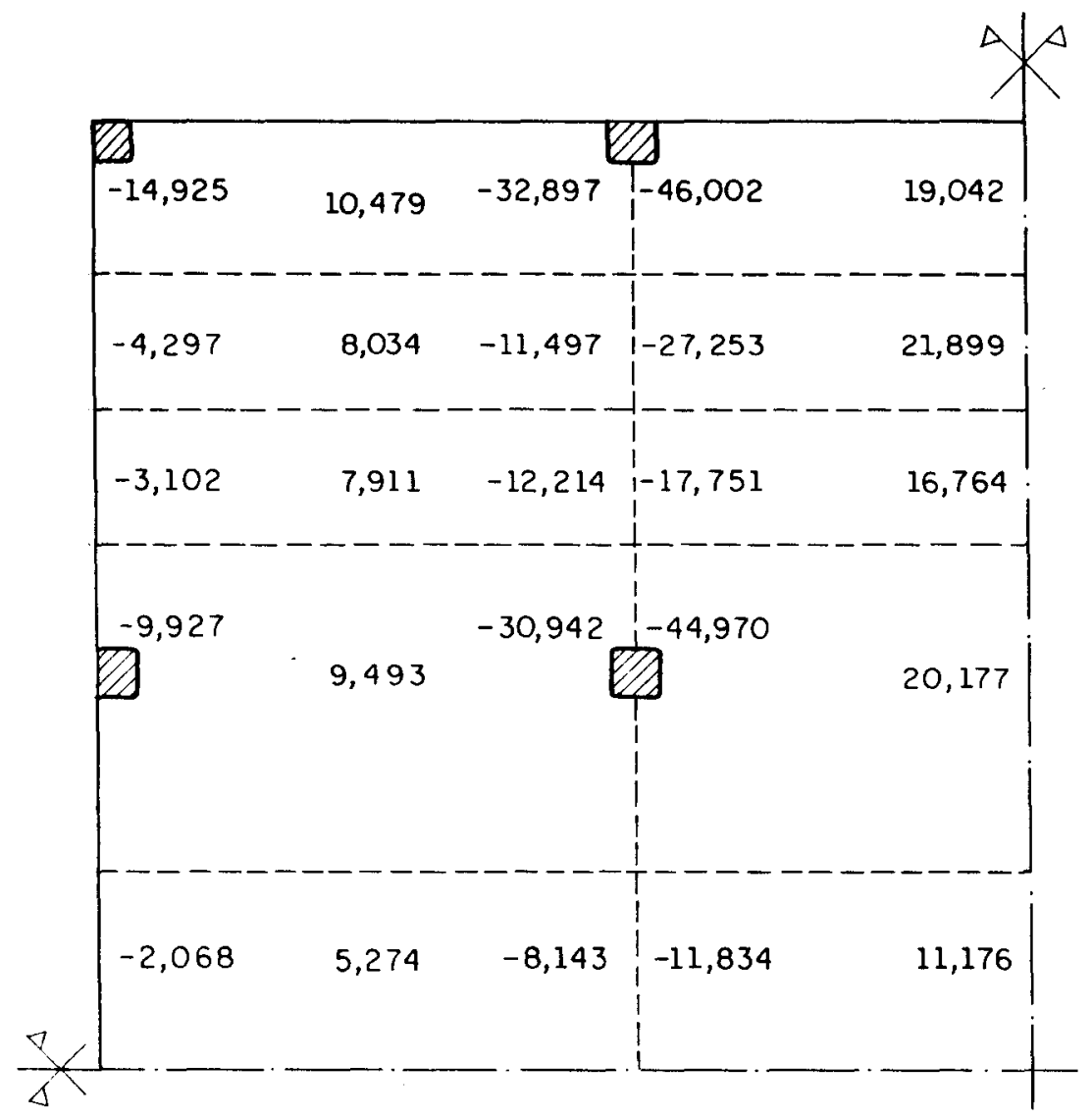

FIGURA 5.8- Momentos elásticos distribuídos nas faixas $(\mathrm{kNm} / \mathrm{m})$.

\subsection{8- Compatibilização dos Momentos Elásticos}

O critério adotado para a compatibilização dos momentos negativos consiste em adotar o maior valor entre a média dos momentos negativos ou $80 \%$ do maior momento, como se faz para as lajes comuns.

Após o cálculo dos momentos negativos compatibilizados, deve-se corrigir os momentos positivos dos painéis que possuiam os maiores momentos negativos, 
aumentando-os da metade da diferença entre o momento negativo original e o momento negativo compatibilizado. Os momentos negativos compatibilizados e os momentos positivos corrigidos são apresentados na figura 5.9.

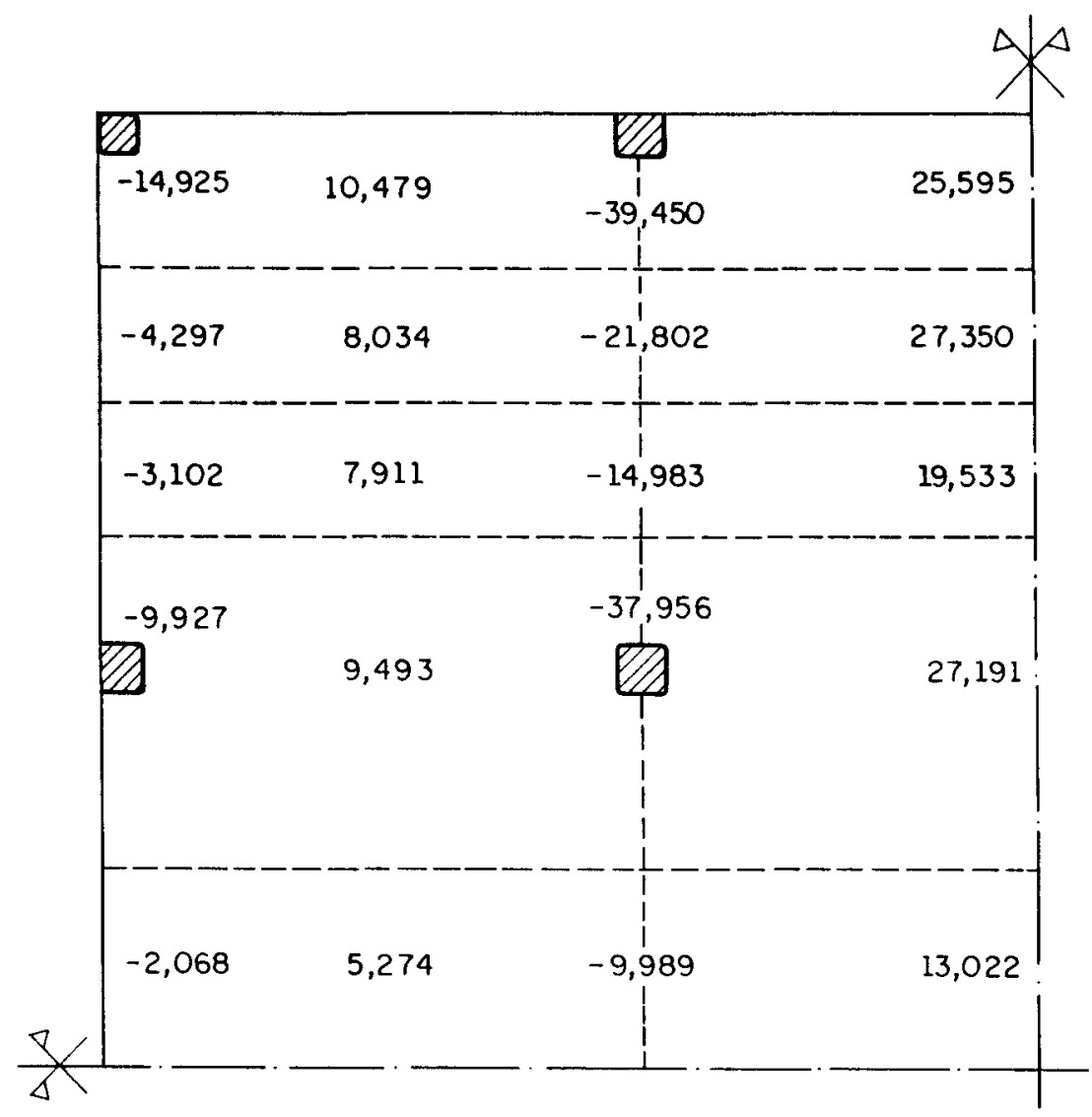

FIGURA 5.9- Momentos negativos compatibilizados e positivos corrigidos $(\mathrm{kNm} / \mathrm{m})$.

\subsection{9- Cálculo das Armaduras de Flexăo Relativas aos Momentos Elásticos}

Para o cálculo das armaduras de flexão seguem-se os critérios apresentados no início deste capitulo. São adotados os seguintes dados para o pavimento:

$\mathrm{f}_{\mathrm{ck}}=20 \mathrm{MPa}$

Aço CA-50A

Área minima de aço:

$$
A_{s, \text { min }}=0,15 \% b h=0,15.18=2,70 \mathrm{~cm}^{2} / \mathrm{m}
$$


Altura útil:

- para a armadura negativa:

$$
d=h-c-\frac{\phi_{b}}{2}=18-0,5-\frac{1,25}{2}=16,875 \mathrm{~cm}
$$

- para a armadura positiva:

$1^{\text {a }}$ camada:

$$
d=h-c-\frac{\phi_{b}}{2}=18-2-\frac{0,8}{2}=15,60 \mathrm{~cm}
$$

$2^{\mathrm{a}}$ camada:

$$
d=h-c-1,5 \phi_{b}=18-2-1,5 \cdot 0,8=14,8 \mathrm{~cm}
$$

A determinação da área de aço é feita utilizando-se a tabela 1.1 de PINHEIRO (1993). Apresenta-se a seguir um exemplo do cálculo da área de aço, utilizando-se essa tabela. Para os demais momentos, as áreas de aço foram calculadas à parte e são apresentadas nas tabelas 5.5 e 5.6 .

Para $\mathrm{m}=-39,450 \mathrm{kNm} / \mathrm{m}=3945 \mathrm{kNcm} / \mathrm{m}$, tem-se

$$
\begin{aligned}
m_{d}=1,4.3945 & =5523 \mathrm{kNcm} / \mathrm{m} \\
K_{c} & =\frac{b d^{2}}{m_{d}}=\frac{100 \cdot 16,875^{2}}{5523}=5,2 \mathrm{~cm}^{2} / \mathrm{kN}
\end{aligned}
$$

Pela tabela 1.1 de PINHEIRO (1993), tem-se

$$
\mathrm{K}_{\mathrm{s}}=0,025 \mathrm{~cm}^{2} / \mathrm{kN}
$$

Portanto,

$$
A_{s}=\frac{K_{s} m_{d}}{d}=\frac{0,025.5523}{16,875}=8,182 \mathrm{~cm}^{2} / \mathrm{m}
$$

que corresponde a uma armadura composta de barras de $10 \mathrm{~mm}$ a cada $9 \mathrm{~cm}(\phi 10$ c. 9). 
TABELA 5.5- Área de aço e armadura dos momentos negativos elásticos.

\begin{tabular}{|c|c|c|}
\hline $\begin{array}{c}\text { Momento } \\
(\mathbf{k N m} / \mathrm{m})\end{array}$ & $\begin{array}{c}\text { Área de aço } \\
\left(\mathbf{c m}^{2} / \mathrm{m}\right)\end{array}$ & Armadura \\
\hline 39,450 & 8,182 & $\phi 10$ c. 9 \\
\hline 21,802 & 4,341 & $\phi 8$ c. 11 \\
\hline 14,983 & 2,983 & $\phi 6,3$ c. 10 \\
\hline 37,956 & 7,872 & $\phi 10$ c. 9 \\
\hline 9,989 & $2,700^{*}$ & $\phi 6,3$ c. 11 \\
\hline 14,925 & 2,972 & $\phi 6,3$ c. 10 \\
\hline 4,297 & $2,700^{\star}$ & $\phi 6,3$ c. 11 \\
\hline 3,102 & $2,700^{*}$ & $\phi 6,3$ c. 11 \\
\hline 9,927 & $2,700^{*}$ & $\phi 6,3$ c. 11 \\
\hline 2,068 & $2,700^{*}$ & $\phi 6,3$ c. 11 \\
\hline
\end{tabular}

* Área mínima de aço. 
TABELA 5.6- Área de aço dos momentos positivos elásticos.

\begin{tabular}{|c|c|c|c|c|}
\hline $\begin{array}{l}\text { Momentos } \\
\text { Positivos } \\
(\mathrm{kNm} / \mathrm{m})\end{array}$ & $\begin{array}{l}\text { Área de Aço } \\
\text { na direção x } \\
\left(\mathrm{cm}^{2} / \mathrm{m}\right)\end{array}$ & $\begin{array}{c}\text { Armadura na } \\
\text { direção } x \\
\text { (1' camada) }\end{array}$ & $\begin{array}{l}\text { Área de Aço } \\
\text { na direção y } \\
\left(\mathrm{cm}^{2} / \mathrm{m}\right)\end{array}$ & $\begin{array}{c}\text { Armadura na } \\
\text { direção y } \\
\text { (2a camada) }\end{array}$ \\
\hline 10,479 & $2,700^{\star}$ & $\phi 6,3$ c. 11 & $2,700^{*}$ & $\phi 6,3$ c. 11 \\
\hline 8,034 & $2,700^{\star}$ & $\phi 6,3$ c. 11 & $2,700^{*}$ & $\phi 6,3$ c. 11 \\
\hline 7,911 & $2,700^{\star}$ & $\phi 6,3$ c. 11 & $2,700^{*}$ & $\phi 6,3$ c. 11 \\
\hline 9,493 & $2,700^{\star}$ & $\phi 6,3$ c. 11 & $2,700^{\star}$ & $\phi 6,3$ c. 11 \\
\hline 5,274 & $2,700^{*}$ & $\phi 6,3$ c. 11 & $2,700^{*}$ & $\phi 6,3$ c. 11 \\
\hline 25,595 & 5,742 & $\phi 8$ c. 8 & 6,053 & $\phi 8$ c. 8 \\
\hline 27,350 & 6,136 & $\phi 8$ c. 7 & 6,468 & $\phi 8$ c. 7 \\
\hline 19,533 & 4,207 & $\phi 8$ c. 11 & 4,435 & $\phi 8$ c. 11 \\
\hline 27,191 & 6,101 & $\phi 8 \mathrm{c} .7$ & 6,430 & $\phi 8$ c. 7 \\
\hline 13,022 & 2,805 & $\phi 6,3$ c. 11 & 2,956 & $\phi 6,3$ c. 10 \\
\hline
\end{tabular}

* Área mínima de aço.

\subsubsection{0- Detalhamento das Armaduras do Cálculo Elástico}

Para o detalhamento das armaduras positiva e negativa foram adotados os critérios já mencionados no início deste capítulo. O comprimento das barras segue o esquema da figura 5.1. Nas figuras 5.10 e 5.11, apresentam-se esses detalhamentos.

$O$ consumo de aço dos detalhamentos das figuras 5.10 e 5.11 encontra-se nas tabelas 5.8 e 5.10 , respectivamente. Nas tabelas 5.7 e 5.9 são apresentados resumos dos detalhamentos das armaduras positiva e negativa. 


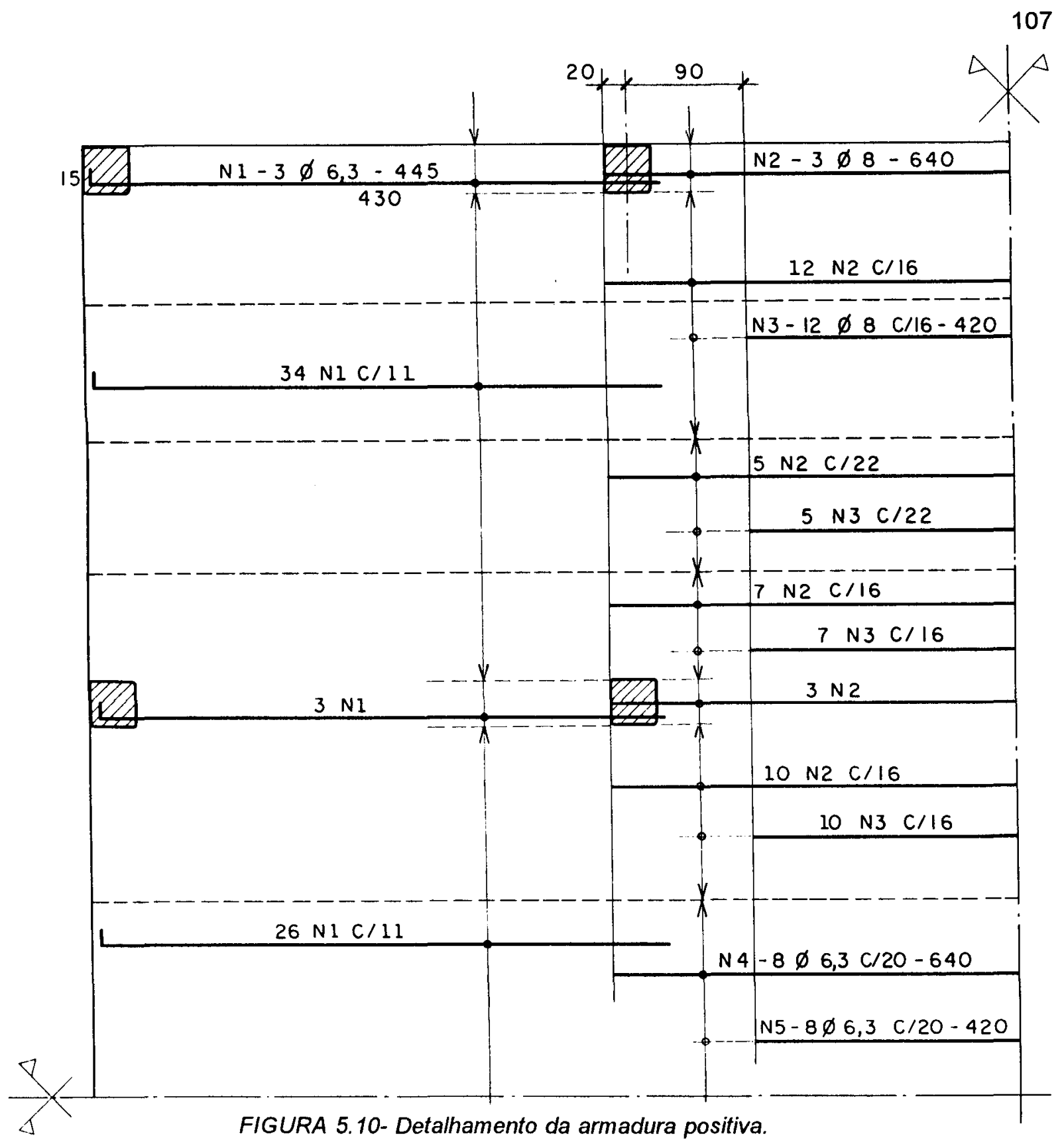

TABELA 5.7- Resumo da armadura positiva.

\begin{tabular}{|c|c|c|c|c|}
\hline $\mathbf{N}$ & $\phi(\mathbf{m m})$ & Quant. & Comp. $(\mathbf{m})$ & $\begin{array}{c}\text { Comp. Total } \\
(\mathbf{m})\end{array}$ \\
\hline 1 & 6,3 & 528 & 4,45 & 2349,6 \\
\hline 2 & 8 & 160 & 6,40 & 1024,0 \\
\hline 3 & 8 & 136 & 4,20 & 571,2 \\
\hline 4 & 6,3 & 32 & 6,40 & 204,8 \\
\hline 5 & 6,3 & 32 & 4,20 & 134,4 \\
\hline
\end{tabular}


TABELA 5.8- Consumo de aço da armadura positiva.

\begin{tabular}{|c|c|c|c|}
\hline \multirow{2}{*}{ Aço } & $\begin{array}{c}\phi \\
(\mathbf{m m})\end{array}$ & $\begin{array}{c}\text { Comp. Total } \\
(\mathbf{m})\end{array}$ & $\begin{array}{c}\text { Massa } \\
(\mathbf{k g})\end{array}$ \\
\hline \multirow{2}{*}{ CA-50A } & 6,3 & 2688,8 & 672 \\
\cline { 2 - 4 } & 8 & 1595,2 & 638 \\
\hline \multicolumn{3}{|c|}{ Massa Total (kg) } & 1310 \\
\hline
\end{tabular}

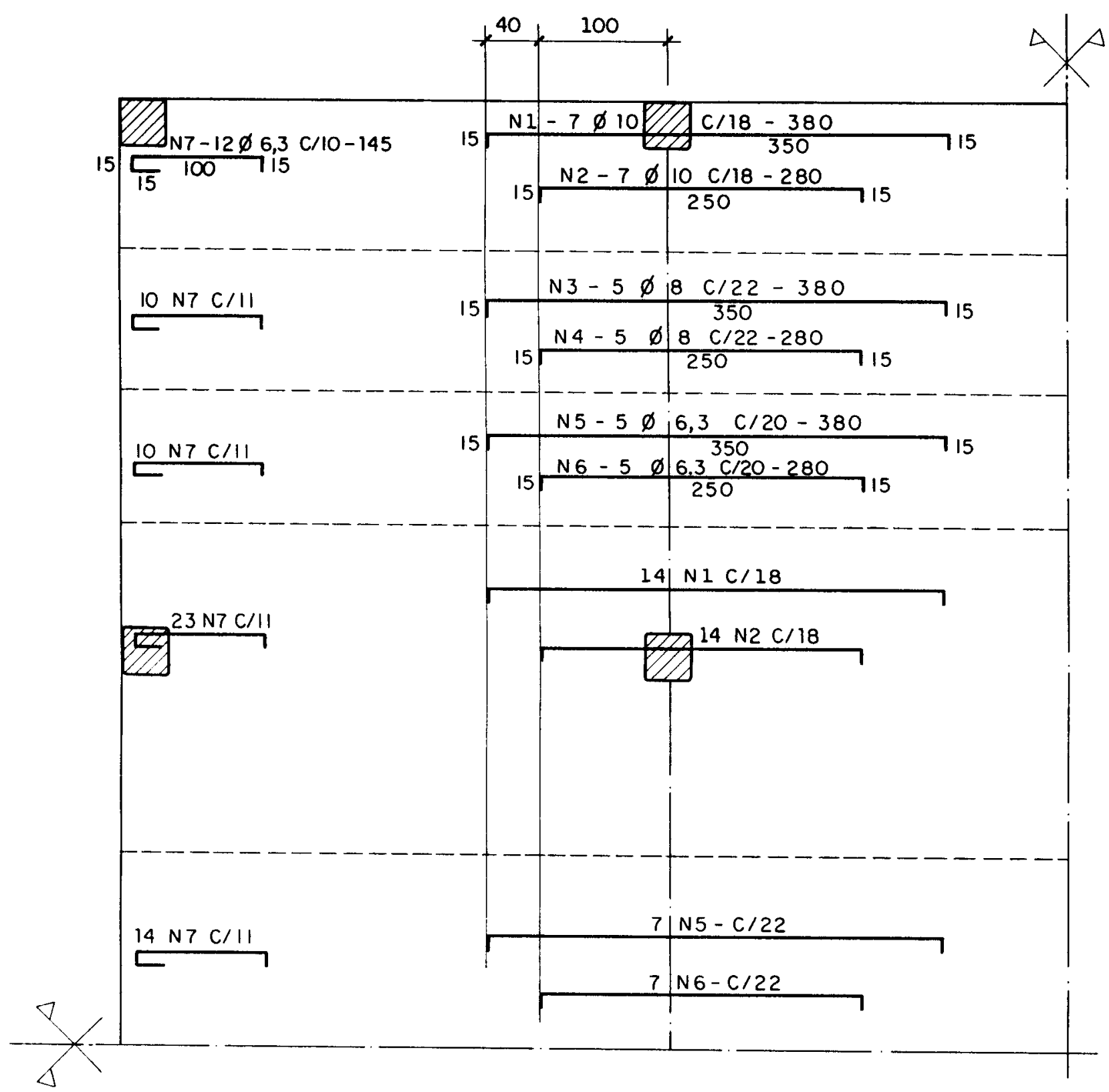

FIGURA 5.11- Detalhamento da armadura negativa. 
TABELA 5.9- Resumo da armadura negativa.

\begin{tabular}{|c|c|c|c|c|}
\hline $\mathbf{N}$ & $\phi(\mathbf{m m})$ & Quant. & Comp. (m) & Comp. total (m) \\
\hline 1 & 10 & 168 & 3,80 & 638,4 \\
\hline 2 & 10 & 168 & 2,80 & 470,4 \\
\hline 3 & 8 & 40 & 3,80 & 152,0 \\
\hline 4 & 8 & 40 & 2,80 & 112,0 \\
\hline 5 & 6,3 & 96 & 3,80 & 364,8 \\
\hline 6 & 6,3 & 96 & 2,80 & 268,8 \\
\hline 7 & 6,3 & 552 & 1,45 & 800,4 \\
\hline
\end{tabular}

TABELA 5.10- Consumo de aço da armadura negativa.

\begin{tabular}{|c|c|c|c|}
\hline \multirow{2}{*}{ Aço } & $\begin{array}{c}\phi \\
(\mathbf{m m})\end{array}$ & $\begin{array}{c}\text { Comp. Total } \\
(\mathbf{m})\end{array}$ & $\begin{array}{c}\text { Massa } \\
(\mathbf{k g})\end{array}$ \\
\hline \multirow{3}{*}{ CA-50A } & 6,3 & 1434,0 & 359 \\
\cline { 2 - 4 } & 8 & 264,0 & 106 \\
\cline { 2 - 4 } & 10 & 1108,8 & 699 \\
\hline \multicolumn{3}{|c|}{ Massa total $\mathbf{( k g )}$} & 1164 \\
\hline
\end{tabular}

\subsubsection{1- Cálculo dos Momentos de Plastificação}

Os momentos de plastificação são calculados a partir dos momentos elásticos, calculados anteriormente. Como, no cálculo plástico, admite-se que os momentos ao longo das charneiras são constantes, para os momentos negativos provenientes do cálculo elástico foi calculada a média ponderada, em relação à largura das faixas, de modo a se ter um momento constante ao longo das charneiras plásticas. Esses momentos médios são apresentados na figura 5.12. 


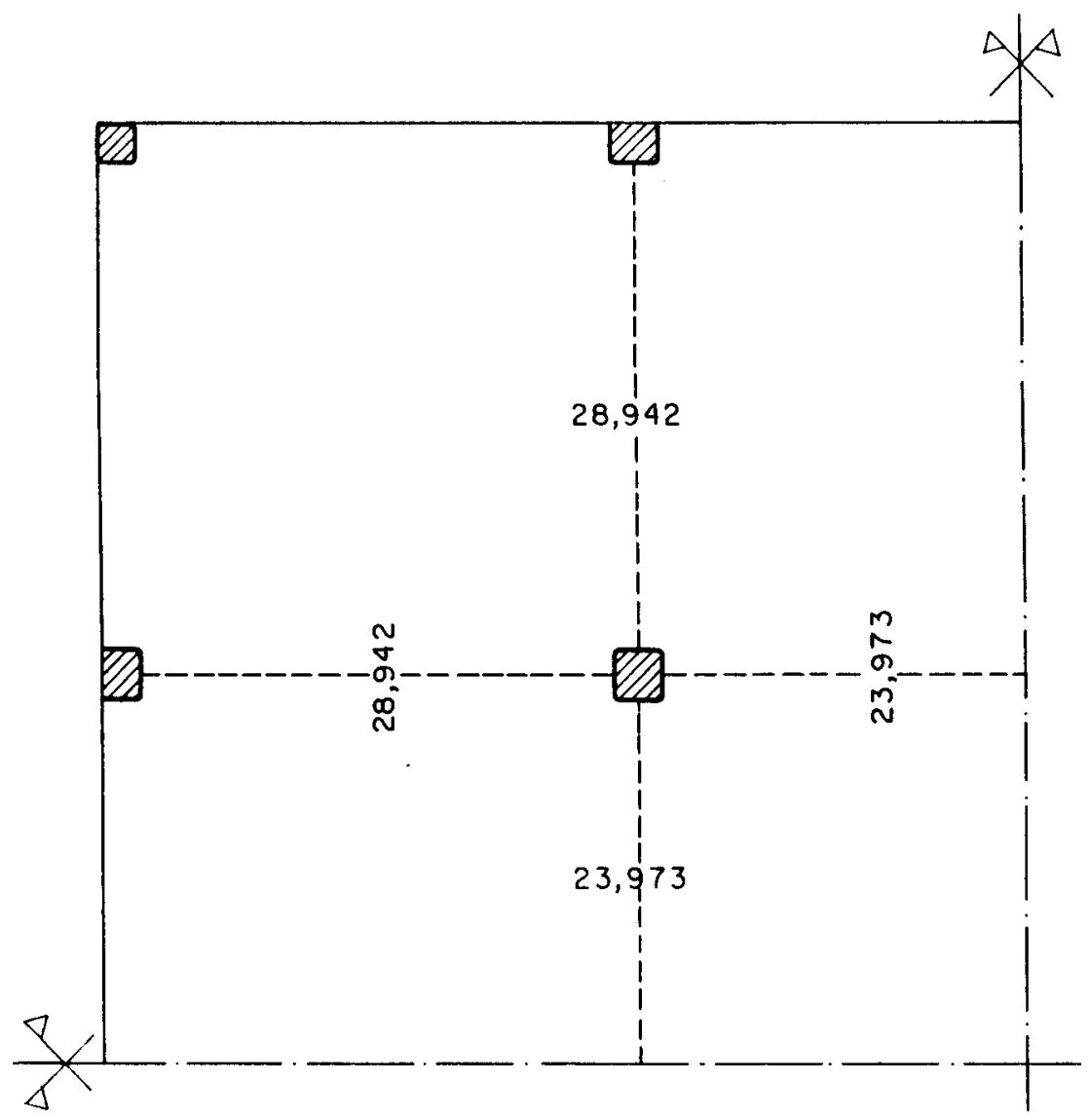

FIGURA 5.12- Momentos negativos elásticos médios $(\mathrm{kNm} / \mathrm{m})$.

Recomenda-se reduzir os momentos negativos elásticos já compatibilizados para lajes apoiadas em vigas. Devido à falta de recomendação para lajes-cogumelo, adotou-se o critério de reduzir os momentos negativos elásticos de tal forma que a razão entre os momentos de plastificação negativo e positivo ficasse entre 1 e 1,5, como recomendam PARK \& GAMBLE (1980). Para isso, inicialmente calcularam-se os momentos de plastificação positivos sem reduzir os momentos negativos elásticos, depois os momentos elásticos negativos foram divididos por 1,1 e posteriormente por 1,2 .

Chamando de $\mathrm{R}$ o fator pelo qua! se divide o momento negativo elástico, obtêm-se os momentos de plastificação apresentados a seguir.

a) Painel de canto

Para o painel de canto, devido à simetria do pavimento, os momentos na direção $x$ são iguais aos da direção $y$, sendo $a=b=4,0 \mathrm{~m}$. 
Adotando-se $R=1,0$, tem-se,

$\mathrm{m}_{1}=28,942 \mathrm{kNm} / \mathrm{m}$

Verificando-se o colapso total do pavimento, pela eq. (4.34), tem-se:

$$
m=\frac{p}{a}\left(\frac{a}{2}-\frac{m_{1}}{p a}\right)^{2}=\frac{10,30}{2}\left(\frac{4,0}{2}-\frac{28,942}{10,30 \cdot 4,0}\right)^{2}=8,670 \mathrm{kNm} / \mathrm{m}
$$

Portanto, a razão entre os momentos de plastificação negativo e positivo é:

$$
\phi=\frac{m_{1}}{m}=\frac{28,942}{8,670}=3,3
$$

Para o colapso na região do apoio, pela eq. (4.4), $\operatorname{com} \phi=3,3$, encontra-se

$$
\begin{aligned}
& m=\frac{p a b}{2 \pi(1+\phi)}=\frac{10,30 \cdot 4,0.4,0}{2 \cdot 3,14 \cdot(1+3,3)}=6,100 \mathrm{kNm} / \mathrm{m} \\
& m_{1}=\phi m=3,3.6,100=20,129 \mathrm{kNm} / \mathrm{m}
\end{aligned}
$$

Esses momentos são menores que os obtidos para a não ocorrência de ruína total do painel.

$$
\begin{aligned}
& \text { Para } \mathrm{R}=1,1: \\
& m_{1}=\frac{28,942}{1,1}=26,311 \mathrm{kNm} / \mathrm{m}
\end{aligned}
$$

Verificando o colapso total do painel, pela eq. (4.34), tem-se o seguinte momento de plastificação:

$$
m=\frac{10,30}{2}\left(\frac{4,0}{2}-\frac{26,311}{10,30 \cdot 4,0}\right)^{2}=9,545 \mathrm{kNm} / \mathrm{m}
$$

sendo

$$
\phi=\frac{m_{1}}{m}=\frac{26,311}{9,545}=2,8
$$


Para a verificação do colapso na região do apoio, tem-se, pela eq. (4.4), com $\phi=2,8$ :

$$
\begin{aligned}
& m=\frac{10,30 \cdot 4,0 \cdot 4,0}{2 \cdot 3,14 \cdot(1+2,8)}=6,902 \mathrm{kNm} / \mathrm{m} \\
& m_{1}=\phi m=2,8 \cdot 6,902=19,326 \mathrm{kNm} / \mathrm{m}
\end{aligned}
$$

Para $R=1,2$ :

$$
m_{1}=\frac{28,942}{1,2}=24,118 \mathrm{kNm} / \mathrm{m}
$$

Pela eq. (4.34):

$$
\begin{aligned}
& m=\frac{10,30}{2}\left(\frac{4,0}{2}-\frac{24,118}{10,30.4,0}\right)^{2}=10,306 \mathrm{kNm} / \mathrm{m} \\
& \phi=\frac{m_{1}}{m}=\frac{24,118}{10,306}=2,3
\end{aligned}
$$

E pela eq. (4.4), com $\phi=2,3$, obtém-se:

$$
\begin{aligned}
& m=\frac{10,30 \cdot 4,0.4,0}{2 \cdot 3,14 \cdot(1+2,3)}=7,948 \mathrm{kNm} / \mathrm{m} \\
& m_{1}=\phi m=2,3 \cdot 7,948=18,281 \mathrm{kNm} / \mathrm{m}
\end{aligned}
$$

b) Painel lateral

Para a direção $x$, os vãos são dados por $a=6,0 \mathrm{~m} \mathrm{e} b=4,0 \mathrm{~m}$.

Adotando $\mathrm{R}=1,0$ :

$m_{1}=m_{2}=28,942 \mathrm{kNm} / \mathrm{m}$

Fazendo-se a verificação do colapso de todo o painel, pela eq. (4.12), o momento de plastificação positivo é dado por: 


$$
\begin{aligned}
& m=\frac{p}{2}\left[\frac{\left(m_{1}-m_{2}\right)^{2}}{p^{2} a^{2}}-\frac{\left(m_{1}+m_{2}\right)}{p}+\frac{a^{2}}{4}\right] \\
& m=\frac{10,30}{2}\left[0-\frac{(28,942+28,942)}{10,30}+\frac{6,0^{2}}{4}\right] \\
& m=17,408 \mathrm{kNm} / \mathrm{m}
\end{aligned}
$$

\section{sendo}

$$
\phi=\frac{m_{1}}{m}=\frac{28,942}{17,408}=1,7
$$

Verificando o colapso ao redor do apoio, pela eq. (4.4), com $\phi=1,7$, tem-se:

$$
\begin{aligned}
& m=\frac{10,30 \cdot 6,0,4,0}{2 \cdot 3,14 \cdot(1+1,70)}=14,572 \mathrm{kNm} / \mathrm{m} \\
& m_{1}=\phi m=1,7.14,572=24,772 \mathrm{kNm} / \mathrm{m}
\end{aligned}
$$

Para $R=1,1$ :

$$
m_{1}=m_{2}=\frac{28,942}{1,1}=26,311 \mathrm{kNm} / \mathrm{m}
$$

Pela eq. (4.12):

$$
\begin{aligned}
& m=\frac{10,30}{2}\left[0-\frac{(26,311+26,311)}{10,30}+\frac{6,0^{2}}{4}\right] \\
& m=20,039 \mathrm{kNm} / \mathrm{m} \\
& \phi=\frac{26,311}{20,039}=1,3
\end{aligned}
$$


E pela eq.(4.4), para a verificação do colapso na região do apoio, com $\phi=1,3$, encontra-se:

$$
\begin{aligned}
& m=\frac{10,30 \cdot 6,0 \cdot 4,0}{2 \cdot 3,14 \cdot(1+1,3)}=17,010 \mathrm{kNm} / \mathrm{m} \\
& m_{1}=m_{2}=\phi m=1,3.17,010=22,113 \mathrm{kNm} / \mathrm{m}
\end{aligned}
$$

Para $R=1,2$ :

$$
m_{1}=m_{2}=\frac{28,942}{1,2}=24,118 \mathrm{kNm} / \mathrm{m}
$$

Pela eq. (4.12):

$$
\begin{aligned}
& m=\frac{10,30}{2}\left[0-\frac{(24,118+24,118)}{10,30}+\frac{6,0^{2}}{4}\right] \\
& m=22,232 \mathrm{kNm} / \mathrm{m} \\
& \phi=\frac{24,118}{22,232}=1,1
\end{aligned}
$$

E pela eq. (4.4), para a verificação do colapso na região do apoio, com $\phi=1,1$, encontra-se:

$$
\begin{aligned}
& m=\frac{10,30 \cdot 6,0 \cdot 4,0}{2 \cdot 3,14 \cdot(1+1,1)}=18,735 \mathrm{kNm} / \mathrm{m} \\
& m_{1}=m_{2}=\phi m=1,1.18,735=20,608 \mathrm{kNm} / \mathrm{m}
\end{aligned}
$$

Ainda para o painel lateral, analisando agora a direção y, os vãos são dados por $a=4,0 \mathrm{~m} \mathrm{e} b=6,0 \mathrm{~m}$.

Para $R=1,0$ :

$$
m_{3}=23,973 \mathrm{kNm} / \mathrm{m}
$$


Para a verificação do colapso total do painel, utiliza-se a eq. (4.16), obtendose:

$$
\begin{aligned}
& m=\frac{p}{2}\left(\frac{a}{2}-\frac{m_{3}}{p a}\right)^{2}=\frac{10,30}{2}\left(\frac{4,0}{2}-\frac{23,973}{10,30 \cdot 4,0}\right)^{2} \\
& m=10,357 \mathrm{kNm} / \mathrm{m} \\
& \phi=\frac{m_{3}}{m}=\frac{23,973}{10,357}=2,3
\end{aligned}
$$

Pela eq. (4.4), com $\phi=2,3$, tem-se:

$$
\begin{aligned}
& m=\frac{10,30 \cdot 6,0 \cdot 4,0}{2 \cdot 3,14 \cdot(1+2,3)}=11,922 \mathrm{kNm} / \mathrm{m} \\
& m_{3}=\phi m=2,3.11,922=27,421 \mathrm{kNm} / \mathrm{m}
\end{aligned}
$$

Esses momentos são maiores do que os momentos relativos ao colapso total do painel; entretanto, como foi apresentado do capítulo 4, item 4.5, na distribuição das armaduras, será colocada na região dos apoios uma armadura negativa correspondente a $1,5 \mathrm{~m}_{3}$ e no meio do vão, uma armadura correspondente a $\mathrm{m}$. Desta forma, na região dos apoios a relação efetiva entre o momento negativo e o momento positivo é dada por:

$$
\phi=\frac{1,5 m_{3}}{m}=\frac{1,5 \cdot 23,973}{10,357}=3,5
$$

Portanto, fazendo novamente a verificação para o colapso ao redor do apoio, pela eq. (4.4), com $\phi=3,5$, tem-se

$$
\begin{aligned}
& m=\frac{10,30 \cdot 6,0 \cdot 4,0}{2 \cdot 3,14 \cdot(1+3,5)}=8,743 \mathrm{kNm} / \mathrm{m} \\
& m_{3}=\phi m=3,5 \cdot 8,743=30,600 \mathrm{kNm} / \mathrm{m}
\end{aligned}
$$


que são menores que os momentos que serão distribuidos na região dos apoios, $m$ $=10,357 \mathrm{kNm} / \mathrm{m}$ e $m_{3}=1,5.23,973=35,960 \mathrm{kNm} / \mathrm{m}$.

$$
\begin{aligned}
& \text { Para R }=1,1: \\
& m_{3}=\frac{23,973}{1,1}=21,794 \mathrm{kNm} / \mathrm{m}
\end{aligned}
$$

Verificando o colapso total do painel, pela eq. (4.16), tem-se:

$$
\begin{aligned}
& m=\frac{10,30}{2}\left(\frac{4,0}{2}-\frac{21,794}{10,30,4,0}\right)^{2} \\
& m=11,144 \mathrm{kNm} / \mathrm{m} \\
& \phi=\frac{m_{3}}{m}=\frac{21,794}{11,144}=2,0
\end{aligned}
$$

e calculando-se a razão efetiva entre os momentos negativo e positivo, de acordo com o exposto anteriormente, obtém-se:

$$
\phi=\frac{1,5 m_{3}}{m}=\frac{1,5 \cdot 21,794}{11,144}=2,9
$$

Pela eq. (4.4), com $\phi=2,9$, tem-se:

$$
\begin{aligned}
& m=\frac{10,30 \cdot 6,0 \cdot 4,0}{2 \cdot 3,14 \cdot(1+2,9)}=10,088 \mathrm{kNm} / \mathrm{m} \\
& m_{3}=\phi m=2,9 \cdot 10,088=29,255 \mathrm{kNm} / \mathrm{m}
\end{aligned}
$$

que também são menores que os calculados pela eq. (4.16) e distribuídos de acordo com o item 4.5.

$$
\begin{aligned}
& \text { Para R }=1,2: \\
& m_{3}=\frac{23,973}{1,2}=19,978 \mathrm{kNm} / \mathrm{m}
\end{aligned}
$$


Verificando o colapso total do painel, pela eq. (4.16), tem-se:

$$
\begin{aligned}
& m=\frac{10,30}{2}\left(\frac{4,0}{2}-\frac{19,978}{10,30 \cdot 4,0}\right)^{2} \\
& m=11,822 \mathrm{kNm} / \mathrm{m} \\
& \phi=\frac{m_{3}}{m}=\frac{19,978}{11,822}=1,7
\end{aligned}
$$

A razão efetiva entre os momentos negativo e positivo é dada por

$$
\phi=\frac{1,5 m_{3}}{m}=\frac{1,5 \cdot 19,978}{11,822}=2,5
$$

Pela eq. (4.4), com $\phi=2,5$, tem-se:

$$
\begin{aligned}
& m=\frac{10,30 \cdot 6,0 \cdot 4,0}{2 \cdot 3,14 \cdot(1+2,5)}=11,241 \mathrm{kNm} / \mathrm{m} \\
& m_{3}=\phi m=2,5 \cdot 11,241=28,103 \mathrm{kNm} / \mathrm{m}
\end{aligned}
$$

que são menores que os calculados pela eq. (4.16) e distribuidos de acordo com o item 4.5: $m=11,822 \mathrm{kNm} / \mathrm{n}$ e $m_{3}=1,5.19,978=29,967 \mathrm{kNm} / \mathrm{m}$.

c) Painel interno

Também para o painel interno, devido à simetria do pavimento, os momentos na direção $x$ são iguais aos da direção $y, \operatorname{com} a=b=6,0 \mathrm{~m}$.

Para $R=1,0$, tem-se:

$m_{1}=m_{2}=23,973 \mathrm{kNm} / \mathrm{m}$

Pela eq. (4.8), faz-se a verificação do colapso total do painel, resultando:

$$
m=\frac{p}{2}\left[\frac{\left(m_{1}-m_{2}\right)^{2}}{p^{2} a^{2}}-\frac{\left(m_{1}+m_{2}\right)}{p}+\frac{a^{2}}{4}\right]
$$




$$
\begin{aligned}
& m=\frac{10,30}{2}\left[0-\frac{(23,973+23,973)}{10,30}+\frac{6,0^{2}}{4}\right] \\
& m=22,377 \mathrm{kNm} / \mathrm{m}
\end{aligned}
$$

sendo a razão efetiva dos momentos negativo e positivo dada por:

$$
\phi=\frac{1,5 m_{1}}{m}=\frac{1,5 \cdot 23,973}{22,377}=1,6
$$

Pela eq. (4.4), com $\phi=1,6$, tem-se:

$$
\begin{aligned}
& m=\frac{10,30 \cdot 6,0 \cdot 6,0}{2 \cdot 3,14 \cdot(1+1,6)}=22,698 \mathrm{kNm} / \mathrm{m} \\
& m_{1}=\phi m=1,6.22,698=36,317 \mathrm{kNm} / \mathrm{m}
\end{aligned}
$$

Esses momentos são os que devem ser usados no dimensionamento do painel interno, pois são maiores que os momentos dados pela eq.(4.8), para verificação do colapso total do painel: $m=22,377 \mathrm{kNm} / \mathrm{m}$ e $m_{1}=1,5.23,973=$ $35,960 \mathrm{kNm} / \mathrm{m}$. Contudo, o momento negativo $m_{1}=36,317 \mathrm{kNm} / \mathrm{m}$ não deve ser multiplicado por 1,5 para ser distribuido na faixa dos pilares, pois as distribuições apresentadas no item 4.5 são recomendadas para os momentos obtidos para a configuração de ruina correspondente ao colapso total do painel.

Para $R=1,1$, tem-se:

$$
m_{1}=m_{2}=\frac{23,973}{1,1}=21,794 \mathrm{kNm} / \mathrm{m}
$$

Pela eq. (4.8), tem-se:

$$
m=\frac{p}{2}\left[\frac{\left(m_{1}-m_{2}\right)^{2}}{p^{2} a^{2}}-\frac{\left(m_{1}+m_{2}\right)}{p}+\frac{a^{2}}{4}\right]
$$




$$
\begin{aligned}
& m=\frac{10,30}{2}\left[0-\frac{(21,794+21,794)}{10,30}+\frac{6,0^{2}}{4}\right] \\
& m=24,556 \mathrm{kNm} / \mathrm{m}
\end{aligned}
$$

sendo a razão efetiva dos momentos negativo e positivo dada por:

$$
\phi=\frac{1,5 m_{1}}{m}=\frac{1,5 \cdot 21,794}{24,556}=1,3
$$

Pela eq. (4.4), com $\phi=1,3$, tem-se:

$$
\begin{aligned}
& m=\frac{10,30 \cdot 6,0 \cdot 6,0}{2 \cdot 3,14 \cdot(1+1,3)}=25,659 \mathrm{kNm} / \mathrm{m} \\
& m_{1}=\phi m=1,3.25,659=33,356 \mathrm{kNm} / \mathrm{m}
\end{aligned}
$$

Esses são os momentos que devem ser usados no dimensionamento do painel interno, pois são maiores que os momentos dados pela eq.(4.8), para verificação do colapso total do painel: $m=24,556 \mathrm{kNm} / \mathrm{m}$ e $m_{1}=1,5.21,794=$ $32,691 \mathrm{kNm} / \mathrm{m}$. Também não se deve multiplicar $m_{1}=33,356 \mathrm{kNm} / \mathrm{m}$ por 1,5 .

Para $R=1,2$, tem-se:

$$
m_{1}=m_{2}=\frac{23,973}{1,2}=19,978 \mathrm{kNm} / \mathrm{m}
$$

Fazendo a verificação do colapso total do painel, pela eq. (4.8), tem-se

$$
\begin{aligned}
& m=\frac{10,30}{2}\left[0-\frac{(19,978+19,978)}{10,30}+\frac{6,0^{2}}{4}\right] \\
& m=26,372 \mathrm{kNm} / \mathrm{m}
\end{aligned}
$$

sendo a razão efetiva dos momentos negativo e positivo dada por:

$$
\phi=\frac{1,5 m_{1}}{m}=\frac{1,5 \cdot 19,978}{26,372}=1,1
$$


Pela eq. (4.4), com $\phi=1,1$, tem-se:

$$
\begin{aligned}
& m=\frac{10,30 \cdot 6,0 \cdot 6,0}{2 \cdot 3,14 \cdot(1+1,1)}=28,102 \mathrm{kNm} / \mathrm{m} \\
& m_{1}=\phi m=1,1.28,102=30,912 \mathrm{kNm} / \mathrm{m}
\end{aligned}
$$

Esses momentos também são maiores que os momentos dados pela eq. (4.8), para verificação do colapso total do painel: $m=26,372 \mathrm{kNm} / \mathrm{m}$ e $m_{1}=1,5 \cdot 19,978=29,967 \mathrm{kNm} / \mathrm{m}$. Também não se deve multiplicar $m_{1}=30,912$ $\mathrm{kNm} / \mathrm{m}$ por 1,5 .

\subsubsection{2- Cálculo das Armaduras de Flexăo Relativas aos Momentos de} Plastificação

Para o cálculo das armaduras de flexão dos momentos plásticos, adotaram-se os mesmos critérios apresentados no item 5.2.9. A determinação das áreas de aço também é feita utilizando-se a tabela 1.1 de PINHEIRO (1993). Nas tabelas $5.11 \mathrm{e}$ 5.12 apresentam-se os resultados.

TABELA 5.11- Áreas de aço e armaduras dos momentos de plastificação

\begin{tabular}{|c|c|c|c|c|c|c|c|}
\hline \multirow{2}{*}{$\mathbf{R}$} & \multicolumn{3}{|c|}{ Momento $(\mathrm{kNm} / \mathrm{m})$} & \multicolumn{2}{|c|}{$A_{s}\left(\mathrm{~cm}^{2} / \mathrm{m}\right)$} & \multicolumn{2}{|c|}{ Armadura } \\
\hline & $m_{1}$ & $1,5 m_{1}$ & $0,5 m_{1}$ & $1,5 m_{1}$ & $0,5 m_{1}$ & $1,5 m_{i}$ & $0,5 m_{i}$ \\
\hline 1,0 & 28,942 & 43,413 & 14,471 & 9,364 & 2,881 & $\phi 10$ c 8 & $\phi 6,3 c 11$ \\
\hline 1,1 & 26,311 & 39,467 & 13,156 & 8,186 & 2,620 & $\phi 10$ c 9 & $\phi 6,3 c 11$ \\
\hline 1,2 & 24,118 & 36,177 & 12,059 & 7,503 & 2,401 & $\phi 10 \mathrm{c} 10$ & $\phi 6,3 c 11$ \\
\hline 1,0 & 36,317 & $36,317^{\star}$ & 18,159 & 7,532 & 3,616 & $\phi 10 c 10$ & $\phi 6,3 \mathrm{c} 8$ \\
\hline 1,1 & 33,356 & $33,356^{\star}$ & 16,678 & 6,918 & 3,321 & $\phi 8 c 7$ & $\phi 6,3 \mathrm{c} 9$ \\
\hline 1,2 & 30,912 & $30,912^{\star}$ & 15,456 & 6,411 & 3,077 & $\phi 8 c 7$ & $\phi 6,3 c 10$ \\
\hline
\end{tabular}
negativos.

* Não precisam ser multiplicados por 1,5, como explicado anteriormente. 
TABELA 5.12- Áreas de aço e armaduras dos momentos positivos plásticos.

\begin{tabular}{|c|c|c|c|c|c|c|c|}
\hline Painel & $\mathbf{R}$ & $\begin{array}{c}\mathrm{m} \\
\text { (kNm/m) } \\
1^{\mathrm{a}} \mathrm{cam} .\end{array}$ & $\begin{array}{c}A_{s} \\
\left(\mathrm{~cm}^{2} / \mathrm{m}\right)\end{array}$ & Armad. & $\begin{array}{c}\mathrm{m} \\
(\mathrm{kNm} / \mathrm{m}) \\
2^{\mathrm{a}} \mathrm{cam}\end{array}$ & $\begin{array}{c}A_{s} \\
\left(\mathrm{~cm}^{2} / \mathrm{m}\right)\end{array}$ & Armad. \\
\hline \multirow{3}{*}{ Canto } & 1,0 & 8,670 & $2,700^{*}$ & $\phi 6,3 c 11$ & 8,670 & 2,968 & $\phi 6,3 c 11$ \\
\hline & 1,1 & 9,545 & $2,700^{*}$ & $\phi 6,3 c 11$ & 9,545 & $2,700^{\star}$ & $\phi 6,3 c 11$ \\
\hline & 1,2 & 10,306 & $2,700^{*}$ & $\phi 6,3 c 11$ & 10,306 & $2,700^{\star}$ & $\phi 6,3 c 11$ \\
\hline \multirow{3}{*}{ Lateral } & 1,0 & 17,408 & 3,749 & $\phi 6,3 \mathrm{c8}$ & 10,357 & $2,700^{\star}$ & $\phi 6,3 \mathrm{c} 11$ \\
\hline & 1,1 & 20,039 & 4,316 & $\phi 6,3 c 7$ & 11,144 & $2,700^{\star}$ & $\phi 6,3 c 11$ \\
\hline & 1,2 & 22,232 & 4,788 & $\phi 8 \subset 10$ & 11,822 & $2,700^{\star}$ & $\phi 6,3 c 11$ \\
\hline \multirow{3}{*}{ Interno } & 1,0 & 22,698 & 5,093 & 中 $8<9$ & 22,698 & 5,368 & $\phi 8<9$ \\
\hline & 1,1 & 25,659 & 5,757 & $\phi 8 c 8$ & 25,659 & 6,068 & $\phi 8 c 8$ \\
\hline & 1,2 & 28,102 & 6,305 & $\phi 8 c 7$ & 28,102 & 6,646 & $\phi 8<7$ \\
\hline
\end{tabular}

\subsubsection{3- Detalhamento das Armaduras do Cálculo Plástico}

Para o detalhamento das armaduras positiva e negativa foram adotados os mesmos critérios do detalhamento do cálculo elástico. Como a redução do momento negativo elástico não é muito grande, pode-se adotar o comprimento das barras de acordo com a figura 5.1. Os detalhamentos são apresentados nas figuras $5.13 \mathrm{e}$ 5.14 .

Nas tabelas 5.13 e 5.15 apresentam-se resumos dos detalhamentos das armaduras positiva e negativa e nas tabelas 5.14 e 5.16 encontram-se os consumos de aço desses detalhamentos, respectivamente. 


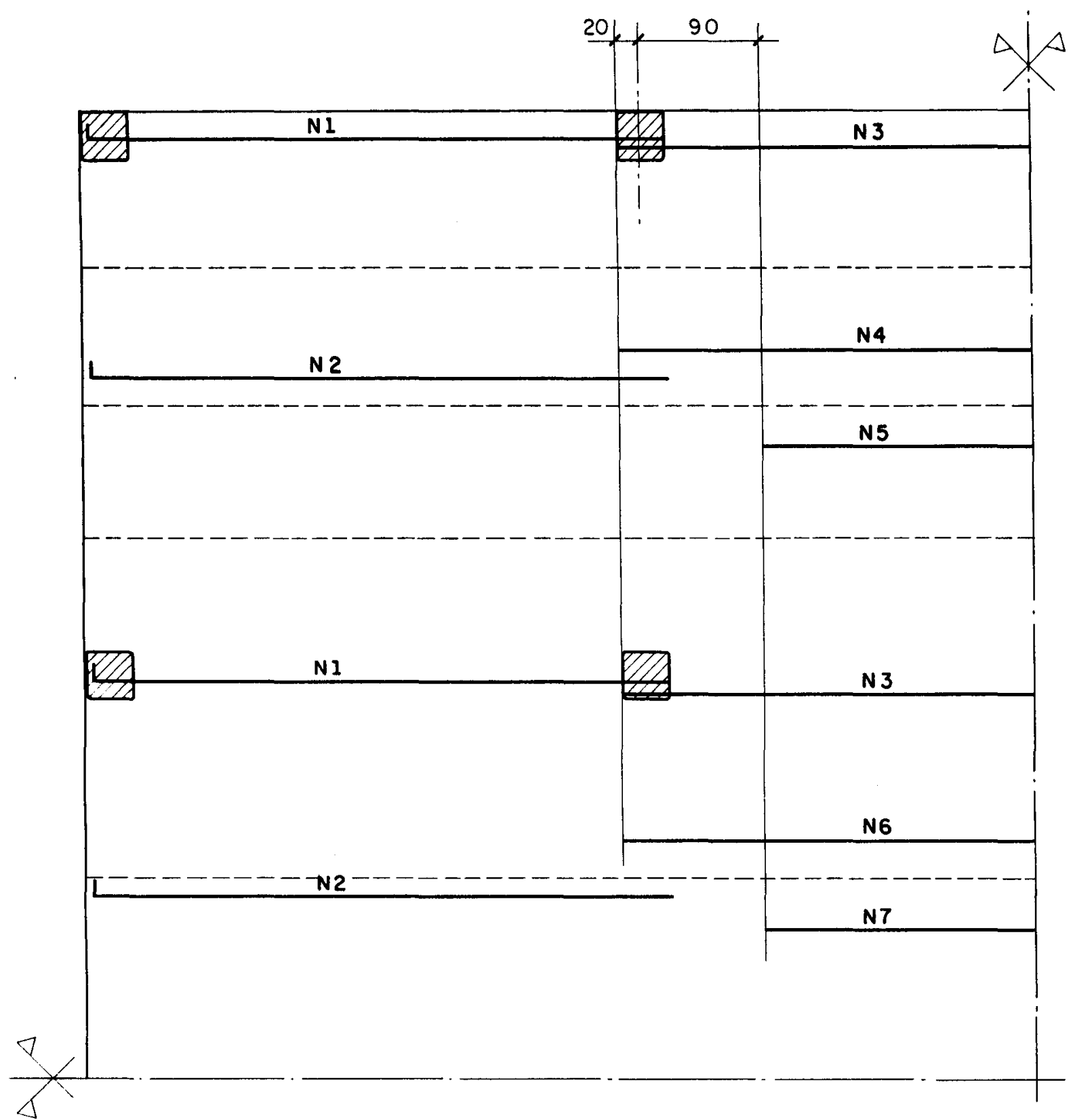

FIGURA 5.13- Detalhamento da armadura positiva. 
TABELA 5.13- Resumo da armadura positiva.

\begin{tabular}{|c|c|c|c|c|c|c|}
\hline $\mathbf{N}$ & $\mathbf{R}$ & $\begin{array}{c}\phi \\
(\mathrm{mm})\end{array}$ & $\begin{array}{c}\mathrm{s} \\
(\mathrm{cm})\end{array}$ & Quant. & $\begin{array}{c}\text { Comp. } \\
(\mathrm{m})\end{array}$ & $\begin{array}{c}\text { Comp. tot } \\
\text { (m) }\end{array}$ \\
\hline \multirow{3}{*}{1} & 1,0 & 6,3 & - & 48 & 4,45 & 213,6 \\
\hline & 1,1 & 6,3 & - & 48 & 4,45 & 213,6 \\
\hline & 1,2 & 6,3 & - & 48 & 4,45 & 213,6 \\
\hline \multirow{3}{*}{2} & 1,0 & 6,3 & 11 & 480 & 4,45 & 2136,0 \\
\hline & 1,1 & 6,3 & 11 & 480 & 4,45 & 2136,0 \\
\hline & 1,2 & 6,3 & 11 & 480 & 4,45 & 2136,0 \\
\hline \multirow{3}{*}{3} & 1,0 & 8 & - & 24 & 6,40 & 153,6 \\
\hline & 1,1 & 8 & - & 24 & 6,40 & 153,6 \\
\hline & 1,2 & 8 & - & 24 & 6,40 & 153,6 \\
\hline \multirow{3}{*}{4} & 1,0 & 8 & 26 & 60 & 6,40 & 384,0 \\
\hline & 1,1 & 8 & 22 & 68 & 6,40 & 435,2 \\
\hline & 1,2 & 8 & 20 & 76 & 6,40 & 486,4 \\
\hline \multirow{3}{*}{5} & 1,0 & 8 & 26 & 60 & 4,20 & 252,0 \\
\hline & 1,1 & 8 & 22 & 68 & 4,20 & 285,6 \\
\hline & 1,2 & 8 & 20 & 76 & 4,20 & 319,2 \\
\hline \multirow{3}{*}{6} & 1,0 & 8 & 18 & 64 & 6,40 & 409,6 \\
\hline & 1,1 & 8 & 16 & 72 & 6,40 & 460,8 \\
\hline & 1,2 & 8 & 14 & 80 & 6,40 & 512,0 \\
\hline \multirow{3}{*}{7} & 1,0 & 8 & 18 & 64 & 4,20 & 268,8 \\
\hline & 1,1 & 8 & 16 & 72 & 4,20 & 302,4 \\
\hline & 1,2 & 8 & 14 & 80 & 4,20 & 336,0 \\
\hline
\end{tabular}


TABELA 5.14- Consumo de aço da armadura positiva.

\begin{tabular}{|c|c|c|c|c|}
\hline & $\phi(\mathrm{mm})$ & $\mathbf{R}=1,0$ & $\mathbf{R}=1,1$ & $\mathbf{R}=1,2$ \\
\hline Comp. Total & 6,3 & 2349,6 & 2349,6 & 2349,6 \\
$(\mathrm{~m})$ & 8 & 1468,0 & 1637,6 & 1807,2 \\
\hline Massa & 6,3 & 588 & 588 & 588 \\
$(\mathrm{~kg})$ & 8 & 587 & 655 & 723 \\
\hline \multicolumn{2}{|c|}{ Massa total (kg) } & 1175 & 1243 & 1311 \\
\hline
\end{tabular}

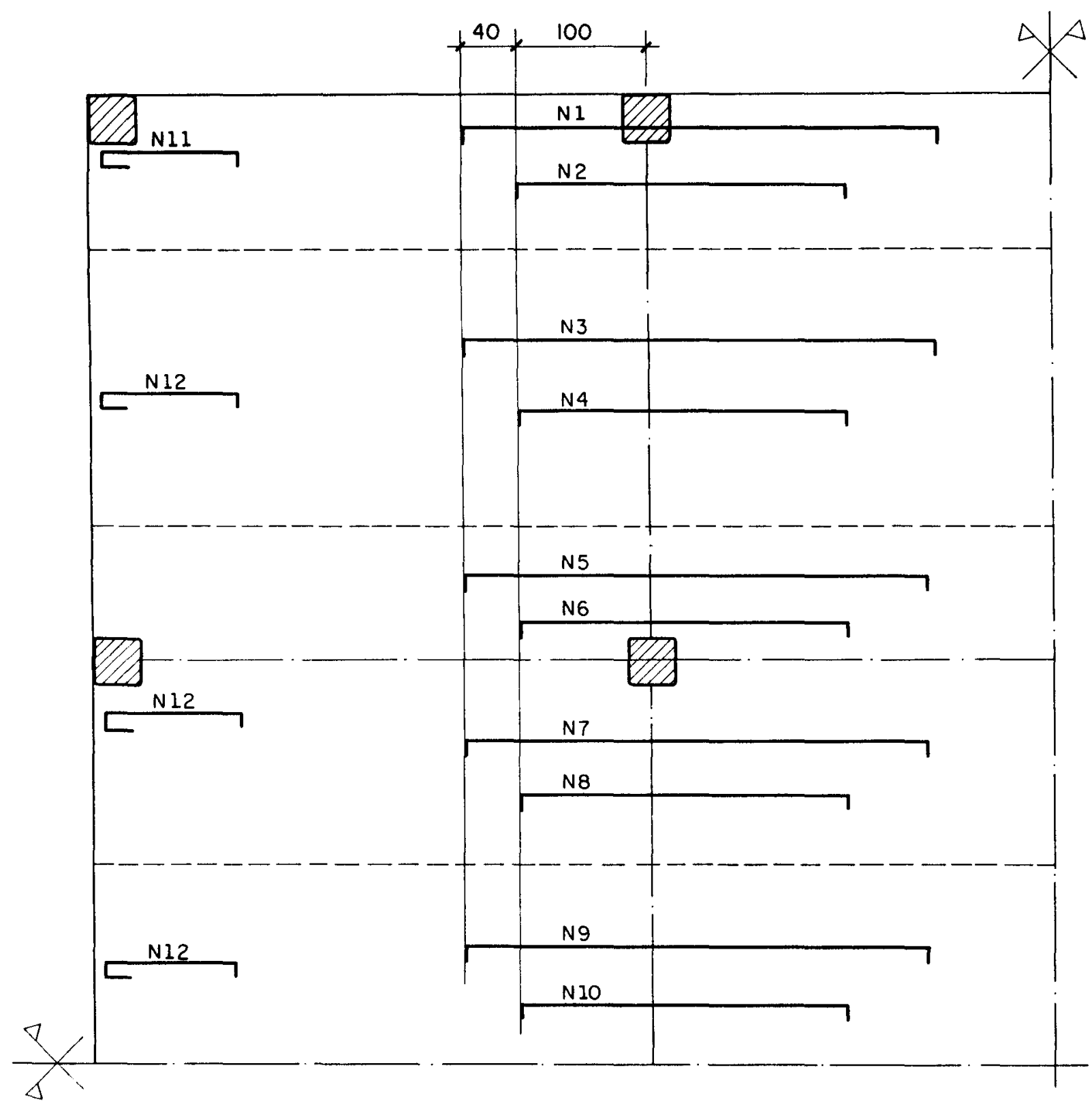

FIGURA 5.14- Detalhamento da armadura negativa. 
TABELA 5.15- Resumo da armadura negativa.

\begin{tabular}{|c|c|c|c|c|c|c|}
\hline$N$ & $\mathbf{R}$ & $\begin{array}{c}\phi \\
(\mathrm{mm})\end{array}$ & $\begin{array}{c}\mathrm{s} \\
(\mathrm{cm})\end{array}$ & Quant. & $\begin{array}{c}\text { Comp. } \\
\text { (m) }\end{array}$ & $\begin{array}{c}\text { Comp. tot. } \\
\text { (m) }\end{array}$ \\
\hline \multirow{3}{*}{1} & 1,0 & 10 & 16 & 64 & 3,80 & 243,2 \\
\hline & 1,1 & 10 & 18 & 56 & 3,80 & 212,8 \\
\hline & 1,2 & 10 & 20 & 48 & 3,80 & 182,8 \\
\hline \multirow{3}{*}{2} & 1,0 & 10 & 16 & 64 & 2,80 & 179,2 \\
\hline & 1,1 & 10 & 18 & 56 & 2,80 & 156,8 \\
\hline & 1,2 & 10 & 20 & 48 & 2,80 & 134,4 \\
\hline \multirow{3}{*}{3} & 1,0 & 6,3 & 20 & 80 & 3,80 & 304,0 \\
\hline & 1,1 & 6,3 & 22 & 72 & 3,80 & 273,6 \\
\hline & 1,2 & 6,3 & 22 & 72 & 3,80 & 273,6 \\
\hline \multirow{3}{*}{4} & 1,0 & 6,3 & 20 & 80 & 2,80 & 224,0 \\
\hline & 1,1 & 6,3 & 22 & 72 & 2,80 & 201,6 \\
\hline & 1,2 & 6,3 & 22 & 72 & 2,80 & 201,6 \\
\hline \multirow{3}{*}{5} & 1,0 & 10 & 16 & 56 & 3,80 & 212,8 \\
\hline & 1,1 & 10 & 18 & 48 & 3,80 & 182,4 \\
\hline & 1,2 & 10 & 20 & 40 & 3,80 & 152,8 \\
\hline \multirow{3}{*}{6} & 1,0 & 10 & 16 & 56 & 2,80 & 156,8 \\
\hline & 1,1 & 10 & 18 & 48 & 2,80 & 134,4 \\
\hline & 1,2 & 10 & 20 & 40 & 2,80 & 112,0 \\
\hline \multirow{3}{*}{7} & 1,0 & 10 & 20 & 64 & 3,80 & 243,2 \\
\hline & 1,1 & 10 & 22 & 56 & 3,80 & 212,8 \\
\hline & 1,2 & 8 & 14 & 88 & 3,80 & 334,4 \\
\hline \multirow{3}{*}{8} & 1,0 & 10 & 20 & 64 & 2,80 & 179,2 \\
\hline & 1,1 & 10 & 22 & 56 & 2,80 & 156,8 \\
\hline & 1,2 & 8 & 14 & 88 & 2,80 & 246,4 \\
\hline
\end{tabular}


TABELA 5.15- Resumo da armadura negativa (continuação).

\begin{tabular}{|c|c|c|c|c|c|c|}
\hline $\mathbf{N}$ & $\mathbf{R}$ & $\begin{array}{c}\phi \\
(\mathbf{m m})\end{array}$ & $\begin{array}{c}\mathbf{s} \\
(\mathbf{c m})\end{array}$ & Quant. & $\begin{array}{c}\text { Comp. } \\
(\mathbf{m})\end{array}$ & $\begin{array}{c}\text { Comp. tot. } \\
(\mathbf{m})\end{array}$ \\
\hline \multirow{3}{*}{9} & 1,0 & 6,3 & 22 & 56 & 3,80 & 212,8 \\
& 1,1 & 6,3 & 22 & 56 & 3,80 & 212,8 \\
& 1,2 & 6,3 & 22 & 56 & 3,80 & 212,8 \\
\hline \multirow{3}{*}{10} & 1,0 & 6,3 & 22 & 56 & 2,80 & 156,8 \\
& 1,1 & 6,3 & 22 & 56 & 2,80 & 156,8 \\
& 1,2 & 6,3 & 22 & 56 & 2,80 & 156,8 \\
\hline \multirow{3}{*}{11} & 1,0 & 6,3 & 10 & 96 & 1,45 & 139,2 \\
& 1,1 & 6,3 & 11 & 88 & 1,45 & 127,6 \\
& 1,2 & 6,3 & 11 & 88 & 1,45 & 127,6 \\
\hline \multirow{3}{*}{12} & 1,0 & 6,3 & 11 & 448 & 1,45 & 649,6 \\
& 1,1 & 6,3 & 11 & 448 & 1,45 & 649,6 \\
& 1,2 & 6,3 & 11 & 448 & 1,45 & 649,6 \\
\hline \multirow{3}{*}{1,2} & & & & &
\end{tabular}

TABELA 5.16- Consumo de aço da armadura negativa.

\begin{tabular}{|c|c|c|c|c|}
\hline & $\phi(\mathbf{m m})$ & $R=1,0$ & $R=1,1$ & $R=1,2$ \\
\hline \multirow{2}{*}{ Comp. Total } & 6,3 & 1686,40 & 1622,00 & 1622,00 \\
$(\mathbf{m})$ & 8 & - & - & 580,80 \\
& 10 & 1214,40 & 1056,00 & 582,00 \\
Massa & 6,3 & 422 & 406 & 406 \\
(kg) & 8 & - & - & 232 \\
& 10 & 765 & 665 & 367 \\
\hline \multicolumn{2}{|c|}{ Massa total (kg) } & 1187 & 1071 & 1005 \\
\hline
\end{tabular}




\section{3- EXEMPLO 2}

É analisado agora o pavimento mostrado na figura 5.15. Assim como no exemplo 1, utiliza-se o Processo dos Pórticos Equivalentes, apresentado no item 2.3, para o cálculo dos momentos elásticos.

Adotou-se a mesma espessura e carregamento do exemplo 1.

A divisão do pavimento em faixas de projeto e pórticos equivalentes é mostrada na figura 5.16 .

\subsection{1 - Propriedades das Barras dos Pórticos}

Considerando todos os pilares com seção transversal de $40 \mathrm{~cm} \times 40 \mathrm{~cm}$ e numerando as barras de acordo com a figura 5.17 , as propriedades das barras são as apresentadas nas tabelas $5.17,5.18,5.19$ e 5.20 .

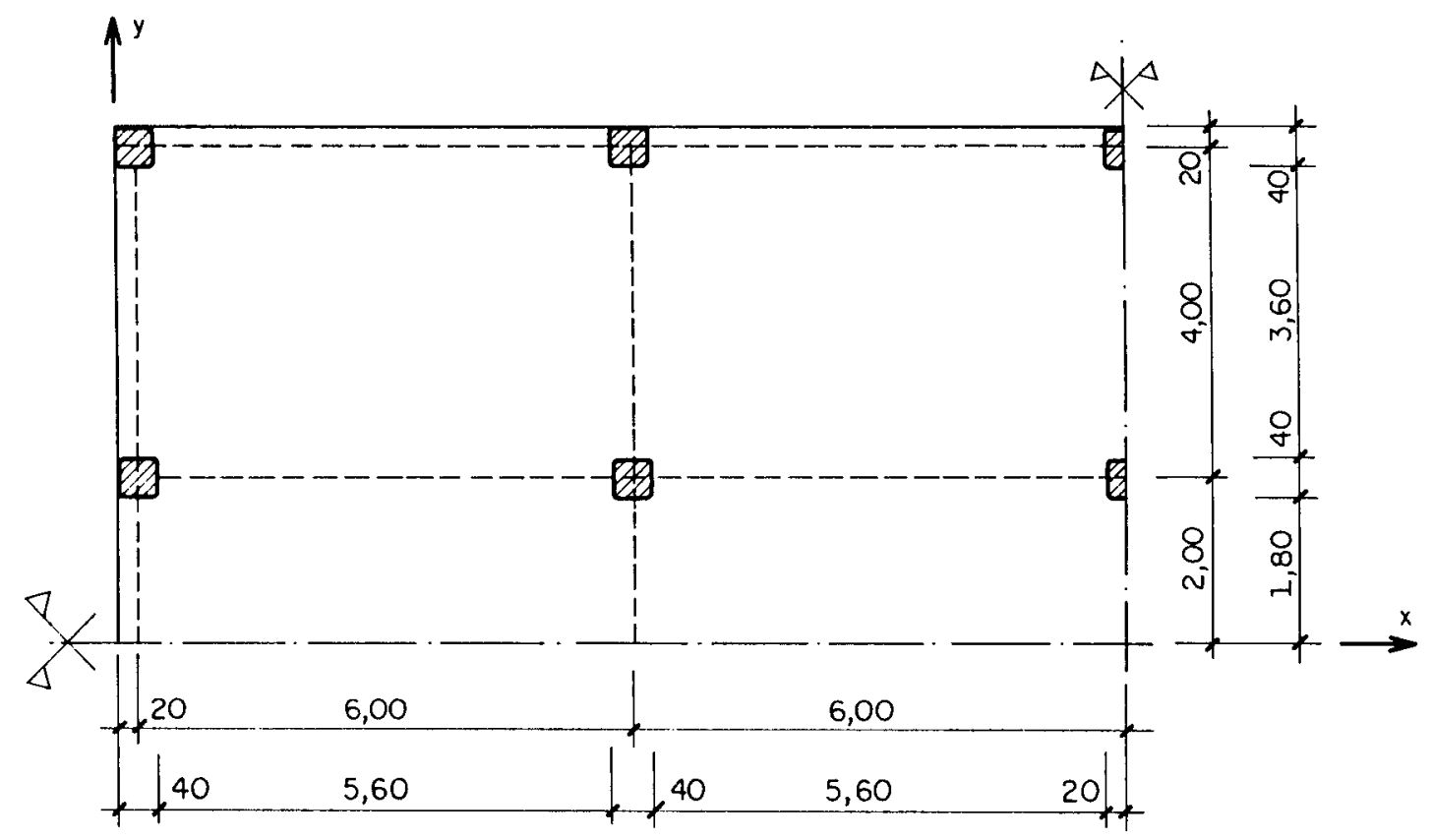

FIGURA 5.15- Pavimento do exemplo 2. 


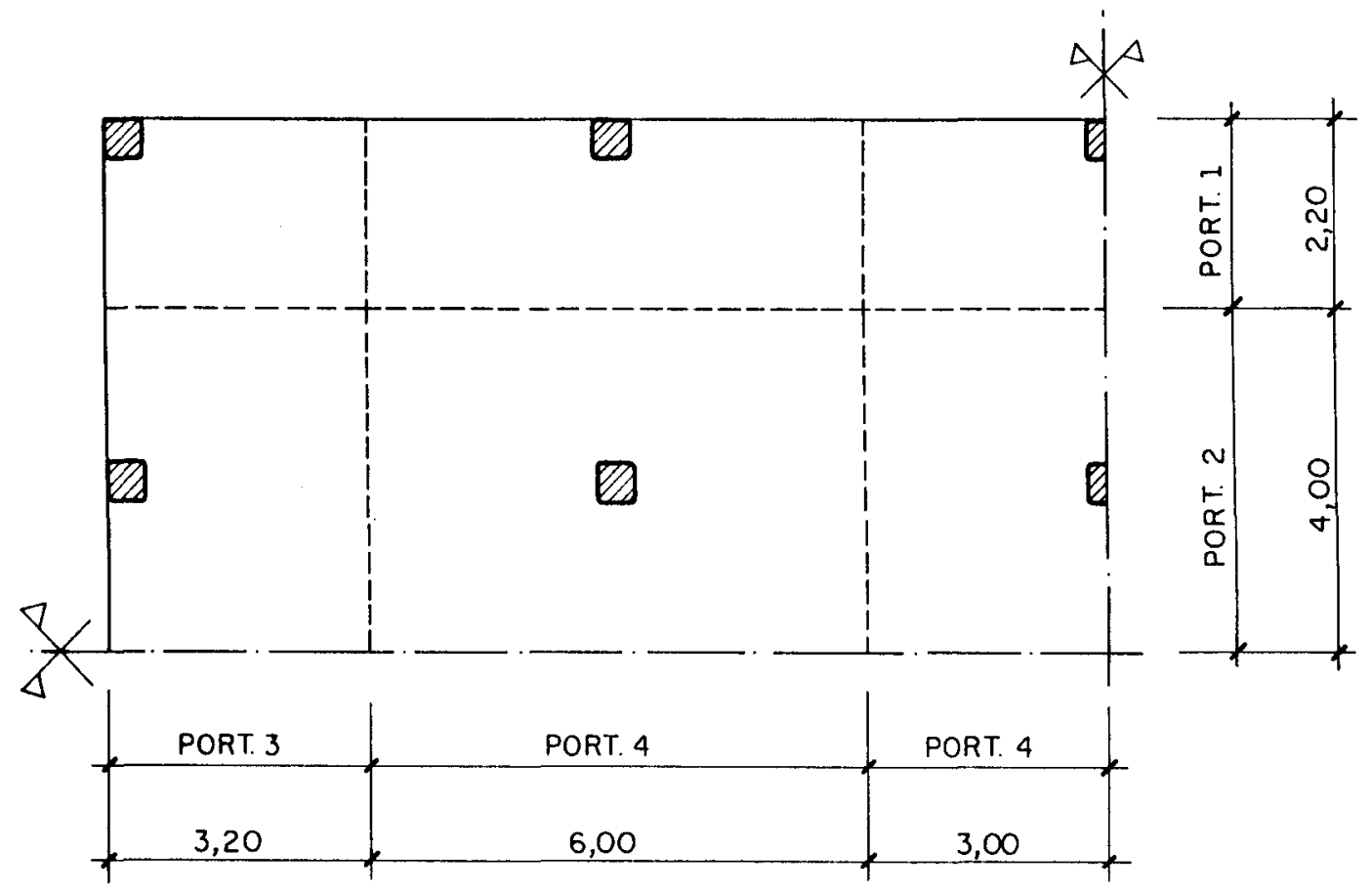

FIGURA 5. 16- Faixas de projeto e pórticos muitiplos.

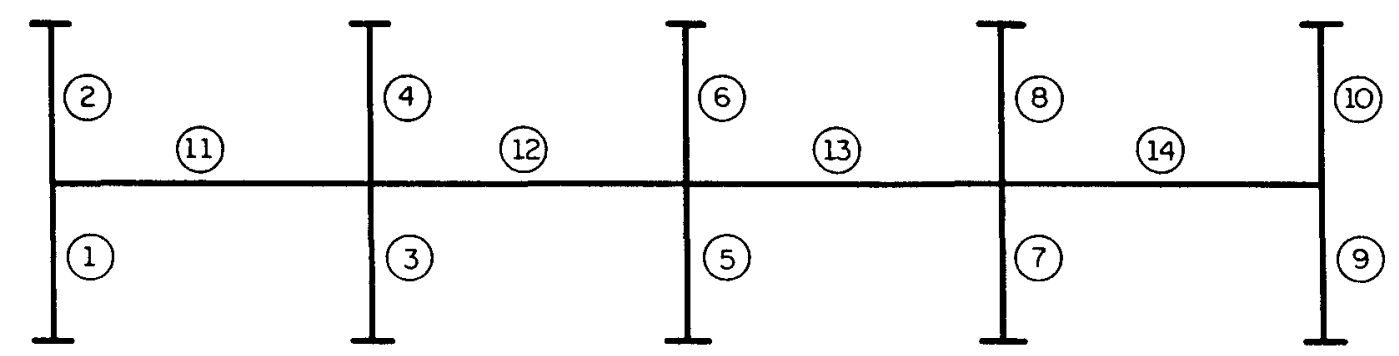

a) PORT. 1 e PORT. 2

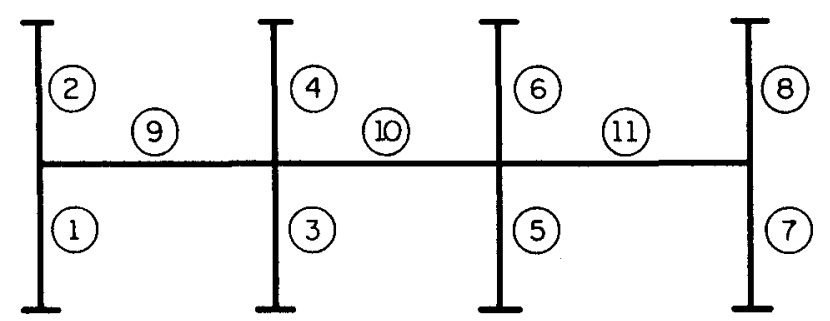

b) PORT. 3 e PORT. 4

FIGURA 5.17- Numeração das barras dos pórticos. 
TABELA 5.17- Propriedades das barras do pórtico PORT 1.

\begin{tabular}{|l|c|c|}
\hline Propriedade & Barras 1,2,3,...,10 & Barras 11,12,13,14 \\
\hline Área $\left(\mathrm{m}^{2}\right)$ & 0,160 & 0,396 \\
\hline M. de Inércia $\left(\mathrm{m}^{4}\right)$ & 0,002133 & 0,001070 \\
\hline
\end{tabular}

TABELA 5.18- Propriedades das barras do pórtico PORT 2.

\begin{tabular}{|l|c|c|}
\hline Propriedade & Barras 1,2,3,..,10 & Barras 11,12,13,14 \\
\hline Área $\left(\mathrm{m}^{2}\right)$ & 0,160 & 0,720 \\
\hline M. de Inércia $\left(\mathrm{m}^{4}\right)$ & 0,002133 & 0,001940 \\
\hline
\end{tabular}

TABELA 5.19 Propriedades das barras do pórtico PORT 3.

\begin{tabular}{|l|c|c|}
\hline Propriedade & Barras $1,2,3, \ldots, 8$ & Barras 9,10,11 \\
\hline Área $\left(\mathrm{m}^{2}\right)$ & 0,160 & 0,576 \\
\hline M. de Inércia $\left(\mathrm{m}^{4}\right)$ & 0,002133 & 0,001560 \\
\hline
\end{tabular}

TABELA 5.20- Propriedades das barras do pórtico PORT 4.

\begin{tabular}{|l|c|c|}
\hline Propriedade & Barras 1,2,3,..,8 & Barras 9,10,11 \\
\hline Área $\left(\mathrm{m}^{2}\right)$ & 0,160 & 1,080 \\
\hline M. de Inércia $\left(\mathrm{m}^{4}\right)$ & 0,002133 & 0,002920 \\
\hline
\end{tabular}

\subsection{2- Determinação do Carregamento dos Pórticos}

Os carregamentos dos pórticos são calculados da mesma forma que no exemplo 1. As figuras $5.18,5.19,5.20$ e 5.21 apresentam os carregamentos dos pórticos PORT1, PORT2, PORT3 e PORT4, respectivamente. 


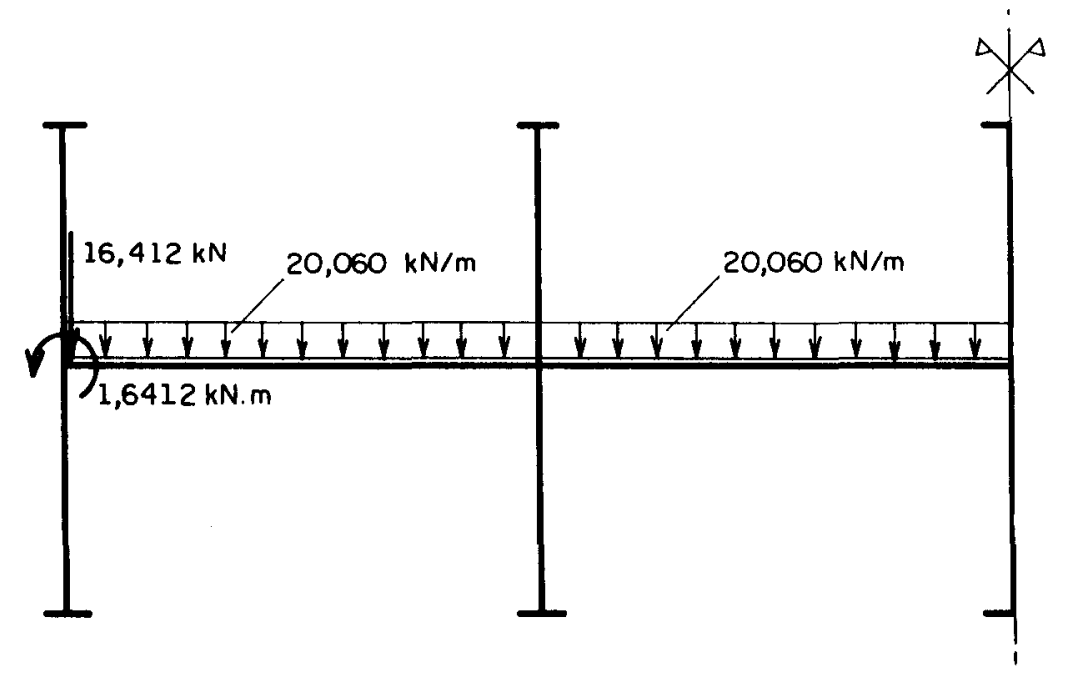

FIGURA 5.18- Carregamento do pórtico PORT1.

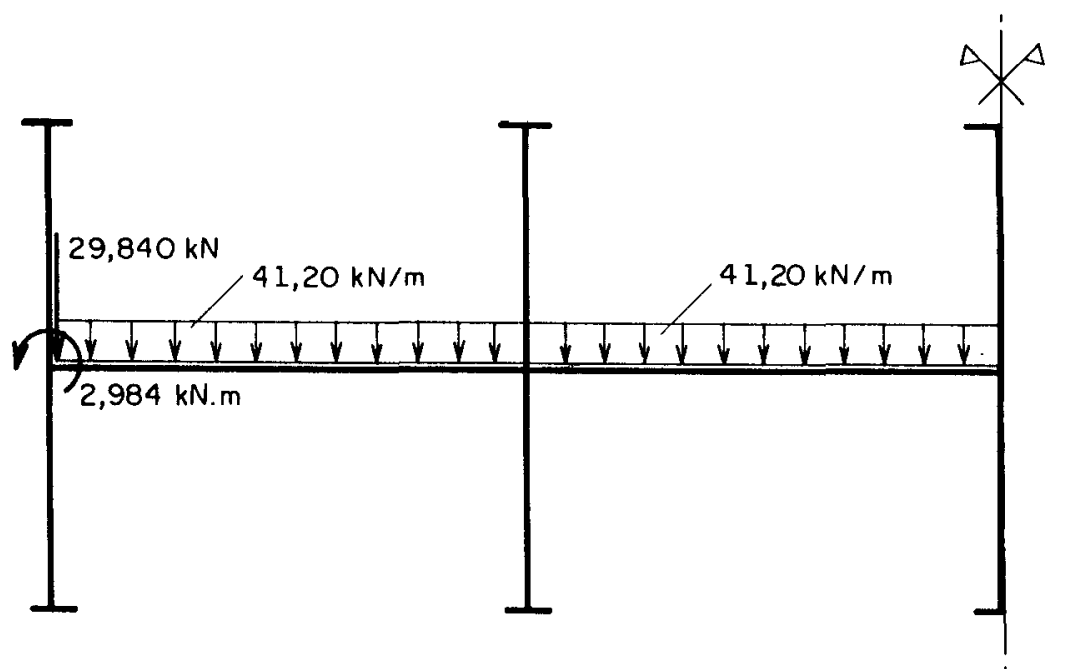

FIGURA 5.19- Carregamento do pórtico PORT2.

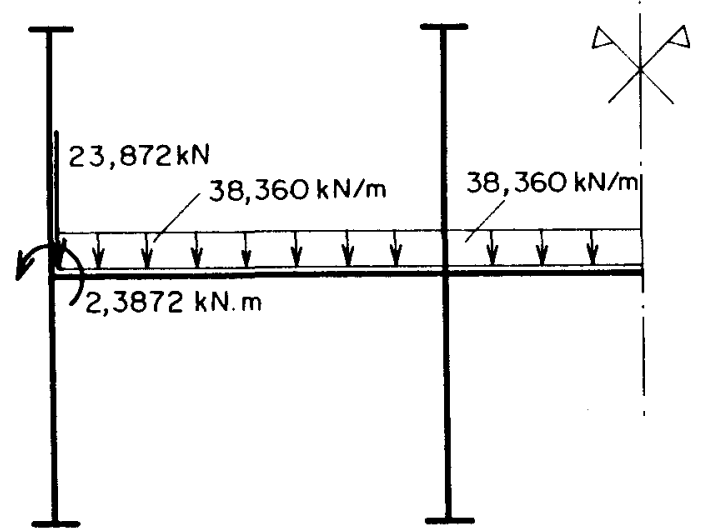

FIGURA 5.20- Carregamento do pórtico PORT3. 


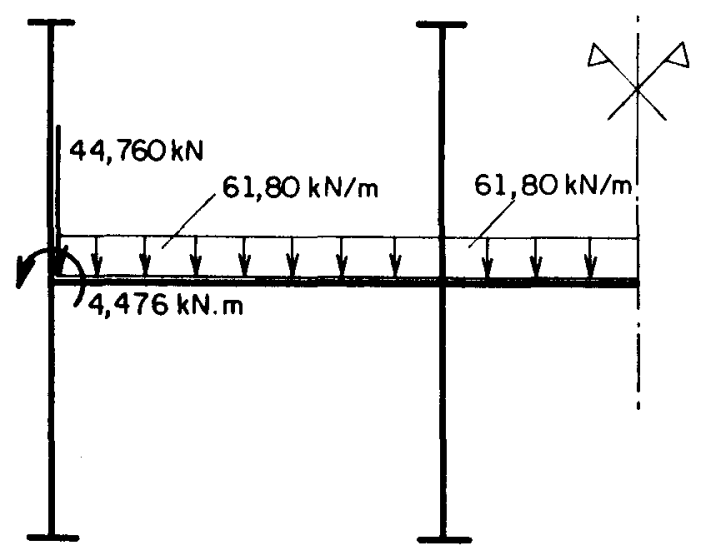

FIGURA 5.21- Carregamento do pórtico PORT4.

\subsection{3- Determinaçăo dos Esforços Solicitantes}

Para a determinação dos esforços solicitantes utilizou-se o mesmo programa de resolução de pórticos planos, como no exemplo 1, e os resultados obtidos encontram-se nas tabelas 5.21 a 5.24 .

TABELA 5.21- Momentos fletores atuantes no pórtico PORT1.

\begin{tabular}{|c|c|}
\hline$x(m)$ & $M(k N m)$ \\
\hline 0,0 & $-75,290$ \\
\hline 3,0 & 44,512 \\
\hline 6,0 & $-88,226$ \\
\hline 6,0 & $-84,627$ \\
\hline 9,0 & 41,977 \\
\hline 12,0 & -83.958 \\
\hline
\end{tabular}


TABELA 5.22- Momentos fletores atuantes no pórtico PORT2.

\begin{tabular}{|c|c|}
\hline$X(m)$ & $M(k N m)$ \\
\hline 0,0 & $-102,212$ \\
\hline 3,0 & 67,870 \\
\hline 6,0 & $-132,848$ \\
\hline 6,0 & $-125,298$ \\
\hline 9,0 & 61,371 \\
\hline 12,0 & $-122,761$ \\
\hline
\end{tabular}

TABELA 5.23- Momentos fletores atuantes no pórtico PORT3.

\begin{tabular}{|c|c|}
\hline$X(m)$ & $M(k N m)$ \\
\hline 0,0 & $-41,291$ \\
\hline 2,0 & 28,484 \\
\hline 4,0 & $-55,181$ \\
\hline 4,0 & $-51,633$ \\
\hline 6,0 & 25,087 \\
\hline
\end{tabular}

TABELA 5.24- Momentos fletores atuantes no pórtico PORT4.

\begin{tabular}{|c|c|}
\hline$X(m)$ & $M(k N m)$ \\
\hline 0,0 & $-57,834$ \\
\hline 2,0 & 48,970 \\
\hline 4,0 & $-91,427$ \\
\hline 4,0 & $-84,244$ \\
\hline 6,0 & 39,356 \\
\hline
\end{tabular}




\subsection{4- Distribuiçăo dos Momentos nas Faixas de Projeto}

A distribuição dos momentos é feita de acordo com o exemplo 1, utilizando-se a tabela 2.2, do item 2.3.3. Os momentos distribuidos são apresentados na figura 5.22 e na figura 5.23, para a direção x e para a direção $y$, respectivamente.

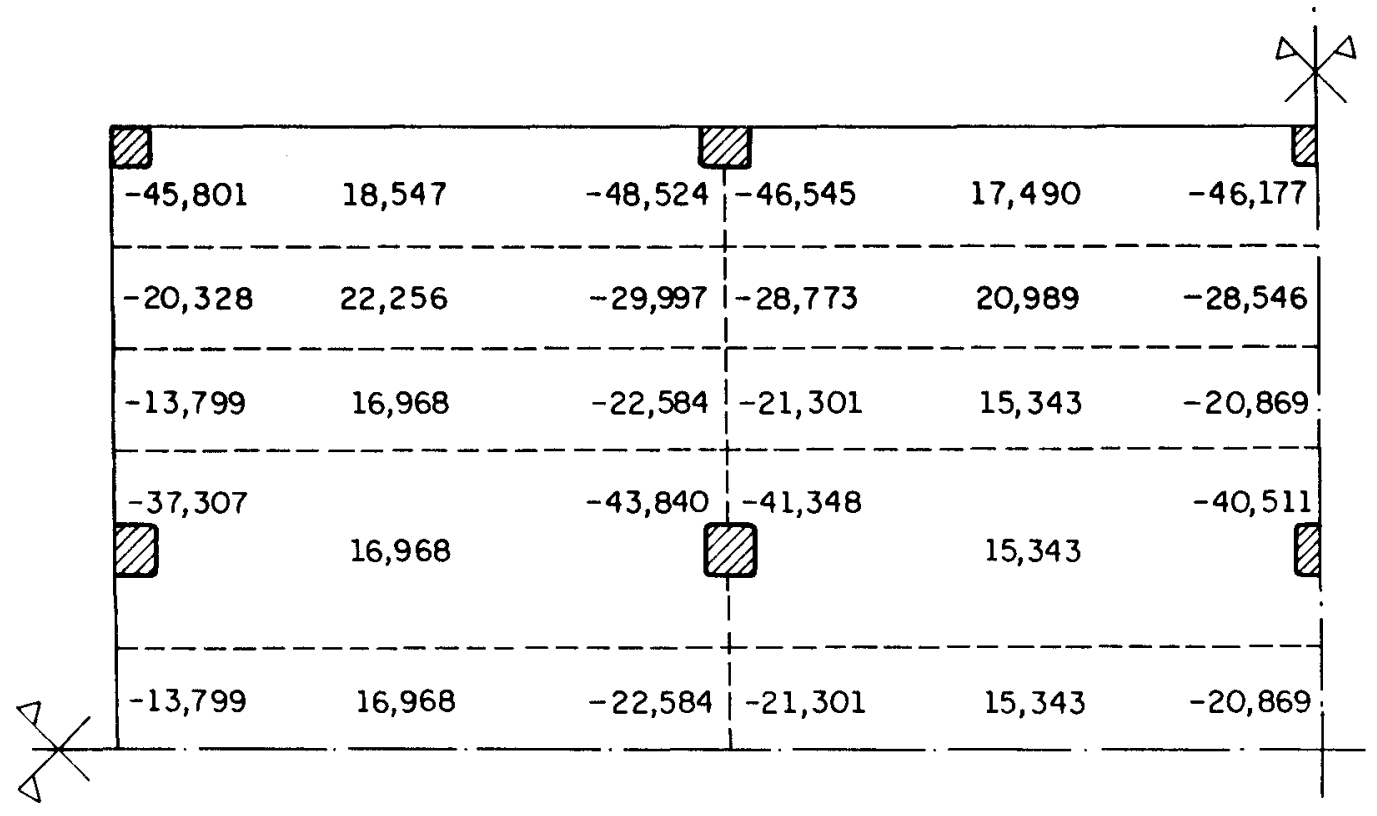

FIGURA 5.22-Momentos distribuidos nas faixas de projeto, para a direção $\times(\mathrm{kNm} / \mathrm{m})$.

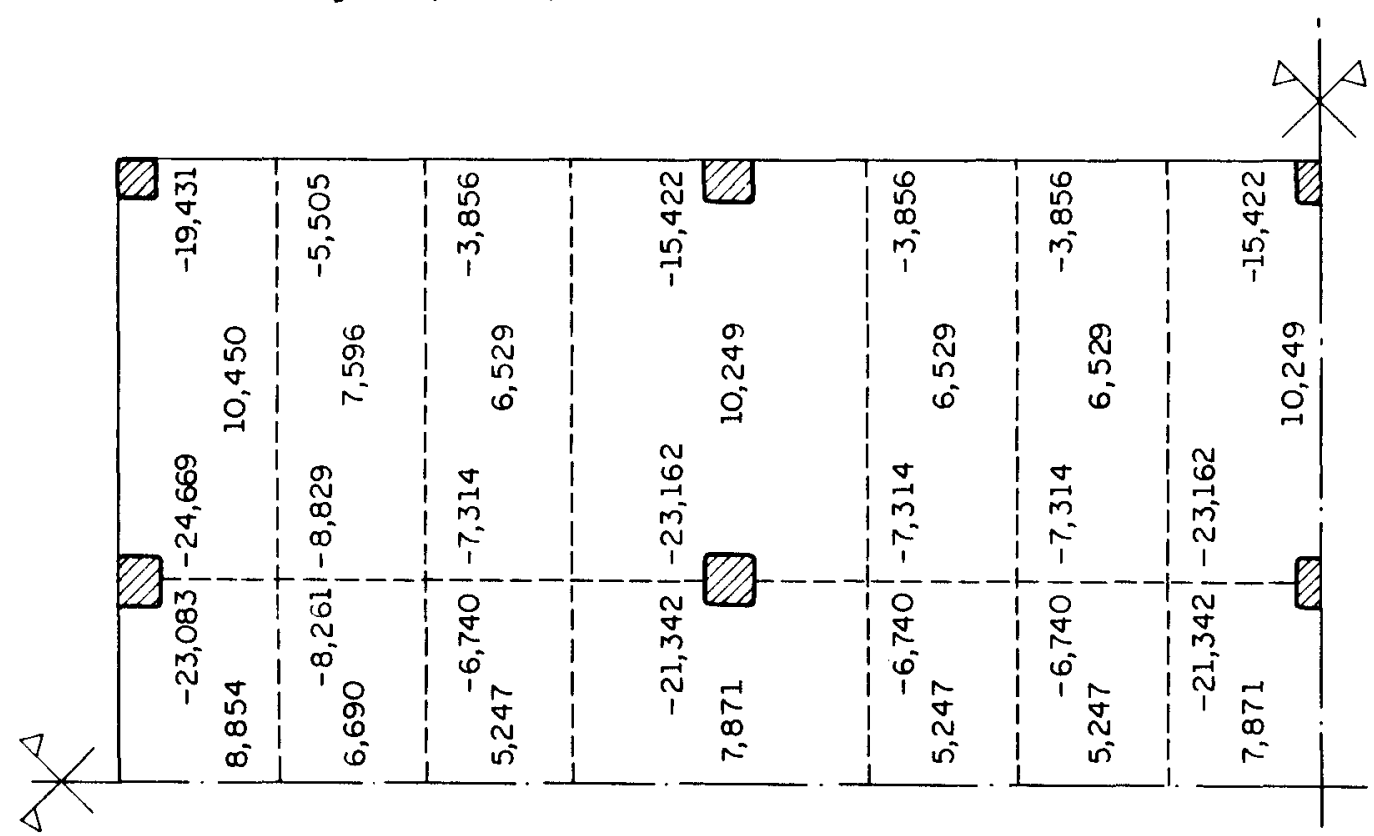

FIGURA 5.23-Momentos distribuidos nas faixas de projeto, para a direção y $(\mathrm{kNm} / \mathrm{m})$. 


\subsection{5- Compatibilizaçăo dos Momentos}

Utilizando-se o critério adotado no exemplo 1, os momentos compatibilizados foram calculados e são apresentados na figura 5.24, para a direção $x$, e na figura 5.25 , para a direção y.

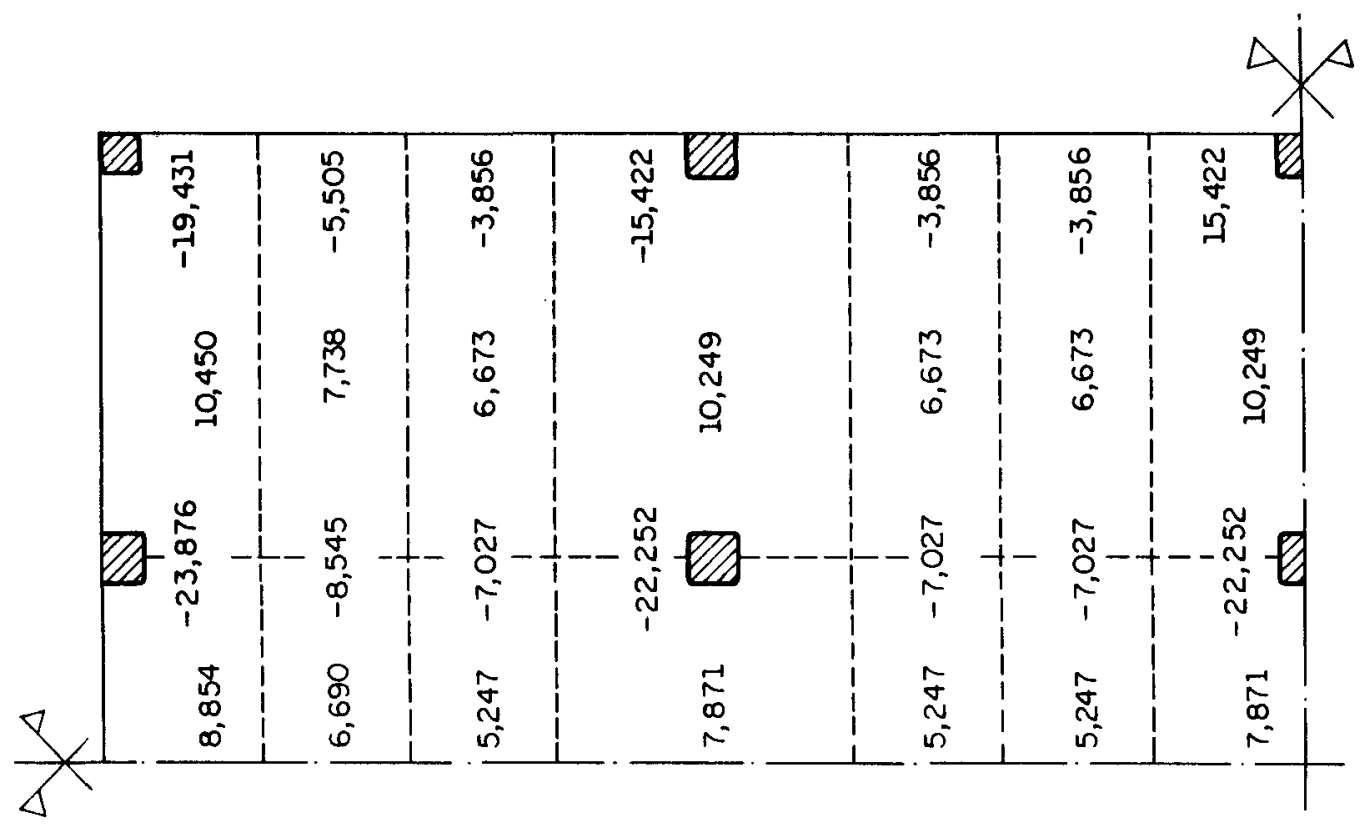

FIGURA 5.24- Momentos negativos compatibilizados e positivos corrigidos, para a direção $\times(\mathrm{kNm} / \mathrm{m})$.

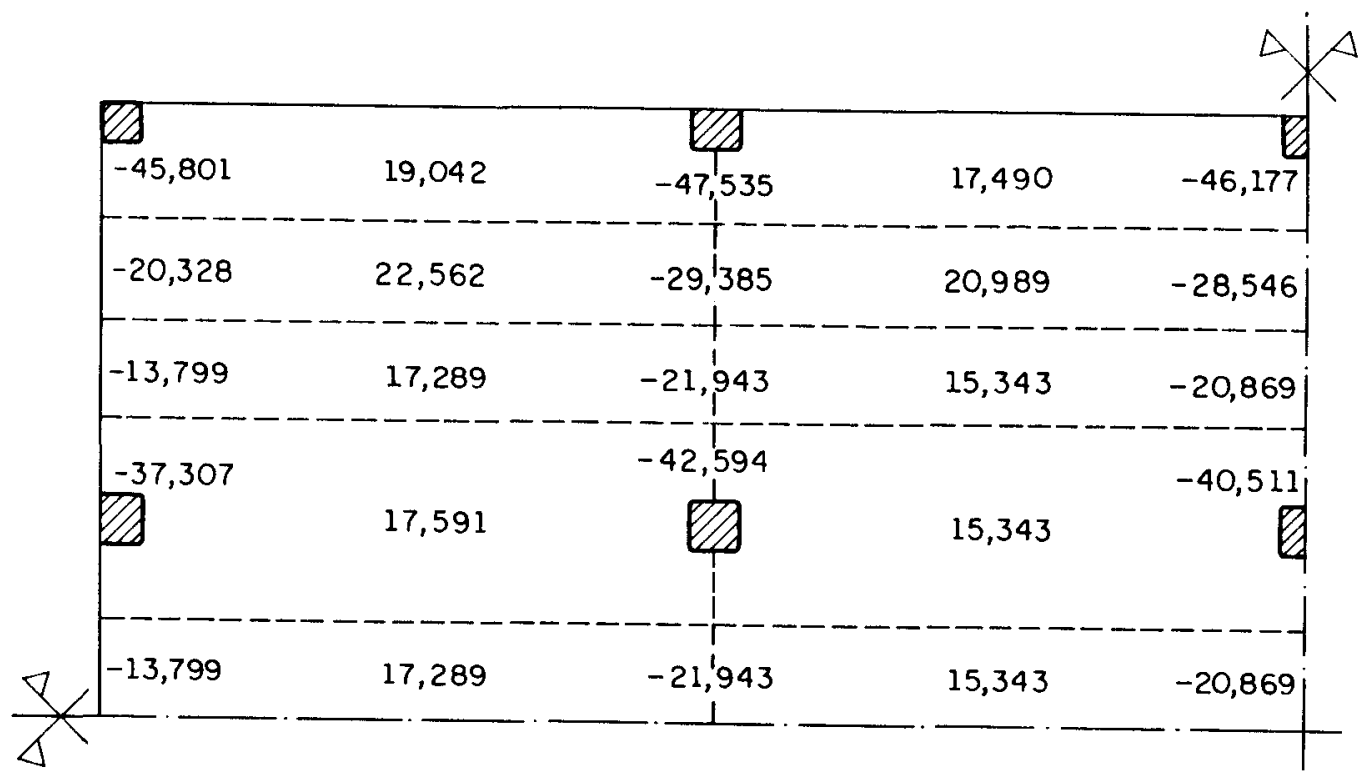

FIGURA 5.25-Momentos negativos compatibilizados e positivos corrigidos, para a direção y $(\mathrm{kNm} / \mathrm{m})$. 


\subsection{6- Cálculo da Armadura de Flexáo}

Para o cálculo das armaduras utilizam-se os mesmos critérios e os mesmos dados do pavimento do exemplo 1, apresentados no item 5.2.9.

Os valores das áreas de aço calculadas foram lançados nas tabelas 5.25 e 5.26, para os momentos negativos, e nas tabelas 5.27 e 5.28 , para os momentos positivos.

TABELA 5.25- Área de aço dos momentos negativos (direção x).

\begin{tabular}{|c|c|c|}
\hline $\begin{array}{c}\text { Momento } \\
(\mathbf{k N m} / \mathrm{m})\end{array}$ & $\begin{array}{c}\text { Área de Aço } \\
\left(\mathbf{c m}^{2} / \mathrm{m}\right)\end{array}$ & Armadura \\
\hline 45,801 & 9,879 & $\phi 10$ c. 7 \\
\hline 20,328 & 4,048 & $\phi 6,3$ c. 7 \\
\hline 13,799 & 2,748 & $\phi 6,3$ c. 11 \\
\hline 37,307 & 7,738 & $\phi 10$ c. 10 \\
\hline 47,535 & 10,253 & $\phi 10$ c. 7 \\
\hline 29,385 & 6,095 & $\phi 8$ c. 8 \\
\hline 21,943 & 4,369 & $\phi 8$ c. 11 \\
\hline 42,594 & 8,834 & $\phi 10$ c. 8 \\
\hline 46,177 & 9,961 & $\phi 10$ c. 7 \\
\hline 28,546 & 5,921 & $\phi 8$ c. 8 \\
\hline 20,869 & 4,155 & $\phi 6,3$ c. 7 \\
\hline 40,511 & 8,402 & $\phi 10$ c. 9 \\
\hline
\end{tabular}


TABELA 5.26- Área de aço dos momentos negativos (direção y).

\begin{tabular}{|c|c|c|}
\hline $\begin{array}{c}\text { Momento } \\
(\mathrm{kNm} / \mathrm{m})\end{array}$ & $\begin{array}{c}\text { Área de Aço } \\
\left(\mathrm{cm}^{2} / \mathrm{m}\right)\end{array}$ & Armadura \\
\hline 19,431 & 3,869 & $\phi 6,3$ c. 8 \\
\hline 5,505 & $2,700^{*}$ & $\phi 6,3$ c. 11 \\
\hline 3,856 & $2,700^{*}$ & $\phi 6,3$ c. 11 \\
\hline 15,422 & 3,071 & $\phi 6,3$ c. 10 \\
\hline 23,876 & 4,754 & $\phi 8$ c. 10 \\
\hline 8,545 & $2,700^{\star}$ & $\phi 6,3$ c. 11 \\
\hline 7,027 & $2,700^{\star}$ & $\phi 6,3$ c. 11 \\
\hline 22,252 & 4,431 & $\phi 8$ c. 11 \\
\hline
\end{tabular}

* Área mínima de aço.

TABELA 5.27- Área de aço dos momentos positivos (direção x).

\begin{tabular}{|c|c|c|}
\hline $\begin{array}{c}\text { Momento } \\
(\mathbf{k N m} / \mathrm{m})\end{array}$ & $\begin{array}{c}\text { Área de Aço } \\
\left(\mathrm{cm}^{2} / \mathrm{m}\right)\end{array}$ & Armadura \\
\hline 19,042 & 4,101 & $\phi 6,3$ c. 7 \\
\hline 22,562 & 5,062 & $\phi 8$ c. 8 \\
\hline 17,289 & 3,724 & $\phi 6,3$ c. 8 \\
\hline 17,591 & 3,789 & $\phi 6,3$ c. 8 \\
\hline 17,490 & 3,767 & $\phi 6,3$ c. 8 \\
\hline 20,989 & 4,521 & $\phi 8$ c. 11 \\
\hline 15,343 & 3,305 & $\phi 6,3$ c. 9 \\
\hline
\end{tabular}


TABELA 5.28- Área de aço dos momentos positivos (direção y).

\begin{tabular}{|c|c|c|}
\hline $\begin{array}{c}\text { Momento } \\
(\mathrm{kNm} / \mathrm{m})\end{array}$ & $\begin{array}{c}\text { Área de Aço } \\
\left(\mathrm{cm}^{2} / \mathrm{m}\right)\end{array}$ & Armadura \\
\hline 10,450 & $2,700^{*}$ & $\phi 6,3$ c. 11 \\
\hline 7,738 & $2,700^{*}$ & $\phi 6,3$ c. 11 \\
\hline 6,673 & $2,700^{*}$ & $\phi 6,3$ c. 11 \\
\hline 10,249 & $2,700^{*}$ & $\phi 6,3$ c. 11 \\
\hline 8,854 & $2,700^{*}$ & $\phi 6,3$ c. 11 \\
\hline 6,690 & $2,700^{\star}$ & $\phi 6,3$ c. 11 \\
\hline 5,247 & $2,700^{*}$ & $\phi 6,3$ c. 11 \\
\hline 7,871 & $2,700^{*}$ & $\phi 6,3$ c. 11 \\
\hline
\end{tabular}

* Área mínima de aço.

\subsection{7- Detalhamento das Armaduras do Cálculo Elástico}

Para o detalhamento das armaduras do cálculo elástico foram utilizados os comprimentos das barras apresentados na figura 5.1 e as áreas de aço calculadas no item anterior.

O detalhamento da armadura positiva é apresentado nas figuras 5.26 e 5.27 , para a direção $x$ e para a direção $y$, respectivamente. Para a armadura negativa, 0 detalhamento é apresentado na figura 5.28, para a direção $x$, e na figura 5.29, para a direção y.

Nas tabelas 5.29 e 5.31 são apresentados resumos com os principais dados do detalhamento da armadura positiva e da armadura negativa, respectivamente. Os consumos de aço desses detalhamentos encontram-se na tabela 5.30, para a armadura positiva, e na tabela 5.32, para a armadura negativa. 


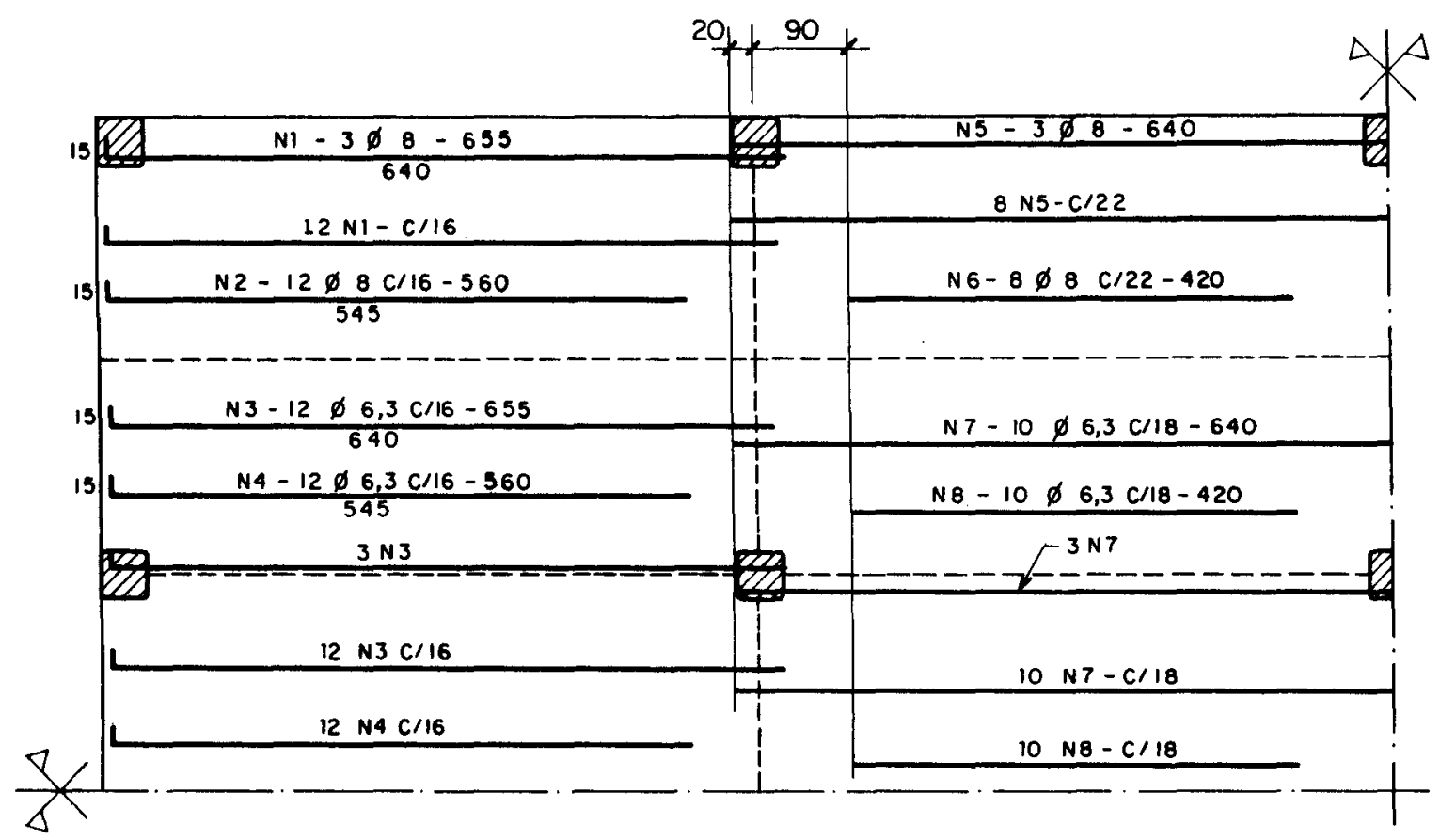

FIGURA 5.26- Detalhamento da armadura positiva (direção $x$ ).

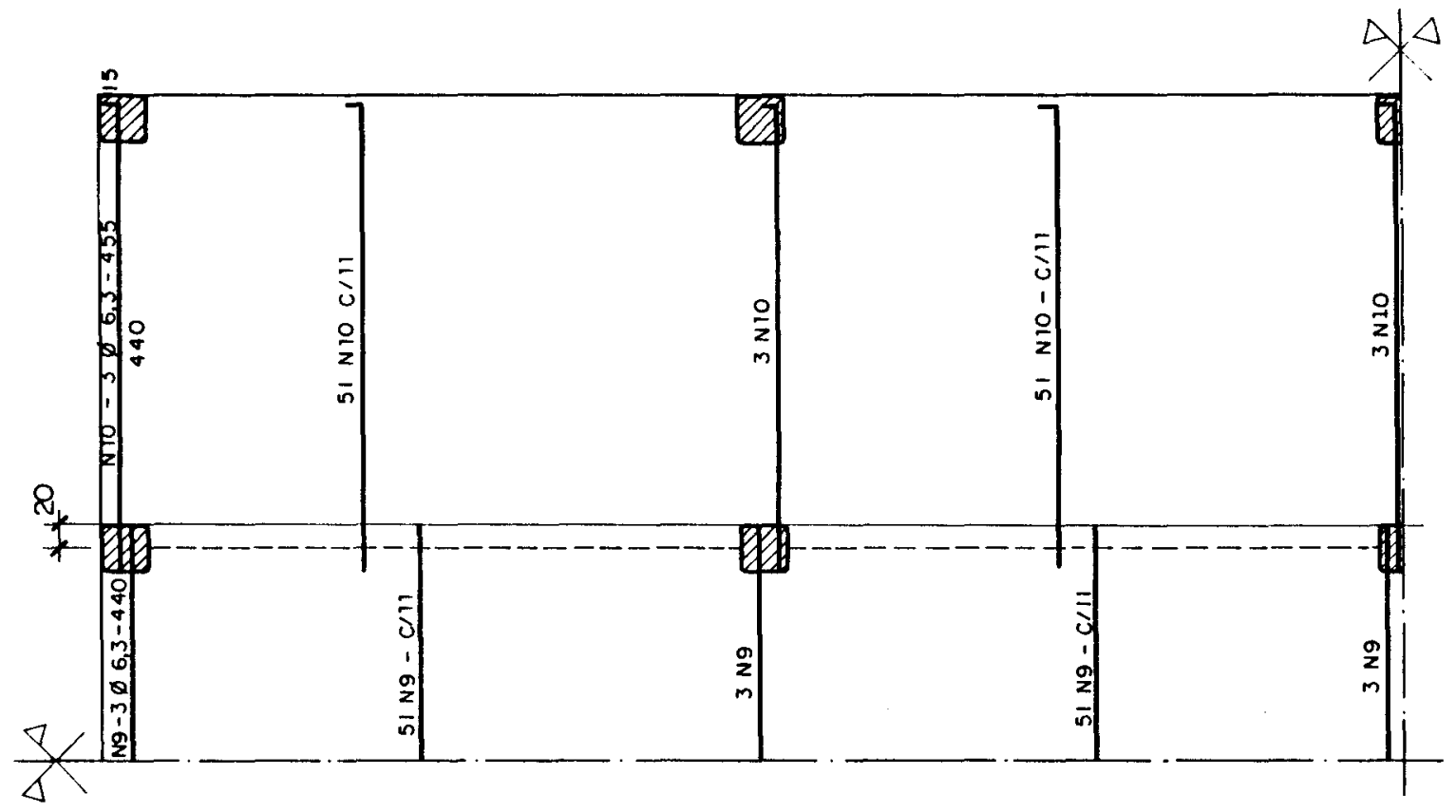

FIGURA 5.27- Detalhamento da armadura positiva (direção y). 


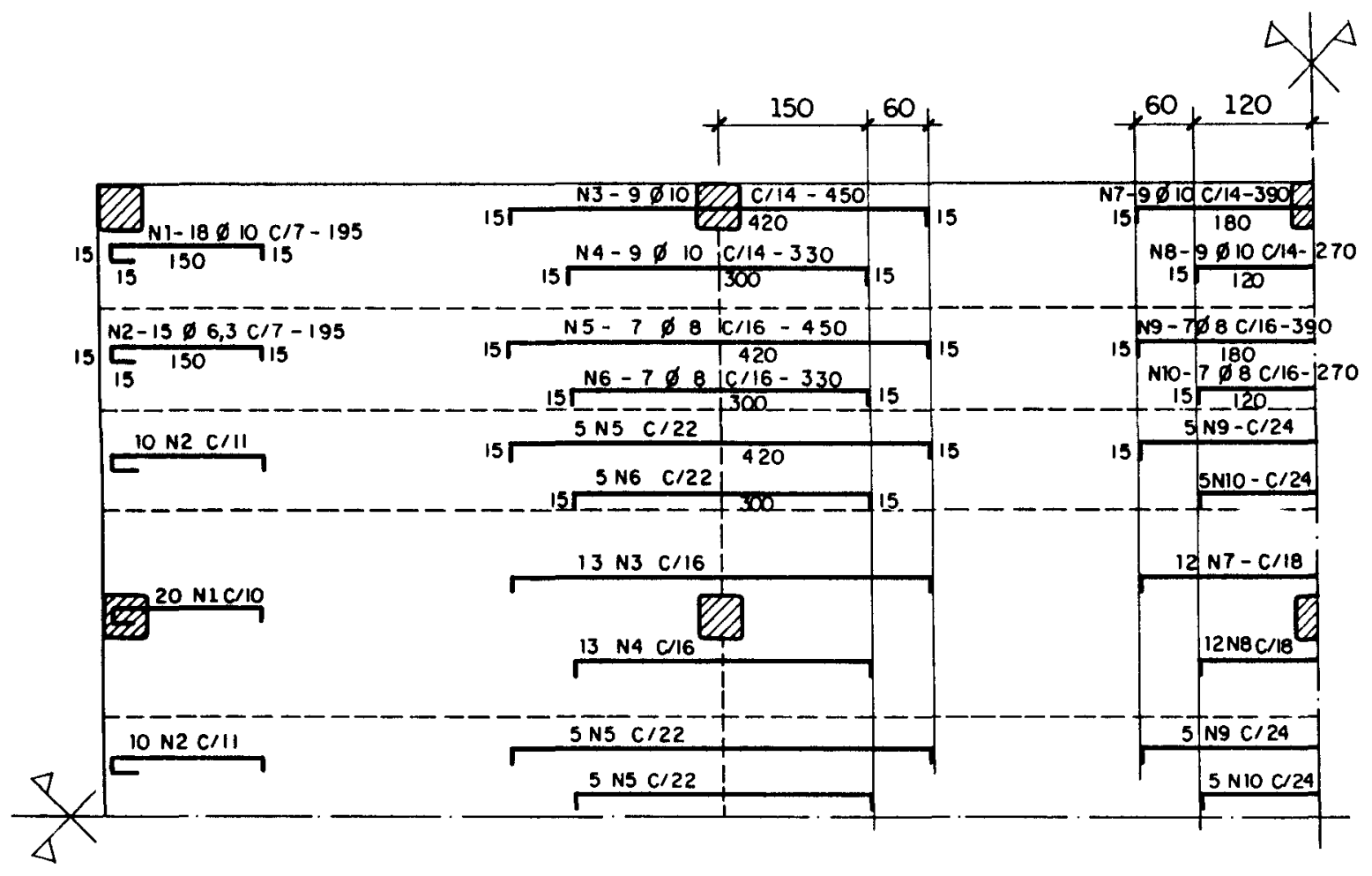

FIGURA 5.28- Detalhamento da armadura negativa (direção $x$ ).

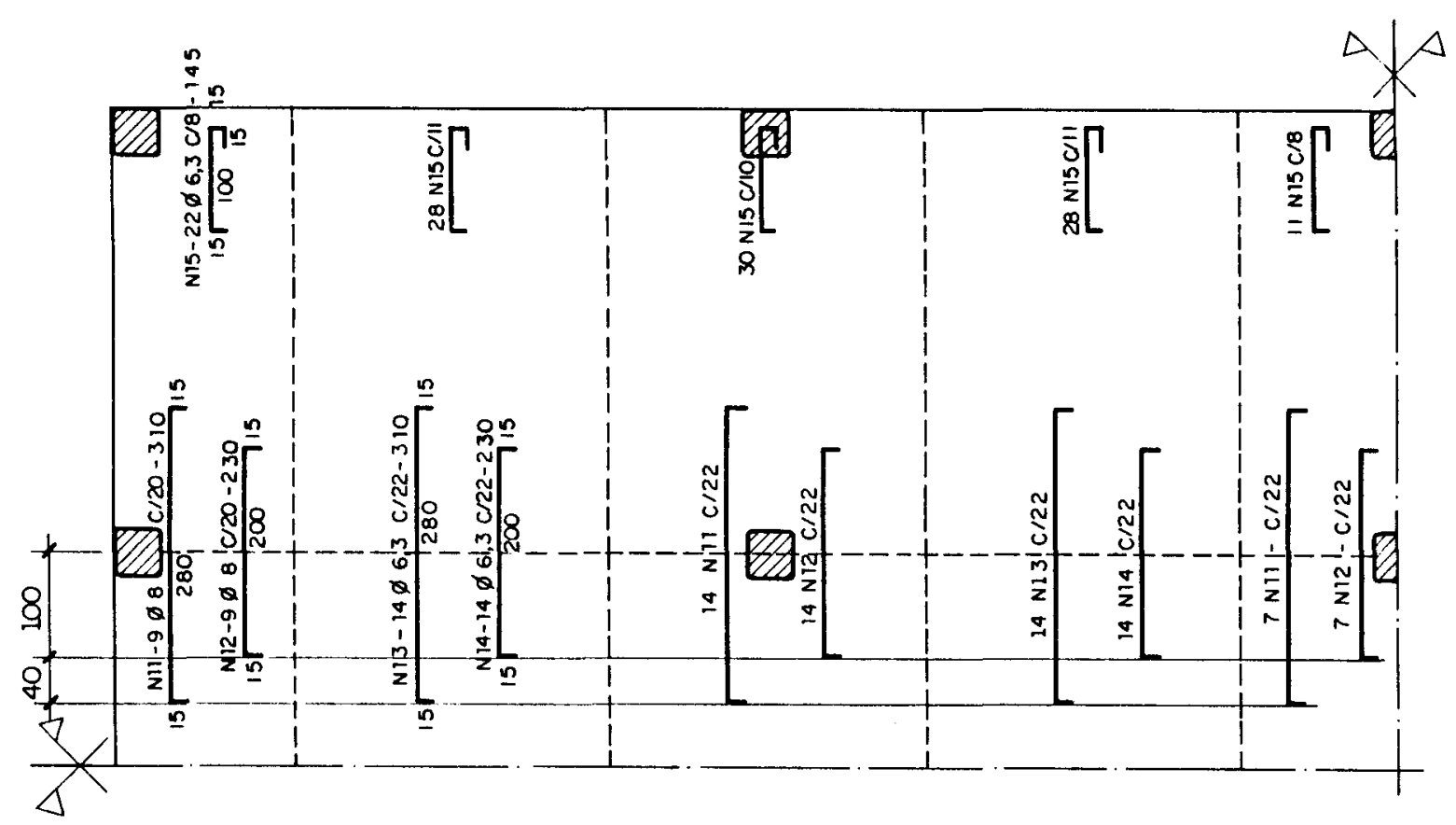

FIGURA 5.29- Detalhamento da armadura negativa (direção y). 
TABELA 5.29- Resumo da armadura positiva.

\begin{tabular}{|c|c|c|c|c|}
\hline $\mathbf{N}$ & $\begin{array}{c}\phi \\
(\mathbf{m m})\end{array}$ & Quant. & $\begin{array}{c}\text { Comp. } \\
(\mathbf{m})\end{array}$ & $\begin{array}{c}\text { Comp. tot. } \\
(\mathbf{m})\end{array}$ \\
\hline 1 & 8 & 60 & 6,55 & 393,0 \\
\hline 2 & 8 & 48 & 5,60 & 268,8 \\
\hline 3 & 6,3 & 108 & 6,55 & 707,4 \\
\hline 4 & 6,3 & 96 & 5,60 & 537,6 \\
\hline 5 & 8 & 44 & 6,40 & 281,6 \\
\hline 6 & 8 & 32 & 4,20 & 134,4 \\
\hline 7 & 6,3 & 92 & 6,40 & 588,8 \\
\hline 8 & 6,3 & 80 & 4,20 & 336,0 \\
\hline 9 & 6,3 & 219 & 4,40 & 963,6 \\
\hline 10 & 6,3 & 438 & 4,55 & 1992,9 \\
\hline
\end{tabular}

TABELA- 5.30- Consumo de aço da armadura positiva.

\begin{tabular}{|c|c|c|c|}
\hline Aço & $\phi(\mathrm{mm})$ & Comp. $(\mathrm{m})$ & Massa $(\mathrm{kg})$ \\
\hline \multirow{2}{*}{ CA-50 A } & 6.3 & 5126,3 & 1282 \\
\cline { 2 - 4 } & 8 & 1077,8 & 431 \\
\hline \multicolumn{3}{|c|}{ Massa Total (kg) } & 1713 \\
\hline
\end{tabular}


TABELA 5.30- Resumo da armadura negativa.

\begin{tabular}{|c|c|c|c|c|}
\hline $\mathbf{N}$ & $\begin{array}{c}\phi \\
(\mathrm{mm})\end{array}$ & Quant. & $\begin{array}{c}\text { Comp. } \\
\text { (m) }\end{array}$ & $\begin{array}{c}\text { Comp. Tot. } \\
\text { (m) }\end{array}$ \\
\hline 1 & 10 & 152 & 1,95 & 296,4 \\
\hline 2 & 6,3 & 140 & 1,95 & 273,0 \\
\hline 3 & 10 & 88 & 4,50 & 396,0 \\
\hline 4 & 10 & 88 & 3,30 & 290,4 \\
\hline 5 & 8 & 68 & 4,50 & 306,0 \\
\hline 6 & 8 & 68 & 3,30 & 224,4 \\
\hline 7 & 10 & 42 & 3,90 & 163,8 \\
\hline 8 & 10 & 42 & 2,70 & 113,4 \\
\hline 9 & 8 & 34 & 3,90 & 132,6 \\
\hline 10 & 8 & 34 & 2,70 & 91,8 \\
\hline 11 & 8 & 120 & 3,10 & 372,0 \\
\hline 12 & 8 & 120 & 2,30 & 276,0 \\
\hline 13 & 6,3 & 112 & 3,10 & 347,2 \\
\hline 14 & 6,3 & 112 & 2,30 & 257,6 \\
\hline 15 & 6,3 & 476 & 1,45 & 690,2 \\
\hline
\end{tabular}

TABELA 5.32- Consumo de aço da armadura negativa.

\begin{tabular}{|c|c|c|c|}
\hline Aço & $\phi(\mathbf{m m})$ & Comp. $(\mathrm{m})$ & Massa $(\mathrm{kg})$ \\
\hline \multirow{3}{*}{ CA-50 A } & 6.3 & 1568,0 & 392 \\
\cline { 2 - 4 } & 8 & 1402,8 & 561 \\
\cline { 2 - 4 } & 10 & 1260,0 & 794 \\
\hline \multicolumn{3}{|c|}{ Massa Total (kg) } \\
\hline
\end{tabular}




\subsection{8- Cálculo dos Momentos de Plastificação e das Áreas de Aço}

Para o cálculo dos momentos de plastificação, assim como no exemplo 1 , foram utilizadas as equações apresentadas no capitulo 4. Para todos os painéis, os momentos que predominaram foram os obtidos verificando-se o colapso total do painel. Os momentos de plastificação calculados, bem como suas áreas de aço, encontram-se nas nas tabelas 5.33, 5.34 e 5.35 .

Os momentos negativos médios, provenientes do cálculo elástico, que servem de base para o cálculo dos momentos de plastificação, são apresentados na figura 5.30 .

Na figura 5.31, mostra-se a denominação dos painéis do pavimento.

-) MOMENTOS NEGATIVOS ELÁSTICOS MÉdIOS (DIRECĀO $x$ )

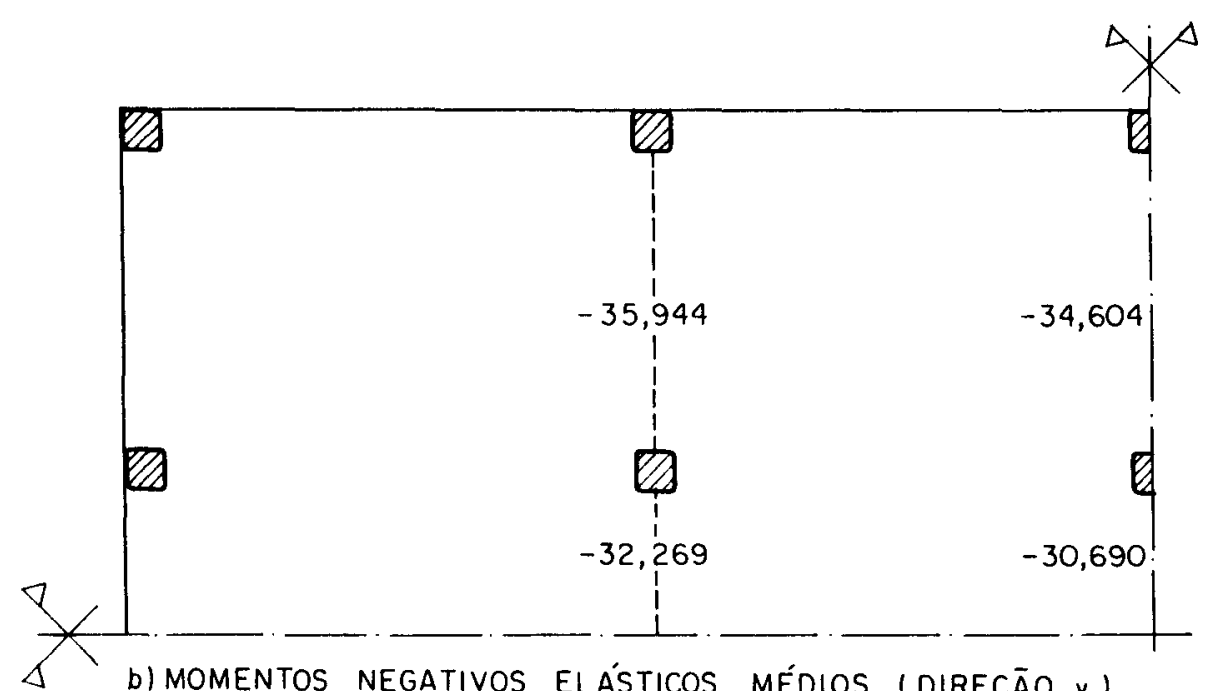

b) MOMENTOS NEGATIVOS ELÁSTICOS MÉDIOS (DIRECĀO Y)

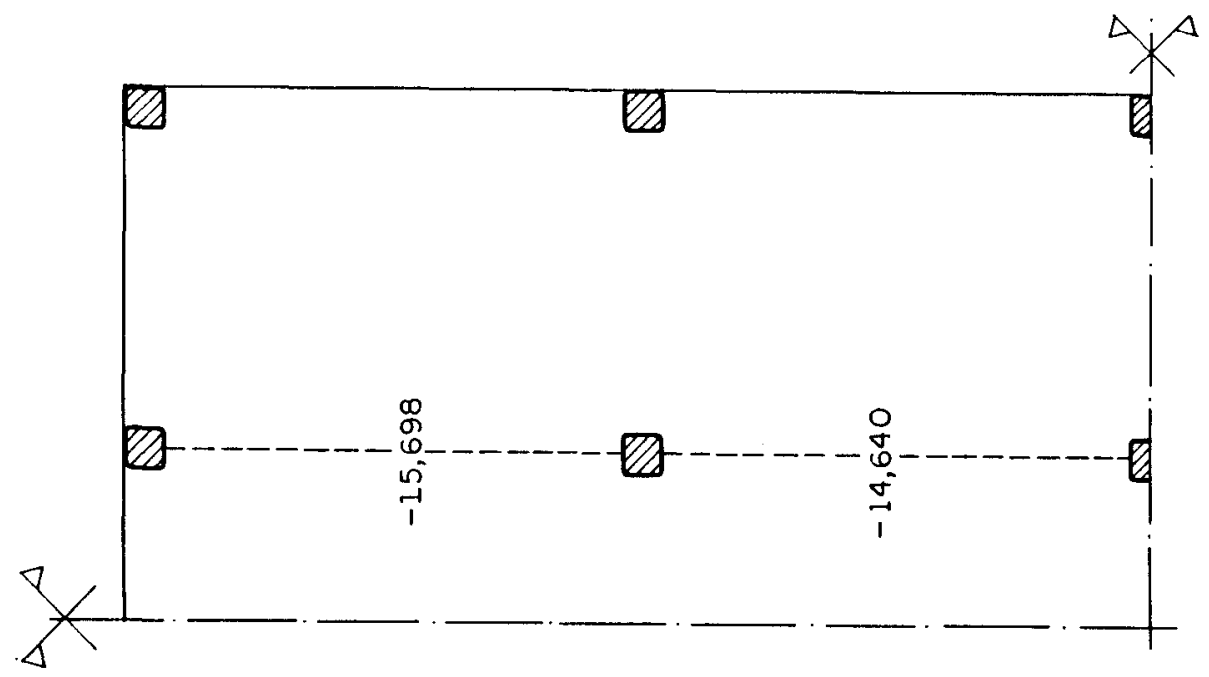

FIGURA 5.30-Momentos negativos elásticos médios $(\mathrm{kNm} / \mathrm{m})$. 


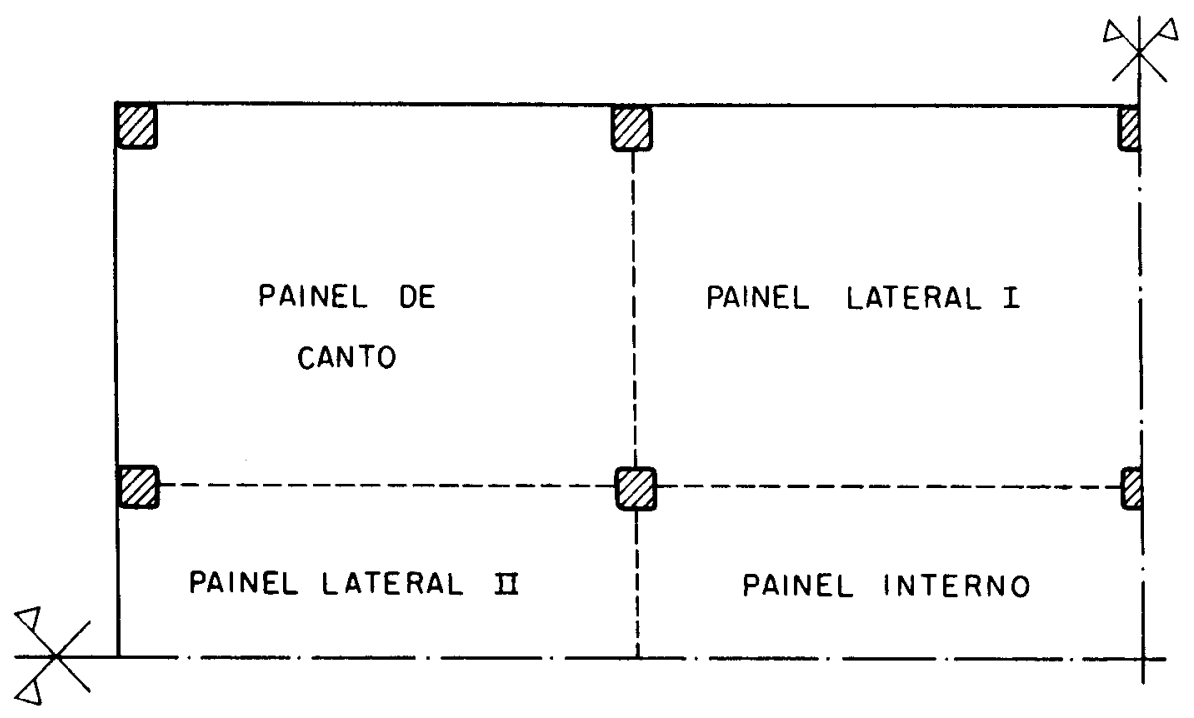

FIGURA 5.31- Denominação dos painéis do pavimento.

TABELA 5.33- Momentos de plastificação positivos e suas áreas de aço.

\begin{tabular}{|c|c|c|c|c|c|c|c|}
\hline Painel & $\mathbf{R}$ & $\begin{array}{c}\mathrm{m} \\
(\mathrm{kNm} / \mathrm{m}) \\
1^{\mathrm{a}} \mathrm{cam} .\end{array}$ & $\begin{array}{c}A_{s} \\
\left(\mathrm{~cm}^{2} / \mathrm{m}\right)\end{array}$ & Armad. & $\begin{array}{c}\mathrm{m} \\
(\mathrm{kNm} / \mathrm{m}) \\
2^{\mathrm{a}} \mathrm{cam}\end{array}$ & $\begin{array}{c}A_{s} \\
\left(\mathrm{~cm}^{2} / \mathrm{m}\right)\end{array}$ & Armad. \\
\hline \multirow{3}{*}{ Canto } & 1,0 & 30,120 & 6,758 & $\phi 8 c .7$ & 13,499 & 3,065 & $\phi 6,3 \mathrm{c} .10$ \\
\hline & 1,1 & 31,452 & 7,057 & $\phi 8 c .7$ & 14,082 & 3,197 & $\phi 6,3 c .9$ \\
\hline & 1,2 & 32,452 & 7,310 & $\phi 10 c .10$ & 14,578 & 3,310 & $\phi 6,3 c .9$ \\
\hline \multirow{3}{*}{$\begin{array}{c}\text { Lateral } \\
1\end{array}$} & 1,0 & 13,930 & 3,000 & $\phi 6,3 c .10$ & 11,078 & $2,700^{*}$ & $\phi 6,3 c .11$ \\
\hline & 1,1 & 14,483 & 3,119 & $\phi 6,3 \mathrm{c} .9$ & 14,285 & 3,243 & $\phi 6,3 c .9$ \\
\hline & 1,2 & 14,952 & 3,220 & $\phi 6,3 c .9$ & 16,957 & 3,850 & $\phi 6,3 c .8$ \\
\hline \multirow{3}{*}{$\begin{array}{c}\text { Lateral } \\
\text { II }\end{array}$} & 1,0 & 31,620 & 7,094 & $\phi 8 c .7$ & 4,902 & $2,700^{\star}$ & $\phi 6,3 c .11$ \\
\hline & 1,1 & 32,843 & 7,369 & $\phi 10 \mathrm{c} .10$ & 6,329 & $2,700^{\star}$ & $\phi 6,3 c .11$ \\
\hline & 1,2 & 33,880 & 7,601 & $\phi 10 c .10$ & 7,518 & $2,700^{\star}$ & $\phi 6,3 c .11$ \\
\hline \multirow{3}{*}{ Interno } & 1,0 & 14,874 & 3,204 & $\phi 6,3 \mathrm{c} .9$ & 5,960 & $2,700^{\star}$ & $\phi 6,3 c .11$ \\
\hline & 1,1 & 17,735 & 3,820 & $\phi 6,3 \mathrm{c} .8$ & 7,291 & $2,700^{\star}$ & $\phi 6,3 c .11$ \\
\hline & 1,2 & 20,119 & 4,333 & $\phi 6,3 c .7$ & 8,400 & $2,700^{*}$ & $\phi 6,3 c .11$ \\
\hline
\end{tabular}

* Area mínima de aço. 
TABELA 5.34- Momentos de plastificação negativos, na direção $x$, e suas áreas de aço.

\begin{tabular}{|c|c|c|c|c|c|c|c|}
\hline \multirow{2}{*}{$\mathbf{R}$} & \multicolumn{3}{|c|}{ Momento $(\mathrm{kNm} / \mathrm{m})$} & \multicolumn{2}{|c|}{$A_{s}\left(\mathrm{~cm}^{2} / \mathrm{m}\right)$} & \multicolumn{2}{|c|}{ Armadura } \\
\hline & $m_{1}$ & $1,5 m_{1}$ & $0,5 m_{i}$ & $1,5 m_{1}$ & $0,5 m_{1}$ & $1,5 m_{1}$ & $0,5 m_{1}$ \\
\hline 1,0 & 35,944 & 53,916 & 17,972 & 11,630 & 3,578 & $\phi 12,5 \mathrm{c} .10$ & $\phi 6,3 c .8$ \\
\hline 1,1 & 32,676 & 49,014 & 16,338 & 10,573 & 3,253 & $\phi 10 \mathrm{c} .7$ & $\phi 6,3 c .9$ \\
\hline 1,2 & 29,953 & 44,930 & 14,977 & 9,691 & 2,982 & $\phi 10 \mathrm{c} .8$ & $\phi 6,3 c .10$ \\
\hline 1,0 & 34,604 & 51,906 & 17,302 & 11,196 & 3,445 & $\phi 10 c .7$ & $\phi 6,3 c .9$ \\
\hline 1,1 & 31,458 & 47,187 & 15,729 & 10,178 & 3,132 & $\phi 10 \mathrm{c} .7$ & $\phi 6,3 c .9$ \\
\hline 1,2 & 28,837 & 43,256 & 14,419 & 8,972 & 2,871 & $\phi 10 \mathrm{c} .8$ & $\phi 6,3 c .10$ \\
\hline 1,0 & 32,269 & 48,403 & 16,134 & 10,441 & 3,213 & $\phi 10 \mathrm{c} .7$ & $\phi 6,3 c .9$ \\
\hline 1,1 & 29,335 & 44,003 & 14,668 & 9,492 & 2,920 & $\phi 10 c .8$ & $\phi 6,3 c .10$ \\
\hline 1,2 & 26,891 & 40,337 & 13,446 & 8,366 & $2,700^{\star}$ & $\phi 10 c .9$ & $\phi 6,3 c .11$ \\
\hline 1,0 & 30,690 & 46,035 & 15,345 & 9,930 & 3,055 & $\phi 10 c .7$ & $\phi 6,3 c .10$ \\
\hline 1,1 & 27,900 & 41,850 & 13,950 & 8,680 & 2,778 & $\phi 10 c .9$ & $\phi 6,3 c .11$ \\
\hline 1,2 & 25,575 & 38,363 & 12,788 & 7,957 & $2,700^{\star}$ & $\phi 10 \mathrm{c} .9$ & $\phi 6,3 c .11$ \\
\hline
\end{tabular}


TABELA 5.35- Momentos de plastificação negativos, na direção y, e suas áreas de aço.

\begin{tabular}{|c|c|c|c|c|c|c|c|}
\hline \multirow{2}{*}{$\mathbf{R}$} & \multicolumn{3}{|c|}{ Momento $(\mathrm{kNm} / \mathrm{m})$} & \multicolumn{2}{|c|}{$A_{s}\left(\mathrm{~cm}^{2} / \mathrm{m}\right)$} & \multicolumn{2}{|c|}{ Armadura } \\
\hline & $\mathbf{m}_{1}$ & $1,5 m_{1}$ & $0,5 m_{1}$ & $1,5 m_{1}$ & $0,5 m_{1}$ & $1,5 m_{1}$ & $0,5 m_{1}$ \\
\hline 1,0 & 15,698 & 23,547 & 7,849 & 4,688 & $2,700^{*}$ & $\phi 8$ c. 10 & $\phi 6,3 c .11$ \\
\hline 1,1 & 14,271 & 21,407 & 7,136 & 4,262 & $2,700^{\star}$ & $\phi 8$ c. 11 & $\phi 6,3 c .11$ \\
\hline 1,2 & 13,082 & 19,623 & 6,541 & 3,907 & $2,700^{*}$ & $\phi 6,3 c .7$ & $\phi 6,3 c .11$ \\
\hline 1,0 & 14,640 & 21,960 & 7,320 & 4,372 & $2,700^{*}$ & $\phi 6,3 c .7$ & $\phi 6,3 c .11$ \\
\hline 1,1 & 13,309 & 19,964 & 6,655 & 3,975 & $2,700^{*}$ & $\phi 6,3 c .7$ & $\phi 6,3 \mathrm{c} .11$ \\
\hline 1,2 & 12,200 & 18,300 & 6,100 & 3,644 & $2,700^{*}$ & $\phi 6,3 c .8$ & $\phi 6,3 c .11$ \\
\hline
\end{tabular}

\subsection{9- Detalhamento das Armaduras de Flexăo}

O detalhamento das armaduras de flexão, referente aos momentos de plastificação, é feito da mesma maneira que no exemplo 1. Nas figuras 5.32 e 5.33 , encontram-se 0 detalhamento da armadura positiva, para a direção $x$ e $y$, respectivamente. E nas figuras 5.34 e 5.35, o detalhamento da armadura negativa.

Os resumos dos detalhamentos das armaduras positiva e negativa são apresentados nas tabelas 5.36 e 5.38 , respectivamente.

Nas tabelas 5.37 e 5.39 , encontram-se os consumos de aço das armaduras positiva e negativa, respectivamente. 


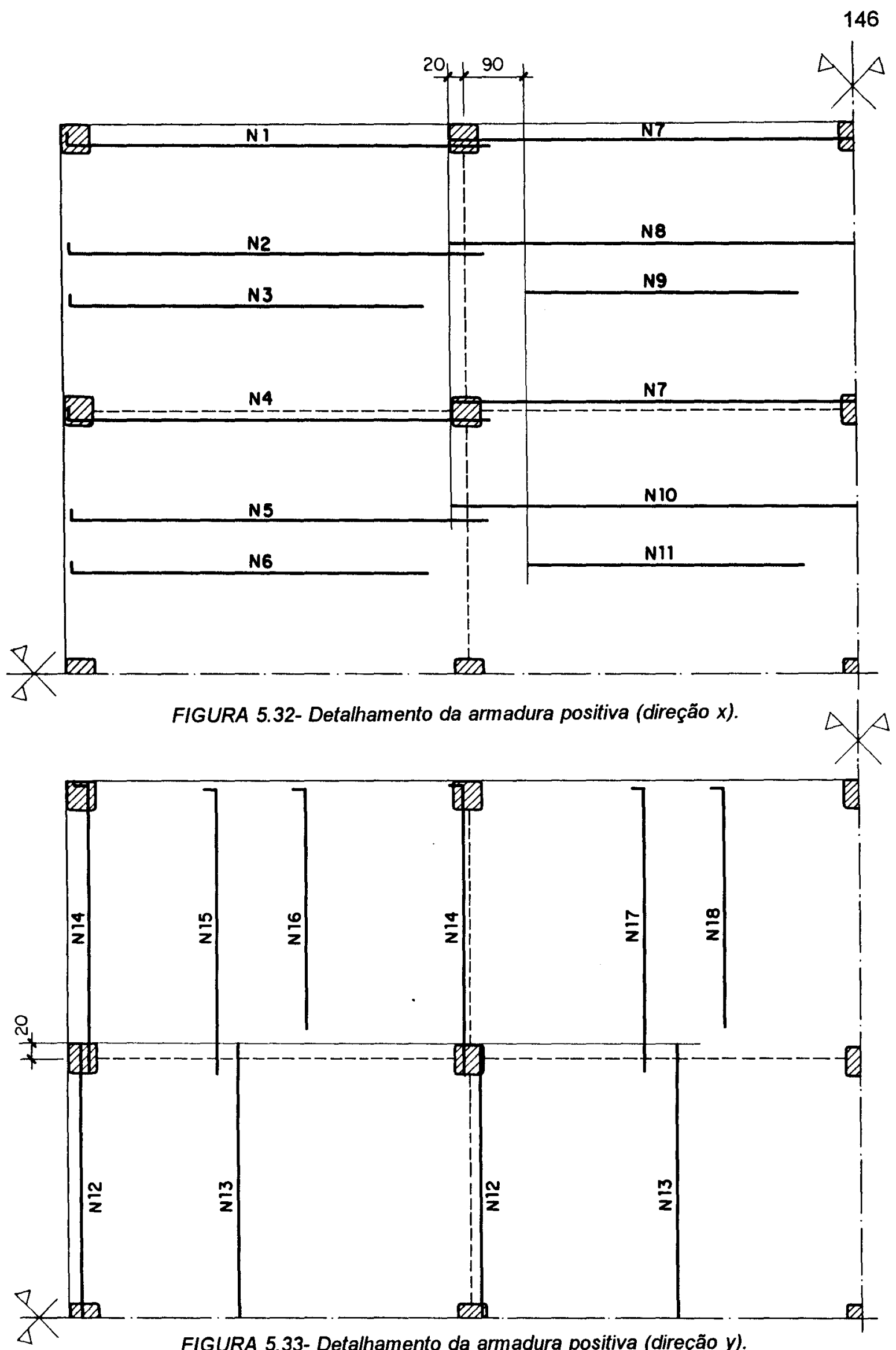



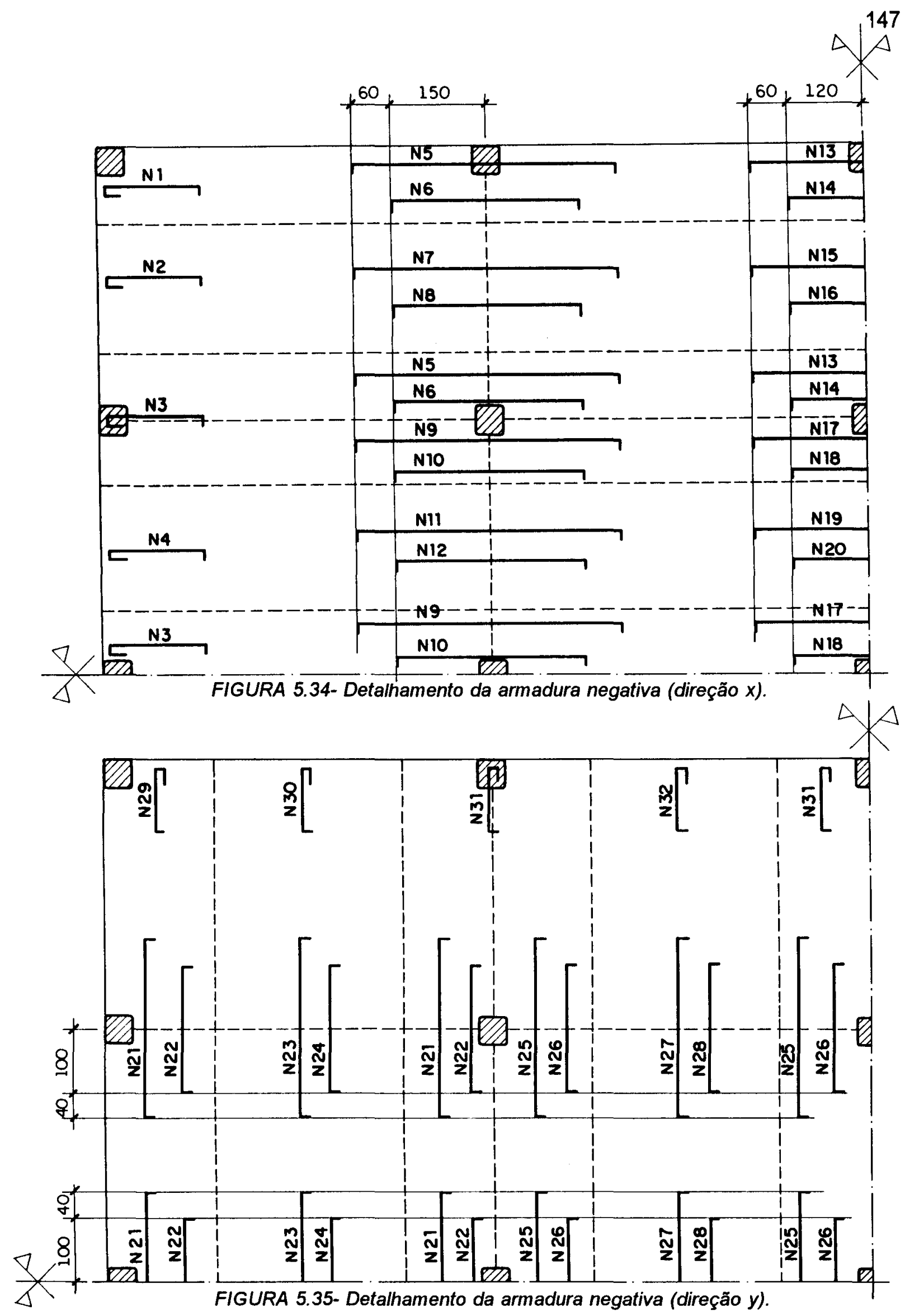
TABELA 5.36- Resumo da armadura positiva.

\begin{tabular}{|c|c|c|c|c|c|c|}
\hline $\mathbf{N}$ & $\mathbf{R}$ & $\begin{array}{c}\phi \\
(\mathrm{mm})\end{array}$ & $\begin{array}{c}s \\
(\mathrm{~cm})\end{array}$ & Quant. & $\begin{array}{c}\text { Comp. } \\
\text { (m) }\end{array}$ & $\begin{array}{l}\text { Comp. tot. } \\
\text { (m) }\end{array}$ \\
\hline 1 & $\begin{array}{l}1,0 \\
1,1 \\
1,2\end{array}$ & $\begin{array}{c}8 \\
8 \\
10\end{array}$ & $\begin{array}{l}- \\
- \\
-\end{array}$ & $\begin{array}{l}12 \\
12 \\
12\end{array}$ & $\begin{array}{l}6,55 \\
6,55 \\
6,55\end{array}$ & $\begin{array}{l}78,6 \\
78,6 \\
78,6\end{array}$ \\
\hline 2 & $\begin{array}{l}1,0 \\
1,1 \\
1,2\end{array}$ & $\begin{array}{c}8 \\
8 \\
10\end{array}$ & $\begin{array}{l}14 \\
14 \\
20\end{array}$ & $\begin{array}{c}104 \\
104 \\
72\end{array}$ & $\begin{array}{l}6,55 \\
6,55 \\
6,55\end{array}$ & $\begin{array}{l}681,2 \\
681,2 \\
471,6\end{array}$ \\
\hline 3 & $\begin{array}{l}1,0 \\
1,1 \\
1,2\end{array}$ & $\begin{array}{c}8 \\
8 \\
10\end{array}$ & $\begin{array}{l}14 \\
14 \\
20\end{array}$ & $\begin{array}{c}104 \\
104 \\
72\end{array}$ & $\begin{array}{l}5,60 \\
5,60 \\
5,60\end{array}$ & $\begin{array}{l}582,4 \\
582,4 \\
403,2\end{array}$ \\
\hline 4 & $\begin{array}{l}1,0 \\
1,1 \\
1,2\end{array}$ & $\begin{array}{c}8 \\
10 \\
10\end{array}$ & $\begin{array}{l}- \\
- \\
-\end{array}$ & $\begin{array}{l}12 \\
12 \\
12\end{array}$ & $\begin{array}{l}6,55 \\
6,55 \\
6,55\end{array}$ & $\begin{array}{l}78,6 \\
78,6 \\
78,6\end{array}$ \\
\hline 5 & $\begin{array}{l}1,0 \\
1,1 \\
1,2\end{array}$ & $\begin{array}{c}8 \\
10 \\
10\end{array}$ & $\begin{array}{l}14 \\
20 \\
20\end{array}$ & $\begin{array}{l}52 \\
36 \\
36\end{array}$ & $\begin{array}{l}6,55 \\
6,55 \\
6,55\end{array}$ & $\begin{array}{l}340,6 \\
235,8 \\
235,8\end{array}$ \\
\hline 6 & $\begin{array}{l}1,0 \\
1,1 \\
1,2\end{array}$ & $\begin{array}{c}8 \\
10 \\
10\end{array}$ & $\begin{array}{l}14 \\
20 \\
20\end{array}$ & $\begin{array}{l}52 \\
36 \\
36\end{array}$ & $\begin{array}{l}5,60 \\
5,60 \\
5,60\end{array}$ & $\begin{array}{l}291,2 \\
201,6 \\
201,6\end{array}$ \\
\hline 7 & $\begin{array}{l}1,0 \\
1,1 \\
1,2\end{array}$ & $\begin{array}{l}6,3 \\
6,3 \\
6,3\end{array}$ & $\begin{array}{l}- \\
- \\
-\end{array}$ & $\begin{array}{l}24 \\
24 \\
24\end{array}$ & $\begin{array}{l}6,40 \\
6,40 \\
6,40\end{array}$ & $\begin{array}{c}153,6 \\
153,6 \\
153,6\end{array}$ \\
\hline 8 & $\begin{array}{l}1,0 \\
1,1 \\
1,2\end{array}$ & $\begin{array}{l}6,3 \\
6,3 \\
6,3\end{array}$ & $\begin{array}{l}11 \\
18 \\
16\end{array}$ & $\begin{array}{c}132 \\
80 \\
92\end{array}$ & $\begin{array}{l}6,40 \\
6,40 \\
6,40\end{array}$ & $\begin{array}{l}844,8 \\
512,0 \\
588,8\end{array}$ \\
\hline 9 & $\begin{array}{l}1,0 \\
1,1 \\
1,2\end{array}$ & $\begin{array}{c}- \\
6,3 \\
6,3\end{array}$ & $\begin{array}{c}- \\
18 \\
16\end{array}$ & $\begin{array}{c}- \\
80 \\
92\end{array}$ & $\begin{array}{c}- \\
4,20 \\
4,20\end{array}$ & $\begin{array}{c}- \\
336,0 \\
386,4\end{array}$ \\
\hline
\end{tabular}


TABELA 5.36- Resumo da armadura positiva (continuação).

\begin{tabular}{|c|c|c|c|c|c|c|}
\hline $\mathbf{N}$ & $\mathbf{R}$ & $\begin{array}{c}\phi \\
(\mathrm{mm})\end{array}$ & $\begin{array}{c}\mathrm{s} \\
(\mathrm{cm})\end{array}$ & Quant. & $\begin{array}{l}\text { Comp. } \\
\text { (m) }\end{array}$ & $\begin{array}{l}\text { Comp. tot. } \\
\text { (m) }\end{array}$ \\
\hline 10 & $\begin{array}{l}1,0 \\
1,1 \\
1,2\end{array}$ & $\begin{array}{l}6,3 \\
6,3 \\
6,3\end{array}$ & $\begin{array}{l}18 \\
16 \\
14\end{array}$ & $\begin{array}{l}40 \\
46 \\
52\end{array}$ & $\begin{array}{l}6,40 \\
6,40 \\
6,40\end{array}$ & $\begin{array}{l}256,0 \\
294,4 \\
332,8\end{array}$ \\
\hline 11 & $\begin{array}{l}1,0 \\
1,1 \\
1,2\end{array}$ & $\begin{array}{l}6,3 \\
6,3 \\
6,3\end{array}$ & $\begin{array}{l}18 \\
16 \\
14\end{array}$ & $\begin{array}{l}40 \\
46 \\
52\end{array}$ & $\begin{array}{l}4,20 \\
4,20 \\
4,20\end{array}$ & $\begin{array}{l}168,0 \\
193,2 \\
218,4\end{array}$ \\
\hline 12 & $\begin{array}{l}1,0 \\
1,1 \\
1,2\end{array}$ & $\begin{array}{l}6,3 \\
6,3 \\
6,3\end{array}$ & $\begin{array}{l}- \\
- \\
-\end{array}$ & $\begin{array}{l}15 \\
15 \\
15\end{array}$ & $\begin{array}{l}4,40 \\
4,40 \\
4,40\end{array}$ & $\begin{array}{l}66,0 \\
66,0 \\
66,0\end{array}$ \\
\hline 13 & $\begin{array}{l}1,0 \\
1,1 \\
1,2\end{array}$ & $\begin{array}{l}6,3 \\
6,3 \\
6,3\end{array}$ & $\begin{array}{l}11 \\
11 \\
11\end{array}$ & $\begin{array}{l}204 \\
204 \\
204\end{array}$ & $\begin{array}{l}4,40 \\
4,40 \\
4,40\end{array}$ & $\begin{array}{l}897,6 \\
897,6 \\
897,6\end{array}$ \\
\hline 14 & $\begin{array}{l}1,0 \\
1,1 \\
1,2\end{array}$ & $\begin{array}{l}6,3 \\
6,3 \\
6,3\end{array}$ & $\begin{array}{l}- \\
-\end{array}$ & $\begin{array}{l}30 \\
30 \\
30\end{array}$ & $\begin{array}{l}4,55 \\
4,55 \\
4,55\end{array}$ & $\begin{array}{l}136,5 \\
136,5 \\
136,5\end{array}$ \\
\hline 15 & $\begin{array}{l}1,0 \\
1,1 \\
1,2\end{array}$ & $\begin{array}{l}6,3 \\
6,3 \\
6,3\end{array}$ & $\begin{array}{l}20 \\
18 \\
18\end{array}$ & $\begin{array}{l}112 \\
128 \\
128\end{array}$ & $\begin{array}{l}4,55 \\
4,55 \\
4,55\end{array}$ & $\begin{array}{l}509,6 \\
582,4 \\
582,4\end{array}$ \\
\hline 16 & $\begin{array}{l}1,0 \\
1,1 \\
1,2\end{array}$ & $\begin{array}{l}6,3 \\
6,3 \\
6,3\end{array}$ & $\begin{array}{l}20 \\
18 \\
18\end{array}$ & $\begin{array}{l}112 \\
128 \\
128\end{array}$ & $\begin{array}{l}3,85 \\
3,85 \\
3,85\end{array}$ & $\begin{array}{l}431,2 \\
492,8 \\
492,8\end{array}$ \\
\hline 17 & $\begin{array}{l}1,0 \\
1,1 \\
1,2\end{array}$ & $\begin{array}{l}6,3 \\
6,3 \\
6,3\end{array}$ & $\begin{array}{l}20 \\
18 \\
18\end{array}$ & $\begin{array}{l}112 \\
128 \\
128\end{array}$ & $\begin{array}{l}4,55 \\
4,55 \\
4,55\end{array}$ & $\begin{array}{l}509,6 \\
582,4 \\
582,4\end{array}$ \\
\hline 18 & $\begin{array}{l}1,0 \\
1,1 \\
1,2\end{array}$ & $\begin{array}{l}6,3 \\
6,3 \\
6,3\end{array}$ & $\begin{array}{l}20 \\
18 \\
18\end{array}$ & $\begin{array}{l}112 \\
128 \\
128\end{array}$ & $\begin{array}{l}3,85 \\
3,85 \\
3,85\end{array}$ & $\begin{array}{l}431,2 \\
492,8 \\
492,8\end{array}$ \\
\hline
\end{tabular}


TABELA 5.37- Consumo de aço da armadura positiva.

\begin{tabular}{|c|c|c|c|c|}
\hline & $\phi(\mathrm{mm})$ & $R=1,0$ & $R=1,1$ & $R=1,2$ \\
\hline \multirow{2}{*}{ Comp. Total } & 6,3 & 4404,1 & 4739,7 & 4930,5 \\
$(\mathrm{~m})$ & 8 & 2052,6 & 1342,2 & - \\
& 10 & - & 516,0 & 1469,4 \\
\hline Massa & 6,3 & 1101 & 1185 & 1233 \\
(kg) & 8 & 821 & 537 & - \\
& 10 & - & 325 & 926 \\
\hline \multicolumn{2}{|r|}{ Massa total (kg) } & 1922 & 2047 & 2159 \\
\hline
\end{tabular}

TABELA 5.38- Resumo da armadura negativa.

\begin{tabular}{|c|c|c|c|c|c|c|}
\hline $\mathbf{N}$ & $\mathbf{R}$ & $\begin{array}{c}\phi \\
(\mathbf{m ~ m})\end{array}$ & $\begin{array}{c}\mathbf{s} \\
(\mathbf{c m})\end{array}$ & Quant. & $\begin{array}{c}\text { Comp. } \\
(\mathbf{m})\end{array}$ & $\begin{array}{c}\text { Comp. tot. } \\
(\mathbf{m})\end{array}$ \\
\hline \multirow{3}{*}{$\mathbf{1}$} & 1,0 & 10 & 7 & 72 & 1,95 & 140,4 \\
& 1,1 & 10 & 9 & 56 & 1,95 & 109,2 \\
& 1,2 & 10 & 9 & 56 & 1,95 & 109,2 \\
\hline \multirow{3}{*}{2} & 1,0 & 6,3 & 11 & 76 & 1,95 & 148,2 \\
& 1,1 & 6,3 & 11 & 76 & 1,95 & 148,2 \\
& 1,2 & 6,3 & 11 & 76 & 1,95 & 148,2 \\
\hline \multirow{3}{*}{3} & 1,0 & 10 & 10 & 80 & 1,95 & 156,0 \\
& 1,1 & 10 & 11 & 76 & 1,95 & 148,2 \\
& 1,2 & 8 & 7 & 116 & 1,95 & 226,2 \\
\hline \multirow{3}{*}{4} & 1,0 & 6,3 & 11 & 76 & 1,95 & 148,2 \\
& 1,1 & 6,3 & 11 & 76 & 1,95 & 148,2 \\
& 1,2 & 6,3 & 11 & 76 & 1,95 & 148,2 \\
\hline \multirow{3}{*}{5} & 1,0 & 12,5 & 20 & 44 & 4,50 & 198,0 \\
& 1,1 & 10 & 14 & 68 & 4,50 & 306,0 \\
& 1,2 & 10 & 16 & 60 & 4,50 & 270,0 \\
\hline \multirow{3}{*}{1,2} & & & & & \\
\hline
\end{tabular}


TABELA 5.38- Resumo da armadura negativa (continuação).

\begin{tabular}{|c|c|c|c|c|c|c|}
\hline $\mathbf{N}$ & $\mathbf{R}$ & $\begin{array}{c}\phi \\
(\mathrm{mm})\end{array}$ & $\begin{array}{c}\mathrm{s} \\
(\mathrm{cm})\end{array}$ & Quant. & $\begin{array}{c}\text { Comp. } \\
\text { (m) }\end{array}$ & $\begin{array}{c}\text { Comp. tot. } \\
\text { (m) }\end{array}$ \\
\hline \multirow{3}{*}{6} & 1,0 & 12,5 & 20 & 44 & 3,30 & 145,2 \\
\hline & 1,1 & 10 & 14 & 68 & 3,30 & 224,4 \\
\hline & 1,2 & 10 & 16 & 60 & 3,30 & 198,0 \\
\hline \multirow{3}{*}{7} & 1,0 & 6,3 & 16 & 52 & 4,50 & 234,0 \\
\hline & 1,1 & 6,3 & 18 & 48 & 4,50 & 216,6 \\
\hline & 1,2 & 6,3 & 20 & 40 & 4,50 & 180,0 \\
\hline \multirow{3}{*}{8} & 1,0 & 6,3 & 16 & 52 & 3,30 & 171,6 \\
\hline & 1,1 & 6,3 & 18 & 48 & 3,30 & 158,4 \\
\hline & 1,2 & 6,3 & 20 & 40 & 3,30 & 132,0 \\
\hline \multirow{3}{*}{9} & 1,0 & 10 & 14 & 32 & 4,50 & 144,0 \\
\hline & 1,1 & 10 & 16 & 28 & 4,50 & 126,0 \\
\hline & 1,2 & 10 & 18 & 24 & 4,50 & 108,0 \\
\hline \multirow{3}{*}{10} & 1,0 & 10 & 14 & 32 & 3,30 & 105,6 \\
\hline & 1,1 & 10 & 16 & 28 & 3,30 & 92,4 \\
\hline & 1,2 & 10 & 18 & 24 & 3,30 & 79,2 \\
\hline \multirow{3}{*}{11} & 1,0 & 6,3 & 18 & 24 & 4,50 & 108,0 \\
\hline & 1,1 & 6,3 & 20 & 20 & 4,50 & 90,0 \\
\hline & 1,2 & 6,3 & 22 & 20 & 4,50 & 90,0 \\
\hline \multirow{3}{*}{12} & 1,0 & 6,3 & 18 & 24 & 3,30 & 79,2 \\
\hline & 1,1 & 6,3 & 20 & 20 & 3,30 & 66,0 \\
\hline & 1,2 & 6,3 & 22 & 20 & 3,30 & 66,0 \\
\hline \multirow{3}{*}{13} & 1,0 & 10 & 14 & 34 & 3,90 & 132,6 \\
\hline & 1,1 & 10 & 14 & 34 & 3,90 & 132,6 \\
\hline & 1,2 & 10 & 16 & 30 & 3,90 & 117,0 \\
\hline \multirow{3}{*}{14} & 1,0 & 10 & 14 & 34 & 2,70 & 91,8 \\
\hline & 1,1 & 10 & 14 & 34 & 2,70 & 91,8 \\
\hline & 1,2 & 10 & 16 & 30 & 2,70 & 81,0 \\
\hline
\end{tabular}


TABELA 5.38- Resumo da armadura negativa (continuação).

\begin{tabular}{|c|c|c|c|c|c|c|}
\hline $\mathbf{N}$ & $\mathbf{R}$ & $\begin{array}{c}\phi \\
(\mathrm{mm})\end{array}$ & $\begin{array}{c}\mathrm{s} \\
(\mathrm{cm})\end{array}$ & Quant. & $\begin{array}{c}\text { Comp. } \\
(\mathrm{m})\end{array}$ & $\begin{array}{l}\text { Comp. tot. } \\
\text { (m) }\end{array}$ \\
\hline 15 & $\begin{array}{l}1,0 \\
1,1 \\
1,2\end{array}$ & $\begin{array}{l}6,3 \\
6,3 \\
6,3\end{array}$ & $\begin{array}{l}18 \\
18 \\
18\end{array}$ & $\begin{array}{l}24 \\
24 \\
20\end{array}$ & $\begin{array}{l}3,90 \\
3,90 \\
3,90\end{array}$ & $\begin{array}{l}93,6 \\
93,6 \\
78,0\end{array}$ \\
\hline 16 & $\begin{array}{l}1,0 \\
1,1 \\
1,2\end{array}$ & $\begin{array}{l}6,3 \\
6,3 \\
6,3\end{array}$ & $\begin{array}{l}18 \\
18 \\
20\end{array}$ & $\begin{array}{l}24 \\
24 \\
20\end{array}$ & $\begin{array}{l}2,70 \\
2,70 \\
2,70\end{array}$ & $\begin{array}{l}64,8 \\
64,8 \\
54,0\end{array}$ \\
\hline 17 & $\begin{array}{l}1,0 \\
1,1 \\
1,2\end{array}$ & $\begin{array}{l}10 \\
10 \\
10\end{array}$ & $\begin{array}{l}14 \\
18 \\
18\end{array}$ & $\begin{array}{l}16 \\
12 \\
12\end{array}$ & $\begin{array}{l}3,90 \\
3,90 \\
3,90\end{array}$ & $\begin{array}{l}62,4 \\
46,8 \\
46,8\end{array}$ \\
\hline 18 & $\begin{array}{l}1,0 \\
1,1 \\
1,2\end{array}$ & $\begin{array}{l}10 \\
10 \\
10\end{array}$ & $\begin{array}{l}14 \\
18 \\
18\end{array}$ & $\begin{array}{l}16 \\
12 \\
12\end{array}$ & $\begin{array}{l}2,70 \\
2,70 \\
2,70\end{array}$ & $\begin{array}{l}43,2 \\
32,4 \\
32,4\end{array}$ \\
\hline 19 & $\begin{array}{l}1,0 \\
1,1 \\
1,2\end{array}$ & $\begin{array}{l}6,3 \\
6,3 \\
6,3\end{array}$ & $\begin{array}{l}20 \\
22 \\
22\end{array}$ & $\begin{array}{l}10 \\
10 \\
10\end{array}$ & $\begin{array}{l}3,90 \\
3,90 \\
3,90\end{array}$ & $\begin{array}{l}39,0 \\
39,0 \\
39,0\end{array}$ \\
\hline 20 & $\begin{array}{l}1,0 \\
1,1 \\
1,2\end{array}$ & $\begin{array}{l}6,3 \\
6,3 \\
6,3\end{array}$ & $\begin{array}{l}20 \\
22 \\
22\end{array}$ & $\begin{array}{l}10 \\
10 \\
10\end{array}$ & $\begin{array}{l}2,70 \\
2,70 \\
2,70\end{array}$ & $\begin{array}{l}27,0 \\
27,0 \\
27,0\end{array}$ \\
\hline 21 & $\begin{array}{l}1,0 \\
1,1 \\
1,2\end{array}$ & $\begin{array}{c}8 \\
8 \\
6,3\end{array}$ & $\begin{array}{l}20 \\
22 \\
14\end{array}$ & $\begin{array}{l}68 \\
60 \\
96\end{array}$ & $\begin{array}{l}3,10 \\
3,10 \\
3,10\end{array}$ & $\begin{array}{l}210,8 \\
186,0 \\
297,6\end{array}$ \\
\hline 22 & $\begin{array}{l}1,0 \\
1,1 \\
1,2\end{array}$ & $\begin{array}{c}8 \\
8 \\
6,3\end{array}$ & $\begin{array}{l}20 \\
22 \\
14\end{array}$ & $\begin{array}{l}68 \\
60 \\
96\end{array}$ & $\begin{array}{l}2,30 \\
2,30 \\
2,30\end{array}$ & $\begin{array}{l}156,4 \\
138,0 \\
220,8\end{array}$ \\
\hline 23 & $\begin{array}{l}1,0 \\
1,1 \\
1,2\end{array}$ & $\begin{array}{l}6,3 \\
6,3 \\
6,3\end{array}$ & $\begin{array}{l}22 \\
22 \\
22\end{array}$ & $\begin{array}{l}56 \\
56 \\
56\end{array}$ & $\begin{array}{l}3,10 \\
3,10 \\
3,10\end{array}$ & $\begin{array}{c}173,6 \\
173,6 \\
173,6\end{array}$ \\
\hline
\end{tabular}


TABELA 5.38- Resumo da armadura negativa (continuação).

\begin{tabular}{|c|c|c|c|c|c|c|}
\hline $\mathbf{N}$ & $\mathbf{R}$ & $\begin{array}{c}\phi \\
(\mathrm{mm})\end{array}$ & $\begin{array}{c}\mathrm{s} \\
(\mathrm{cm})\end{array}$ & Quant. & $\begin{array}{c}\text { Comp. } \\
\text { (m) }\end{array}$ & $\begin{array}{l}\text { Comp. tot. } \\
\text { (m) }\end{array}$ \\
\hline \multirow{3}{*}{24} & 1,0 & 6,3 & 22 & 56 & 2,30 & 128,8 \\
\hline & 1,1 & 6,3 & 22 & 56 & 2,30 & 128,8 \\
\hline & 1,2 & 6,3 & 22 & 56 & 2,30 & 128,8 \\
\hline \multirow{3}{*}{25} & 1,0 & 6,3 & 14 & 88 & 3,10 & 272,8 \\
\hline & 1,1 & 6,3 & 14 & 88 & 3,10 & 272,8 \\
\hline & 1,2 & 6,3 & 16 & 80 & 3,10 & 248,0 \\
\hline \multirow{3}{*}{26} & 1,0 & 6,3 & 14 & 88 & 2,30 & 202,4 \\
\hline & 1,1 & 6,3 & 14 & 88 & 2,30 & 202,4 \\
\hline & 1,2 & 6,3 & 16 & 80 & 2,30 & 184,0 \\
\hline \multirow{3}{*}{27} & 1,0 & 6,3 & 22 & 56 & 3,10 & 173,6 \\
\hline & 1,1 & 6,3 & 22 & 56 & 3,10 & 173,6 \\
\hline & 1,2 & 6,3 & 22 & 56 & 3,10 & 173,6 \\
\hline \multirow{3}{*}{28} & 1,0 & 6,3 & 22 & 56 & 2,30 & 128,8 \\
\hline & 1,1 & 6,3 & 22 & 56 & 2,30 & 128,8 \\
\hline & 1,2 & 6,3 & 22 & 56 & 2,30 & 128,8 \\
\hline \multirow{3}{*}{29} & 1,0 & 6,3 & 8 & 88 & 1,45 & 127,6 \\
\hline & 1,1 & 6,3 & 8 & 88 & 1,45 & 127,6 \\
\hline & 1,2 & 6,3 & 9 & 76 & 1,45 & 110,2 \\
\hline \multirow{3}{*}{30} & 1,0 & 6,3 & 11 & 112 & 1,45 & 162,4 \\
\hline & 1,1 & 6,3 & 11 & 112 & 1,45 & 162,4 \\
\hline & 1,2 & 6,3 & 11 & 112 & 1,45 & 162,4 \\
\hline \multirow{3}{*}{31} & 1,0 & 6,3 & 10 & 180 & 1,45 & 261,0 \\
\hline & 1,1 & 6,3 & 11 & 168 & 1,45 & 243,6 \\
\hline & 1,2 & 6,3 & 11 & 168 & 1,45 & 243,6 \\
\hline \multirow{3}{*}{32} & 1,0 & 6,3 & 11 & 112 & 1,45 & 162,4 \\
\hline & 1,1 & 6,3 & 11 & 112 & 1,45 & 162,4 \\
\hline & 1,2 & 6,3 & 11 & 112 & 1,45 & 162,4 \\
\hline
\end{tabular}


TABELA 5.39- Consumo de aço da armadura negativa.

\begin{tabular}{|c|c|c|c|c|}
\hline & $\phi(\mathrm{mm})$ & $R=1,0$ & $R=1,1$ & $R=1,2$ \\
\hline & 6,3 & 2907,0 & 2827,2 & 3196,2 \\
Comp. Total & 8 & 367,2 & 324,0 & 226,2 \\
$(\mathrm{~m})$ & 10 & 876,0 & 1309,8 & 1041,6 \\
& 12.5 & 343,2 & - & 799 \\
& 6,3 & 727 & 707 & 91 \\
Massa & 8 & 147 & 130 & 656 \\
(kg) & 10 & 552 & 825 & - \\
& 12.5 & 343 & - & 1546 \\
\hline
\end{tabular}




\section{6- CONSIDERAÇÕES FINAIS}

Neste capítulo final é apresentada uma análise dos resultados obtidos no capitulo anterior, as conclusões e algumas sugestões para novas pesquisas.

\section{1- ANÁLISE DOS RESULTADOS}

Nas tabelas 6.1 e 6.2, mostra-se o consumo de aço das armaduras positiva e negativa dos exemplos 1 e 2 , respectivamente.

TABELA 6.1- Consumo de aço do exemplo 1 (kg).

\begin{tabular}{|l|c|c|c|c|}
\hline \multirow{2}{*}{ Armadura } & \multirow{2}{*}{$\begin{array}{c}\text { Cálculo } \\
\text { elástico }\end{array}$} & \multicolumn{3}{|c|}{ Cálculo plástico } \\
\cline { 3 - 5 } & & $\mathbf{R = 1 , 0}$ & $\mathbf{R = 1 , 1}$ & $\mathbf{R = 1 , 2}$ \\
\hline Positiva & 1310 & 1175 & 1243 & 1311 \\
\hline Negativa & 1164 & 1187 & 1071 & 1005 \\
\hline Total & 2474 & 2362 & 2314 & 2316 \\
\hline
\end{tabular}

TABELA 6.2- Consumo de aço do exemplo $2(\mathrm{~kg})$.

\begin{tabular}{|l|c|c|c|c|}
\hline \multirow{2}{*}{ Armadura } & \multirow{2}{*}{$\begin{array}{c}\text { Cálculo } \\
\text { elástico }\end{array}$} & \multicolumn{3}{|c|}{ Cálculo plástico } \\
\cline { 3 - 5 } & & $\mathrm{R}=1,0$ & $\mathrm{R}=1,1$ & $\mathrm{R}=1,2$ \\
\hline Positiva & 1713 & 1922 & 2047 & 2159 \\
\hline Negativa & 1747 & 1769 & 1662 & 1546 \\
\hline Total & 3460 & 3691 & 3709 & 3705 \\
\hline
\end{tabular}


Comparando o consumo das armaduras, percebe-se que não há diferença significativa entre os valores obtidos com o cálculo elástico e com o cálculo plástico. No exemplo 1, há uma pequena redução no consumo de aço no cálculo plástico, sendo maior a redução correspondente ao cálculo com os momentos negativos divididos por $R=1,1$. Para o exemplo 2 , o consumo de aço referente ao cálculo plástico é maior, sendo máximo para os momentos negativos divididos por $R=1,1$.

Percebe-se também, que para o cálculo de lajes-cogumelo pela Teoria das Charneiras Plásticas há um aumento no consumo da armadura positiva, devido à sua forma de distribuição, e uma redução no consumo da armadura negativa.

A razão entre os momentos de plastificação negativo e positivo $\phi$ para cada painel dos exemplos é apresentada nas tabelas 6.3 e 6.4 .

TABELA 6.3- Razão entre os momentos de plastificação negativo e positivo (exemplo 1).

\begin{tabular}{|c|c|c|c|c|}
\hline Painel & Direçăo & $R=1,0$ & $R=1,1$ & $R=1,2$ \\
\hline $\begin{array}{c}\text { Painel de } \\
\text { canto }\end{array}$ & $\mathrm{X}$ & 3,3 & 2,8 & 2,3 \\
\cline { 2 - 5 } & $\mathrm{Y}$ & 3,3 & 2,8 & 2,3 \\
\hline \multirow{2}{*}{$\begin{array}{c}\text { Painel } \\
\text { lateral }\end{array}$} & $\mathrm{X}$ & 1,7 & 1,3 & 1,1 \\
\hline \multirow{2}{*}{$\begin{array}{c}\text { Painel } \\
\text { interno }\end{array}$} & $\mathrm{Y}$ & 2,3 & 2,0 & 1,7 \\
\cline { 2 - 5 } & $\mathrm{Y}$ & 1,1 & 0,9 & 0,8 \\
\hline
\end{tabular}


TABELA 6.4- Razão entre os momentos de plastificação negativo e positivo (exemplo 2).

\begin{tabular}{|c|c|c|c|c|}
\hline Painel & Direçăo & $R=1,0$ & $R=1,1$ & $R=1,2$ \\
\hline \multirow{2}{*}{$\begin{array}{c}\text { Painel de } \\
\text { canto }\end{array}$} & $x$ & 1,3 & 1,1 & 1,0 \\
\hline & $\mathbf{Y}$ & 1,2 & 1,0 & 0,9 \\
\hline \multirow{3}{*}{$\begin{array}{c}\text { Painel } \\
\text { lateral I }\end{array}$} & \multirow{2}{*}{$x$} & 3,2 & 2,3 & 1,8 \\
\hline & & 3,1 & 1,8 & 1,7 \\
\hline & $\mathbf{Y}$ & 1,1 & 0,9 & 0,8 \\
\hline \multirow{2}{*}{$\begin{array}{c}\text { Palnel } \\
\text { lateral II }\end{array}$} & $x$ & 1,0 & 0,9 & 0,8 \\
\hline & $Y$ & 5,4 & 3,3 & 2,4 \\
\hline \multirow{3}{*}{$\begin{array}{l}\text { Painel } \\
\text { interno }\end{array}$} & \multirow{2}{*}{$x$} & 2,2 & 1,7 & 1,3 \\
\hline & & 2,1 & 1,6 & 1,3 \\
\hline & $\mathbf{Y}$ & 7,4 & 4,0 & 2,8 \\
\hline
\end{tabular}

Analisando-se os valores das razões entre os momentos de plastificação negativo e positivo $\phi$, para cada painel, pode-se observar que para o cálculo plástico com momentos de plastificação negativos tomados integralmente do cálculo elástico, sem redução $(R=1,0)$, esses valores, em alguns casos, se afastam bastante dos valores recomendados de 1,0 a 1,5, como é o caso do painel de canto do exemplo 1, que apresenta $\phi=3,3$; do painel lateral $I$, do painel lateral II e do painel interno do exemplo 2, que apresentam $\phi=3,2, \phi=5,4$ e $\phi=7,4$, respectivamente. Nota-se então, que os valores mais próximos dos valores recomendados são os obtidos para os momentos de plastificação negativos reduzidos em $16,7 \%(R=1,2)$ em relação ao cálculo elástico. 


\section{2- CONCLUSÕES}

O aumento no consumo de aço do exemplo 2 e a pequena redução no exemplo 1 deve-se, principalmente à distribuição da armadura positiva, uniforme em todo o painel. Baseando-se no cálculo elástico, nota-se que esta distribuição é exagerada nas faixas centrais dos painéis, pois os valores que são distribuidos nessas faixas são consideravelmente maiores que os provenientes do cálculo elástico.

A partir da análise dos resultados dos exemplos, item 6.1, percebe-se que, para a fixação dos momentos de plastificação negativos, deve-se reduzir os momentos provenientes do cálculo elástico em torno de $16,7 \%(R=1,2)$ pois, apesar do consumo de aço ser bastante parecido com os dos outros detalhamentos do cálculo plástico, as razões entre os momentos negativo e positivo são mais compativeis com os valores recomendados.

$O$ fato de terem sido feitos apenas dois exemplos, com características bastantes semelhantes, não permite que se chegue a mais conclusões. Por isso, outros exemplos deverão ser resolvidos, variando-se a forma (colocação de vigas no contorno do pavimento, por exemplo) e o carregamento.

\section{3- SUGESTÕES PARA OUTRAS PESQUISAS}

Visando uma melhor distribuição da armadura positiva e a diminuição do consumo de aço, é interessante que sejam analisadas formas de se reduzir a armadura positiva na região das faixas centrais e melhorar a distribuição das armaduras negativas. Como o cálculo elástico fornece distribuição de armadura melhor que o cálculo plástico, sugere-se que seja feita uma análise, pelo método dos elementos finitos, para se determinarem novos coeficientes de distribuição dos momentos de plastificação positivo e negativo. Seria conveniente que fosse desenvolvida também uma pesquisa experimental, no sentido de se verificarem tais coeficientes. 
Os comprimentos das barras de aço, calculados nos exemplos do capítulo 5 , foram adotados iguais aos do cálculo elástico. Sugere-se algum estudo no sentido de se calcular o ponto de interrupção da armadura negativa como apresentado por RIOS (1990), para lajes de sistemas estruturais convencionais.

Uma vez definida nova distribuição para a armadura positiva e os comprimentos das barras através, também, da Teoria das Charneiras Plásticas, devese verificar a possibilidade de se reduzir ainda mais os momentos de plastificação negativos, o que pode ser feito também com o apoio de pesquisa experimental.

E ainda conveniente a análise de procedimentos que permitam a sistematização do cálculo dos momentos de plastificação.

Finalizando, conclui-se que o trabalho apresentado representa uma contribuição ao cálculo das lajes-cogumelo pela Teoria das Charneiras Plásticas e que sua complementação com a realização das pesquisas sugeridas pode trazer um bom aprimoramento para este cálculo. 


\section{REFERÊNCIAS BIBLIOGRÁFICAS}

AMERICAN CONCRETE INSTITUTE. Committee 318. (1989). Building code requirements for reinforced concrete ( $A C l$ 318-89) and commentary ( $A C l 318 R$ 89). Detroit, American Concrete Institute. 353p.

ASSOCIAÇÃO BRASILEIRA DE NORMAS TÉCNICAS. (1978). NBR 6118 - Projeto e execução de obras de concreto armado. Rio de Janeiro.

ASSOCIAÇÃO BRASILEIRA DE NORMȦS TÉCNICAS. (1980). NBR 6120 - Cargas para o cálculo de estruturas de edificações. Rio de Janeiro.

BACH, C.; GRAF, O. (1915). Tests of square and rectangular reinforced concrete slabs supported on all sides (Versuche mit allseitig aufliegenden quadratischen und rechteckigen eisenbetonplatten). Deutscher Ausschuss für Elsenbeton, Berlim, n.30, 309p.

BARKER, J. A. (1967). Reinforced concrete detailing. Oxford, Oxford University Press.

BAYKOV, V. N.; SIGALOV, E. E. (1980). Estructuras de hormigon armado: curso general. Moscou, MIR.

BRAYTON, L. F. (1910). Methods for the computation of reinforced concrete flat slabs. Engineering News, v.64, n.8, p. 364-67. 
CASTELO BRANCO, A. F. V. (1989). Contribuição para o projeto de lajes-cogumelo. São Carlos. 217p. Dissertação (mestrado) - Escola de Engenharia de São Carlos, Universidade de São Paulo.

CEB-FIP Model Code 1990, First draft. (1990). CEB Bulletin d'Information, n. 195/196, Mars.

EUROCODE No. 2. (1989). Design of concrete structures. Part 1: General rules and rules for buildings.

FERGUSON, P. M. (1973). Reinforced concrete fundamentals. New York, John Wiley \& Sons.

FIGUEIREDO FILHO, J. R. (1989). Sistemas estruturais de lajes sem vigas: subsídios para o projeto e execução. São Carlos. 262p. Tese (doutorado) Escola de Engenharia de São Carlos, Universidade de São Paulo.

GRAF, O. (1933). Tests of reinforced concrete slabs under concentrated load applied near one suport. Deutscher Ausschuss für Eisenbeton, n.73, 28p.

HAMBLY, E. C. (1976). Brigde deck behaviour. London, Chapman and Hall.

HOGNESTAD, E. (1953). Shearing strength of reinforced column footings. ACl Journal, v.50, n.3, p.189-208.

INGERSLEV, A. (1923). The strength of rectangular slabs. The Institution of Structural Engineer's Journal, Jan.

JOHANSEN, K. W. (1932). Bruchmoment der kreuzweise bewehrten platten. Mémoires, Association Internationale des Ponts et Charpents, p. 277-296.

JOHANSEN, K. W. (1943). Brudlinieteorier. Genoptrykt, Polyteknisk Forening. 189p. 
JOHANSEN, K. W. (1962). Linhas de ruptura: teoria e prática. Rio de Janeiro, Ao Livro Técnico.

KINNUNEN, S. (1960). Punching of concrete slabs with two-way reinforcement. Kungliga Tekniska Högskolan, n.158.

LANGENDONCK, T. (1970). Teoria elementar das charneiras plásticas. São Paulo, ABCP. v.1.

LANGENDONCK, T. (1975). Teoria elementar das charneiras plásticas. São Paulo, ABCP. v. 2 .

LEONHARDT, F.; MÖNNIG, E. (1978). Construções de concreto: principios básicos sobre a armação de estruturas de concreto armado. Rio de Janeiro, Interciência. v.3.

MACGREGOR, J. G. (1992). Reinforced concrete: mechanics and design. New Jersey, Prentice Hall.

MARCUS, H. (1924). Die theorie elasticher gewebe und ihre anwendung auf die berechnung biegsamer platten. Berlim, Julius Springer.

MCMILLAN, A. B. (1910). A comparison of methods of computing the strength of flat reinforced plates. Engineering News, v.64, n.8, p. 210-211.

MOE, J. (1961). Shearing strength of reinforced concrete slabs and footings under concentrated loads. Portland Cement Association, Research and Development Laboratories, Bull. D47, Apr. 130p.

MONTOYA, P. J.; MESSEgUER, A. G.; CABRE, F. M. (1976). Hormigon armado. 8.ed. Barcelona, Gustavo Gili. 2v. 
PARK, R.; GAMBLE, W. L. (1980). Reinforced concrete slabs. New York, John Wiley \& Sons.

PINHEIRO, L. M. (1988). Análise elástica e plástica de lajes retangulares de edifícios. São Carlos. 303p. Tese (doutorado) - Escola de Engenharia de São Carlos, Universidade de São Paulo.

PINHEIRO, L. M. (1993). Concreto armado: tabelas e ábacos. São Carlos, EESCUSP.

PINHEIRO, L. M.; SCANLON, A. (1993). Análise de flechas em lajes-cogumelo pela analogia das vigas cruzadas e pelo processo dos elementos finitos. In: JORNADAS SUDAMERICANAS DE INGENIERIA ESTRUCTURAL, 26., Montevideo, Uruguay, 1993. Anais. v.2, p.219-230.

RICHART, F. (1948). Reinforced concrete wall and column footings. ACl Journal, v. 45, n. 2, p.97-127, Oct. ; v. 45, n.3, p.237-260, Nov.

RIOS, P. M. (1990). Lajes retangulares de edifícios: associação do cálculo elástico com a teoria das charneiras plásticas. São Carlos. 246p. Dissertação (mestrado) Escola de Engenharia de São Carlos, Universidade de São Paulo.

RUSCH, H. (1980). Concreto armado e protendido: propriedades dos materiais e dimensionamento. Rio de Janeiro, Campus.

STUCCHI, F. R.; KNAPP, L. M. (1993). Punção em lajes. In: SIMPÓSIO EPUSP SOBRE ESTRUTURAS DE CONCRETO, 3., São Paulo, 1-3 dez. 1993. Anais. São Paulo, EPUSP. p. 209-232.

TAKEYA, T. et al. (1985). Recomendações para o projeto e a execução da estrutura em lajes-cogumelo pertencentes às UBS do plano de saúde. São Carlos, EESCUSP. (Relatório técnico). 
TALBOT, A. (1913). Reinforced concrete walls, footings and column footings. University of Illinois, Engineering Experiment Station, Bull n.67, Mar. 1913. 144p.

TURNER, C. (1905). Discussion of reinforced concrete ware-house for Northwest Knitting Co. Engineering News, v.54, n.15, Oct.

UNIVERSIDADE DE SÃO PAULO. Escola de Engenharia de São Carlos. Serviço de Biblioteca. (1993). Diretrizes para elaboração de dissertações e teses na EESCUSP. São Carlos. 56p.

ZIENKIEWICZ, O. C. (1980). El metodo de los elementos finitos. 3.ed. Barcelona, Reverté. 